\author{
Universidade de São Paulo \\ Instituto de Química de São Carlos \\ Programa de Pós-graduação em Química Analítica e Inorgânica
}

\begin{abstract}
DESENVOLVIMENTO DE COLUNAS CAPILARES E APLICAÇÃO DE PROGRAMAÇÃO DE TEMPERATURA EM CROMATOGRAFIA LÍQUIDA CAPILAR
\end{abstract}

Vivane Lopes Leal

São Carlos

2018 


\section{DESENVOLVIMENTO DE COLUNAS CAPILARES E APLICAÇÃO DE PROGRAMAÇÃO DE TEMPERATURA EM CROMATOGRAFIA LÍQUIDA CAPILAR}

Tese apresentada ao Instituto de Química de São Carlos da Universidade de São Paulo como parte dos requisitos para obtenção do título de Doutor em Química.

Área de concentração: Química Analítica e Inorgânica.

Orientador: Prof. Dr. Fernando Mauro Lanças

São Carlos 
Autorizo a reprodução e divulgação total ou parcial deste trabalho, por qualquer meio convencional ou eletrônico para fins de estudo e pesquisa, desde que citada a fonte.

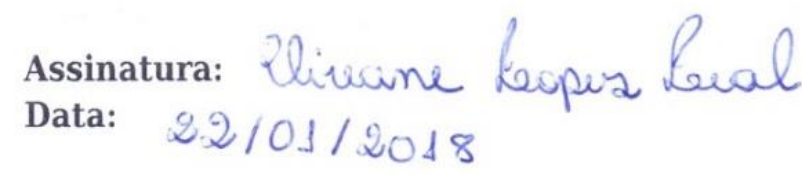

Ficha Catalográfica elaborada pela Seção de Referência e Atendimento ao Usuário do SBI/IQSC

Leal, Vivane Lopes

Desenvolvimento de colunas capilares e aplicação de programação de temperatura em cromatografia líquida capilar / Vivane Lopes Leal. - São Carlos, 2018.

$134 \mathrm{f}$.

Tese (Doutorado em Química Analítica e Inorgânica) - Instituto de Química de São Carlos / Universidade de São Paulo, 2018.

Orientador: Prof. Dr. Fernando Mauro Lanças

1. Química analítica. 2. Método cromatográfico. 3. Cromatografia líquida capilar. 4. Colunas tubulares aberta. 5. Programação de temperatura. I. Título.

Referências Bibliográficas

conferidas pelo SBI/IQSC

Sonia Alves - CRB: 4280/8 


\section{Q Dedicatória}

Q Dedico esse manuserito às duas principais pessoas que me inspiraram e incentivaram para que eu prosseguisse em um caminho ainda pauco comum e nãa devidamente valorizado, como a pesquisa brasileira. OAo OProfessor ODr. Eedmilson Miranda de Moura pela ética profissional, competência e amor com a qual exerce a profissão de químico e que tanto me inspircu, a ponto de seguir seuśs passos quando minha prioridade tendia a outra área acadêmica. Se haje cheguei até aqui, foi porque tive exemplos profissionais como ele. Aso meu namorado Glaudic OPace Spanospor me fazer sentir amada, em casa e em familia, quando. na verdade, estava a mais de dois mil quilômetros de casa. STambém, por sempre me contar a história, irritante, do início da carreira de Ofyluester Stallane, quando tive dívidas se estava no caminho correto. Seu apoio e ajuda foram verdadeiras fontes de sustentasão durante todos esses anos. Diante da incapacidade de expressar minha gratidão por vocês só me vesta disser muito abrigada. 


\section{Ffgradecimentos}

MODeuspelas grasas e bènsãos concedidas, por estar presente na minha vida e me conduzindo a cada passo dado, por ser fonte de sabedoria, page amor. Obrigada senhor pois sei que nada seria se náa fosse seu infinito amor.

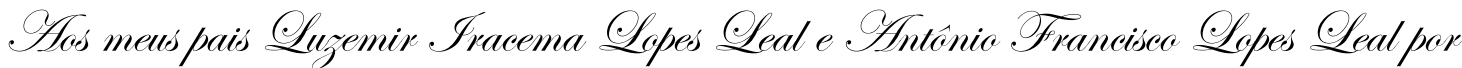
tamanho amor e compreensáo, épor vocês que levanto todos os dias, épor vocês a vontade que tenho de viver e por vocês meu maior e mais puro amor. Y/ âo existe uma palavra que possa expressar a minha gratidão por me apaiarem e me incentivarem em todos as passos que dou, saibam que tudo que já alcancei e que vou alcansar foi vacês e ODeus que me propiciaram. Gostaria de agradecer, especialmente, por me ensinarem que oúnico meio que eu poderia seguir para mudar a minha vealidade era a educasãa. Mhito obrigada, amo muito vacès.

Mos meus irmãos, Mylsone Gleide e ao meu sabrinho, Oictor, pelo amor, carinho, ajuda e incentiva durante todos esses anos, vocès foram fundamentais nessa etapa da minha caminhada.

OAo OProf. ODr. Fremando Mauro QLansas pela orientasão e conhecimentos repassados, abrigada por me aceitar no grupo de cromatografia e por contribuir para meu crescimento profissional.

OAs meus familiares, que de forma diveta ou indireta contribuúram nessa etapa da minha vida.

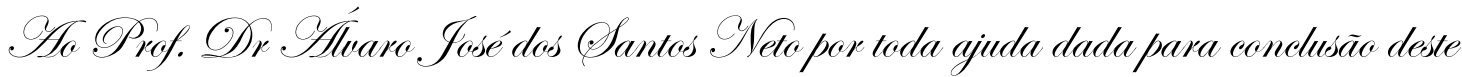
trabalho.

OSos téenicos, EClaine e Guilherme, pela ajuda, incentivo e paciência durante ésses anos.

OSo Orof. ODr. Éder Oadeu Gomes Gavalheiro è OProfa. ODra. Maria Olimpia de Oliveira Rezendepela oportunidade de vealizasão dos estágios OPC E. que contribuúram para men crescimento profissional.

OS agradáveis e boas surpresas, que ganhei durante o doutorado. Tha Qfucia. Marcela, Mariane, OPatricia e. Amanda, vocês tornaram essa caminhada mas leve e alegre, vocếs são amigas queridas, que estarão no meu covasão.

OA todos os colegas do grupo de cromatografia pelas contribuisōes, companhia, auxilio e momentos de distrasão durante todos esses anos de doutorado.

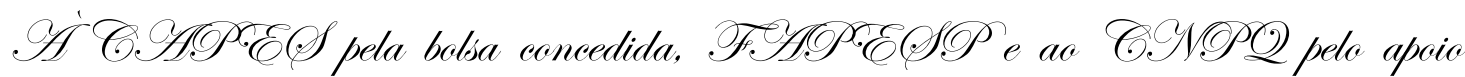
financeiro concedido ao grupo de cromatografia, que contribuiu para o desenuolvimento do meu doutorado.

OjOUlniversidade de Sâa Paulo e ao. Instituto de Química pela infraestrutura e auxiliós concedidos. 
Gosto dos caminhos que se abrem no meio das matas espessas, na subida das montanhas. ODos que abrem passagens nas rochas. dos que beiram as estradas com espinhos. ODos caminhos que me sugerem outra diresão, mas que por teimosia, prefiro prosseguir... Samara Rassene 


\section{RESUMO}

O presente estudo visa o desenvolvimento de pesquisas em uma área altamente promissora da cromatografia líquida moderna, denominada genericamente de cromatografia líquida capilar (cLC). Sua principal característica é o uso de instrumentação miniaturizada, cujos benefícios em relação à HPLC são fartamente documentados. O Grupo de Cromatografia do IQSC-USP vem desenvolvendo, há vários anos, instrumentação e colunas para esta área, havendo construído um sistema, para micro e nano LC, completo. O objetivo deste trabalho foi ampliar o emprego do mesmo, através do uso de programação de temperatura em cromatografia líquida capilar, fazendo uso de colunas empacotadas e tubulares abertas (OT), desenvolvidas no laboratório. Uma metodologia relativamente simples foi desenvolvida para preparar as colunas capilares com fases estacionárias C18 com boa repetitividade. Para tal, a influência de várias características da coluna, tais como, tamanho da partícula, comprimento, diâmetro interno, tipos de hardwares empregados como corpo da coluna e sistema de bombeamento, foram avaliadas, sendo estabelecida uma relação entre as mesmas e o desempenho da coluna. As microcolunas empacotadas obtidas apresentaram excelente desempenho. Colunas tubulares abertas do tipo WCOT e PLOT (com diferentes tipos de fases, comprimentos e diâmetros internos) foram produzidas e avaliadas, utilizando uma mistura de alquilbenzenos. Os resultados sugerem um desempenho ainda insatisfatório das colunas OTLC, embora os compostos avaliados tenham sido separados indicando, de forma promissora, que uma otimização nas características das colunas poderá contribuir para se alcançarem maiores eficiências. Foi aplicada programação de temperatura na separação de diferentes classes de compostos resultando na redução de, pelo menos, metade do tempo de análise com aumento da eficiência de, no mínimo 2 vezes, quando comparado à separação realizada em condição isotérmica. Isto ilustra a importância da utilização da programação de temperatura em cromatografia líquida capilar. Por último, foi avaliado o desempenho de uma coluna capilar empacotada em um sistema cLC comercial e no cLC desenvolvido no laboratório, em que se observou que o desempenho da coluna foi melhor quando utilizada no cromatógrafo líquido capilar desenvolvido pelo grupo (“homemade”).

Palavras-chave: Miniaturização. Programação de temperatura. Coluna tubular aberta. 


\begin{abstract}
The present study aims to develop research in a highly promising area of modern liquid chromatography, generally referred to as capillary liquid chromatography (cLC). Its main feature is the use of miniaturized instrumentation, whose benefits in relation to HPLC are well documented. The Chromatography Group of IQSC-USP has been developing, several years ago, instrumentation and columns for this area, having built a system, for micro and nano LC, complete. The objective of this work was to extend the use of the same, by using temperature programming in capillary liquid chromatography, making use of packed and open tubular columns (OT), developed in the laboratory. A relatively simple methodology was developed to prepare capillary columns with C18 stationary phases with good repeatability. To do this, the influence of various column characteristics, such as particle size, length, internal diameter, types of hardware used as column body and pumping system, were evaluated, establishing a relationship between them and the performance of the column. The packaged microcolumns obtained showed excellent performance. Open tubular columns of type WCOT and PLOT (with different types of phases, lengths and internal diameters) were produced and evaluated using a mixture of alkylbenzenes. The results suggest a still unsatisfactory performance of the OTLC columns, although the compounds evaluated were promising, indicating that an optimization of the characteristics of the columns could contribute to higher efficiencies. Temperature programming was applied in the separation of different classes of compounds resulting in the reduction of at least half of the analysis time with increase of the efficiency of at least 2 times when compared to the separation realized in isothermal condition. This illustrates the importance of using temperature programming in capillary liquid chromatography. Finally, the performance of a capillary column packed in a commercial cLC system and in the cLC developed in the laboratory was evaluated, where it was observed that the performance of the column was better when used in the liquid capillary chromatograph developed by the group ("homemade").
\end{abstract}

Key words: Miniaturization. Temperature programming. Open tubular column. 


\section{LISTA DE FIGURAS}

Figura 1- Tipos de colunas capilares empregadas em cromatografia líquida miniaturizada: (a)

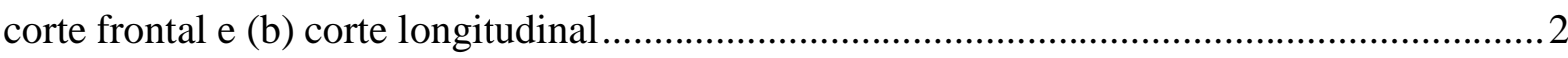

Figura 2 - Cromatograma típico para cálculo de parâmetros cromatográficos ...................... 20

Figura 3 - Sobreposição das formas reduzidas das equações de Van Deemter, Giddings e Knox

Figura 4 - Comparação, em escala, entre os diversos diâmetros internos de colunas. a) convencional $(4,6 \mathrm{~mm})$; b) microbore $(2,1 \mathrm{~mm})$; c) capilar $(320 \mu \mathrm{m})$; d) WCOT $(20 \mu \mathrm{m}) \ldots . .26$

Figura 5 - Imagem do sistema cromatográfico liquido capilar homemade empregado neste trabalho 31

Figura 6 - Imagem do cromatógrafo liquido UltiMateTM 3000 RSLCnano da Termo Scientific Dionex 32

Figura 7 - Primeiro modelo de "hardware" empregado para confecção de colunas capilares empacotadas.

Figura 8 - Segundo modelo de Hardware empregado para confecção de colunas capilares empacotadas.

Figura 9 - Sistema de empacotamento das colunas capilares empregando a bomba Haskel (a) e a Bomba Shimadzu (b)

Figura 10 - Gráficos da variância em função do volume de retenção ao quadrado dos equipamentos Homemade (a) e UtiMate 3000 (b) 37

Figura 11 - Esquema das principais etapas envolvidas na confecção das colunas empacotadas

Figura 12 - Imagem das colunas capilares confeccionadas pela técnica "slurry-packing”..... 42 Figura 13 - Cromatograma obtido com a coluna OTLC-1, utilizando como fase móvel ACN/H2O 60:40 v/v, fluxo de $6 \mu \mathrm{L}$ min-1 e comprimento de onda de $254 \mathrm{~nm}$ 44

Figura 14 - Cromatogramas obtidos com as colunas capilares de $250 \mu \mathrm{m}$ d.i., $15 \mathrm{~cm}$ de comprimento e partículas de fase estacionária C18 de 2,0 $\mu \mathrm{m}$. Ordem de eluição: (1) uracila, (2) naftaleno, (3) fenantreno, (4) antraceno e (5) pireno

Figura 15 - MEV das F.E C18 com diâmetros de partículas indicados pelo fabricante, iguais a $2 \mu \mathrm{m}$ (a), $3 \mu \mathrm{m}$ (b), 3,5 $\mu \mathrm{m}$ (c), $5 \mu \mathrm{m}$ (d), $10 \mu \mathrm{m}$ (e) e coluna de sílica fundida de $250 \mu \mathrm{m}$ d.i. (f). O microscópio foi operado a $20 \mathrm{kV}$ e magnificação de 1000 a 12000x.... 48

Figura 16 - Gráfico da distribuição do tamanho das partículas obtido através das medições realizadas nas imagens de MEV para cada uma das F.E empregadas..... 
Figura 17 - Gráfico da distribuição do tamanho das partículas obtido através das medições realizadas nas imagens de MEV para cada uma das F.E empregadasErro! Indicador não definido.

Figura 18 - Gráfico de Van Deemter para um composto não retido (naftaleno) empregando as colunas confeccionadas com fase $\mathrm{C} 18$ de partículas de 2,0; 3,0;3,5; 5,0 e 10,0 $\mu \mathrm{m}$.

Figura 19 - Cromatogramas das separações de PAH's empregando as colunas C18 de 15 cm, $250 \mu \mathrm{m}$ d.i. e partículas de 2; 3; 3,5; 5 e $10 \mu \mathrm{m}$. Ordem de eluição: (1) uracila, (2) naftaleno, (3) fenantreno, (4) antraceno e (5) pireno. 55

Figura 20 - Gráfico Knox (variação de h em função de v) para as colunas empacotadas com partículas $\mathrm{C} 18$ de $2 ; 3 ; 3,5 ; 5$ e $10 \mu \mathrm{m}$ de diâmetro. 58

Figura 21 - Cromatogramas da separação da mistura de PAH's realizados em colunas C18 de $250 \mu \mathrm{m}$ d.i., partículas 3,5 $\mu \mathrm{m}$ e comprimentos de 5, 15 e $25 \mathrm{~cm}$. Ordem de eluição: (1) uracila, (2) naftaleno, (3) fenantreno, (4) antraceno e (5) pireno

Figura 22 - Efeito da variação da Pressão em função do fluxo volumétrico para as colunas de $15 \mathrm{~cm}$, F. E. C18 com partículas de 3,5 $\mu \mathrm{m}$ e d.i. iguais a 250, 320 e $500 \mu \mathrm{m}$ 64

Figura 23 - Gráfico de Van Deemter (a) e Knox (b) para as colunas com d.i. iguais a 500, 320 e $250 \mu \mathrm{m}$

Figura 24 - Cromatogramas da separação dos PAH's realizadas em colunas C18, partículas 3,5 $\mu \mathrm{m}$, comprimento de $15 \mathrm{~cm}$ e d.i de 250, 320 e $500 \mu \mathrm{m}$. Ordem de eluição: (1) uracila, (2) naftaleno, (3) fenantreno, (4) antraceno e (5) pireno. 66

Figura 25 - Cromatogramas da separação dos PAH's realizadas em colunas C18 de partículas 3,5 $\mu \mathrm{m}$, comprimento de $15 \mathrm{~cm}$ diâmetro interno de $100 \mu \mathrm{m}$. Ordem de eluição: (1) uracila, (2) naftaleno, (3) fenantreno, (4) antraceno e (5) pireno. 68

Figura 26 - Efeito da variação da pressão em função do fluxo volumétrico para as colunas C18 (15 cm x $500 \mu \mathrm{m} \times 3,5 \mu \mathrm{m})$ confeccionadas em PEEK, aço inox, sílica fundida e açosil 69

Figura 27 - Gráfico de Van Deemter (a) e Knox (b) para as colunas confeccionadas em PEEK, aço inox, sílica fundida e açosil

Figura 28 - Cromatogramas da separação dos PAH's realizadas em colunas C18 (15 cm x 500 $\mu \mathrm{m} \times$ 3,5 $\mu \mathrm{m}$ ) confeccionadas em tubos de Sílica, PEEK, AçoInox e AçoSil. Ordem de eluição: (1) uracila, (2) naftaleno, (3) fenantreno, (4) antraceno e (5) pireno

Figura 29 - Efeito da variação da pressão em função do fluxo volumétrico para as colunas C18 (15 cm x $500 \mu \mathrm{m} \times 3,5 \mu \mathrm{m})$ empregando pressões de empacotamento iguais a 220, 680 e 1034 bar. 
Figura 30 - Gráfico de Van Deemter (a) e Knox (b) para as colunas C18 (15 cm x $500 \mu \mathrm{m}$ x 3,5 $\mu \mathrm{m}$ ) empregando pressões de empacotamento iguais a 220, 680 e 1034 bar

Figura 31 - Cromatogramas da separação dos PAH's empregando colunas C18 (15 cm x 500 $\mu \mathrm{m} \times 3,5 \mu \mathrm{m})$ empacotadas a pressões iguais a 220, 680 e 1034 bar. Ordem de eluição: (1) uracila, (2) naftaleno, (3) fenantreno, (4) antraceno e (5) pireno

Figura 32 - Efeito da variação da pressão em função do fluxo volumétrico para as colunas C18 (15 cm x $250 \mu \mathrm{m} \times 3,5 \mu \mathrm{m})$ empacotadas em uma bomba Haskel e uma bomba Shimadzu... 78 Figura 33 - Gráfico de Van Deemter (a) e Knox (b) para as colunas C18 (15 cm x $250 \mu \mathrm{m}$ x 3,5 $\mu \mathrm{m}$ ) empacotadas em uma bomba Haskel e uma bomba Shimadzu 79

Figura 34 - Cromatogramas ilustrando a separação dos PAH's realizadas em colunas C18 (15 cm x $500 \mu \mathrm{m}$ x 3,5 $\mu \mathrm{m}$ ) empacotadas em uma bomba Haskel e em uma bomba Shimadzu. Ordem de eluição: (1) uracila, (2) naftaleno, (3) fenantreno, (4) antraceno e (5) pireno. 79

Figura 35 - Efeito da variação da pressão em função do fluxo volumétrico para as colunas C18 $(15 \mathrm{~cm} \times 250 \mu \mathrm{m} \times 3,5 \mu \mathrm{m})$ confeccionadas empregando os hardwares 1 e 2 . 82

Figura 36 - Gráfico de Van Deemter (a) e Knox (b) para as colunas C18 (15 cm x $250 \mu \mathrm{m}$ x $3,5 \mu \mathrm{m})$ confeccionadas empregando os hardwares 1 e 2

Figura 37 - MEV dos Frits de aço inoxidável e fibra de vidro empregados nestes trabalho. O microscópio foi operado a $20 \mathrm{kV}$ e magnificação de 1000 a 1500 x

Figura 38 - Cromatogramas da separação dos PAH's realizadas em colunas C18 (15 cm x 500 $\mu \mathrm{m} \times 3,5 \mu \mathrm{m}$ ) confeccionadas empregando os hardwares 1 e 2. Ordem de eluição: (1) uracila, (2) naftaleno, (3) fenantreno, (4) antraceno e (5) pireno 85

Figura 39 - Cromatogramas da separação de PAH's usando a coluna e o cLC homemade (a) a coluna homemade e o cLC comercial (b) e a coluna comercial e o cLC comercial (c) Ordem de eluição: (1) uracila, (2) naftaleno, (3) fenantreno, (4) antraceno e (5) pireno

Figura 40 - Diagrama esquemático do sistema empregado para confecção das colunas PLOT

Figura 41 - Efeito da variação da pressão $(\mathrm{P})$ em função da velocidade linear aplicada $(\mu)$ para as colunas OTLC-1, OTLC-2, OTLC-3 e OTLC-4. 98

Figura 42 - Gráfico de Van Deemter para um composto retido (butilbenzeno) empregando as quatro colunas OTLC estudadas. As curvas foram plotadas usando regressão clássica dos mínimos quadrados

Figura 43 - Curva de Knox ( $\log$ h x $\log$ v) para as coluna OTLC-1, OTLC-2, OTLC-3 e OTLC4 . 100 
Figura 44 - Comportamento de k em função da quantidade de solvente orgânico na fase móvel. A vazão empregada foi de $6 \mu \mathrm{L} / \mathrm{min}$

Figura 45 - Cromatogramas obtidos com as colunas capilares OTLC. Ordem de eluição: uracila, tolueno, etilbenzeno, butilbenzeno e propilbenzeno.

Figura 46 - Imagens de microscopia eletrônica de varredura (MEV) de várias colunas OT-PSDVB sintetizadas (a) PS-DVB $25 \mu \mathrm{m}$ d.i (b) PS-DVB $25 \mu \mathrm{m}$ d.i. detalhada (c) PS-DVB $50 \mu \mathrm{m}$ d.i. (d) PS-DVB $50 \mu \mathrm{m}$ d.i. detalhada (e) PS-DVB $75 \mu \mathrm{m}$ d.i. (f) PS-DVB $100 \mu \mathrm{m}$ d.i....... 105 Figura 47 - Imagens de MEV de (a) tubo de sílica fundida vazio e (b) Coluna OT-PS-DVB

Figura 48 - - Cromatogramas da separação dos alquibenzenos usando as colunas PLOT (a) PSDVB $25 \mu \mathrm{m}$ d.i., (b) PS-DVB $50 \mu \mathrm{m}$ d.i., (c) PS-DVB $75 \mu \mathrm{m}$ d.i. e (d) PS-DVB $100 \mu \mathrm{m}$ d.i. Ordem de eluição: uracila, tolueno, etilbenzeno, butilbenzeno e propilbenzeno 107

Figura 49 - Gráfico da Pressão em função do fluxo volumétrico para as colunas OT-PS-DVB de 50 e $25 \mu \mathrm{m}$ de d.i.

Figura 50 - Gráfico de Van Deemter (a) e Knox (log h x $\log$ v) (b) para as colunas OT-PSDVB de 50 e $25 \mu \mathrm{m}$ de d.i.

Figura 51 - Imagens de microscopia eletrônica de varredura (MEV) das colunas OT-ODS (a) ODS de $25 \mu \mathrm{m}$ d.i. (b) ODS de $25 \mu \mathrm{m}$ d.i. detalhada (c) e (d) ODS de $10 \mu \mathrm{m}$ de d.i.

Figura 52 - Cromatogramas da separação de uma mistura de alquilbenzenos empregando a coluna OT-ODS de $25 \mu \mathrm{m}$ d.i. e 2 metros de comprimento. Ordem de eluição: uracila, tolueno, etilbenzeno, butilbenzeno e propilbenzeno

Figura 53 - Separação de PAHs em coluna capilare empacotada C18 (14 cm x $250 \mu \mathrm{m}$ x 3,5 $\mu \mathrm{m}$ ) (a) sem programação de temperatura e (b) com programação de temperatura. Naftaleno (1), acenaftileno (2), acenafteno (3), fluoreno (4), fenantreno (5), antraceno (6), crisen....... 117

Figura 54 - Separação de sulfonamidas em coluna capilare empacotada C18 (14 cm x $250 \mu \mathrm{m}$ x 3,5 $\mu \mathrm{m}$ ), (a) sem programação de temperatura e (b) com programação de temperatura. (1) Sulfatiazol, (2) sulfacetamida, (3) sulfametizol, (4) sulfamerazina, (5) sulfadiazina (6) sulfametazina, (7) sulfacloropiridazina, (8) sulfametazol, (9) sulfadimetoxina e (10) sulfaquinoxalina

Figura 55 - Separação dos compostos de parabeno em coluna capilare empacotada C18 $(14 \mathrm{~cm}$ x $250 \mu \mathrm{m} \times 3,5 \mu \mathrm{m}$ ), (a) sem programação de temperatura e (b) com programação de temperatura. (1) metilparabeno, (2) propilparabeno, (3) butilparabeno, (4) etilparabeno, e (5) benzilparabeno 121 
Figura 56 - Separação dos compostos de Alquibenzeno utilizando coluna WCOT (5 m x 50 $\mu \mathrm{m}$ de d.i.) (a) sem programação de temperatura e (b) com programação de temperatura. Uracila (1), tolueno (2), etilbenzeno (3), butilbenzeno (4), pentilbenzeno e (5) heptilbenzeno 123

Figura 57 - Separação dos compostos de Alquibenzeno utilizando coluna PLOT (5 m x $50 \mu \mathrm{m}$ de d.i.) (a) sem programação de temperatura e (b) com programação de temperatura. Uracila (1), tolueno (2), etilbenzeno (3), butilbenzeno (4), pentilbenzeno e (5) heptilbenzeno .......... 123 


\section{LISTA DE TABELA}

Tabela 1- Descrição da composição, especificação USP e código comercial de algumas fases estacionaria fabricadas para cromatografia a partir do polímero PDMS................................ 11

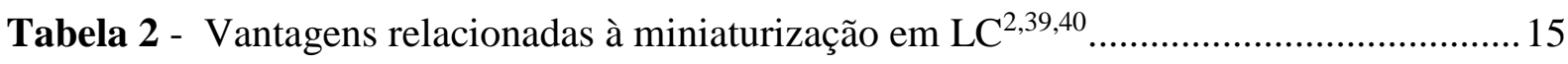

Tabela 3- Nomenclatura proposta por Ishii et al. para LC em função do d.i. da coluna ${ }^{2} \ldots . . .25$

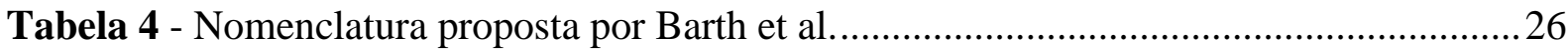

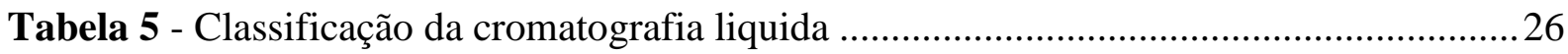

Tabela 6 - Características e procedência das fases estacionárias empregadas na confecção das colunas empacotadas

Tabela 7 - Características dos tubos capilares utilizados no primeiro modelo de hardware das colunas empacotadas

Tabela 8 - Parâmetros das colunas cromatográficas obtidos a partir dos dados gerados nos cromatogramas apresentados na Figura 14

Tabela 9 - Valores de P determinados através do test-t entre as três colunas confeccionadas para cada F.E. C18 estudada, a um nível de significância de 0,05

Tabela 10 - Diâmetros de partículas especificados pelo fabricante; diâmetro Sauter (dSauter); diâmetro médio (dp, med); diâmetro mínimo (dp,min) e máximo (dp,max); e razão dp90/dp10 obtidos a partir de imagens de MEV

Tabela 11 - Parâmetros das colunas obtidos a partir dos dados gerados nos cromatogramas apresentados na Figura 19

Tabela 12 - Parâmetros das colunas obtidos a partir dos dados gerados nos cromatogramas apresentados na Figura 19

Tabela 13 - Parâmetros da coluna obtidos a partir dos dados gerados nos cromatogramas apresentados na Figura 24

Tabela 14 - Parâmetros da coluna obtidos a partir dos dados gerados nos cromatogramas apresentados na Figura 28

Tabela 15 - Parâmetros da coluna obtidos a partir dos dados gerados nos cromatogramas apresentados na Figura 31

Tabela 16 - Parâmetros da coluna obtidos a partir dos dados gerados nos cromatogramas apresentados na Figura 34

Tabela 17 - Parâmetros da coluna obtidos a partir dos dados gerados nos cromatogramas apresentados na Figura 38 
Tabela 18 - Comparação entre os parâmetros obtidos com a coluna 1 no cromatógrafo homemade e comercial, e comparação entre os parâmetros obtidos com a coluna produzida em laboratório e coluna comercial, operadas no cromatógrafo comercial .................................... 88

Tabela 19 - Característica das colunas WCOT utilizadas ....................................................93

Tabela 20 - Diagrama esquemático do sistema empregado para confecção das colunas PLOT 103

Tabela 21 - Parâmetros obtidos a partir dos dados dos cromatogramas gerados com as colunas OT-PS-DVB de 25, 50, 75 e $100 \mu \mathrm{m}$ de d.i. 108

Tabela 22 - Parâmetros extraídos dos cromatogramas da Figura 53, onde foram realizadas separações no modo isotérmico e com programação de temperatura 


\section{LISTA DE ABREVIATURAS E SIGLAS}

ACN - Acetonitrila

Aço Inox - Tubo capilar confeccionado com aço inoxidável

AçoSil - tubo de sílica fundida revestido externamente por aço inoxidável

C18 - Fase estacionária octadecil

C8 - Fase estacionária octil

$\mathrm{CE}$ - Eletroforese capilar

CEC - Eletrocromatografia capilar

cLC - Cromatografia liquida capilar

d.e. - Diâmetro externo

d.i. - Diâmetro interno

DAD - Detector de Arranjo de Diôdos (do inglês Detection Array Detector)

$\mathrm{d}_{\mathrm{p}, \max }$ - Diâmetro máximo das partículas

$\mathrm{d}_{\mathrm{p}, \mathrm{med}}$ - Diâmetro médio das partículas

$\mathrm{d}_{\mathrm{p}, \min }$ - Diâmetro mínimo das partículas

$\mathrm{d}_{\text {Sauter }}$ - Diâmetro de partícula nominal calculada definido pela equação de Sauter

ECV - Volume extra coluna

ECD - Detector por captura de elétrons

F.E. - Fase Estacionária

FID - Detector por ionização em clama

F.M - Fase móvel

$\mathrm{F}_{\mathrm{c}}-$ Fluxo

$\mathrm{GC}$ - Cromatografia gasosa

HPLC - Cromatografia líquida de alta eficiência (do inglês High-Performance Liquid Chromatography)

HT-HRGC - Cromatografia gasosa de alta temperatura

IPA - Álcool Isopropílico

LC - Cromatografia Líquida

LC capilar - Cromatografia Líquida Capilar

$\mathrm{MeOH}$ - Metanol

MEV - Microscópio Eletrônico de Varredura

MS - Espectrômetro de massa

$\mathrm{n}_{\mathrm{i}}$ - Número de partículas 
nLC - Cromatografia liquida nano

ODS - Octadecil

OT - Tubular aberta

TP - Programação de Temperatura

PAHs - Hidrocarbonetos Policíclicos Aromáticos

PEEK - Poliéter-éter-cetona (do inglês PoliÉther-Ether-Ketone)

PeekSil - Tubo de sílica fundida revestida externamente por PEEK

PLOT - Coluna tubular aberta com parede recoberta com material poroso (do inglês Porous Layer Open Tubular)

PS-DVB - Estireno divinilbenzeno

PTFE - Politetrafluoretileno

SFC - Cromatografia com fluido supercrítico

THF - Tetrahidrofurano

UV-Vis - Detecção por absorção ultravioleta

WCOT - Coluna tubular aberta com parede recoberta (do inglês Wall-Coated Open Tubular) 


\section{LISTA DE SÍMBOLOS}

$\Delta \mathrm{d}_{\mathrm{p}}$ - Diferença entre $\mathrm{d}_{\mathrm{p}, \max }$ e $\mathrm{d}_{\mathrm{p}, \max }$

$\mu$ - Velocidade linear média da fase móvel

A - Primeiro termo da equação de Van Deemter

$\mathrm{A}_{\mathrm{s}(10 \%)}$ - Fator de assimetria a $10 \%$ da altura do pico

B - Segundo termo da equação de Van Deemter

C - Terceiro termo da equação de Van Deemter

$\mathrm{d}_{\mathrm{c}}-$ Diâmetro interno da coluna

$\mathrm{d}_{\mathrm{f}}-$ Espessura da camada da fase estacionária

$\mathrm{D}_{\mathrm{m}}$ - Coeficiente de difusão molecular

dp - Diâmetro da partícula

$\mathrm{D}_{\mathrm{s}}$ - Coeficiente de dissolução do soluto na fase estacionária

E - Impedância de separação

$\mathrm{E}_{\min }$ - Impedância de separação mínima

F - Fluxo volumétrico

$\mathrm{H}$ - Altura equivalente a um prato teórico

h - Altura reduzida

$\mathrm{k}$ - fator de retenção

$\mathrm{L}$ - Comprimento

$\mathrm{N}$ - Numero de pratos teóricos

N/m - Número de pratos teóricos por metro

$\mathrm{R}$ - Constante universal dos gases

$\mathrm{R}_{\mathrm{s}}$ - Resolução

$\mathrm{T}$ - Temperatura

$t_{M}$ - Tempo de eluição de um composto não retido ou tempo morto

$t_{R}$ - Tempo de retenção

$\mathrm{v}$ - Velocidade reduzida

$\mathrm{W}_{\mathrm{b}(50 \%)}$ - Largura da base do pico a meia altura

$\varnothing$ - Resistência ao fluxo

$\alpha$ - fator de separação

$\Delta \mathrm{H}^{\mathrm{o}}$ - Entalpia

$\Delta \mathrm{P}-$ Queda da pressão 
$\Delta \mathrm{S}^{\mathrm{o}}$ - Entropia

$\eta$ - Viscosidade

$\varepsilon_{\mathrm{T}}$ - Porosidade total 


\section{Sumário}

1.1.

INTRODUÇÃO

1.1.1 Miniaturização das colunas para cromatografia Líquida................................................. 1

1.1.2. Alicerce da miniaturização das colunas (cLC) ...........................................................

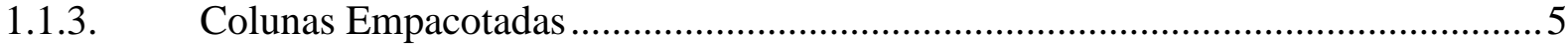

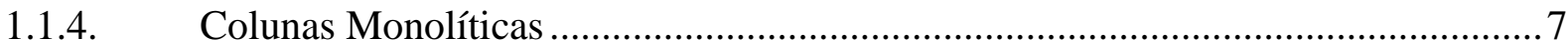

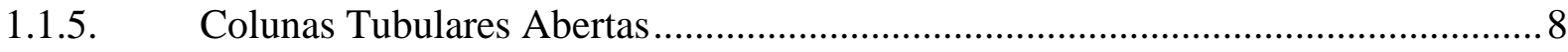

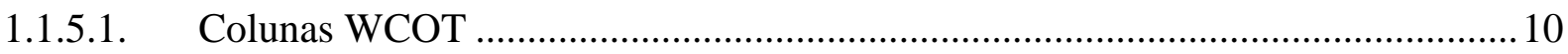

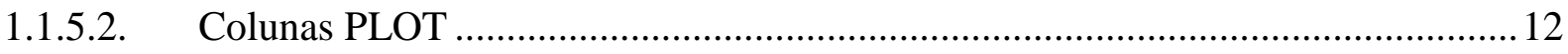

1.1.6. Vantagens e desvantagens da cromatografia líquida capilar .............................. 13

1.1.7. Aplicabilidade de programação de temperatura em cromatografia líquida............16

1.1.7.1. Efeitos da temperatura na eficiência da coluna ................................................ 16

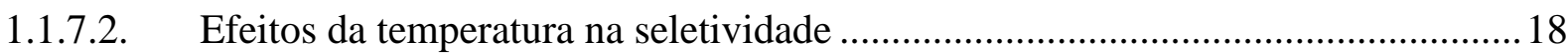

1.1.7.3 Histórico da programação de temperatura em cLC ............................................... 19

1.1.8. Parâmetros utilizados para avaliar o desempenho cromatográfico........................20

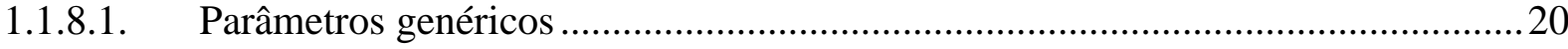

1.1.8.2. Parâmetros reduzidos ou parâmetros de Knox .....................................................23

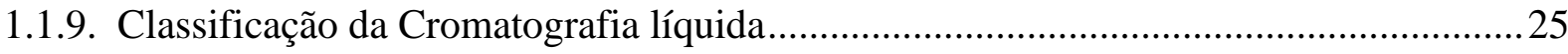

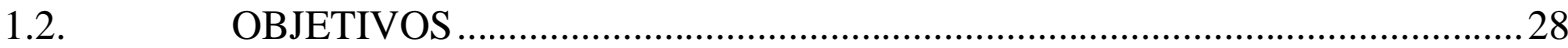

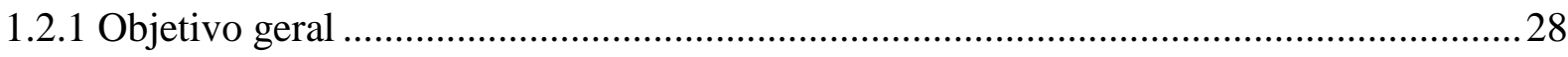

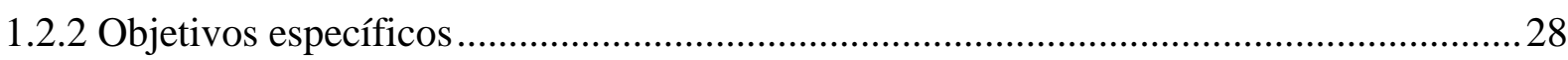

CAPÍTULO 2: Cromatografia líquida capilar em colunas empacotadas ...............................29

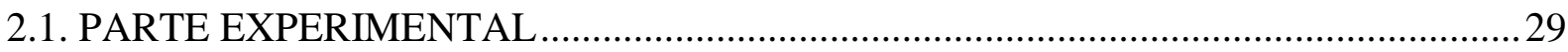

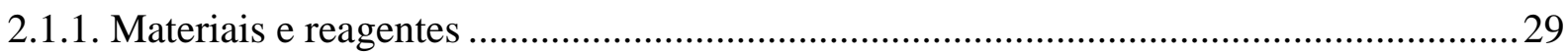

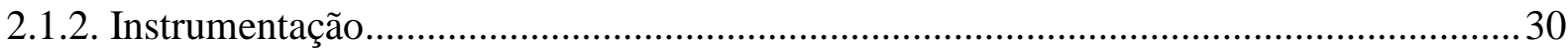

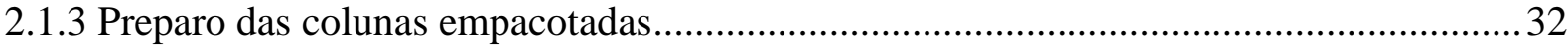

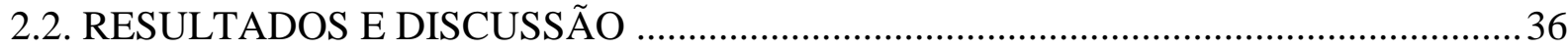




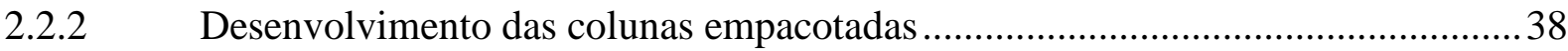

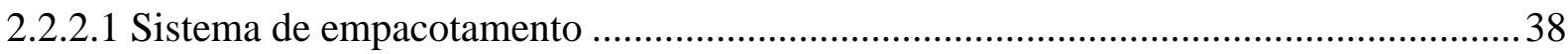

2.2.2.2 Avaliação da repetitividade da metodologia de empacotamento ................................ 42

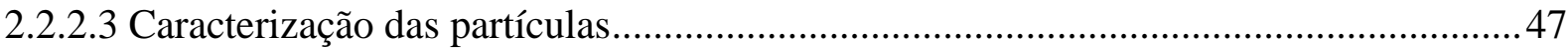

2.2.2.4 Avaliação da influência do tamanho da partícula da fase estacionária no

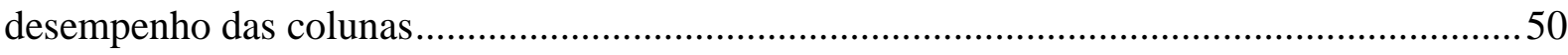

2.2.2.5 Avaliação da influência do comprimento da coluna ...................................................60

2.2.2.6. Avaliação da influência do diâmetro interno no desempenho das colunas ................ 63

2.2.2.7 Avaliação da influência do tipo de material empregado como suporte no desempenho da coluna

2.2.2.8 Avaliação da influência da pressão de empacotamento no desempenho da coluna .....73

2.2.2.9 Avaliação da influência do tipo de bomba empacotadora no desempenho da coluna .77

2.2.2.10 Avaliação da influência dos modelos de hardware utilizados no desempenho da coluna

4.2.2.11. Efeitos do equipamento nas características das colunas 86 CONCLUSÕES DO CAPÍTULO 91

CAPÍTULO 3: Desenvolvimento e avaliação de colunas Tubulares Abertas para cromatografia líquida capilar 92

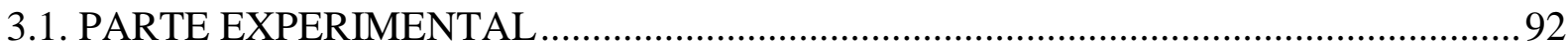

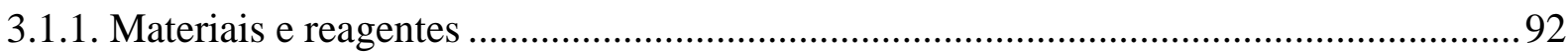

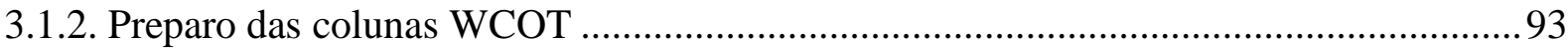

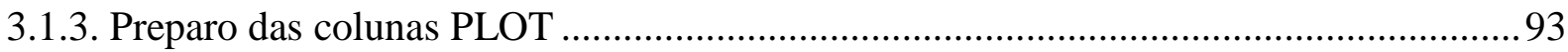

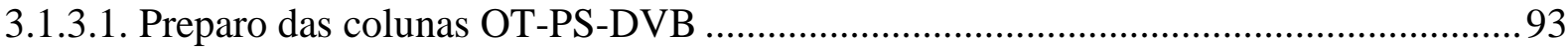

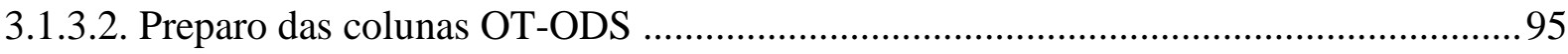

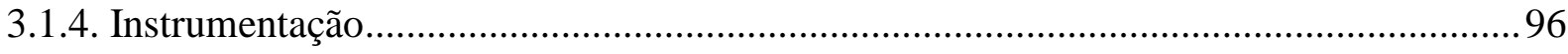

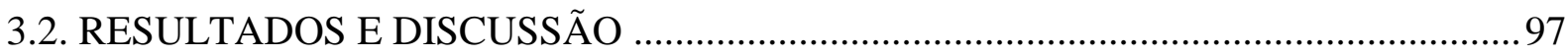

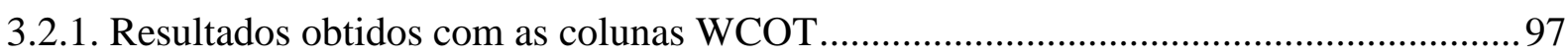


3.2.2. Resultados obtidos com as colunas PLOT

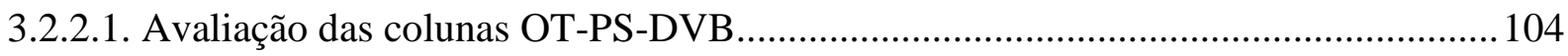

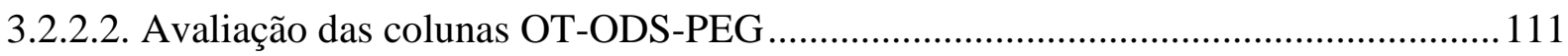

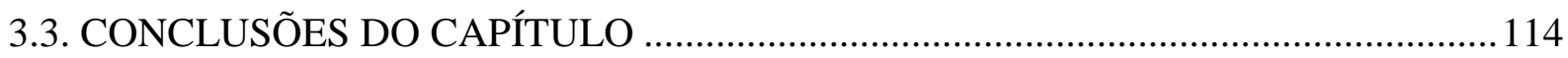

CAPÍTULO 4: Programação de Temperatura em cLC ......................................................... 115

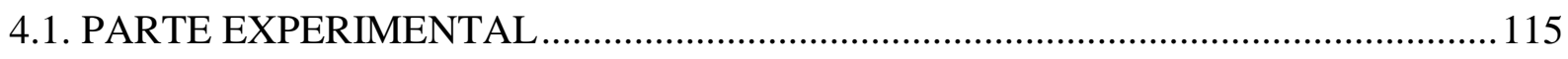

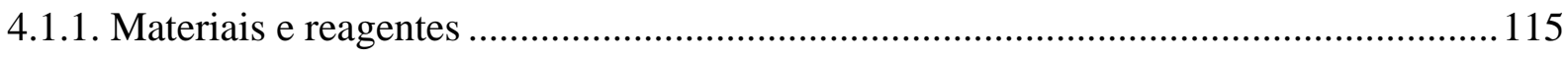

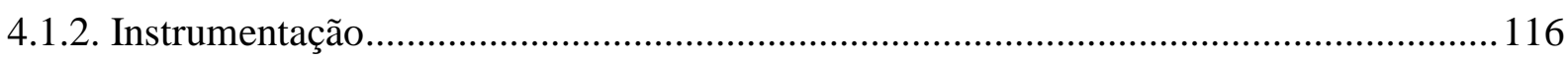

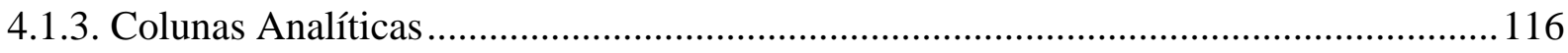

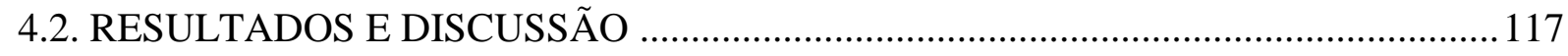

4.2.1. Efeitos da programação de temperatura nas colunas empacotadas .............................. 117

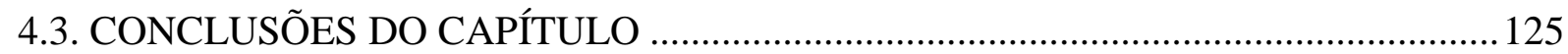

Capítulo 5 - Conclusões gerais e perspectivas futuras ..................................................... 1124므.

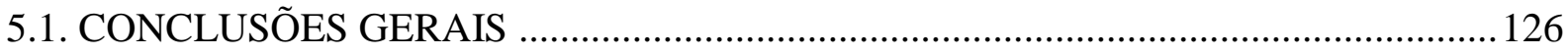

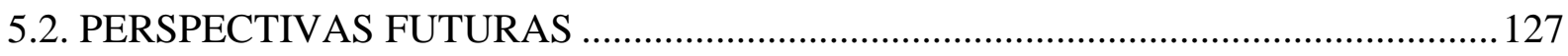

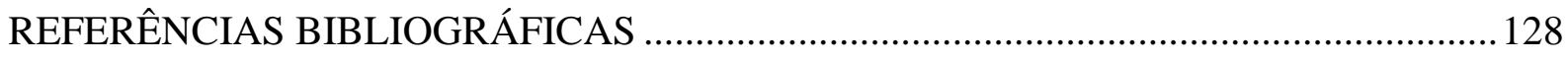




\subsection{INTRODUÇÃO}

\subsubsection{Miniaturização das colunas para cromatografia Líquida}

A cromatografia é uma das principais técnicas de separação a qual, desde a sua descoberta, vem sendo vastamente explorada em suas diversas modalidades (cromatografia liquida, gasosa e supercrítica). Entretanto muito ainda pode ser explorado, sobretudo no que se refere à miniaturização da técnica, cujos avanços têm ocorrido de forma bastante lenta considerando-se principalmente, o fato de que esta é uma das técnicas de separação mais empregadas e sua existência antecede a existência da cromatografia gasosa, cuja versão capilar há muito tempo foi consolidada ${ }^{1}$

A coluna de separação é o componente mais importante do sistema cromatográfico. A miniaturização da cromatografia líquida (conhecida genericamente como Cromatografia Líquida Capilar - cLC) é voltada especialmente à miniaturização das colunas, o que, consequentemente, acarreta na adaptação de todo o restante do sistema como, por exemplo, o fluxo de solvente, o volume de injeção e o sistema de detecção, tornando-os compatíveis com a dimensão da coluna e evitando interferências causadas pelo volume extra coluna ${ }^{2}$.

Uma das principais vantagens da miniaturização da coluna é a possibilidade de empregar diferentes materiais como suporte da coluna, como no caso dos tubos capilares de sílica fundida. Estes consistem em um material mais inerte do que os tubos de metal tradicionalmente empregados em cromatografia líquida, já que a concentração de metais e grupos silanol é relativamente baixa. Uma outra vantagem relaciona-se ao custo da coluna, pois como o diâmetro interno (d.i.) é reduzido, emprega-se menores quantidades de fase estacionária (F.E.), possibilitando inclusive a aplicação de fases de custo mais elevado ${ }^{1}$. Muito ainda pode ser pesquisado e estudado no que se refere à miniaturização das colunas para Cromatografia Líquida (LC) pois, além dos diferentes tipos de materiais que podem ser aplicados como fases estacionárias, pode-se ainda investigar os diferentes tipos de colunas cromatográficas em uma variedade de dimensões (comprimento, diâmetro interno e tamanho de partícula e/ou espessura do filme empregado como fase estacionária).

Existem, basicamente, dois tipos de colunas capilares para cromatografia líquida: colunas cujo tubo é totalmente preenchido (microempacotadas e monolíticas) e tubulares abertas (WCOT e PLOT). As tubulares abertas diferem entre si devido a porosidade na fase estacionária empregada; as colunas WCOT são constituídas por um material não poroso e as colunas PLOT por um material poroso. Uma representação esquemática dessas colunas com 
corte frontal e longitudinal é apresentados na Figura 1. Suas características e aplicações serão discutidas em tópicos no decorrer do texto ${ }^{1,3}$.

(a) (b)

1) Colunas microempacotadas

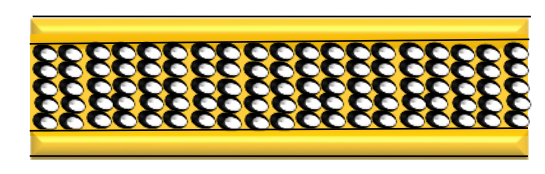

2) Colunas monolíticas
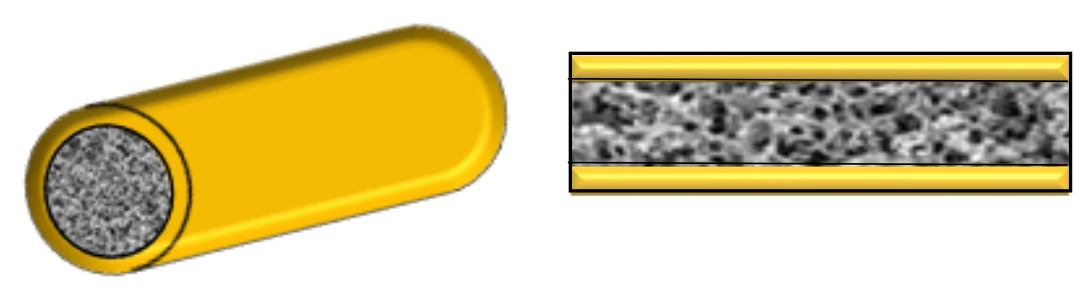

3) Colunas tubulares abertas

3.1) WCOT
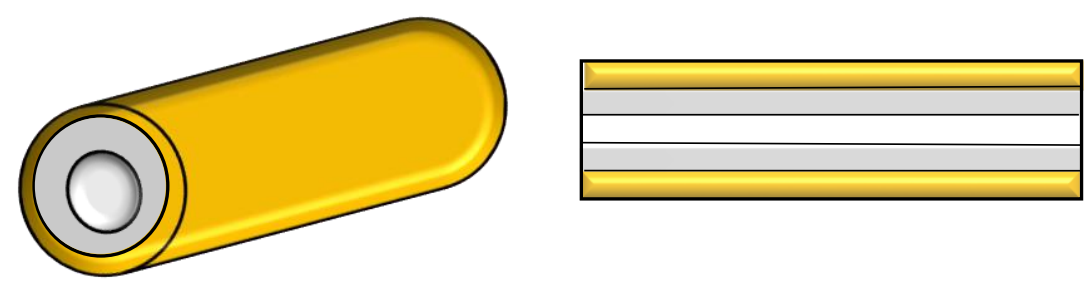

3.2) PLOT
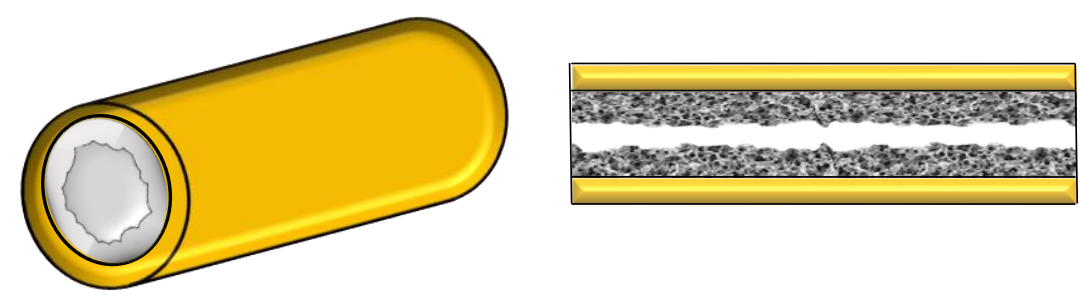

Figura 1- Tipos de colunas capilares empregadas em cromatografia líquida miniaturizada: (a) corte frontal e (b) corte longitudinal 


\subsubsection{Alicerce da miniaturização das colunas (cLC)}

O primeiro relato na tentativa de miniaturização das colunas para cromatografia líquida foi registrado em 1967 quando Horváth et al. ${ }^{4}$, empregaram colunas tubulares abertas de aproximadamente $0,28 \mathrm{~mm}$ e colunas empacotadas de $1 \mathrm{~mm}$ de diâmetro interno (D.I), ambas confeccionadas em tubos de aço inoxidável, na tentativa de se conseguir as condições ótimas para microanálises. Ainda que as colunas abertas não tenham apresentado o desempenho desejado, nas condições empregadas, os resultados das colunas empacotadas apresentaram-se comparáveis aos obtidos em cromatografia gasosa e demonstraram uma boa eficiência na separação de ribonucleotideos ${ }^{5,6}$.

Os trabalhos seguintes remontam a 1976, quando Scott e Kucera ${ }^{7}$ utilizaram uma coluna de sílica gel de $1 \mathrm{~mm}$ de d.i. e $10 \mathrm{~m}$ de comprimento para separar uma série de alquilbenzenos e obtiveram uma eficiência de 250 mil pratos teóricos. Em 1977 Ishii e colaboradores ${ }^{8}$ dedicaram esforços no desenvolvimento de um sistema de cromatografia líquida de alta eficiência na escala micro, que pudesse eliminar o efeito extra coluna gerado no equipamento; para isso, apresentaram uma proposta de um sistema com baixa vazão de fase móvel (F. M), um sistema de injeção da amostra que variava de 0,05-0,5 uL, uma cela de detecção adequada para micro fluxos, um método de gradiente de solvente para eluição dos analitos e, pela primeira vez, propôs-se o emprego de colunas com diâmetro interno de $0,5 \mathrm{~mm}$. As colunas foram produzidas em tubos de PTFE (politetrafluoretileno) com comprimentos de até $30 \mathrm{~cm}$ e empacotadas com partículas de octadecilcilano de $30 \mu \mathrm{m}$ de diâmetro. Após avaliarem as condições ideais para realizar separações na escala micro, conseguiram demonstrar o bom desempenho das colunas na separação de hidrocarbonetos aromáticos e, posteriormente, na separação de ftalatos, vários tipos de oligômeros e de polímeros ${ }^{9}$.

Tsuda e Novotny $(1978)^{10}$ inovaram com colunas empacotadas de diâmetro interno ainda menores $(200,70$ e $50 \mu \mathrm{m})$ e utilizaram como fase estacionária partículas de alumina de diâmetros iguais a 100, 30 e $10 \mu \mathrm{m}$, respectivamente. Como suporte da coluna utilizaram tubos de vidro de diferentes comprimentos (3,6 a $40 \mathrm{~m}$ ). Embora todas tenham apresentado desempenho satisfatório, a eficiência das colunas contendo partículas de 10 um foram menores do que as demais, tal fato foi atribuído ao método de empacotamento empregado que mostrouse menos adequado para esse tamanho de partícula. Mesmo utilizando colunas de vários metros, as pressões geradas não foram muito elevadas a ponto de interferir na eficiência das colunas ${ }^{10}$.

Scott e Kucera (1979) ${ }^{11}$ levaram em consideração os efeitos extra coluna citados por Ishii et. al (1978) e desenvolveram um sistema adequado de LC para microcolunas e um método 
de empacotamento para as mesma. Assim foi possível avaliar os efeitos do tamanho das partículas da fase estacionária e do diâmetro interno do tubo na eficiência da coluna. Para isso utilizaram partículas com diâmetros ainda menores $(5 \mu \mathrm{m})$ do que os que já tinham sido empregados em trabalhos anteriores. Também utilizaram colunas com partículas de 10 um e as compararam com as colunas confeccionadas com partículas de $20 \mu \mathrm{m}$ (bem estabelecidas em colunas convencionais de 4,6 mm de d.i.). Embora os resultados não mostrassem superioridade das colunas de 5 e $10 \mu \mathrm{m}$ de diâmetro com relação às colunas contendo partículas de $20 \mu \mathrm{m}$ (provavelmente devido ao método de empacotamento que favorecia partículas maiores), as mesmas foram capazes de gerar eficiências elevadas ${ }^{9,11}$.

Paralelamente Hirata e Novotny (1979) ${ }^{12}$ conseguiram realizar a separação de uma mistura contendo 16 compostos da classe dos hidrocarbonetos policíclicos aromáticos, utilizando uma coluna de $55 \mathrm{~m}$ de comprimento e $70 \mu \mathrm{m}$ de d.i. e empacotada com partículas de octadecilsilano-alumina de $30 \mu \mathrm{m}$. Eles desenvolveram um método de gradiente de solvente adequado para esse tipo de coluna e realizaram a detecção em série, empregando absorção por UV e fluorescência, tornando possível a separação e identificação dos compostos ${ }^{12}$.

Um grande avanço no desenvolvimento de colunas capilares para cromatografia líquida ocorreu em 1981 quando Takeuchi e Ishii ${ }^{13}$ utilizaram tubos de sílica fundida de 250 $\mu \mathrm{m}$ de d.i. para confecção das mesmas. Tais colunas apresentaram maiores vantagens que aquelas confeccionadas em tubos de aço inox, PTFE e vidro, e isso foi atribuído ao fato que a sílica fundida é considerada um material vítreo mais inerte, mais flexível e de relativa resistência mecânica ${ }^{13}$. A superfície interna do tubo de sílica apresenta maior uniformidade e inercia e tais características também foram apontadas como responsáveis pela maior eficiência das colunas. Produzindo colunas em tubos de sílica de 3 a $80 \mathrm{~cm}$, observaram que os melhores resultados foram obtidos com as colunas entre 3 a $30 \mathrm{~cm}$. As colunas de $10 \mathrm{~cm}$ apresentaram eficiência comparável a eficiência das colunas convencionais de Cromatografia líquida de alta eficiência (HPLC) ${ }^{13}$.

No mesmo período Yang (1982) ${ }^{14}$ também dedicou-se à investigação da miniaturização da colunas para LC, dando grande contribuição com relação à influência do diâmetro interno, do comprimento da coluna, do tamanho das partículas da fase estacionaria, vazão da fase móvel, entre outros fatores que influenciam no desempenho cromatográfico ${ }^{14}$.

Dessa forma, todos os trabalhos citados acima podem ser considerados a base do desenvolvimento da cromatografia líquida capilar. Posteriormente outros trabalhos surgiram, relatando além do uso de colunas capilares empacotadas ${ }^{15}$, colunas tubulares abertas ${ }^{16,17,18,19}$ e, mais recentemente o emprego das colunas monolíticas ${ }^{20,21}$. 


\subsubsection{Colunas Empacotadas}

As colunas empacotadas (também denominadas de recheadas) consistem no tipo de coluna miniaturizada mais empregada até o momento, caracterizadas por apresentarem a fase estacionária na forma de micropartículas de diâmetros médios frequentemente de 3 a $5 \mu \mathrm{m}$, embora diâmetros de partículas de 1,0; 1,8 e 2,0 $\mu \mathrm{m}$ também tenham sido empregados. As partículas devem estar distribuídas ao longo da extensão do tubo capilar da forma mais uniforme possível. A diminuição do tamanho das partículas da fase estacionária (F.E.) promove aumento da eficiência, porém provoca diminuição da permeabilidade da fase móvel (F. M.) e, consequente, aumento da pressão, dificultando o emprego de colunas com partículas menores que $3 \mu \mathrm{m}$ em equipamentos não apropriados para trabalhar com pressões mais elevadas que as usuais $^{3}$.

Com relação ao aumento da pressão é importante ressaltar que, desejando-se trabalhar com pressões que excedam 1000 bar é desejavel a miniaturização das colunas empacotadas, uma vez que em colunas convencionais o calor gerado no interior da mesma, devido ao atrito, é fracamente dissipado. Em colunas "adiabáticas", ou seja, aquelas em que não ocorre a troca de calor, o aumento da temperatura é causada pela vazão do fluxo e pelo gradiente de pressão; dessa forma, diminuindo-se o d.i. da coluna por um fator de 10, espera-se uma diminuição do aumento de temperatura gerada no final da coluna por um fator de 100. Já em coluna com funcionamento isotérmico o efeito deletério do gradiente de temperatura radial aumenta para a sexta potência do raio da coluna, o que representa uma vantagem da miniaturização das colunas empacotadas $^{22}$.

As colunas microempacotadas mais utilizadas são as de diâmetros internos de 100 à 250 $\mu \mathrm{m}$; geralmente, possuem $15 \mathrm{~cm}$ de comprimento. Por possuírem menor diâmetro interno, as colunas empacotadas para cromatografia liquida capilar (cLC) apresentam, em teoria, cerca de 10 vezes mais pratos teóricos do que as colunas empacotadas destinadas a LC convencional $\left(\right.$ HPLC) ${ }^{3}$. Isso pode ser explicado através da equação de Van Deemter ${ }^{23}$ (constituída pelos termos $\mathrm{A}, \mathrm{B}$ e $\mathrm{C})$, a qual estabelece que a altura equivalente a um trato $(\mathrm{H})$ é dependente basicamente de quatro fatores: dispersões devido aos múltiplos caminhos (termo A), dispersão devido à difusão longitudinal (termo B) e dispersões devido à resistência à transferência de massa na fase móvel $\left(\mathrm{C}_{\mathrm{m}}\right)$ e na fase estacionária (termo $\mathrm{C}_{\mathrm{s}}$ ), sendo esses os fatores que contribuem para o alargamento da banda cromatográfica. Desta forma, quanto menor for o diâmetro da coluna, menores serão os efeitos causados pelas dispersões do analito no interior da mesma e, então, maior será a sua eficiência ${ }^{2,3}$. 
Os materiais de preenchimento mais utilizados em colunas microempacotadas são as partículas de sílica, as mesmas utilizadas em colunas de HPLC, recobertas com filmes orgânicos, mais comumente contendo grupamentos octil (C8) e octadecil (C18), ou ligados quimicamente à superfície da sílica, resultando em fases denominadas reversas. As mesmas podem ser obtidas com diferentes porosidades, sendo as de maior porosidade $\left(300^{\circ} \mathrm{A}\right)$ aplicadas na análise de moléculas maiores, como as biomoléculas e as de menor porosidade, aplicadas na análise de moléculas pequenas. As partículas de sílica também podem ser modificadas com diferentes tipos de grupamentos químicos, dando origem a uma variedade de fases estacionárias como, por exemplo, as fases quirais aplicadas na separação de compostos enantioméricos ${ }^{1,3}$.

Outro tipo de partículas disponíveis comercialmente e frequentemente utilizadas para preenchimento das colunas são as partículas de núcleo fundido (como um núcleo sólido e um invólucro poroso), encontradas na faixa de tamanho de 2,5-5 $\mu \mathrm{m}$. Elas têm sido amplamente utilizadas por apresentarem separações altamente eficientes, pressões razoavelmente baixas e permitirem análises rapidas na separação de moléculas pequenas, grandes e/ou complexas 3,24 .

Embora já existam diferentes fases estacionárias para colunas empacotadas miniaturizadas, disponíveis comercialmente a variedade, quando comparada às disponíveis para LC convencional, é muito menor. Além disso, o elevado custo de aquisição das colunas capilares tem incentivado pesquisas no estudo e desenvolvimento de novas fases estacionárias para cLC a fim de se obter não apenas fases com diferentes polaridades como, também, fases que sejam constituídas de materiais mais permeaveis, porosos e seletivos, com o objetivo de permitir a separação de uma grande variedade de compostos com elevada eficiência ${ }^{25}$.

Dentre as novas alternativas de fases estacionárias, que tem sido utilizadas em colunas empacotadas para cLC, destacam-se as colunas empacotadas com materiais poliméricos, colunas empacotadas com grafeno, nanoparticulas, dentre uma infinidade de materiais desenvolvidos, utilizando a sílica como suporte e funcionalizados com diferentes materiais ${ }^{25}$.

Não só o tamanho das partículas e o diâmetro interno do tubo influenciam na eficiência das coluna miniaturizadas, como também o método de preenchimento das mesmas, pois caso não se mostre perfeitamente adequado, as colunas não apresentarão bom desempenho. $\mathrm{O}$ empacotamento das colunas pode ser feito usando-se três técnicas principais: empacotamento a seco, empacotamento por fluido supercrítico e empacotamento com partículas em suspenção. Esta última técnica é a mais empregada, tanto no preparo de colunas convencionais, como no preparo das colunas capilares e consiste em preparar uma suspensão das partículas em um solvente apropriado, denominada "slurry packing". Esta é armazenada em um reservatório adequado, sendo uma de suas extremidades conectada a uma bomba de alta pressão, contendo 
um solvente apropriado, e a outra extremidade do reservatório deverá ser conectada ao tubo capilar que dará origem à coluna. Assim, quando a bomba impulsionar o solvente, a suspensão da fase estacionária será direcionada ao tubo capilar, dando origem à coluna cromatográfica. Essa técnica destaca-se pela sua simplicidade instrumental e tem sido utilizada com sucesso no empacotamento de colunas com partículas de diâmetros de 1 a 3 mícrons ${ }^{1,3,26}$.

No empacotamento a seco as partículas são impulsionadas para o tubo capilar com auxílio de um gás, no entanto, essa técnica apresenta limitações quanto ao diâmetro das partículas da fase estacionária, pois partículas com diâmetros muito pequenos tendem a se aglomerar podendo resultar em um empacotamento não uniforme. Além disso, não se deve utilizar pressões muito elevadas para, assim, evitar que as partículas se fragmentem durante o empacotamento $^{26}$.

Já o empacotamento com fluido supercrítico reúne as vantagens do empacotamento com partículas em suspenção e do empacotamento a seco, uma vez que o fluido supercrítico apresenta propriedades intermediarias entre os líquidos e os gases. Assim, a baixa viscosidade e o alto poder de difusão do fluido supercrítico permitem uma maior homogeneidade do leito cromatográfico, resultando em colunas com maior eficiência. Em contrapartida, essa técnica necessita de uma instrumentação mais sofisticada ${ }^{26}$.

\subsubsection{Colunas Monolíticas}

As colunas monolíticas se constituem de uma forma de coluna similar à microempacotada, desenvolvida mais recentemente (década de 80 ), na qual ao invés de partículas, apresentam um leito cromatográfico preenchido com um monólito. Um monolito é um material que apresenta propriedades únicas, constituindo-se de uma estrutura sólida, com um esqueleto composto por poros com tamanho da ordem de micrometros. Essa morfologia confere alta permeabilidade à coluna, maior que nas colunas empacotadas com partículas, resultado da menor restrição à passagem de solvente. Com isso é possível utilizar maiores vazões, sem elevar muito a pressão do sistema cromatográfico, o que resulta em análises mais rápidas e na possibilidade de se utilizar colunas maiores que as convencionais $(15 \mathrm{~cm})^{5,6}$.

As colunas monolíticas são classificadas de acordo com o material monolítico utilizado, podendo ser divididas em colunas monolíticas preparadas a partir de polímeros orgânicos ou a partir de sílica. Diversos monômeros, ou a mistura deles, podem ser empregados no preparo de colunas monolíticas capilares à base de polímeros orgânicos, como acrilatos, acrilamidas, estirenos, divinil benzeno, entre outros. Esse tipo de coluna monolítica é a mais utilizada devido 
à facilidade do seu preparo, sendo mais comumente empregada na separação de moléculas grandes. Um dos principais inconvenientes da utilização dessas colunas é a instabilidade das fases estacionárias na presença de solventes orgânicos, utilizados como fase móvel, pois os polímeros orgânicos tendem a dilatar ${ }^{3,26}$.

As colunas monolíticas à base de sílica apresentam poros menores e, por isso, são empregadas na separação de moléculas pequenas, podendo ser preparadas a partir de uma grande variedade de percussores ou da mistura deles, como o tetrametoxisilano, metiltrietoxisilano, etiltrimetoxisilano entre outros. Embora apresentem boa estabilidade frente às fases moveis orgânicas, elas apresentam como principal inconveniente a dificuldade de adesão do monólito à parede do tubo capilar. Quando comparadas às colunas a base de polímeros orgânicos, apresentam menor estabilidade química em faixas extremas de $\mathrm{pH}^{26}$.

Os tubos capilares de sílica fundida, na maioria dos casos, são mais adequados ao preparo das colunas monolíticas, isso porque é possível realizar um pré-tratamento na superfície interna do tubo de sílica e, dessa forma, o monolito pode se ligar quimicamente a ela, impedindo que a fase estacionária sofra deslocamento durante as separações ${ }^{3}$.

As colunas monolíticas se destacam pela facilidade na preparação e versatilidade de funcionalização, pois estas podem ser realizadas em uma mesma etapa, além do rápido transporte de massa. Como diferentes grupos podem ser utilizados para funcionalizar o monólito, as mesmas apresentam um caráter mais seletivo. Aliado a este fato, as colunas monolíticas apresentam baixo custo e menor tempo de análise. Estas colunas, mais recentemente, foram disponibilizadas comercialmente, tanto na escala convencional, como capilar, à base de sílica e de polímeros orgânicos ${ }^{5,26,27}$.

\subsubsection{Colunas Tubulares Abertas}

As colunas tubulares abertas consistem em um tubo capilar, geralmente de sílica fundida, na qual a fase estacionária encontra-se imobilizada na parede interna do capilar, mantendo o centro do tubo aberto, daí o nome coluna tubular aberta do inglês open tubular column (OT). A utilização das mesmas em cromatografia gasosa já está bem consolidada, no entanto, foram pouco estudadas e menos desenvolvidas na cromatografia líquida até o momento ${ }^{1}$.

Teoricamente as colunas OT deveriam ser o tipo de colunas mais adequadas para cLC, pois apresentam maior permeabilidade do que as colunas micro empacotadas e monolíticas, gerando pressões muito menores no seu interior. Tal fato pode ser observado através do cálculo 
da resistência ao fluxo $(\varnothing)$, que é um dos parâmetros reduzidos adimensionais e corresponde a uma medida da permeabilidade da coluna. Com relação a este parâmetro observou-se que nas colunas OT o valor é de aproximadamente 32, enquanto nas colunas empacotadas o valor de $\varnothing$ fica em torno de 800. Uma outra vantagem refere-se à menor eficácia nos processos de dispersão conectiva, sendo estes os principais fatores responsáveis por promover um maior número de pratos em uma coluna cromatográfica ${ }^{1,10}$.

Um outro parâmetro utilizado na comparação da eficiência de vários tipos de colunas cromatográficas é a impedância de separação (E), que corresponde a uma medida de desempenho da coluna e permite uma comparação direta entre colunas com diferentes características, como por exemplo, colunas empacotadas e tubular aberta. Quando se compara uma coluna OT em LC, a impedância de separação mínima ( $\left.E_{\min }\right)$ pode ser 100 vezes menor que nas colunas empacotadas. Teoricamente, isso provocaria uma redução de 100 vezes no tempo de análise ou, caso mantenha o tempo constante, seria observado um aumento de 10 vezes na resolução ${ }^{3,28}$.

A principal desvantagem que pode ser citada com relação às colunas OT é a sua baixa capacidade de carga em massa, pois, como a fase estacionária é uma fina película aderida à parede do tubo capilar a sua área de superfície é menor, e por isso, a quantidades de amostra injetada deve ser pequena a fim de se obter uma interação efetiva com a F.E. Dessa forma, é necessário que o diâmetro interno das colunas OT seja bastante pequeno $(<100 \mu \mathrm{m})$ e o comprimento seja o maior possível (maior que os usualmente utilizados em colunas convencionais de LC), o que não consiste em um problema, já que a maior permeabilidade dessas colunas possibilita o uso de colunas com comprimentos na ordem de alguns metros ${ }^{1,28}$.

Mesmo fazendo uso de fases que proporcionem maior área superficial de contato e maior resistência mecânica, ainda assim as colunas OT apresentam menor capacidade de massa quando comparadas com suas respectivas empacotadas provocando, também, limitações da faixa linear de detecção. Para contornar esses problemas, fases mais espessas devem ser empregadas e, assim, aumentar a capacidade de carga das colunas ${ }^{28,29}$.

A influência da espessura da fase estacionaria também pode ser vista através da Equação de Golay expandida (Equação 1); nela observa-se que a altura do prato (H) aumenta de modo inversamente proporcional ao coeficiente de difusão do soluto na fase estacionaria $\left(D_{s}\right)$ e proporcionalmente ao quadrado da espessura da camada de fase estacionária $\left(\mathrm{d}_{\mathrm{f}}\right)$. Assim, a difusão do soluto em uma camada de F. E. mais espessa aumenta, resultando em maior valor de $\mathrm{Ds}^{30,31,32}$ 


$$
H=\frac{2 \mathrm{Dm}}{\mu}+\frac{\mathrm{d}_{\mathrm{c}}^{2}\left(1+6 \mathrm{k}+11 \mathrm{k}^{2}\right) \mu}{96 \mathrm{D}_{\mathrm{m}}(1+\mathrm{k})^{2}}+\frac{\mathrm{d}_{\mathrm{f}}^{2} 2 \mathrm{k} \mu}{3 \mathrm{D}_{\mathrm{s}}(1+\mathrm{k})^{2}} \quad \text { Equação } 1
$$

Onde: $\mathrm{D}_{\mathrm{m}}=$ coeficiente de difusão do soluto na fase móvel;

$\mathrm{D}_{\mathrm{s}}=$ coeficiente de dissolução do soluto na fase estacionária;

$\mu=$ velocidade linear da fase móvel;

$\mathrm{d}_{\mathrm{c}}=$ diâmetro interno da coluna capilar;

$\mathrm{d}_{\mathrm{f}}=$ espessura da camada da fase estacionária;

$\mathrm{k}=$ fator de retenção.

A eficiência das colunas OT pode ser obtida a partir da altura dea um prato $(\mathrm{H})$ determinada pela equação de Golay expandida (Equação 1$)^{30}$.

Nesse caso, o termo A (coeficiente da difusão turbulenta ou efeito dos múltiplos caminhos), correspondente ao mesmo termo na equação de Van Deemter, não contribui para o alargamento do pico, uma vez que, na ausência de partículas, o alargamento causado pelo efeito dos múltiplos caminhos, percorridos pelas moléculas da amostra, é inexistente. Dessa forma, os termos determinantes da eficiência cromatográfica são os referentes à transferência de massa na fase móvel e na fase estacionária ${ }^{30}$.

Levando em consideração que os coeficientes de difusão dos líquidos são pequenos, o segundo termo da equação de Golay mostra que, quanto menor for o diâmetro interno da coluna OT, menor será o valor de H. Em cromatografia gasosa, as colunas capilares que apresentam melhor eficiência até o momento, e por isso são as mais utilizadas atualmente, possuem d.i. iguais a 100, 250, 320 e $530 \mu \mathrm{m}$. Como o coeficiente de difusão dos gases é em torno de 1000 vezes maior que dos líquidos, espera-se que na cromatografia liquida as colunas OT tenham diâmetro interno menor que os utilizados na gasosa, a fim de se obter eficiência mais elevada ${ }^{31}$.

Conforme descrito anteriormente, as colunas utilizadas na cromatografia liquida capilar podem ser divididas em dois tipos: colunas WCOT (do inglês Wall Coated Open Tubular) e colunas PLOT (Porous Layer Open Tubular), sendo a última coluna mais comumente empregada em LC capilar ${ }^{1,23,33}$.

\subsubsection{Colunas WCOT}

Nas colunas WCOT a fase estacionária (F.E) é composta de um material não poroso, geralmente imobilizado na parede do capilar ou aderido a ele a partir de processos de 
entrecruzamento (cross-linking). A utilização da mesma, em cromatografia gasosa, já está bem consolidada. Essas colunas também vêm sendo bastante exploradas na eletroforese capilar, e na eletrocromatografia capilar. Tsuda, et. al., $1978^{10}$ foram os primeiros a obter êxito em realizar separações eficientes, empregando colunas WCOT em cromatografia liquida (LC); mesmo assim, pouco se tem explorado a aplicação das mesmas em LC.

A fase estacionaria na coluna WCOT é mais fina que nas colunas PLOT; assim, a área superficial de contato em que ocorre a interação analíto/fase estacionária é ainda menor, conferindo a essas colunas baixa capacidade de amostra. Isso consiste no principal motivo das colunas WCOT terem sido pouco exploradas; por outro lado, essa característica torna-se ideal quando se dispõe de pequenas quantidades de amostras, como é o caso de algumas áreas como a proteômica, genômica, análise forense, biomédicos, entre muitas outras. Uma forma de aumentar a área superficial de contato da fase F.E, quando assim desejar, seria empregar fases mais espessas para, com isso, aumentar a capacidade de carga em massa da coluna ${ }^{28,34}$.

As fases estacionárias mais empregadas em colunas WCOT são as mesmas que tem sido utilizada em cromatografia gasosa, sendo o polímero líquido de polidimetilsiloxano (PDMS) o mais empregado. A partir desse polímero pode-se produzir uma grande quantidade de novas fases pela inserção de novos grupos funcionais nos grupos pendentes dos siloxanos como, por exemplo, fenil e ciano ${ }^{35}$.

Na Tabela 1 encontra-se a composição química de algumas fases estacionárias derivadas do PDMS utilizadas comercialmente ${ }^{36}$.

$\begin{array}{lll}\text { COMPOSIÇÃO } & \text { USP } & \begin{array}{l}\text { CÓDIGO DO } \\ \text { FABRICANTE }\end{array} \\ \begin{array}{l}5 \% \text { fenil } \\ 95 \% \text { dimetilpolisiloxano }\end{array} & \mathrm{G} 27 & \mathrm{OV}-5 \\ \begin{array}{l}50 \% \text { fenil } \\ 50 \% \text { petilpolisiloxano }\end{array} & \mathrm{G} 3 & \mathrm{OV}-17 \\ \begin{array}{l}14 \% \text { Cianopropilfenil } \\ 86 \% \text { metilpolisiloxano }\end{array} & \mathrm{G} 46 & \mathrm{OV}-1701 \\ \begin{array}{l}6 \% \text { Cianopropilfenil } \\ 94 \% \text { dimetilpolisiloxano }\end{array} & \mathrm{G} 43 & \mathrm{OV}-1301 \\ \begin{array}{l}35 \% \text { fenil } \\ 65 \% \text { dimetilvinilsiloxano }\end{array} & \mathrm{G} 46 & \mathrm{OV}-35\end{array}$

Tabela 1- Descrição da composição, especificação USP e código comercial de algumas fases estacionaria fabricadas para cromatografia a partir do polímero PDMS 
As F.E.s para WCOT podem ser obtidas pelo processo sol-gel ou processos alternativos de revestimentos químicos. A confecção das colunas pode se dar através de duas técnicas: recobrimento dinâmico ou recobrimento estático ${ }^{35}$.

No procedimento dinâmico a solução de fase estacionária é empurrada, com auxílio de um gás, através do tubo capilar deixando um depósito de filme fino na parede; embora consista em uma técnica fácil e simples, resulta em uma menor proporção de fase. Já no recobrimento estático, o tubo capilar é mantido a temperatura elevada para que o solvente da solução da fase estacionária evapore e o vapor seja deslocado para fora da coluna com auxílio do vácuo exercido em uma das extremidades da coluna. Assim, quando a frente da solução recua por causa da evaporação do solvente, um pouco da solução é mantida na parede da coluna aumentando a área efetiva para evaporação e formando um filme de fase estacionária. Essa última destaca-se devido à possibilidade de se trabalhar com fases de grandes massas molares, apresentando como principais vantagens à possibilidade de predizer a espessura do filme de F.E., através da variação da concentração de polímero em solução, além de se tratar de um recobrimento pouco influenciado por fatores externos ${ }^{28,35}$.

\subsubsection{Colunas PLOT}

As colunas PLOT são o tipo de coluna tubular aberta mais empregada em cromatografia líquida capilar até o presente. Embora, a maioria dos trabalhos disponíveis na literatura descrevam o emprego dessas colunas na cromatografia gasosa, nos últimos anos elas vêm ganhando bastante destaque na cromatografia líquida, principalmente quando aplicadas nas separações de moléculas grandes, como no caso da área de proteômica ${ }^{27,28}$.

A fase estacionária das colunas PLOT consiste de um material poroso, geralmente baseado em sílica ou derivado de um monolito (formado a partir de um polímero orgânico ou inorgânico) aderido à superfície do tubo com o centro da coluna permanecendo aberto. Uma das vantagens com relação à utilização dos monolitos é que a camada polimérica pode ser formada in situ e sua adesão ao tubo ocorre através de ligações covalentes, resultando assim, em uma estrutura mecanicamente estável, ou seja, não será empurrada para fora do tubo durante a passagem do solvente. Outra alternativa para a confecção das colunas PLOT é através da deposição de camadas sólidas de adsorvente sobre a parede do tubo, permitindo a imobilização das partículas da F. E.. Entretanto, este método não confere a mesma estabilidade oferecida pelo método in situ s, $27,37^{\text {. }}$ 
A polimerização da fase pode ser iniciada termicamente ou pode ser fotopolimerizada. Algumas das características desse tipo de fase estacionária consiste na funcionalização que facilita sua utilização em tubos capilares. A estrutura física do polímero pode ser modificada e adaptada a determinados tipos de analitos, tornando-as altamente seletivas, sendo quimicamente e termicamente estáveis (suportam condições extremas de $\mathrm{pH}$ e temperaturas elevadas $)^{3,27}$.

Já as colunas PLOT de sílica são fabricadas como uma camada monolítica porosa; comparadas às colunas poliméricas, elas apresentam maior área superficial, são mecanicamente mais estáveis, e mais resistentes ao inchaço ou à retração causada pelo solvente. Em contrapartida, a fabricação do monólito de sílica é mais trabalhosa e a faixa de operação é limitada a uma faixa estreita de $\mathrm{pH}$. Uma variedade de outras fases também pode ser empregada como fases estacionárias para colunas PLOT como, por exemplo, óxidos de metais como zircônia, alumina e titânia ${ }^{28,38}$.

Como já mencionado anteriormente, as fases porosas proporcionam uma maior área de superfície para interação com a fase móvel; assim, as moléculas do soluto que se encontram dissolvidas na F.M. podem migrar (através dos processos de partição ou adsorção) de forma mais efetiva para a F. E., resultando em melhores retenções. Além de conferir maior capacidade de amostra que as coluna $\mathrm{WCOT}^{28}$.

\subsubsection{Vantagens e desvantagens da cromatografia líquida capilar}

As vantagens em relação à miniaturização da coluna em LC não se referem ao decréscimo do tamanho da instrumentação, mas sim, às vantagens relacionadas ao custo e a eficiência da técnica, o que permite a aplicação da cLC em áreas onde a HPLC convencional não se mostra totalmente adequada ${ }^{2}$.

Embora a miniaturização da LC apresente inúmeras vantagens, algumas das quais incluídas de forma resumida na Tabela 2, ela também apresenta alguns inconvenientes como por exemplo:

Necessidade de instrumentação dedicada - uma vez que toda a instrumentação deve ser compatível com as dimensões das colunas miniaturizadas, as tubulações, volume de injeção, volume da cela de detecção devem ser diminuídos. A bomba também deve apresentar um erro absoluto do fluxo muito inferior que as bombas de HPLC. Outro ponto importante são os cuidados adicionais que devem ser tomados, como filtrar tanto a amostra como o solvente em 
que ela for diluída, assim como a fase móvel empregada, pois, qualquer fragmento presente pode provocar entupimento da coluna ou em outras partes do equipamento ${ }^{1}$.

Desenvolvimento de novas colunas - Como a cLC é algo recente, a oferta de colunas capilares pode ser considerada restrita se comparadas as colunas convencionais, mesmo para às fases mais populares, como C-18 ${ }^{1}$.

Número ainda limitado de aplicações práticas - devido a disponibilidade das colunas e instrumentação, ainda são poucas as aplicações em cLC. A maioria das aplicações são mais comuns na área de bioanalítica a qual experimentou grande crescimento nos últimos anos graças, principalmente, aos novos desenvolvimentos e investimentos na área farmacêutica e correlatas ${ }^{1}$.

Competição de técnicas similares - algumas técnicas que competiam com a cLC, como a eletroforese capilar (CE) e a eletrocromatografia capilar (CEC), receberam maior investimento de fabricantes de equipamento e conseguiram se estabelecer mais rapidamente no mercado. Algumas outras técnicas como a cromatografia com fluido supercrítico (SFC) e a cromatografia gasosa de alta temperatura (HT-HRGC), também surgiram próximas ao desenvolvimento da cLC e acabaram dividindo seus nichos de aplicações, adiando o desenvolvimento da cLC naquele momento ${ }^{1}$.

\begin{tabular}{|c|l|}
\hline VANTAGENS & \multicolumn{1}{c|}{ DESCRIÇÃo } \\
\hline $\begin{array}{c}\text { Menor consumo } \\
\text { da Fase } \\
\text { Estacionária } \\
\text { (F.E) }\end{array}$ & $\begin{array}{l}\text { - É considerada a vantagem mais imediata na redução do diâmetro interno (d.i.) } \\
\text { das colunas cromatográficas; }\end{array}$ \\
& $\begin{array}{l}\text { O volume que a fase estacionária ocupa dentro de uma coluna empacotada é } \\
\text { proporcional ao comprimento da coluna e ao quadrado do diâmetro interno da } \\
\text { mesma e essa redução pode tornar viável o uso de fases estacionárias não } \\
\text { utilizadas na HPLC devido ao seu alto custo ou pequena disponibilidade. }\end{array}$ \\
\hline $\begin{array}{c}\text { Menor consumo } \\
\text { da Fase Móvel } \\
\text { (F.M) }\end{array}$ & $\begin{array}{l}\text { A redução do consumo da F.M. ocorre em função da separação cromatográfica } \\
\text { depender da velocidade linear média ( } \mu \text { ) da fase móvel e não do fluxo } \\
\text { volumétrico. Desta forma, uma mesma separação poderá ser atingida em duas } \\
\text { colunas semelhantes, porém, de diferentes diâmetros internos, se mantivermos } \\
\text { a mesma velocidade média linear para ambas; } \\
\text { Essa redução possibilitará o uso de F.M. de alto custo (como fases com } \\
\text { modificadores quirais e solventes deuterados), assim como F.M. tóxicas e } \\
\text { inflamáveis, sem que os mesmos forneçam grandes riscos à segurança do } \\
\text { laboratório ou à saúde dos analistas. }\end{array}$ \\
\hline $\begin{array}{c}\text { Pequenas } \\
\text { quantidades de } \\
\text { amostras }\end{array}$ & $\begin{array}{l}\text { Como a quantidade de F.E na coluna capilar é menor, a quantidade de amostra } \\
\text { também deve ser bem menor para não sobrecarregar a coluna; } \\
\text { Esta característica é de extrema importância em situação que não se dispõe de } \\
\text { grandes quantidades de amostra. }\end{array}$ \\
\hline
\end{tabular}




\begin{tabular}{|c|c|}
\hline $\begin{array}{l}\text { Aumento da } \\
\text { sensibilidade }\end{array}$ & $\begin{array}{l}\text { - A concentração de um analito eluído em uma coluna capilar de } 0,32 \mathrm{~mm} \text { de } \\
\text { d.i. será } 200 \text { vezes maior que a concentração em uma coluna de 4,6 mm de d.i. } \\
\text { (se realizadas em condições cromatográficas semelhantes), pois o processo de } \\
\text { diluição dentro de uma coluna cromatográfica é inversamente proporcional ao } \\
\text { quadrado do seu diâmetro interno. Assim, se detectores sensíveis à } \\
\text { concentração (UV-vis, fluorescência, índice de refração, etc.) forem } \\
\text { utilizados, a sensibilidade na detecção dos picos eluídos será maior. }\end{array}$ \\
\hline $\begin{array}{l}\text { Acoplamento a } \\
\text { diversos } \\
\text { sistemas de } \\
\text { detecção }\end{array}$ & $\begin{array}{l}\text { - O baixo fluxo utilizado na cLC torna viável o acoplamento direto com } \\
\text { diferentes sistemas de detecção como o espectrômetro de massas (MS) e os } \\
\text { detectores normalmente utilizados apenas em CG como o detector por } \\
\text { ionização em chama (FID) e detector por captura de elétrons (ECD). }\end{array}$ \\
\hline $\begin{array}{c}\text { Melhor } \\
\text { permeabilidade } \\
\text { das colunas }\end{array}$ & $\begin{array}{l}\text { Estudos demonstram que as colunas capilares possuem permeabilidade cerca } \\
\text { de duas vezes maior que as colunas de HPLC convencional, o que proporciona } \\
\text { uma significativa redução da pressão da coluna e partículas menores poderão } \\
\text { ser utilizadas ou colunas mais compridas, o que permitirá, em ambos os casos, } \\
\text { analises com alta eficiência. }\end{array}$ \\
\hline $\begin{array}{l}\text { Melhor inércia } \\
\text { química }\end{array}$ & $\begin{array}{l}\text { - Colunas de sílica fundida apresentam uma inercia química característica que } \\
\text { reduz significativamente a influência de traço de metais presentes no material } \\
\text { de empacotamento. }\end{array}$ \\
\hline $\begin{array}{l}\text { Diminuição do } \\
\text { fluxo ótimo }\end{array}$ & $\begin{array}{l}\text { - As colunas de cLC possuem o valor de velocidade linear ótima de } 2 \text { a } 3 \text { vezes } \\
\text { menor que o esperado quando comparado às colunas convencionais e essa } \\
\text { diminuição faz com que a utilização de fluxos lentos reduza a pressão do } \\
\text { sistema. }\end{array}$ \\
\hline $\begin{array}{l}\text { Possibilidade de } \\
\text { construção de } \\
\text { colunas longas }\end{array}$ & $\begin{array}{l}\text { - Como a pressão em cLC é menor é possível utilizar longas colunas, o que } \\
\text { resulta num elevado número de pratos. Isto se deve à diminuição da difusão } \\
\text { por múltiplos caminhos e pela eficiente transferência de calor gerado pela } \\
\text { queda de pressão na coluna. A geração de calor afeta o processo de } \\
\text { transferência de massa, resultando numa baixa eficiência. }\end{array}$ \\
\hline $\begin{array}{l}\text { Utilização de } \\
\text { colunas menores }\end{array}$ & $\begin{array}{l}\text { - Devido à grande eficiência das colunas utilizadas na cLC, existe também a } \\
\text { possibilidade de se utilizar colunas mais curtas com materiais de } \\
\text { empacotamento de diâmetros menores, oferecendo vantagens sobre as } \\
\text { convencionais como, por exemplo, a diminuição do custo e do tempo de } \\
\text { análise e a possibilidade de se analisar amostras instáveis. }\end{array}$ \\
\hline $\begin{array}{l}\text { Facilidade de } \\
\text { manutenção }\end{array}$ & $\begin{array}{l}\text { - Como as colunas de sílica fundida são parcialmente transparentes, pode-se } \\
\text { inspecionar visualmente problemas como vazios, canais, etc. } \\
\text { - Se necessário pode-se utilizar revestimento externo totalmente transparente } \\
\text { como silicone ao invés de poliimida, uma vez que as colunas de LC, ao } \\
\text { contrário das de GC, não são submetidas a temperaturas muito elevadas. }\end{array}$ \\
\hline $\begin{array}{l}\text { Cromatografia } \\
\text { unificada }\end{array}$ & $\begin{array}{l}\text { - Uma das principais vantagens da miniaturização da LC, CG e da } \\
\text { Cromatografia por Fluido Supercrítico (SFC), é a possibilidade do } \\
\text { desenvolvimento da cromatografia unificada. Como apontado por Giddings, à } \\
\text { divisão da cromatografia em várias técnicas é artificial e improdutiva; a GC, a } \\
\text { LC e a SFC são apenas diferentes formas de se apresentar a mesma técnica } \\
\text { devido às particularidades na fase móvel. }\end{array}$ \\
\hline $\begin{array}{l}\text { Aplicabilidade } \\
\text { de Programação } \\
\text { de Temperatura } \\
\quad \text { (TP) }\end{array}$ & $\begin{array}{l}\text { O que impossibilita a aplicação da programação de temperatura em HPLC é o } \\
\text { gradiente radial de temperatura dentro da coluna formado pelo alto fluxo da } \\
\text { fase móvel. Como em cLC o fluxo utilizado é pequeno, assim como o d.i. da } \\
\text { coluna e por isso possui baixa capacidade térmica trona-se viável a aplicação } \\
\text { de TP. }\end{array}$ \\
\hline
\end{tabular}

Tabela 2 - Vantagens relacionadas à miniaturização em LC $\mathrm{LC}^{2,39,40}$ 


\subsubsection{Aplicabilidade de programação de temperatura em cromatografia líquida}

A variável considerada mais importante na obtenção de separações eficientes na cromatografia gasosa é a temperatura da coluna. Assim como na cromatografia gasosa, em cromatografia com fluido supercrítico este parâmetro vem sendo otimizado ao longo do desenvolvimento e consolidação da técnica. Do mesmo modo, em LC a temperatura da coluna também deve ser considerada uma importante variável a ser pesquisada, uma vez que exerce efeitos consideráveis sobre algumas propriedades como a viscosidade da fase móvel, solubilidade, polaridade e a difusividade dos analitos. Deste modo, quase todos os parâmetros de importância na cromatografia, tais como o tempo de retenção, seletividade, eficiência, pressão do sistema e várias outras propriedades da fase estacionária, serão mais ou menos influenciados por variações da temperatura da coluna ${ }^{41,2}$. Como exemplo, pode-se citada a redução da viscosidade quando temperaturas mais elevadas são aplicadas, fazendo com que a velocidade de transferência de massa entre a fase estacionária e a fase móvel seja aumentada e com ela a eficiência, tornando possível diminuir substancialmente o tempo de análise $\mathrm{e}^{2,41,42}$.

A aplicação de temperatura em LC não foi ainda amplamente explorada devido à possibilidade de degradação térmica dos analitos quando expostos a altas temperaturas, e às características físicas das colunas utilizadas. As propriedades dos materiais empregados no preparo das colunas convencionais, assim como suas dimensões, fazem com que a temperatura não seja distribuída de maneira uniforme o equilíbrio térmico, tornando inviável a aplicação de Programação de Temperatura (TP $)^{41}$.

Já na cLC a programação de temperatura torna-se possível devido ao fato do diâmetro interno (d.i.) das colunas utilizadas serem bastante reduzidos e, geralmente, as colunas serem confeccionadas em tubos de sílica fundida recobertas por poliimida. Assim, a baixa quantidade de massa constituinte da coluna capilar faz com que a distribuição de calor, quando variações de temperaturas são aplicadas, ocorra de forma rápida e uniforme ${ }^{2,26}$.

\subsubsection{Efeitos da temperatura na eficiência da coluna}

A eficiência das colunas cromatográficas pode ser expressa numericamente através da determinação do número de pratos $(\mathrm{N})$ ou da altura do prato $(\mathrm{H})$. Sua relação com a velocidade linear média $(u)$ da fase móvel é dada através da equação originalmente formulada por Van Deemter $^{23}$ (Equação 2) 


$$
\mathrm{H}=\mathrm{A}+\mathrm{B} / \mu+\left(\mathrm{C}_{\mathrm{s}}+\mathrm{C}_{\mathrm{m}}\right) \mu
$$

Equação 2

O termo A é um termo relacionado ao efeito dos múltiplos caminhos através dos quais um analito pode percolar a coluna. Conforme a Equação 3 observa-se que este termo é diretamente proporcional à qualidade do empacotamento $(\lambda)$ e ao tamanho das partículas $\left(d_{p}\right)^{26,43,44}$.

$$
A=2 \lambda d_{p}
$$

Equação 3

Embora ainda seja incerta a dependência do termo A com a temperatura, é esperado, que os efeitos não sejam muito significativos; a elevação da temperatura pode melhorar o perfil laminar do fluxo da fase móvel e aumente a difusão lateral das moléculas do analito. Este tempo é mais dependente do tamanho das partículas, $d_{p}$, o qual é inexistente nas colunas tubulares $\operatorname{abertas}^{26,43}$.

O termo B está relacionado à difusão longitudinal do analito, através da Equação 4

$$
B=2 \gamma D_{m}
$$

sendo $\gamma$ a constante relacionada a variável do empacotamento da coluna, e $D_{m}$ o coeficiente de difusão do analito na fase móvel. A elevação da temperatura pode provocar um aumento desse termo em função do aumento do coeficiente de difusão $\left(\mathrm{D}_{\mathrm{m}}\right)$. No entanto, esse termo só se torna significativo em velocidades lineares médias muito baixas ${ }^{26,43}$.

Os termos $\mathrm{C}_{\mathrm{s}}$ e $\mathrm{C}_{\mathrm{m}}$ são relacionados ao transporte de massa do analito entre a fase móvel e a fase estacionária, podendo ser expressos pelas equações 5 e 6

$$
C_{s}=\frac{f_{s}(k) d_{f}^{2}}{D_{s}} \quad \text { Equação } 5 \quad \text { e } \quad C_{m}=\frac{f_{m}(k) d_{p}^{2}}{D_{m}} \quad \text { Equação } 6
$$

sendo $f_{\mathrm{s}}(\mathrm{k})$ e $f_{\mathrm{m}}(\mathrm{k})$ funções complexas do fator de retenção $\mathrm{k}$ e $\mathrm{d}_{f}$ a espessura da fase estacionária, $d_{p}$ o diâmetro da partícula, $D_{s}$ e $D_{m}$ o coeficiente de difusão do analito na fase estacionária e na fase móvel, respectivamente. Quando a temperatura é elevada, os valores dos termos $\mathrm{C}_{\mathrm{s}}$ e $\mathrm{C}_{\mathrm{m}}$ são reduzidos devido ao aumento do coeficiente de difusão do analito na fase móvel e estacionária ${ }^{26,43,45}$. 
Deste modo, o aumento da temperatura é benéfico à eficiência da coluna, com exceção apenas dos casos nos quais um grande coeficiente de atividade de difusão molecular, quando associado com a utilização de uma baixa velocidade linear média da fase móvel, eleva muito o termo B da equação de van Deemter ${ }^{26,43,45}$.

\subsubsection{Efeitos da temperatura na seletividade}

A influência da temperatura $(\mathrm{T})$ no fator de capacidade $(\mathrm{K})$ é usualmente expressa através da equação d Van’t Hoff, Equação 7

$$
\ln \mathrm{k}=-\left(\Delta \mathrm{H}^{\circ} / \mathrm{RT}\right)+\left(\Delta \mathrm{S}^{\circ} / \mathrm{R}\right) \quad \text { Equação } 7
$$

onde: $\Delta \mathrm{H}^{\circ}=$ entalpia do sistema; $\Delta \mathrm{S}^{\circ}=$ entropia do sistema; $\mathrm{T}=$ temperatura absoluta $(\mathrm{K}) ; \mathrm{R}=$ constante universal dos gases $\left(8,31441 \mathrm{~J} \mathrm{~K}^{-1} \mathrm{~mol}^{-1}\right) ; \mathrm{k}=$ fator de retenção; $\emptyset=$ Razão do volume entre a fase estacionária e a móvel ${ }^{41}$.

Essa relação mostra que, para uma mesma mudança na temperatura, o fator de retenção para o soluto com maior $\Delta \mathrm{H}$ é mais afetado do que para soluto com menor valor de $\Delta \mathrm{H}$, fornecendo diferente seletividade em diferentes temperaturas. Assim, uma mudança pode permitir uma separação entre solutos, que não seria obtida empregando-se a temperatura originalmente utilizada. Entretanto, o efeito da temperatura na retenção é pequeno quando comparado com um aumento na força do solvente de eluição. Estudos com diferentes eluentes e faixas de temperatura sugerem que um aumento de $5{ }^{\circ} \mathrm{C}$ na temperatura corresponde a um aumento de $1 \%$ de acetonitrila na fase móvel em fase reversa. A relação linear existente entre $\mathrm{k}$ e 1/T, amplamente estudada em fases reversas empregando distintas condições, tem sido igualmente observada para separações em fase normal e até mesmo em cromatografia de troca iônica ${ }^{41,42}$.

Apesar de que a seletividade em LC pode ser modificada através de vários parâmetros (fase estacionária, fase móvel, $\mathrm{pH}$, natureza do solvente orgânico, dentre outros) a temperatura, até recentemente, tem sido negligenciada como parâmetro de controle de seletividade. Com o surgimento de fornos tecnologicamente mais adequados para LC e o barateamento do seu valor, acredita-se que, em breve, a modificação de seletividade da separação através de modificação (geralmente aumento) da temperatura será mais popular. Deve ser lembrado que este é um dos 
parâmetros mais fáceis de ser ativado e controlado, usualmente através do software ou no painel do instrumento ${ }^{41}$.

\subsubsection{Histórico da programação de temperatura em cLC}

Historicamente, o efeito da temperatura na retenção foi retratado, pela primeira vez, há mais de 50 anos por Strain $^{46}$. Vinte anos depois, Hesse e Engelhardt ${ }^{47}$, demonstraram pela primeira vez a programação de temperatura em LC, utilizando colunas de fase normal com 11 $\mathrm{mm}$ de d.i. e aplicando uma rampa de temperatura de $7{ }^{\circ} \mathrm{C} /$ hora para separar quatro compostos em 10 horas de análise.

$\mathrm{Na}$ década seguinte, outros trabalhos relacionados com programação de temperatura em LC foram relatados na literatura ${ }^{48}$. No entanto, os primeiros estudos dos efeitos da temperatura em cLC só foram realizados na década de 1980 por Takeuchi et al. ${ }^{13}$, Hirata e Sumiya ${ }^{49}$, Bowermaster e McNair ${ }^{50}$, McNair e Bowermaster ${ }^{51}$ e Jinno et $\mathrm{al}^{52}$.

Um pouco mais tarde, o emprego de temperaturas bastante altas (até $200^{\circ} \mathrm{C}$ ) em análises por LC foi demonstrado com a utilização de colunas tubulares abertas com $50 \mu \mathrm{m}$ de d.i. ${ }^{53}$. Contudo, devido às grandes limitações instrumentais encontradas naquele período, e ao emprego de colunas com tais dimensões e a dificuldades em se obter um recobrimento de fase estacionária com boa estabilidade térmica e química, os avanços relacionados ao estudo de temperatura e ao uso de gradiente de temperatura foram sendo mais desenvolvidos com o emprego de colunas capilares empacotadas ${ }^{54,55,56}$.

Estudos comparativos sobre os efeitos da composição do solvente em relação aos observados quando a temperatura sofria variações foram realizados por Bowermaster e McNair $^{57}$. Segundo os autores, o aumento de $1 \%$ na concentração do metanol foi proporcional ao efeito observado quando a temperatura era aumentada de aproximadamente $4{ }^{\circ} \mathrm{C}$. Poucos anos depois, Chen e Horvàth ${ }^{58}$ relataram um efeito similar em analises de alquilbenzeno em fase móvel contendo acetonitrila e água em sua composição.

Atualmente os instrumentos de LC são equipados com dispositivos de aquecimento, seja eles para manter a estabilidade térmica ou para operar em temperaturas elevadas sendo poucos dispositivos utilizados para programação de temperatura, tanto como complemento ou como substituto do gradiente de eluição ${ }^{41,59}$. 


\subsubsection{Parâmetros utilizados para avaliar o desempenho cromatográfico}

A partir dos cromatogramas são extraídos os parâmetros fundamentais, que fornecem informações qualitativas e quantitativas a respeito dos compostos investigados, assim como fornecem informações sobre a qualidade da separação e do desempenho da coluna.

A seguir são descritas as equações mais empregadas na cromatografia líquida para tais finalidades.

\subsubsection{Parâmetros genéricos}

Tempo de retenção $\left(\mathbf{t}_{\mathbf{R}}\right)$ - é o tempo gasto entre a introdução da amostra na coluna e a obtenção do pico correspondente a um dos compostos da amostra. O tempo de retenção de um composto pouco retido pela coluna é definido como tempo morto $\left(\mathrm{t}_{\mathrm{M}}\right)$. A diferença entre o tempo de retenção e o tempo morto é igual ao tempo de retenção ajustado $\left(t_{R}{ }^{\prime}\right)$, a Figura 2 ilustra cada um dos parâmetros no cromatograma ${ }^{60}$.

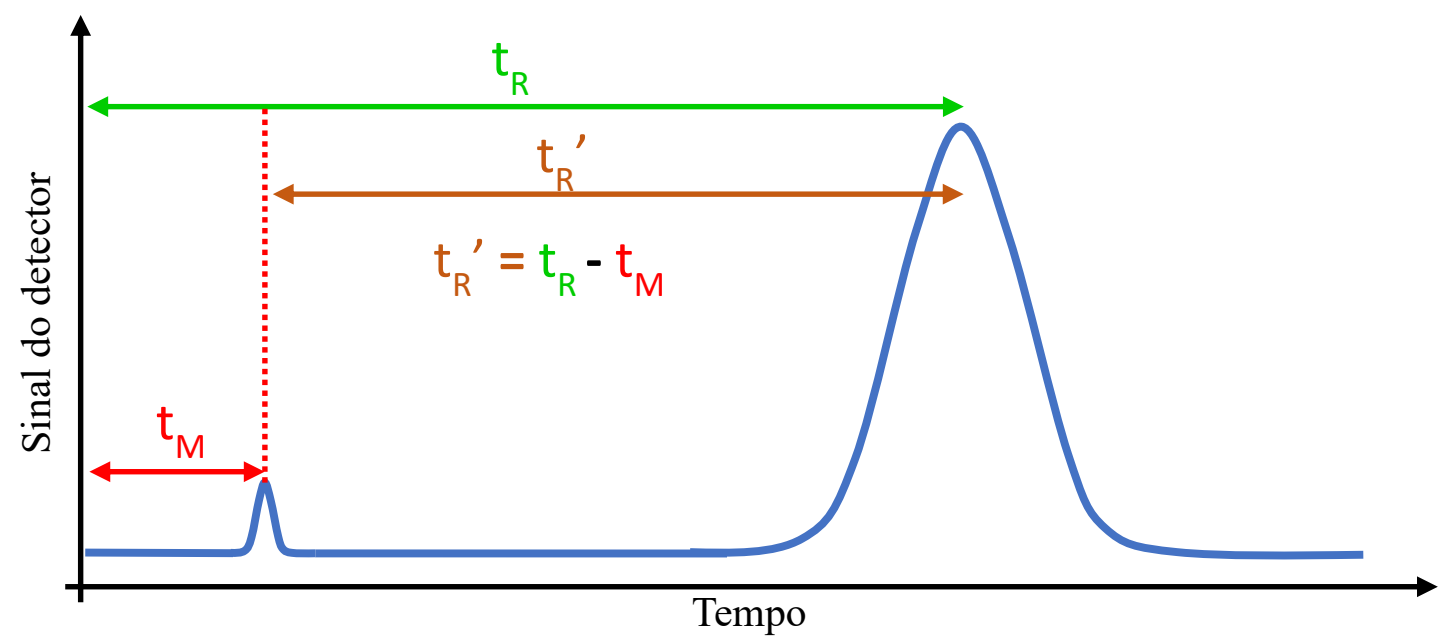

Figura 2 - Cromatograma típico para cálculo de parâmetros cromatográficos Fonte: Adaptado de MEYER, V. R., 2010, p. $426^{61}$

$\checkmark$ Fator de retenção (k) - é a medida do tempo de retenção ajustado, em minutos, de um analito dividido pelo tempo de retenção de um pico não retido. Portanto, expressa a relação do tempo que o analito passa na fase estacionária $\left(t_{s}\right)$ e o tempo que o analito passa na fase móvel $\left(\mathrm{t}_{\mathrm{M}}\right)^{60}$.

$$
\mathrm{k}=\frac{t_{R}-t_{M}}{t_{M}}
$$


Fator de separação $(\boldsymbol{\alpha})$ - é definido pela razão do fator de separação entre dois compostos, assim, para que ocorra separação entre os compostos, os valores de k devem ser diferentes. Corresponde a um parâmetro com característica puramente química ou termodinâmica e pode ser usado para demonstrar se a química permanece invariável, na transferência da separação entre colunas ${ }^{23}$.

$$
\alpha=\frac{k_{2}}{k_{1}}=\frac{t_{R}^{\prime}(2)}{t_{R}^{\prime}(1)}
$$

$\checkmark \quad$ Número de pratos (N) - é uma medida da qualidade da separação, que leva em conta a dispersão do pico. E pode ser determinado por meio da relação entre o tempo de retenção de um composto e a largura de sua base $\left(\mathrm{W}_{\mathrm{b}}\right)$, como mostra a Equação $10^{62}$.

$$
\mathrm{N}=16 \times\left(\frac{t_{R}}{W_{b}}\right)^{2}
$$

Equação 10

Apesar da simplicidade deste enfoque, existem muitas críticas a ele, pois a eficiência $(\mathrm{N})$ depende do tipo de analito escolhido e das condições experimentais. Desta forma, deve-se manter o mesmo composto e as mesmas condições experimentais, para que a medida de $\mathrm{N}$ de uma coluna seja comparável com as das demais. Outros fatores como, o comprimento da coluna (L) e a distribuição das partículas também podem afetar o valor de $\mathrm{N}^{62}$.

Altura equivalente a um prato (H ou HETP) - expressa a eficiência de uma coluna cromatográfica, a partir da relação do comprimento da coluna com o número de pratos teóricos, conforme Equação $11^{23}$.

$$
\mathrm{H}=\frac{\mathrm{L}}{\mathrm{N}}
$$

Colocando um gráfico de $\mathrm{H}$ em função da velocidade linear, é possível obter uma curva (conhecida como curva de Van Deenter), cujo ponto mínimo corresponde ao menor valor de H, obtido em uma velocidade linear ótima. Esta relação pode ser descrita por várias equações como: Equação de Van Deemter (Equação 2), Equação de Giddings (Equação 12) e Equação de Knox (Equação 13) ${ }^{23}$.

$$
\mathrm{H}=\frac{\mathrm{B}}{\mu}+\mathrm{C} \mu+\frac{\mathrm{E}^{*}}{\mathrm{~A}+\frac{\mathrm{B}}{\mu}}
$$


onde E representa uma constante que contém as flutuações de velocidade ao longo de uma distância característica ${ }^{23}$.

$$
\mathrm{h}=\mathrm{Axv} \mathrm{v}^{0,33}+\frac{\mathrm{B}}{\mathrm{v}}+\mathrm{Cv}
$$

onde $\mathrm{h}$ corresponde à altura reduzida e $\mathrm{v}$ à velocidade reduzida, ambos serão discutidos mais adiante. Os termos A, B e C correspondem à dispersão causada pelo fluxo aleatório, à difusão longitudinal e à resistência à transferência de massa, respectivamente ${ }^{23,60}$.

A Figura 3 apresenta as curvas típicas da eficiência da coluna contra a velocidade linear ${ }^{23}$.

Resolução $\left(\mathbf{R}_{\mathbf{s}}\right)$ - A resolução também representa uma medida da qualidade da separação entre dois componentes da amostra, ou seja, é uma medida da relação da distância entre dois picos consecutivos e pode ser calculada a partir da Equação $14^{23,60}$.

$$
\mathrm{R}_{\mathrm{S}}=2 \times \frac{\left(t_{R 2}-t_{R 1}\right)}{\left(W_{b 1}+W_{b 2}\right)}
$$

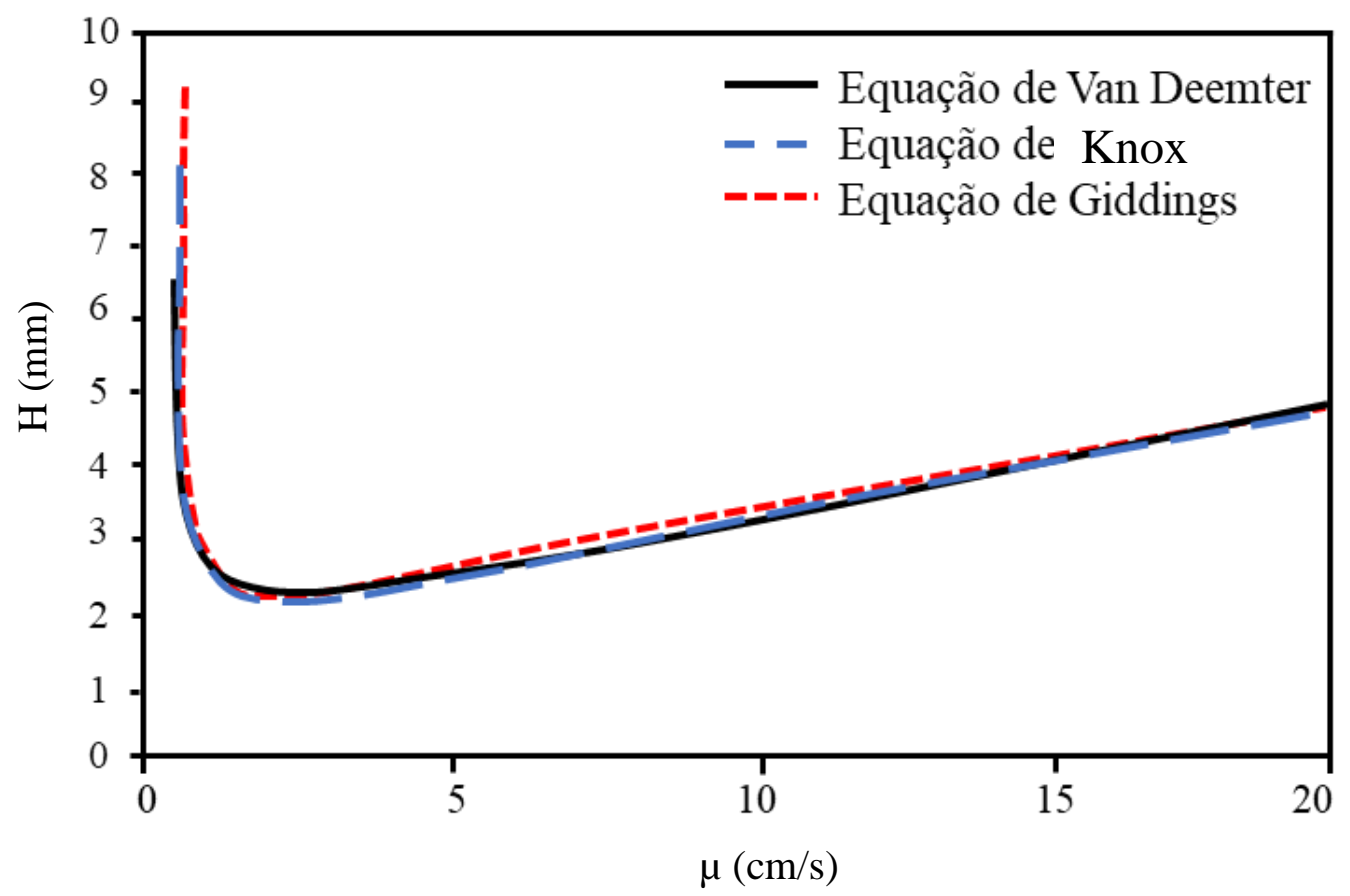

Figura 3 - Sobreposição das formas reduzidas das equações de Van Deemter, Giddings e Knox

Fonte: Adaptado de NEUE, U. D, 1997, p. 29 
Fator de assimetria do pico (As10\%) - é uma outra propriedade importante da coluna cromatográfica, que mede as distorções frontais ou posteriores (caudais), que induzem a superposição dos picos. A determinação da assimetria do pico pode ser calculada dividindo o pico em duas metades (a e b). A razão da largura da base das duas metades (1/2 $\mathrm{W}_{\mathrm{b}(\mathrm{a})} \mathrm{e}^{1 / 2}$ $\mathrm{W}_{\mathrm{b}(\mathrm{b})}$ ) é calculada a $10 \%$ da altura do pico e representa o fator de assimetria (Equação $15)^{63}$.

$$
\mathrm{A}_{\mathrm{S}(10 \%)}=\frac{1 / 2 \mathrm{~W}_{\mathrm{b}(\mathrm{a})}}{1 / 2 \mathrm{~W}_{\mathrm{b}(\mathrm{b})}}
$$

Equação 15

\subsubsection{Parâmetros reduzidos ou parâmetros de Knox}

Uma boa interpretação do desempenho cromatográfico ou eficiência de uma coluna, pode ser feita através dos seguintes parâmetros adimensionais ou reduzidos: impedância $(E)$, altura reduzida (h), resistência ao fluxo (Ø) e a velocidade reduzida (v), descritos a seguir. Eles permitem uma comparação entre os resultados obtidos com colunas de diferentes características como, por exemplo, colunas de diversos comprimentos, partículas de diâmetros diferentes, comparação entre coluna capilar ou convencional, entre fase normal e fase reversa e a comparação quando se usa eluentes com diferentes viscosidades e solutos com diferentes coeficientes de difusão ${ }^{60,64}$.

Para avaliar os efeitos da vazão na eficiência cromatográfica, geralmente usa-se as expressões reduzidas h e v (equação 16 e 17); esses parâmetros levam em consideração o tamanho da partícula da fase estacionária $\left(\mathrm{d}_{\mathrm{p}}\right)$, no caso de colunas empacotadas (ou do diâmetro interno do tubo capilar $\left(\mathrm{d}_{\mathrm{c}}\right)$, quando se utilizam colunas OT), o comprimento da coluna (L), e o coeficiente de difusão dos analítos na fase móvel $\left(\mathrm{Dm}_{\mathrm{m}}\right)$. As equações 16 e 17 mostram como determinar os valores de $\mathrm{h}$ e $\mathrm{v}^{32,64,65}$ :

$$
\begin{aligned}
& \text { Colunas empacotadas colunas tubulares abertas } \\
& \begin{array}{llll}
\mathrm{h}=\frac{\mathrm{L}}{\mathrm{N} \mathrm{d} \mathrm{d}_{\mathrm{p}}} & \text { ou } & \mathrm{h}=\frac{\mathrm{L}}{\mathrm{Nd}_{\mathrm{c}}} & \text { Equação 16 } \\
\mathrm{V}=\frac{\mu \mathrm{d}_{\mathrm{p}}}{\mathrm{D}_{\mathrm{m}}} & \text { ou } & \mathrm{V}=\frac{\mu \mathrm{d}_{\mathrm{c}}}{\mathrm{D}_{\mathrm{m}}} & \text { Equação 17 }
\end{array}
\end{aligned}
$$

onde $\mathrm{N}$ é o número de prato teórico e $\mu$ é a velocidade linear da fase móvel. 
A velocidade reduzida mede a velocidade do fluxo relativa à velocidade de difusão do composto sobre uma partícula da fase estacionária.

A resistência ao fluxo $(\varnothing)$ substitui a permeabilidade da coluna $(K)$ empregada em colunas convencionais ( $\mathrm{K}$ é usualmente utilizada para se obter informações sobre a qualidade do empacotamento da coluna). Para cálculo de $\varnothing$ relaciona-se vários parâmetros com a queda de pressão, o diâmetro da partícula ou o diâmetro interno da coluna com o tempo morto $\left(\mathrm{t}_{\mathrm{M}}\right)$, a viscosidade da fase móvel e o comprimente da coluna, assim como ilustrado na Equação $18^{32,64,65:}$

Colunas empacotadas colunas tubulares abertas

$$
\emptyset=\frac{\Delta \mathrm{Pt}_{\mathrm{m}} \mathrm{d}_{\mathrm{p}}^{2}}{\eta \mathrm{L}^{2}} \quad \text { ou } \quad \varnothing=\frac{\Delta \mathrm{Pt}_{\mathrm{m}} \mathrm{d}_{\mathrm{c}}^{2}}{\eta \mathrm{L}^{2}} \quad \text { Equação } 18
$$

A impedância de separação (E) em LC foi introduzida em 1977 por Knox e Bristow ${ }^{66}$, com o intuito de avaliar colunas com diferentes características, independentemente das condições cromatográficas utilizadas. A Equação 20 representa a forma que propuseram para calcular a impedância ${ }^{60}$.

$$
E=\frac{t_{M} \Delta P}{N^{2} \eta(1+k)}
$$

Equação 20

Nota-se pela Equação 20 que a impedância de separação mede a eficiência de uma coluna considerando o tempo morto $\left(\mathrm{t}_{\mathrm{M}}\right)$, a queda de pressão $(\Delta \mathrm{P})$, o número de pratos $(\mathrm{N})$, a viscosidade do eluente $(\eta)$ e do fator de retenção $(k)$.

Considera-se que uma determinada coluna terá seu desempenho ótimo quando operada em condições que minimizem o valor de E; isso implica que os demais parâmetros reduzidos (h, v e Ø) também devam ser otimizados ${ }^{60,66}$.

Considerando uma coluna empacotada, o valor de E não deve ser maior que 20.000, caso contrário a coluna não apresentará um bom desempenho. Vários fatores podem contribuir para elevar o valor de E como, por exemplo, quando o leito cromatográfico é constituído por partículas muito finas, resultantes da quebra de partículas durante o empacotamento da coluna, o que também eleva o valor de $\varnothing$. Quando o fluxo em que a coluna está sendo operada não é o ideal, pode resultar em alto valor de $\mathrm{h}$, indicando que a velocidade reduzida está acima ou abaixo do valor ideal; isso também elevaria a impedância de separação $0^{60,65}$. 
O fluxo ótimo a ser utilizado na coluna capilar empacotada, pode ser definido através de um gráfico de h versus v, o qual deve ser ajustado a uma das equações da altura reduzida como, por exemplo, a equação de Knox (Equação 13) ${ }^{66}$ :

Assim, a velocidade reduzida ótima ( $\left.\mathrm{v}_{0}\right)$ para um dado composto, pode ser obtida onde o menor valor da altura reduzida $\left(h_{\min }\right)$ é encontrado. O valor de h em uma coluna empacotada deve ser menor que 10, e o valor de v deve ser de no máximo 20, para que a mesma possa ser considerada uma boa coluna. Caso apresentem valores de $\mathrm{h}$ menores que 5 , pode ser classifica como uma excelente coluna. Já os valores de $\varnothing$ para esse tipo de coluna devem ficar entre 100 e $300^{60,65}$.

\subsubsection{Classificação da Cromatografia líquida}

Existem diferentes classificações empregadas para colunas em cromatografia líquida, sendo as mais populares, aquelas que levam em consideração o diâmetro interno das colunas e, como consequência, a faixa de fluxo da fase móvel. A Tabela 3 apresenta a classificação da cromatografia liquida proposta por Ishii et al. ${ }^{9}$ com base no diâmetro das colunas.

\begin{tabular}{ll}
\hline Diâmetro interno $(\mathrm{mm})$ & Nomenclatura \\
\hline 4,6 & HPLC convencional \\
1,5 & Semi-micro HPLC \\
0,46 & Micro-HPLC \\
0,15 & Ultramicro-HPLC \\
$0,2-0,05$ & Colunas micro-capilares empacotadas \\
$0,06-0,01$ & Coluna (capilar) tubular aberta \\
\hline
\end{tabular}

Tabela 3- Nomenclatura proposta por Ishii et al. para LC em função do d.i. da coluna ${ }^{2}$ escala real.

A Figura 4 ilustra uma comparação dos diâmetros das colunas empregadas em LC em 


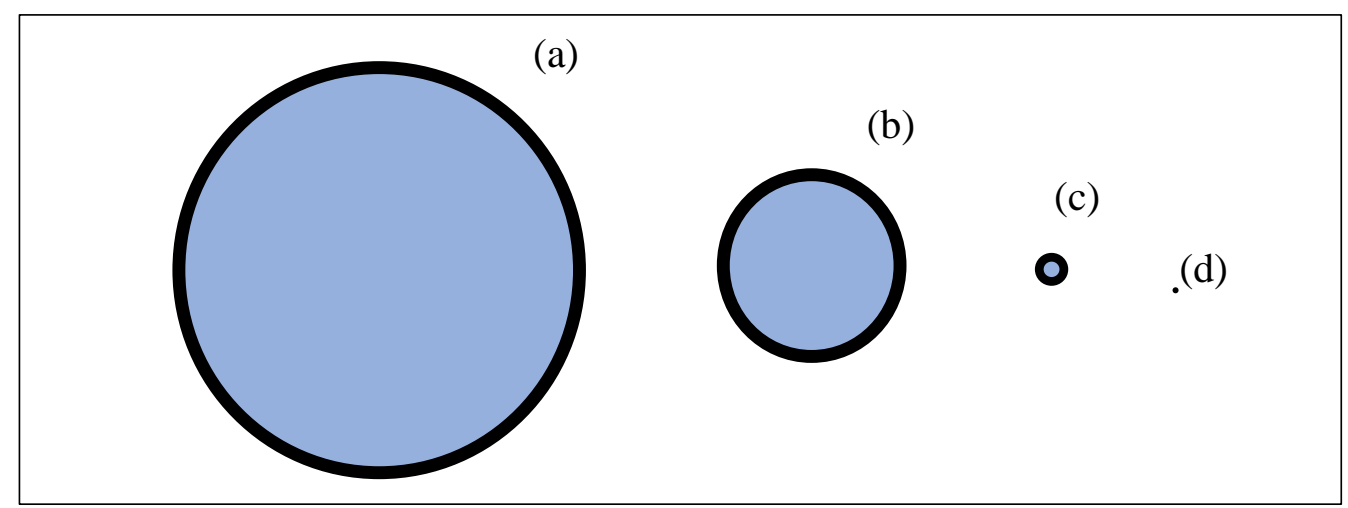

Figura 4 - Comparação, em escala, entre os diversos diâmetros internos de colunas. a) convencional $(4,6 \mathrm{~mm})$; b) microbore $(2,1 \mathrm{~mm})$; c) capilar $(320 \mu \mathrm{m})$; d) $\operatorname{WCOT}(20 \mu \mathrm{m})$

Fonte: Adaptado de COUTINHO, L.F.M. e LANÇAS, F.M., 2011; p. 119

Uma classificação simplificada foi apresentada por Barth et al. ${ }^{67}$ que também se baseava no diâmetro interno do tubo (Tabela 4).

\begin{tabular}{ll}
\hline Diâmetro interno $(\mathrm{mm})$ & Nomenclatura \\
\hline $2-0,5$ & Colunas microbore \\
$<0,5$ & Colunas de micro-LC \\
\hline
\end{tabular}

Tabela 4 - Nomenclatura proposta por Barth et al.

Fonte: Adaptado de COUTINHO, L.F.M e LANÇAS, F.M., 2011; p. 119

Posteriormente, Chervet et al. ${ }^{36}$ e Vissers ${ }^{68}$ introduziram uma classificação da LC de acordo com a faixa de fluxo da fase móvel (Tabela 5) que atualmente é uma das mais empregadas pelos cromatografistas ${ }^{2}$.

\begin{tabular}{lll}
\hline Diâmetro interno & Fluxo & Nomenclatura \\
\hline $4,6-3,2 \mathrm{~mm}$ & $0,5-2,0 \mathrm{~mL} / \mathrm{min}$ & HPLC convencional \\
$3,2-1,5 \mathrm{~mm}$ & $100-500 \mu \mathrm{L} / \mathrm{min}$ & HPLC microbore \\
$1,5-0,5 \mathrm{~mm}$ & $10-100 \mu \mathrm{L} / \mathrm{min}$ & Micro-LC \\
$500-150 \mu \mathrm{m}$ & $1-10 \mu \mathrm{L} / \mathrm{min}$ & LC capilar \\
$150-10 \mu \mathrm{m}$ & $10-1000 \mathrm{~nL} / \mathrm{min}$ & nano-LC \\
\hline
\end{tabular}

Tabela 5 - Classificação da cromatografia liquida

Fonte: Adaptado de COUTINHO, L.F.M e LANÇAS, F.M., 2011; p. 119 
No entanto, apesar de algumas classificações associarem o termo "cromatografia líquida capilar" ("LC capilar" ou "cLC") a um tipo específico de coluna, esse termo atualmente é frequentemente utilizado para se referir, de uma forma geral, a todas as técnicas que utilizam colunas de diâmetros internos menores que as utilizadas normalmente na HPLC (ou seja, inferiores a $1 \mathrm{~mm}$ de d.i. $)^{2}$.

Embora as diversas classificações citadas difiram em um ou mais pontos, todas consideram que as colunas de diâmetro interno menor que 1,0 mm não são mais classificadas como colunas de HPLC convencional. Neste trabalho, iremos considerar colunas para cromatografia liquida capilar como sendo aquelas que apresentam diâmetros internos de 150 a $500 \mu \mathrm{m}$. 


\subsection{OBJETIVOS}

\subsubsection{Objetivo geral}

O principal objetivo deste estudo é estabelecer as melhores condições para o desenvolvimento de colunas capilares empacotas e colunas tubulares abertas, para cromatografia líquida. Após o desenvolvimento e caracterização das colunas, estudar os efeitos de programação de temperatura em cromatografia líquida capilar (empacotadas e tubulares abertas).

\subsubsection{Objetivos específicos}

$\checkmark \quad$ Desenvolver e avaliar colunas do tipo empacotadas em relação ao seu desempenho (packed columns, p-c-LC);

$\checkmark \quad$ Avaliar como algumas características fisicas das colunas empacotadas como tamanho das partículas da fase estacionária, comprimento, diâmetro interno, material empregado como suporte e modelos de hardware podem influenciar no seu desempenho;

$\checkmark \quad$ Avaliar a influência dos tipos de bombas e das pressões de empacotamento empregadas, assim como, comparar os efeitos de diferentes sistemas cromatográficos capilares nas características das colunas empacotadas;

$\checkmark \quad$ Avaliar a utilização de colunas tubulares abertas do tipo WCOT em cLC (WCOT-WallCoated-Open-Tubular ou OTLC);

$\checkmark \quad$ Desenvolver e avaliar o desempenho de colunas tubulares abertas do tipo PLOT em cLC (PLOT - Porous Layer Open Tubular);

$\checkmark \quad$ Fazer uso de programação ideal de temperaturas para aplicar em cLC com as microcolunas empacotadas e tubulares abertas, desenvolvidas. 
Tapitula Q: Gromatografia liuvida capilax em colunas empacotadas 


\section{CAPÍTULO 2: Cromatografia líquida capilar em colunas empacotadas}

Tradicionalmente a coluna empacotada foi o tipo de coluna que se consolidou na cromatografia líquida convencional, sendo a coluna de aço inoxidável, de diâmetro interno (d.i.) de 4,6 mm, a mais popular. Embora não se saiba ao certo o motivo pela preferência por esse tipo de coluna, acredita-se que seja em função da facilidade de manipulação e de adaptação à instrumentação.

Com os avanços industriais e tecnológicos a ciência tem buscado alternativas para minimizar os impactos ambientais. Desta forma, a miniaturização da LC é uma tendência comum e necessária para a adequação à química verde. Mas, diferente da LC convencional, ainda não se tem, por exemplo, um modelo de coluna bem estabelecido, sendo necessário o desenvolvimento de pesquisas que possam avaliar as diferentes características das colunas, como por exemplo o diametro interno, a estrutura, as fases estacionárias, entre outros.

Sendo assim, o presente capítulo descreve os estudos a respeito de colunas capilares, em cromatografia líquida. Uma vez que, a teoria a respeito dessas colunas foi apresentada no capítulo anterior, neste, descreve-se a parte experimental, resultado, discussões e conclusões a respeito do tema.

\subsection{PARTE EXPERIMENTAL}

\subsubsection{Materiais e reagentes}

A limpeza dos materiais utilizados foi realizada com uma solução alcalina de Extra 20 $\%$, onde permaneceram de molho por alno mínimo uma hora e, em seguida, foram enxaguadas com água de torneira e depois com água desionizada. Os solventes utilizados foram: metanol $(\mathrm{MeOH})$ e acetonitrila (ACN) grau HPLC fornecidos pela Tedia, tetrahidrofurano (THF 99\%) e álcool isopropílico (IPA) obtidos da J. T Baker e da Merck, respectivamente. A usabilidade e eficiência das colunas foram testadas com padrões dos hidrocarbonetos aromáticos polinucleares (PAHs) naftaleno, fenantreno, antraceno e pireno, disponibilizados pela Sulpeco.

Como marcador de tempo morto foi utilizada uracila, adquirida da Sigma Aldrich. Ácido fórmico foi empregado para acidificação da F.M..

As soluções estoque com concentração de $500 \mathrm{mg} / \mathrm{L}$ de cada padrão foram preparadas e armazenadas a $-18^{\circ} \mathrm{C}$; as soluções intermediarias foram preparadas pela diluição das soluções estoque em concentrações que dependiam da resposta dos instrumentos de análise. No preparo 
de todas as soluções empregou-se água desionizada de alta pureza (resistividade $18,2 \mu \Omega \mathrm{cm}^{-}$ ${ }^{1}$ ), purificada por um sistema Milli-Q (Millipore).

No preparo das colunas utilizaram-se tubos de sílica fundida de diâmetro interno (d.i.) iguais a 500, 320, 250 e $100 \mu \mathrm{m}$, adquiridos da Polymicro Technologies Inc. e da MicroQuartz. Tubo de poliéter-étrer-cetona (PEEK) e aço inox de $500 \mu \mathrm{m}$ d.i. foram fornecidos pela IDEX Health \& Science; também utilizou-se tubo de sílica de $500 \mu \mathrm{m}$ d.i. revestido externamente por aço (AçoSil). Como frit utilizou-se fibras de vidro da Whatman e frits de aço com poros de 1 $\mu \mathrm{m}$ fornecidos pela Valco Instruments Co. Inc.; as uniões de aço também foram fornecidas por essa empresa. Para colagem dos tubos capilares foi utilizado adesivo Epóxi Araldite Professional da Huntsman. Os conectores e as luvas de teflon foram adquiridos pela Upchurch Scientific $^{\circledR}$

As fases estacionárias empregadas no empacotamento das colunas, assim como suas características e procedências são apresentadas na Tabela 6.

\subsubsection{Instrumentação}

As colunas capilares apresentam volumes internos muito pequenos e, em função disso, toda a instrumentação necessária (injetor, tubulação, conexões celas de detecção e etc.) deve ser redimensionada para se obter o máximo de desempenho da técnica. Dessa forma, foi desenvolvido no grupo CROMA (IQSC - USP) um sistema de cLC (Figura 5) que consta de uma bomba do tipo seringa de baixo volume para evitar dispersão da banda cromatográfica; sistema de injeção equipado com um rotor apropriado à técnica com volume de circuito interno igual a $60 \mathrm{~nL}$ (Valco Instruments, Houston, USA), um detector de Arranjo de Diodos (DAD), modelo SPD-M10AVP e contendo uma cela capilar com configuração em U de volume de 35 $\mathrm{nL}$ conectado a uma controladora modelo CBM-20AD da Shimadzu (Kyoto, Japão) ${ }^{69}$.

\begin{tabular}{lllll}
\hline \multirow{2}{*}{ Fase } & Fórmula estrutural & $\begin{array}{l}\text { Tamanho da } \\
\text { partícula }(\mu \mathrm{m})\end{array}$ & $\begin{array}{l}\text { Tamanho do } \\
\text { poro }(\AA)\end{array}$ & Procedência \\
\hline \multirow{3}{*}{ C18 } & 2 & 100 & Cromatorex \\
& & 3 & 100 & Cromatorex \\
& & 3,5 & 100 & Cromatorex \\
& & 5 & 100 & Cromatorex \\
& 10 & 100 & Cromatorex \\
\hline
\end{tabular}

Tabela 6 - Características e procedência das fases estacionárias empregadas na confecção das colunas empacotadas 


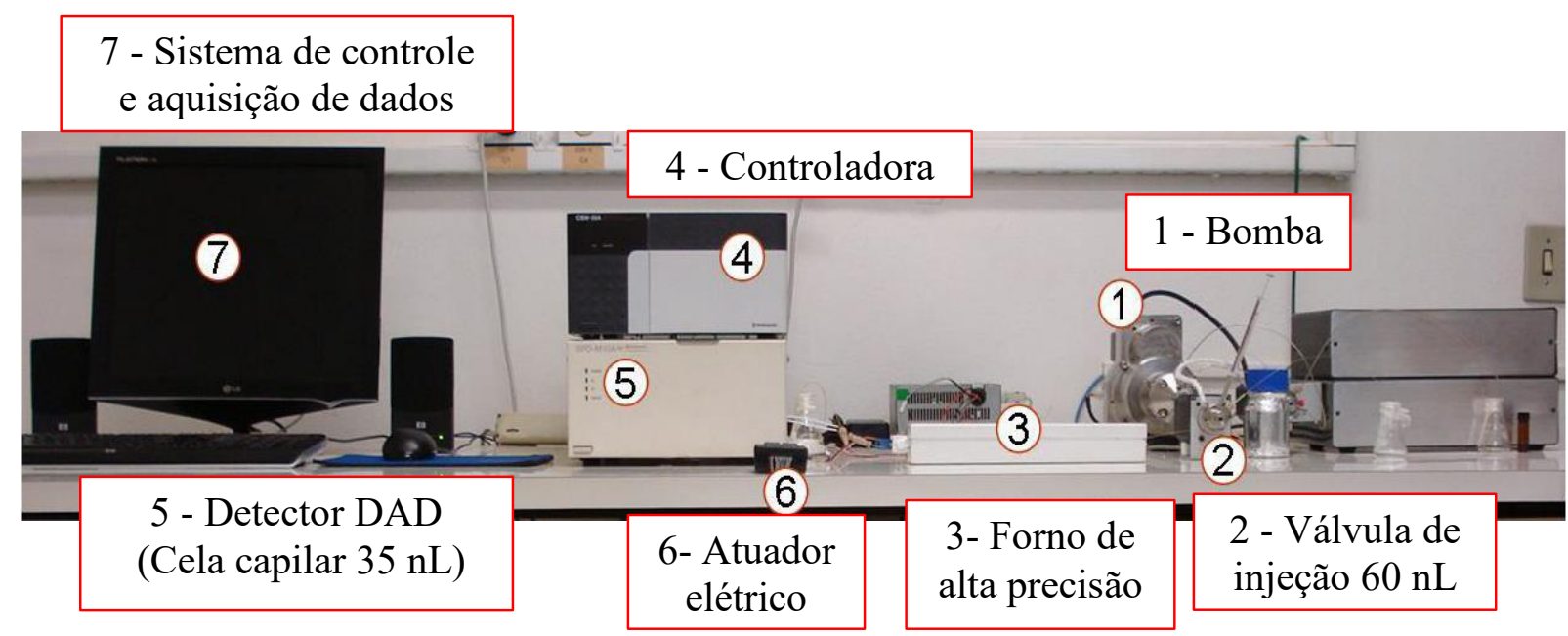

Figura 5 - Imagem do sistema cromatográfico liquido capilar homemade empregado neste trabalho

A utilização de programação de temperatura requer o uso de sistemas diferenciados dos comumente empregados em LC, ou seja, que contenha um sistema de aquecimento com alta precisão e reprodutibilidade para, desta forma, possibilitar resultados satisfatórios/confiáveis e fazer com que as análises apresentem repetitividade aceitável. Desta forma, para empregar a programação de temperatura em sistemas miniaturizados foi desenvolvido um sistema de aquecimento robusto, automatizado e capaz de promover mudanças rápidas de temperatura (Iten 3 da Figura 5) ${ }^{69}$.

Com a intenção de avaliar o desempenho das colunas em sistemas cromatográficos diferentes, utilizou-se também um cromatógrafo capilar comercial, UltiMate ${ }^{\mathrm{TM}} 3000$ RSLCnano da Termo Scientific Dionex (Figura 6), que permite realizar análises tanto na escala convencional, como nas escalas nano, capilar ou micro. Possui amostrador automático com controle de temperatura e válvula para injeção de diferentes volumes de amostra. O loop selecionado neste trabalho foi $60 \mathrm{~nL}$, a coluna é acomodada num forno termostatizado e a detecção é feita na região do UV-Vis com auxílio de um Arranjo de Diodos (DAD) dotado de uma cela de volume igual a $45 \mathrm{~nL}$.

Para empacotamento das colunas foram utilizadas uma bomba reciprocante modelo LC20AT da Shimadzu e uma bomba pneumática amplificadora de alta capacidade (Haskel, modelo DSF-122).

Um Microscópio de Varredura Eletrônica (MEV), ZEISS LEO modelo 440 da Electron Microscopy Inc.(Canbridge, Inglaterra) com detector OXFORD modelo 7060, operado com feixe de elétrons de $20 \mathrm{kV}$, foi usado na caracterização das fases estacionárias utilizadas. 


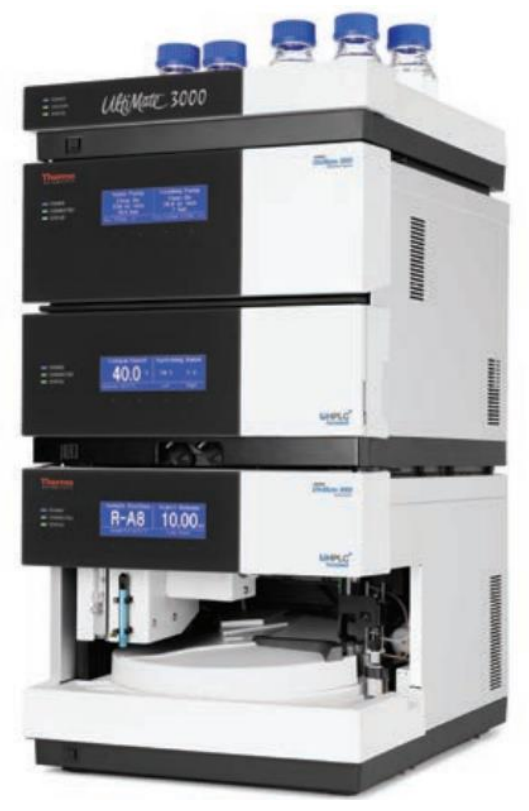

Figura 6 - Imagem do cromatógrafo liquido UltiMateTM 3000 RSLCnano da Termo Scientific Dionex

Fonte: Thermo Fisher Scientífic, 2018

\subsubsection{Preparo das colunas empacotadas}

Foram preparados dois tipos de estruturas "hardware" para as colunas capilares, o primeiro modelo consistia de um tubo capilar que daria origem ao corpo da coluna, onde a fase estacionária seria depositada; nas laterais do tubo foram encaixados dois frits metálicos com auxílio de duas uniões Valco, como ilustra o esquema do hardware na Figura 7.

Diferentes tubos capilares foram empregados na confecção de colunas com esse tipo de hardware, a Tabela 7 apresenta as especificações dos vários tubos utilizados.

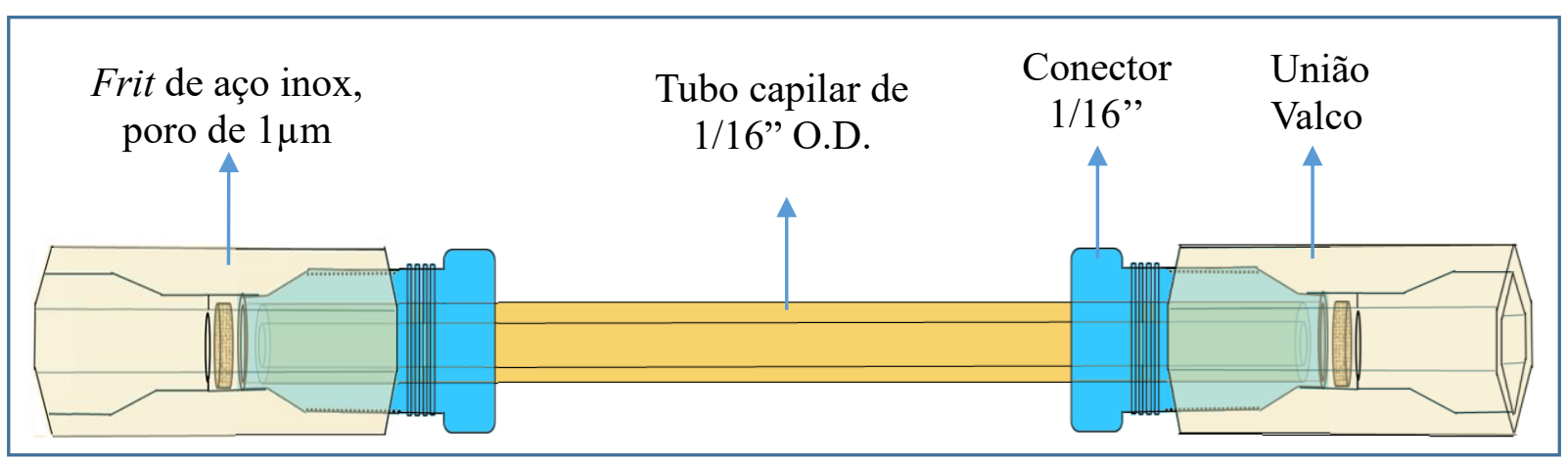

Figura 7 - Primeiro modelo de "hardware" empregado para confecção de colunas capilares empacotadas 


\begin{tabular}{lllll}
\hline Tipo de tubo & d.i. $(\mu \mathrm{m})$ & d.e. $(\mu \mathrm{m})$ & Comprimento $(\mathrm{cm})$ & Pressão máxima $($ bar $)$ \\
\hline Sílica fundida & 100 & 360 & 15 & $>400^{* *}$ \\
Sílica fundida & 250 & 350 & 25,15 e 5 & $400^{* *}$ \\
Sílica fundida & 320 & 465 & 15 & $350^{* *}$ \\
Sílica fundida & 500 & 660 & 15 & $220^{* *}$ \\
PEEK & 500 & 1587,5 & 15 & $345^{*}$ \\
Aço Inox & 500 & 1587,5 & 15 & $>1000^{*}$ \\
AçoSil & 500 & 1587,5 & 15 & $>1000^{*}$ \\
\hline
\end{tabular}

Tabela 7 - Características dos tubos capilares utilizados no primeiro modelo de hardware das colunas empacotadas

*Pressão informada pelo fabricante

**Pressão na qual houve a quebra do tubo durante os testes experimentais de empacotamento

O segundo modelo de hardware foi montado a partir de um tubo capilar de sílica fundida de $250 \mu \mathrm{m}$ de d.i. e $20 \mathrm{~cm}$ de comprimento. Em uma das extremidades desse tubo foi introduzido um filtro de fibra de vidro de mais ou menos $0,1 \mathrm{~mm}$ de espessura, cuja função foi manter as partículas da fase estacionária dentro do tubo durante e após o processo de empacotamento. Em seguida, com auxílio de um tubo capilar de $50 \mu \mathrm{m}$ de d.i. e $8 \mathrm{~cm}$ de comprimento, a fibra de vidro (frit) foi posicionada a aproximadamente $1 \mathrm{~cm}$ da extremidade, funcionando como um restritor, impedindo que o frit e a fase estacionária saíssem do tubo e permitindo que a saída da coluna fosse conectada à entrada do detector. O conjunto foi fixado com adesivo Epóxi, para garantir maior resistência às colunas. A região de junção entre os capilares foi recoberta pelo tubo de sílica fundida de $500 \mu \mathrm{m}$ de d.i. e $1 \mathrm{~cm}$ de comprimento, o qual em seguida foi preenchido com adesivo Epóxi. Formadas as estruturas das colunas elas foram postas para secar à temperatura ambiente, para não correr o risco de temperaturas elevadas deslocarem a massa de adesivo para outras regiões da estrutura. A Figura 8 ilustra o esquema desse tipo de hardware. 


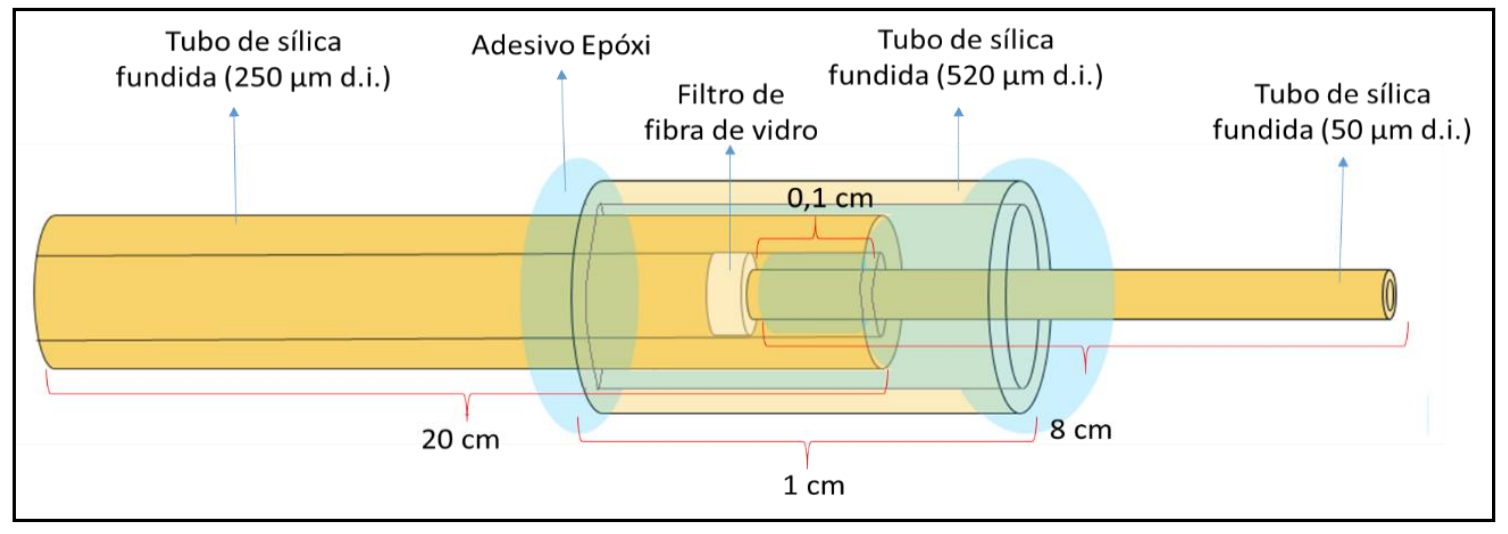

Figura 8 - Segundo modelo de Hardware empregado para confecção de colunas capilares empacotadas

O empacotamento de todas as colunas capilares deste trabalho foi realizado com a técnica de partículas em suspenção "Slurry Packing"; para isso, pesou-se cerca de 6,5; 16,0; 20,5 e 32,0 mg de fase estacionária para as colunas de 100, 250, 320 e $500 \mu \mathrm{m}$ de d.i., respectivamente, e adicionou-se 0,7 mL de uma solução de proporção 1:6 (v/v) THF/IPA. A mistura foi então homogeneizada em Vórtex por $1 \mathrm{~min}$. Utilizou-se para o empacotamento de algumas colunas, uma bomba reciprocante (modelo LC-20AT da Shimadzu), que opera em volumes constantes e para outras colunas, uma bomba hidropneumática (Haskel, modelo SDF122) que opera em pressões constantes. As colunas foram conectadas às bombas através de tubulações acopladas à entrada de um reservatório de aço inox, onde se encontrava a suspenção.

As tubulações conectadas na parte inferior do reservatório eram de aço inoxidável e tinham tamanhos iguais ou superiores a $5 \mathrm{~cm}$; o diâmetro interno variou conforme o diâmetro interno do tubo capilar a ser empacotado. Colocou-se uma união de volume reduzido para conectar os capilares previamente preparados. Assim, quando o solvente da bomba é impulsionado através do sistema, ele empurra a suspenção de partículas para dentro da coluna. Os sistemas de empacotamento empregados estão ilustrados na Figura 9.

O processo de empacotamento durou em média 60 minutos, o solvente utilizado foi metanol (100\%) e a pressão inicial de empacotamento foi igual a 200 bar. Passado esse tempo o sistema de bombeamento foi desligado e esperou-se mais 60 minutos; para que o sistema fosse completamente despressurizado. Em seguida as colunas foram lavadas com um fluxo de cerca de $0,08 \mathrm{~mL} / \mathrm{min}$ com água deionizada durante $30 \mathrm{~min}$ e por fim, acetonitrila $100 \%$ por mais 30 min. Terminada a despressurização, a coluna foi conectada a uma união com volume reduzido (Upchurch Scientific) ligada a um tubo restritor $(50 \mu \mathrm{m}$ de d.i.) que permite seu acoplamento à válvula de injeção do sistema cromatográfico. 


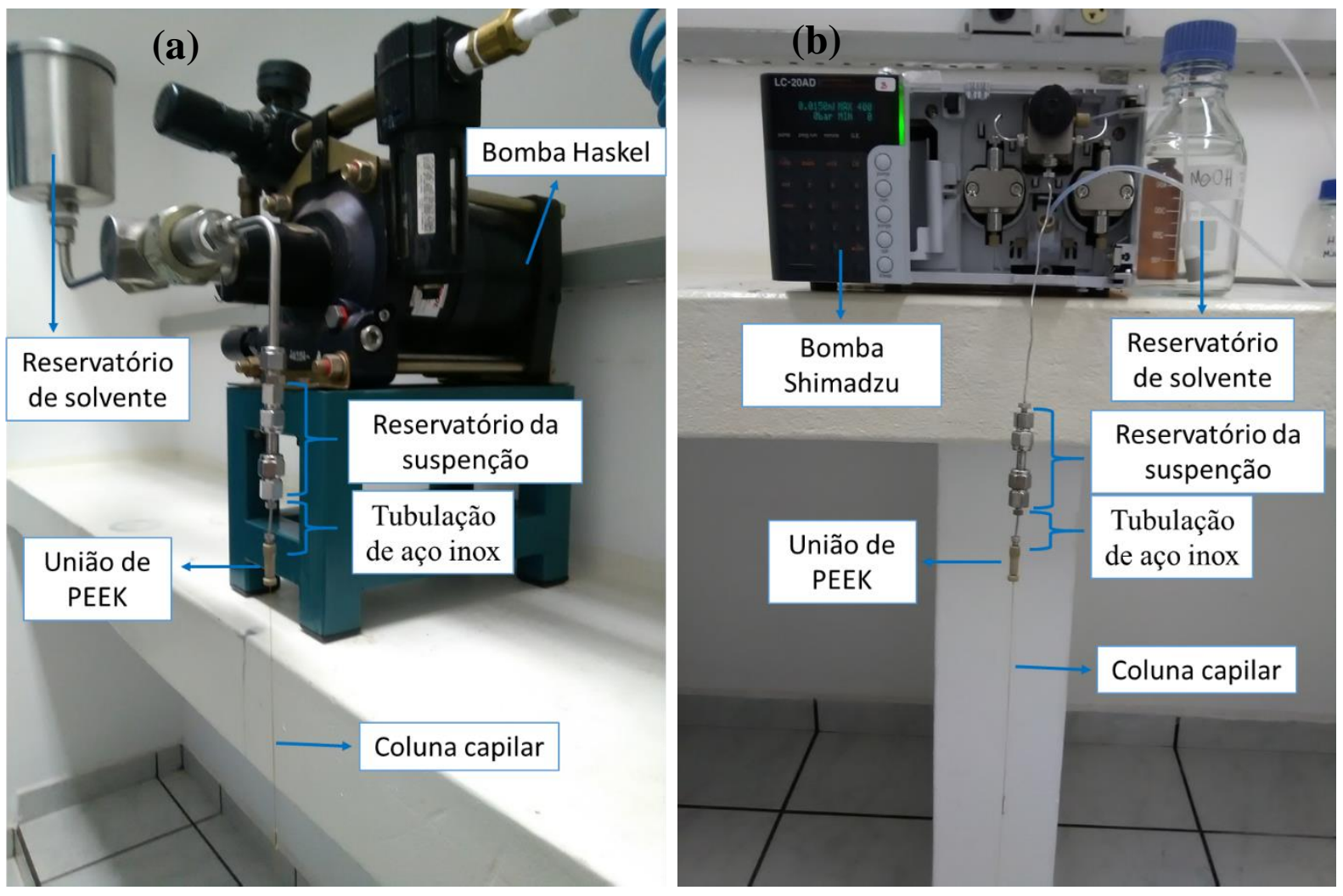

Figura 9 - Sistema de empacotamento das colunas capilares empregando a bomba Haskel (a) e a Bomba Shimadzu (b) 


\subsection{RESULTADOS E DISCUSSÃO}

\subsubsection{Avaliação do efeito extra coluna (ECV)}

Quando se trabalha com as técnicas cromatográficas, uma das principais preocupações é o alargamento de banda, o qual resulta na diminuição da eficiência da coluna e da resolução. As origens do alargamento de banda são duas: excessos de volume morto nos componentes instrumentais ou na coluna. Idealmente os processos de dispersão deveriam estar relacionados apenas com a coluna, mas o equipamento também pode ser uma potencial fonte de dispersão e sendo este fator muito mais acentuado na cLC do que em LC convencional, uma vez que os volumes dos picos eluidos são muito menores, sendo mais susceptíveis a irregularidades na coluna ou problemas fora dela.

Como neste trabalho um dos propósitos foi avaliar a eficiência das colunas cromatográficas produzidas "homemade", foi necessário, inicialmente, investigar se o equipamento poderia ser uma potencial fonte de dispersão pois, caso afirmativo, as eficiências obtidas para as colunas analisadas não corresponderiam aos valores reais. Uma das formas de estimar as contribuições das diferentes fontes de dispersão fora da coluna é através da medida do volume extra coluna (ECV); pode também ser calculada diretamente a partir da dispersão total da banda extracoluna, que está diretamente relacionada à variância extracoluna $\left(\sigma_{\mathrm{ec}}{ }^{2}\right)$.

Sendo assim, a $\sigma_{\mathrm{ec}}{ }^{2}$ foi medida através do método de regressão linear. Para isso foi injetada uma solução contendo os compostos: uracila, naftaleno, fenantreno, antraceno e pireno a uma vazão de $5 \mu \mathrm{L} / \mathrm{min}$. A composição de fase móvel foi escolhida de forma que os analitos apresentassem fatores de retenção $(\mathrm{k})$ entre 1 e 5 , para isso foi empregada $\mathrm{ACN} / \mathrm{H}_{2} \mathrm{O}$ na proporção 70:30 (v/v), sendo alterada a configuração do sistema de detecção, mantendo-se o tempo de resposta no menor valor possível ( 0,2 segundos) e a taxa de aquisição no maior valor permitido no detector $(12,5 \mathrm{~Hz})$. Com os dados obtidos foi construída uma curva das varianças das colunas $\left(\sigma_{\mathrm{col}}{ }^{2}\right)$ em função dos volumes de retenção $\left(\mathrm{V}_{\mathrm{R}}^{2}\right)$ dos picos dos PAHs (Figura 10). Os valores dos interceptos da reta de regressão linear destes gráficos equivalem ao valor de $\sigma_{\mathrm{ec}}{ }^{2} \mathrm{e}$ as inclinações correspondem ao inverso da eficiência $(1 / \mathrm{N})$ das colunas. Desta forma, $\sigma_{\mathrm{ec}}{ }^{2}$ para o sistema homemade e Ultimate 3000 foram iguais a $0,0044 \mu \mathrm{L}^{2}$ e $0,0362 \mu \mathrm{L}^{2}$, respectivamente. Consequentemente o ECV do sitema homemade foi de $0,27 \mu \mathrm{L}$ e do cLC UtiMate 3000 foi de $0,76 \mu \mathrm{L}$ e a eficiências intrínsecas das colunas foram iguais a 17.943 e 11.087, respectivamente.

A $\sigma_{\text {ex }}{ }^{2}$ do sistema convencional UtiMate 3000 corresponde a cerca de $13 \%$ da variância total do pico, a qual corresponde a uma perda de eficiência em torno de 1600 pratos teóricos. 
Comumente é aceita uma $\sigma_{\mathrm{ex}}^{2}$ correspondente a até $10 \%$ da variância total do pico assim como foi observado para o sistema homemade.
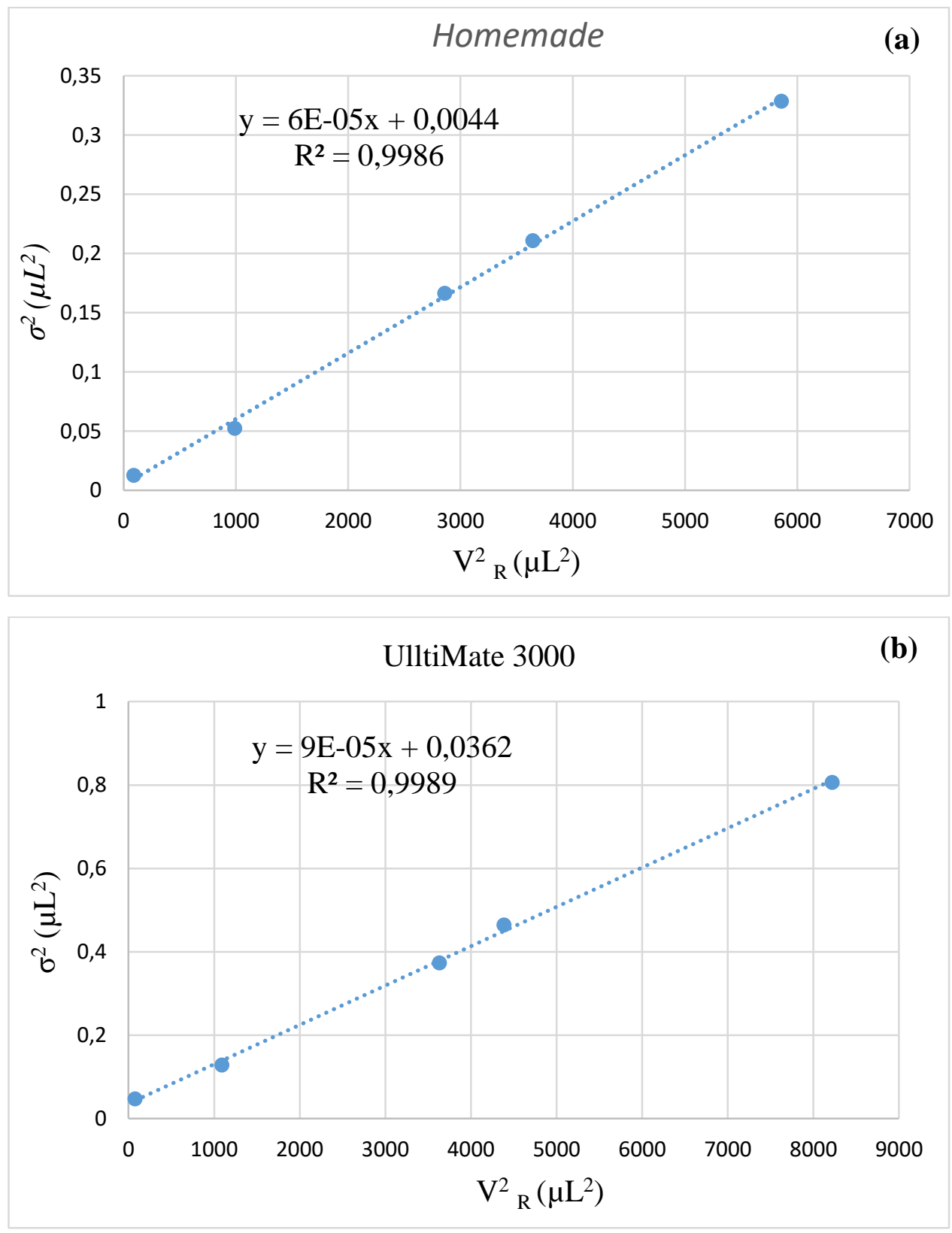

Figura 10 - Gráficos da variância em função do volume de retenção ao quadrado dos equipamentos Homemade (a) e UtiMate 3000 (b) 


\subsubsection{Desenvolvimento das colunas empacotadas}

Neste trabalho buscou-se desenvolver colunas capilares empacotadas para utilizar em cromatografia liquida capilar com programação de temperatura. Para isso era importante que a troca de calor entre a coluna e o sistema de aquecimento ocorresse de forma rápida e que o gradiente radial formado dentro da coluna fosse o menor possível. Sendo assim, o tubo de sílica fundida capilar apresentava-se como uma das opções mais adequadas para ser utilizada como "hardware" da coluna.

Desta forma, o foco inicial foi desenvolver colunas capilares em tubos de sílica fundida e otimizar as condições de empacotamento para que se conseguisse o melhor desempenho possível com estas colunas. Além das condições de empacotamento também foram avaliadas algumas características referentes à estrutura das colunas que poderiam interferir no desempenho das mesmas, tais como: diâmetro interno e comprimento dos tubos, tamanho das partículas das fases estacionárias, tipos de hardware empregados como suportes e a influência do tipo de material do tubo capilar. Também foi verificada a influência da pressão de empacotamento e se o sistema de bombeamento poderia interferir na eficiência das colunas.

Os desempenhos das colunas capilares foram realizados comparando-se os parâmetros cromatográficos calculados, tais como: N/m (número de pratos teóricos por metro), $\mathrm{H}$ (altura equivalente a um prato teórico), k (fator de retenção), h (altura reduzida), v (velocidade reduzida), $\mu$ (velocidade linear média da fase móvel), $\varnothing$ (resistência ao fluxo), E (impedância de separação), $\alpha$ (fator de separação), $\varepsilon_{\mathrm{T}}$ (porosidade total) e $\mathrm{R}_{\mathrm{S}}$ (resolução). Para determiná-los foi injetada uma mistura teste de 4 padrões de PAHs (naftaleno, fenantreno, antraceno e pireno), amplamente descrita na literatura como adequada na avaliação desse tipo de coluna ${ }^{31}$. Empregou-se uracila, como marcador de tempo morto $\left(\mathrm{t}_{\mathrm{M}}\right)$.

Os experimentos foram realizados utilizando-se como fase móvel (70\% acetonitrila e $30 \%$ água) e comprimento de onda de $254 \mathrm{~nm}$. A concentração dos padrões analíticos de PAHs e uracila foram de $10 \mathrm{mg} \mathrm{L}^{-1}$, sendo a temperatura da coluna mantida em $30{ }^{\circ} \mathrm{C}$.

\subsubsection{Sistema de empacotamento}

O processo de empacotamento das colunas capilares pela técnica de partículas em suspensão (slury packed) mostrou-se relativamente simples. O fato do tubo capilar de sílica fundida ser praticamente transparente, facilitou na identificação de eventuais espaços vazios no 
tubo, auxiliando no descarte da coluna, diferentemente das colunas confeccionadas em tubos de PEEK, aço inoxidável e AçoSil, cuja falhas causadas no empacotamento só poderiam ser observadas depois de analisadas no cromatógrafo. O principal inconveniente da técnica consistiu nas altas pressões necessárias para o empacotamento, o que deixou o sistema mais susceptível a vazamentos entre as conexões, exigindo que todo o processo fosse monitorado com muita atenção.

Inúmeros experimentos foram realizados a fim de se conseguir as melhores condições de empacotamento. As principais variáveis investigadas são descritas a seguir:

$\checkmark$ Pressão de empacotamento: Primeiramente aplicou-se pressões de valores mais baixos (cerca de 20 bar) aumentando-se gradativamente. Observou-se que a fase estacionária não ficou uniforme, apresentando falhas ao longo da coluna. Posteriormente realizou-se o empacotamento utilizando pressões iniciais de 50,100 e 200 bar. Verificou-se que a maioria das colunas empacotadas com pressões iniciais de 100 e 200 bar não apresentaram falhas na fase estacionária ao longo da coluna; entretanto, quando aplicados 100 bar, o tempo necessário para empacotamento variava bastante, desde alguns minutos até horas. Sendo assim, foi mantida a pressão inicial de empacotamento em 200 bar, onde o tempo médio de empacotamento foi de aproximadamente $8 \mathrm{~min}$.

Solvente: $\mathrm{MeOH}$ e $\mathrm{ACN}$ foram estudados como solventes de empacotamento, cuja função foi impulsionar a suspenção de fase estacionária do reservatório para o tubo capilar. Verificou-se que tais variações não provocaram diferenças significativas na eficiência das colunas analíticas, portanto; o $\mathrm{MeOH}$ foi fixado como solvente de empacotamento.

$\checkmark$ Solvente da suspensão: os solventes ACN, MeOH, THF:IPA na proporção 6:1 $(v / v)$ e THF:IPA na proporção 1:6 (v/v), foram empregados para preparo da suspenção; observou-se que a mistura THF/IPA (1:6, v/v) mostrou-se mais adequada, uma vez que a suspenção permaneceu inalterada por um maior período de tempo com relação às demais. Provavelmente tal fato ocorreu devido à energia de superfície das fases modificadas com C8 e C18 serem baixas e, portanto, solventes com energia de superfícies menores como o IPA tornam-se mais adequados, pois promoverão uma maior "molhabilidade" das fases formando suspenções mais resistentes à sedimentação. Como o IPA é um solvente muito viscoso, a adição de THF se faz necessária para que a suspenção não se torne demasiadamente viscosa e não interfira na velocidade de empacotamento ${ }^{70,71}$. 
$\checkmark$ Concentração da suspensão: Alguns trabalhos abordam a concentração da suspenção como uma das principais variáveis a serem consideradas no empacotamento da coluna, pois, dependendo dela, o leito formado pode se apresentar bastante heterogêneo. Por exemplo, nos casos em que a concentração da suspenção é baixa, a tendência durante o empacotamento é que forme uma segregação do tamanho das partículas, com desvio local da densidade de empacotamento perto da parede do tubo. Torna-se também provável a formação de espaços vazios no leito, resultando em colunas com baixa eficiência.

Pensando nisso foram testadas três concentrações de suspenção iguais a 6, 11 e 23 $\mathrm{mg} / \mathrm{mL}$ (essas concentrações foram utilizadas na confecção das colunas de $250 \mu \mathrm{m}$ de d.i. e 15 cm de comprimento). Observou-se que as colunas empacotadas com a suspenção de $23 \mathrm{mg} / \mathrm{mL}$ não só apresentaram melhor desempenho, como também uma drástica redução no tempo necessário para que o tubo fosse totalmente preenchido com a F.E. Deve ser lembrar que essa concentração corresponde a uma quantidade de F.E muito superior a necessária para preencher um tubo capilar de $250 \mu \mathrm{m} \times 15 \mathrm{~cm}^{72}$.

$\checkmark \quad$ Modo de homogeneização da suspensão: a homogeneização da suspenção foi feita em ultrassom e em agitador Vórtex. É importante que a suspenção permaneça a mais homogênea por um maior período de tempo possível, para que, quando impulsionada pelo solvente de bombeamento para dentro do tubo capilar, as partículas escoem de forma gradativa, sem formação de aglomerados. Desta forma, diferentes tempos de sonicação e agitação em vórtex foram avaliados, sendo possível perceber que em 1 minuto de agitação da suspenção em vórtex a suspenção escoou continuamente para dentro do tubo, sem interrupções, diferentemente do que acontecia quando a suspenção era sonicada.

Despressurização do sistema: notou-se que o tempo de despressurização do sistema não influenciava nos resultados, desde que a pressão do sistema fosse completamente zerada. Quando a coluna era removida antes disso, erro observado que as partículas da fase estacionária eram deslocadas para fora do tubo capilar, devido à diferença de pressão entre o ambiente e o interior da coluna. Assim, as colunas só foram removidas após total despressurização do sistema.

Após escolher as condições para empacotamento das colunas, elas foram conectadas ao cLC para iniciar o condicionamento das mesmas; verificou-se que a pressão do sistema capilar oscilava bastante. Na tentativa de sanar as variações de pressão, foram confeccionadas outras 
colunas onde, após cessar o empacotamento, passou-se água deionizada e acetonitrila $100 \%$ através da coluna por 30 min cada.

O sistema cromatográfico, quando operado com essas novas colunas, apresentou maior estabilidade da pressão. Tal fato deve-se, provavelmente, à diferença de viscosidade entre a água e o metanol; como a água é mais viscosa, pode ter contribuído para uma melhor compactação das partículas da F.E, auxiliando na uniformidade do fluxo da F.M através da coluna.

Para confecção das colunas com diâmetros internos inferiores e superiores a $250 \mu \mathrm{m}$, e para as colunas com comprimentos inferiores e superiores a $15 \mathrm{~cm}$, utilizou-se uma quantidade de F.E no preparo da suspenção, proporcional à quantidade empregada nas colunas de $250 \mu \mathrm{m}$ d.i. por $15 \mathrm{~cm}$ comprimento.

As etapas de empacotamento das colunas empregadas nesse trabalho foram esquematizadas, para uma melhor compreensão, na Figura 11, enquanto que a Figura 12 ilustra algumas colunas empacotadas confeccionadas com os vários tipos de materiais utilizados durante o desenvolvimento deste trabalho.

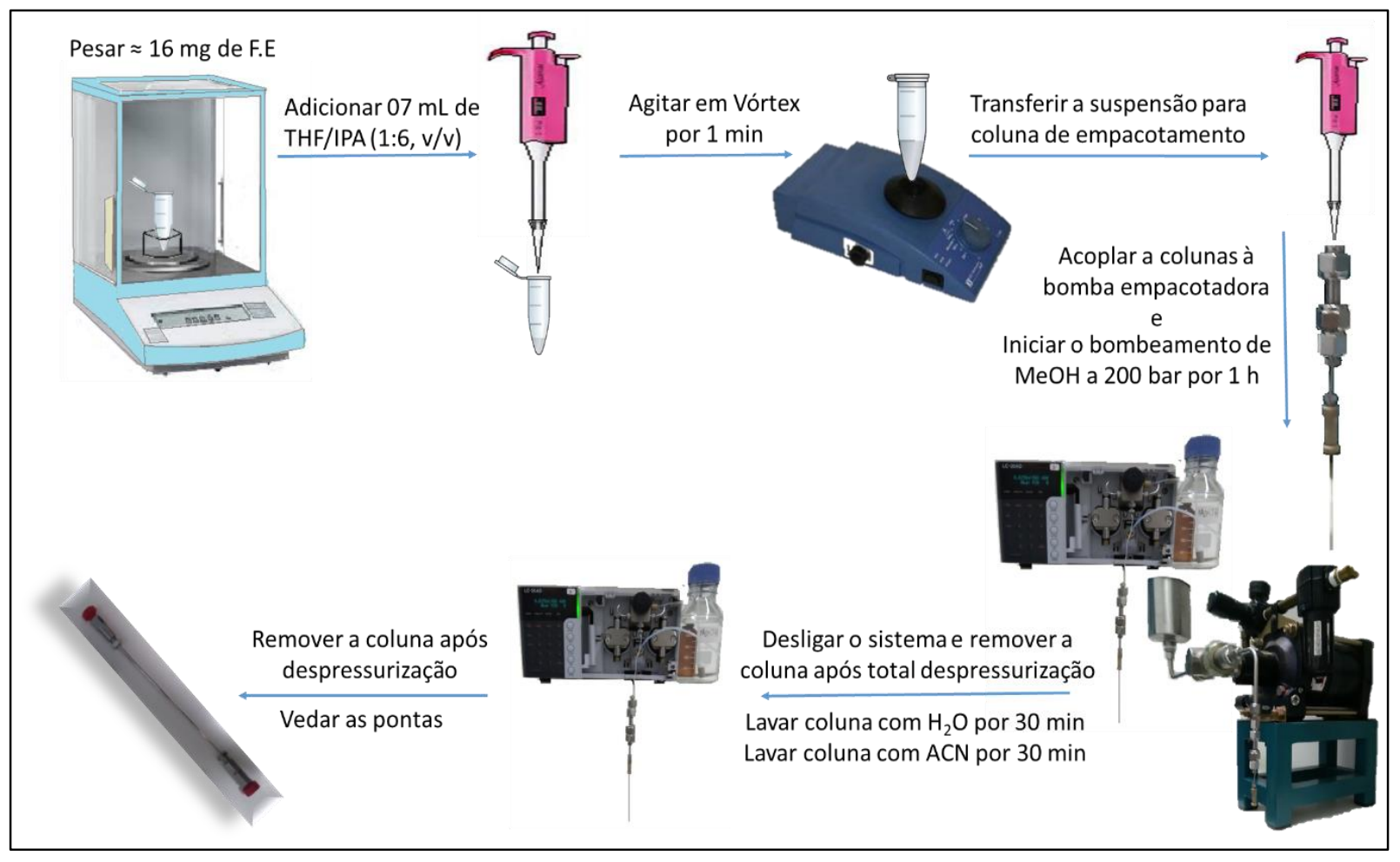

Figura 11 - Esquema das principais etapas envolvidas na confecção das colunas empacotadas 


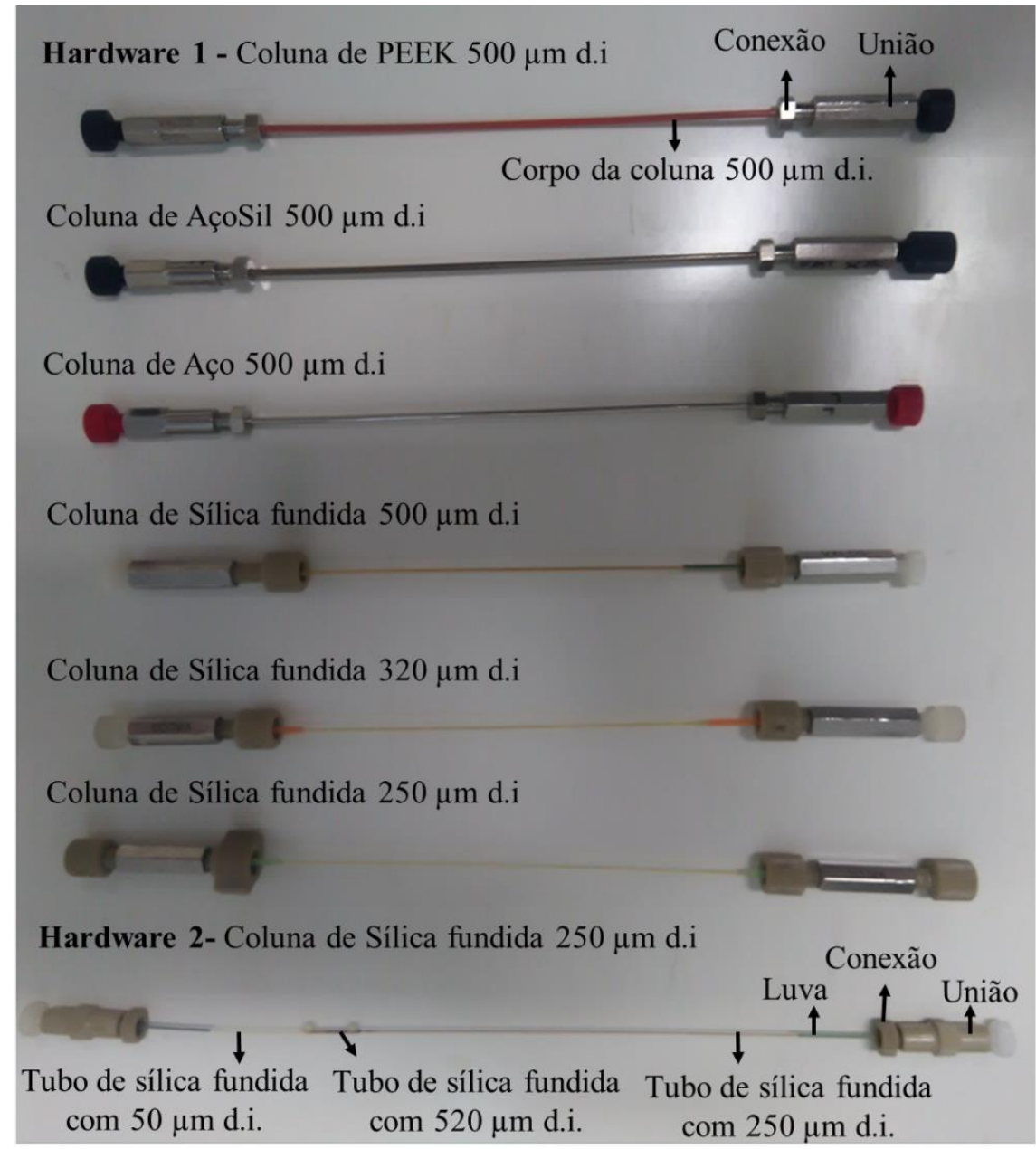

Figura 12 - Imagem das colunas capilares confeccionadas pela técnica "slurry-packing"

\subsubsection{Avaliação da repetitividade da metodologia de empacotamento}

Após estabelecidas as melhores condições de empacotamento, foram confeccionadas colunas capilares empregando o modelo 2 de "hardware", com $15 \mathrm{~cm}$ de comprimento e diâmetro interno de $250 \mu \mathrm{m}$. Utilizou-se fases estacionárias C18 com partículas de diferentes tamanhos: 2,0; 3,0; 3,5; 5,0 e 10,0 $\mu \mathrm{m}$. Para cada tipo de F.E foram confeccionadas colunas em triplicata (descritas como colunas $\mathrm{N}^{\circ} 1, \mathrm{~N}^{\circ} 2$ e $\mathrm{N}^{\circ} 3$ ).

O estudo da reprodutibilidade, assim como a avaliação do desempenho de todas as colunas empacotadas desenvolvidas neste trabalho, foram realizados empregando a mistura teste de PAHs, composta pelos padrões de naftaleno (primeiro composto eluido da coluna) dos isômeros antraceno e fenantreno (cuja separação cromatográfica é um bom indicativo de $\mathrm{R}$ e $\mathrm{k}$ da coluna) e do pireno, composto mais retido e que, por isso, tende a apresentar maior alargamento de banda e menor intensidade. 
Para definir o tempo para eluir um pico não retido, usualmente denominados de tempo morto $\left(\mathrm{t}_{\mathrm{M}}\right)$, foi realizado um teste com as soluções de uracila $(50 \mathrm{ppm})$, metanol/água (40:60 $v / v)$ e acetonitrila/água $(40: 60 \mathrm{v} / v)$ para escolher qual a solução mais apropriada. Na literatura encontram-se sugestões de que um bom marcador de tempo morto seria uma mistura contendo proporções de solventes contrárias às proporções de solventes empregados como fase móvel. Por exemplo, ao se utilizar uma F.M composta por $60 \%$ de acetonitrila e $40 \%$ de água, um bom marcador de tempo morto seria uma solução contendo $40 \%$ de acetonitrila ou metanol e $60 \%$ de água.

Nesta parte do trabalho as colunas foram confeccionadas em série, tentando reproduzir ao máximo possível as condições de empacotamento. A bomba de empacotamento empregada foi a Haskel e as colunas foram analisadas no cromatógrafo líquido capilar Ultimate 3000 da Thermo Fisher Scientific, sob as condições cromatográficas descritas anteriormente. Com excessão apenas, dos testes realizados para escolha do indicador de tempo morto, que foram realizados no cLC homemade.

A Figura 13 apresenta os cromatogramas da injeção das soluções utilizadas como indicadores de tempo morto.

Observa-se que os tempos de retenção foram iguais para todas as soluções e assim, qualquer uma delas poderia, em princípio, ser usada como marcador de tempo morto. No entanto, como o pico da uracila apresentou intensidade maior que as demais, optou-se por utilizá-la.

Embora todas as 15 colunas tenham sido avaliadas (para cada uma das 5 F.Es. empregadas foram feitas 3 colunas) serão apresentados, para simplificação, os dados cromatográficos correspondentes apenas às colunas confeccionadas com a F.E de 2,0 $\mu \mathrm{m}$ de diâmetro de partícula, uma vez que todos os conjuntos de colunas avaliadas se apresentaram muito semelhantes. Os cromatogramas apresentados na Figura 14 foram sobrepostos para que fosse possível observar com maior clareza a semelhança dos tempos de retenção dos analitos eluidos nas colunas de F.E de 2,0 $\mu \mathrm{m}$, aqui denominadas de colunas $\mathrm{N}^{\circ} 1, \mathrm{~N}^{\circ} 2$ e $\mathrm{N}^{\circ} 3$. 

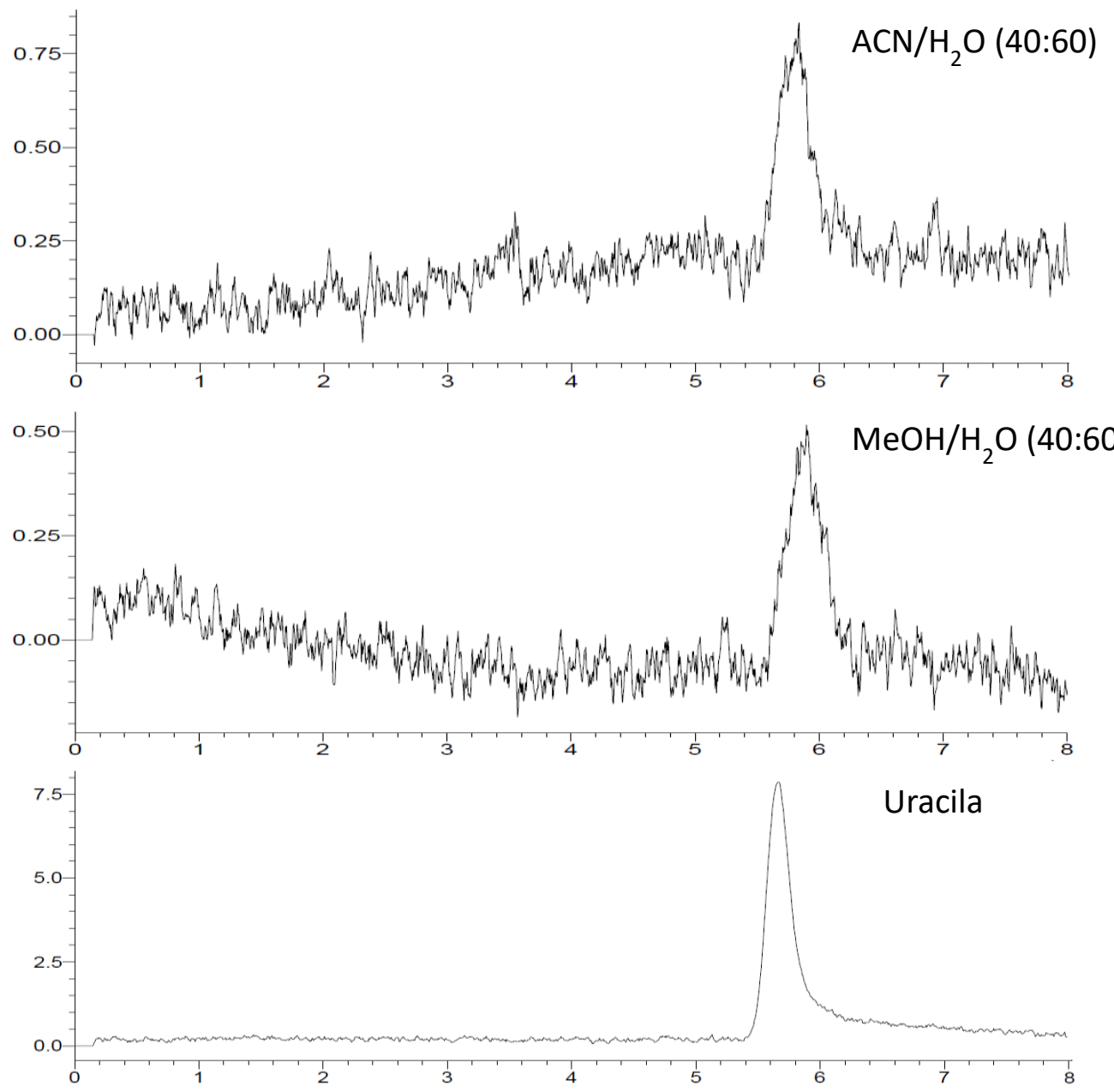

Figura 13 - Cromatograma obtido com a coluna OTLC-1, utilizando como fase móvel ACN/H2O 60:40 v/v, fluxo de $6 \mu \mathrm{L}$ min-1 e comprimento de onda de $254 \mathrm{~nm}$

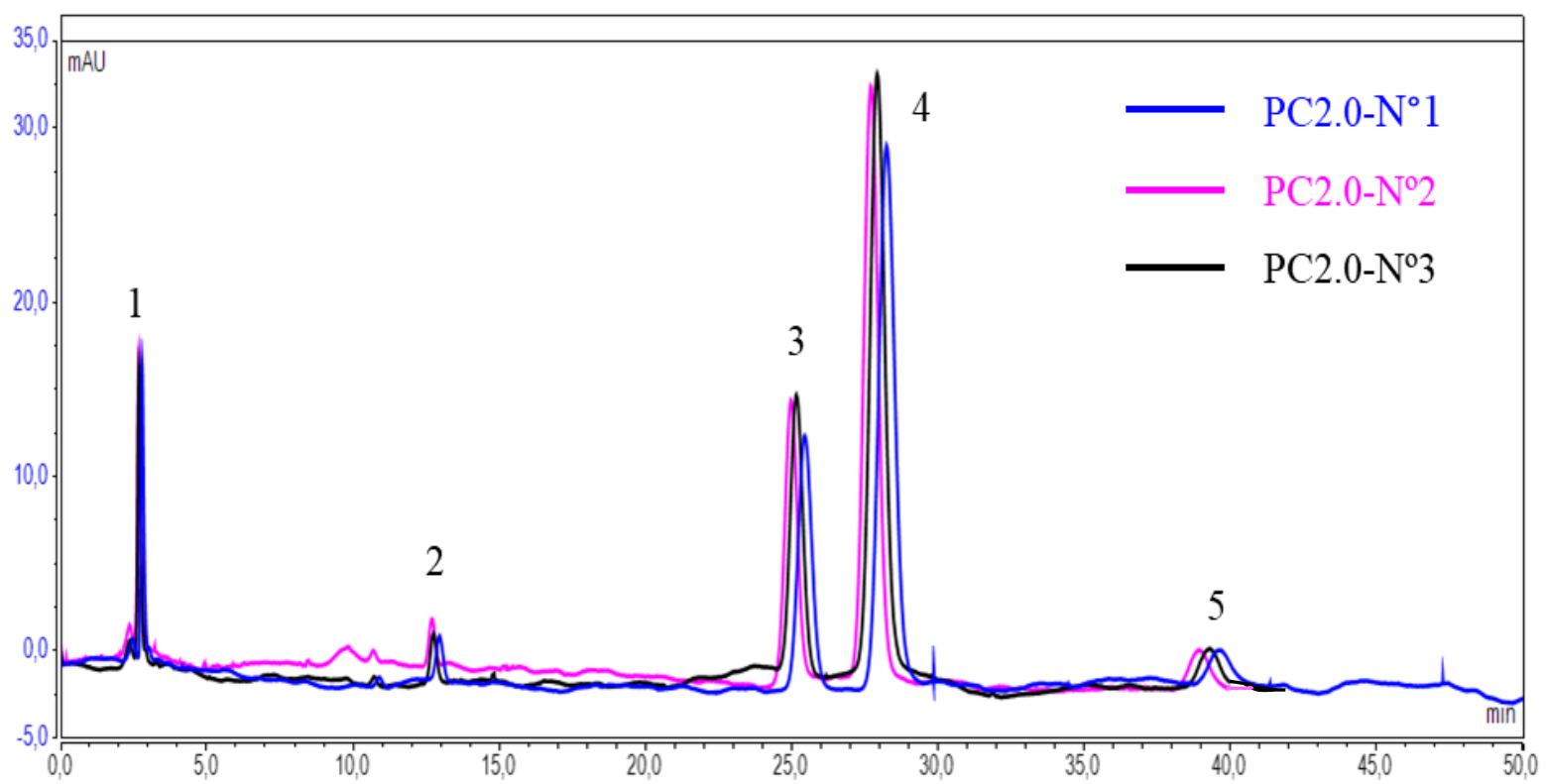

Figura 14 - Cromatogramas obtidos com as colunas capilares de $250 \mu \mathrm{m}$ d.i., $15 \mathrm{~cm}$ de comprimento e partículas de fase estacionária C18 de 2,0 $\mu \mathrm{m}$. Ordem de eluição: (1) uracila, (2) naftaleno, (3) fenantreno, (4) antraceno e (5) pireno 
Uma melhor comparação pode ser feita a partir da observação dos valores dos parâmetros cromatográficos expostos na Tabela 8 , calculados a partir dos cromatogramas exibidos acima. Devido ao grande volume de dados gerados optou-se, também, por expor apenas as informações referentes a um único pico eluido, tornando, desta forma, mais fácil a comparação entre as colunas. Sendo assim, os valores dos parâmetros $W_{h}, N, H, A s, v, h, k$ e E foram calculados em relação ao fenantreno $\left(D_{\mathrm{m}}=1,32 \times 10^{-9} \mathrm{~m}^{2} / \mathrm{s}\right)$, os valores de $\alpha$ e $R_{\mathrm{s}}$ foram calculados considerando os picos dos analitos fenantreno e antraceno. Os valores de $\varnothing$ correspondem aos picos da uracila. $\mathrm{O}$ valor empregado para a viscosidade de fase móvel ( $\eta$ ) considerando a proporção $\mathrm{ACN} / \mathrm{H} 2 \mathrm{O}(60: 40)$ à $30^{\circ} \mathrm{C}$, foi de $0,65 \mathrm{mPa}$.

Para melhor entendimento sobre a precisão e a repetitividade dos dados entre as três colunas analíticas, foram calculados os desvios padrão (SD) e o desvios padrão relativos (RSD), que medem a percentagem dos desvios.

\begin{tabular}{|c|c|c|c|c|c|c|}
\hline \multirow[b]{2}{*}{ Parâmetros } & \multicolumn{6}{|c|}{ Colunas empacotadas com fase $\mathrm{C} 18$ de $2,0 \mu \mathrm{m}$} \\
\hline & $\mathrm{N}^{\circ} 1$ & $\mathrm{~N}^{\circ} 2$ & $\mathrm{~N}^{\circ} 3$ & MÉDIA & SD & RSD \\
\hline$t_{\mathrm{M} \text { uracila }}(\min )$ & 2,79 & 2,68 & 2,69 & 2,72 & 0,06 & 2,24 \\
\hline$t_{\mathrm{R} \text { naftaleno }}(\mathrm{min})$ & 12,97 & 12,70 & 12,75 & 12,81 & 0,14 & 1,12 \\
\hline$t_{\mathrm{R} \text { fenantreno }}(\min )$ & 25,45 & 24,99 & 25,17 & 25,20 & 0,23 & 0,92 \\
\hline$t_{\mathrm{R} \text { antraceno }}(\mathrm{min})$ & 28,24 & 27,71 & 27,93 & 27,96 & 0,27 & 0,95 \\
\hline$t_{\mathrm{R} \text { pireno }}(\min )$ & 39,61 & 38,93 & 39,29 & 39,28 & 0,34 & 0,87 \\
\hline$w_{b}(50 \%)$ fenantreno $(\mathrm{min})$ & 0,52 & 0,48 & 0,50 & 0,50 & 0,02 & 4,00 \\
\hline$N$ & 13070 & 15264 & 14146 & 14160 & 1097 & 7,75 \\
\hline$H(\mu \mathrm{m})$ & 11,48 & 9,83 & 10,60 & 10,64 & 0,83 & 7,76 \\
\hline As $(10 \%)$ & 1,06 & 1,04 & 1,04 & 1,05 & 0,01 & 1,10 \\
\hline$v$ & 1,36 & 1,41 & 1,41 & 1,39 & 0,03 & 2,07 \\
\hline$h$ & 5,74 & 4,91 & 5,30 & 5,32 & 0,42 & 7,81 \\
\hline$k$ & 8,14 & 8,33 & 8,37 & 8,28 & 0,12 & 1,48 \\
\hline$\alpha$ & 1,12 & 1,12 & 1,12 & 1,12 & 0,00 & 0,00 \\
\hline$R_{s}$ & 2,91 & 3,14 & 3,08 & 3,04 & 0,12 & 3,92 \\
\hline$\varnothing$ & 1211 & 1275 & 1013 & 1166 & 136 & 11,71 \\
\hline$E$ & 39877 & 30782 & 28485 & 33048 & 6024 & 18,23 \\
\hline$\Delta \mathrm{P}($ bar $)$ & 265,0 & 290,0 & 230,0 & 261 & 30,14 & 11,52 \\
\hline
\end{tabular}

Tabela 8 - Parâmetros das colunas cromatográficas obtidos a partir dos dados gerados nos cromatogramas apresentados na Figura 14 
Os desvios padrão relativos para todos os parâmetros foram menores que $10 \%$, com exceção apenas da resistência ao fluxo $(\varnothing)$ e da impedância de separação (E), que estão diretamente relacionados com a queda de pressão $(\Delta \mathrm{P})$ que, por sua vez, também apresentou um RSD maior que $10 \%$. No entanto, esses valores mais altos podem não estar relacionados com a metodologia de empacotamento, mas sim, a problemas de conexões das colunas no micro-LC, pois para conectá-las são necessários utilizar luvas e conexões de PEEK que são acoplados às tubulações de PEEKSil do equipamento e, dependendo da intensidade do aperto para a fixação das colunas, pode ou não ser promovido o esmagamento ou ranhuras nas tubulações ou conexões, resultando no aumento da pressão. Tais fatos podem ser corrigidos empregando-se uniões e tubulações fabricadas em aço inoxidável ou outros materiais mais rígidos.

Ainda para avaliar a semelhança entre as colunas, foram realizados test-t de Student para duas amostras, com um nível de significância estatístico de 0,05 e empregando as variâncias $\left(0^{2}\right)$ dos quatro picos dos padrões de PAHs e do pico da uracíla. Através da comparação dos valores de prova (P), Tabela 9, para um teste bi-caldal com o nível de significância estabelecido, pode-se afirmar que estatisticamente não existem diferenças significativas entre as três colunas confeccionadas com a mesma fase estacionária, uma vez que $\mathrm{P}>0,05$. Os resultados demonstraram, portanto, que a metodologia de empacotamento empregada neste trabalho, foi reprodutível.

\begin{tabular}{l|lllll}
\hline \multirow{2}{*}{ Colunas } & \multicolumn{5}{|c}{ Valor de P para as colunas } \\
& Fase $2,0 \mu \mathrm{m}$ & Fase $3,0 \mu \mathrm{m}$ & Fase $3,5 \mu \mathrm{m}$ & Fase $5,0 \mu \mathrm{m}$ & Fase $10,0 \mu \mathrm{m}$ \\
\hline $\mathrm{N}^{\circ} 1$ e No2 & 0,99 & 0,75 & 0,39 & 0,61 & 0,56 \\
$\mathrm{~N}^{\circ} 1$ e No3 & 0,77 & 0,59 & 0,21 & 0,77 & 0,76 \\
\hline $\mathrm{N}^{\circ} 2$ e $\mathrm{N}^{\circ} 3$ & 0,78 & 0,83 & 0,54 & 0,83 & 0,41 \\
\hline
\end{tabular}

Tabela 9 - Valores de $\mathrm{P}$ determinados através do test-t entre as três colunas confeccionadas para cada F.E. C18 estudada, a um nível de significância de 0,05 


\subsubsection{Caracterização das partículas}

As fases estacionárias empregadas neste trabalho foram caracterizadas por MEV para averiguar o tamanho nominal e uniformidade das partículas. A Figura 15 mostra algumas das imagens obtidas por MEV, onde é possível observar irregularidades na distribuição dos tamanhos das partículas, assim como pequenos pedaços resultantes da quebra das mesmas.

As imagens obtidas por MEV foram então carregadas no programa ImageJ para determinação nominal do diâmetro das partículas (dp). Linhas retas correspondentes aos diâmetros de 510 partículas foram traçadas manualmente para cada fase estacionária. O método manual foi preferido porque permitiu determinar a posição da circunferência das partículas com maior certeza e precisão. A Figura 16 mostra a distribuição do tamanho de partículas para cada uma das F.E empregadas.

O gráfico da Figura 16 confirma o que foi observado nas imagens de MEV, ou seja, que existe uma variação elevada de tamanho de partículas, principalmente para a F.E de $10 \mu \mathrm{m}$, a qual apresentou a maior variação, seguida pela F.E de $5 \mu$ m. As F.E de diâmetros mais próximos, 3 e 3,5 $\mu \mathrm{m}$, apresentaram uma distribuição do tamanho das partículas muito semelhantes. Já a F.E de $2 \mu \mathrm{m}$ apresentou uma menor variação na distribuição do tamanho das partículas; uma vez que as F.E empregadas pertenciam ao mesmo fabricante, foi possível concluir que os lotes de partículas de maior tamanho possuem também uma maior distribuição do tamanho das partículas.

A partir do diagrama de distribuição de frequência de partículas foram calculados os diâmetros Sauter (d $\mathrm{d}_{\text {Sauter }}$ ) a partir da Equação 21, a qual corresponde ao diâmetro de uma esfera que possui a mesma razão da área superficial de uma partícula e que, frequentemente é empregado na cromatografia para contagem de partículas

$$
d_{\text {Sauter }}=\frac{\sum n_{i} d_{p, i}^{3}}{\sum n_{i} d_{p, i}^{2}}
$$

onde $\mathrm{n}_{\mathrm{i}}$ corresponde ao número de partículas ${ }^{71}$.

Também foram calculadas as razões percentuais, $d_{p 90} / d_{p 10}$ que correspondem às razões em $90 \%$ e $10 \%$ da distribuição do tamanho, os diâmetros médios ( $\mathrm{d}_{\mathrm{p}}$, med), os diâmetros máximos $\left(\mathrm{d}_{\mathrm{p}, \max }\right)$ e os diâmetro mínimo $\left(\mathrm{d}_{\mathrm{p}, \min }\right)$ das partículas de todas as F.E. Os valores obtidos estão expostos na Tabela 10. 

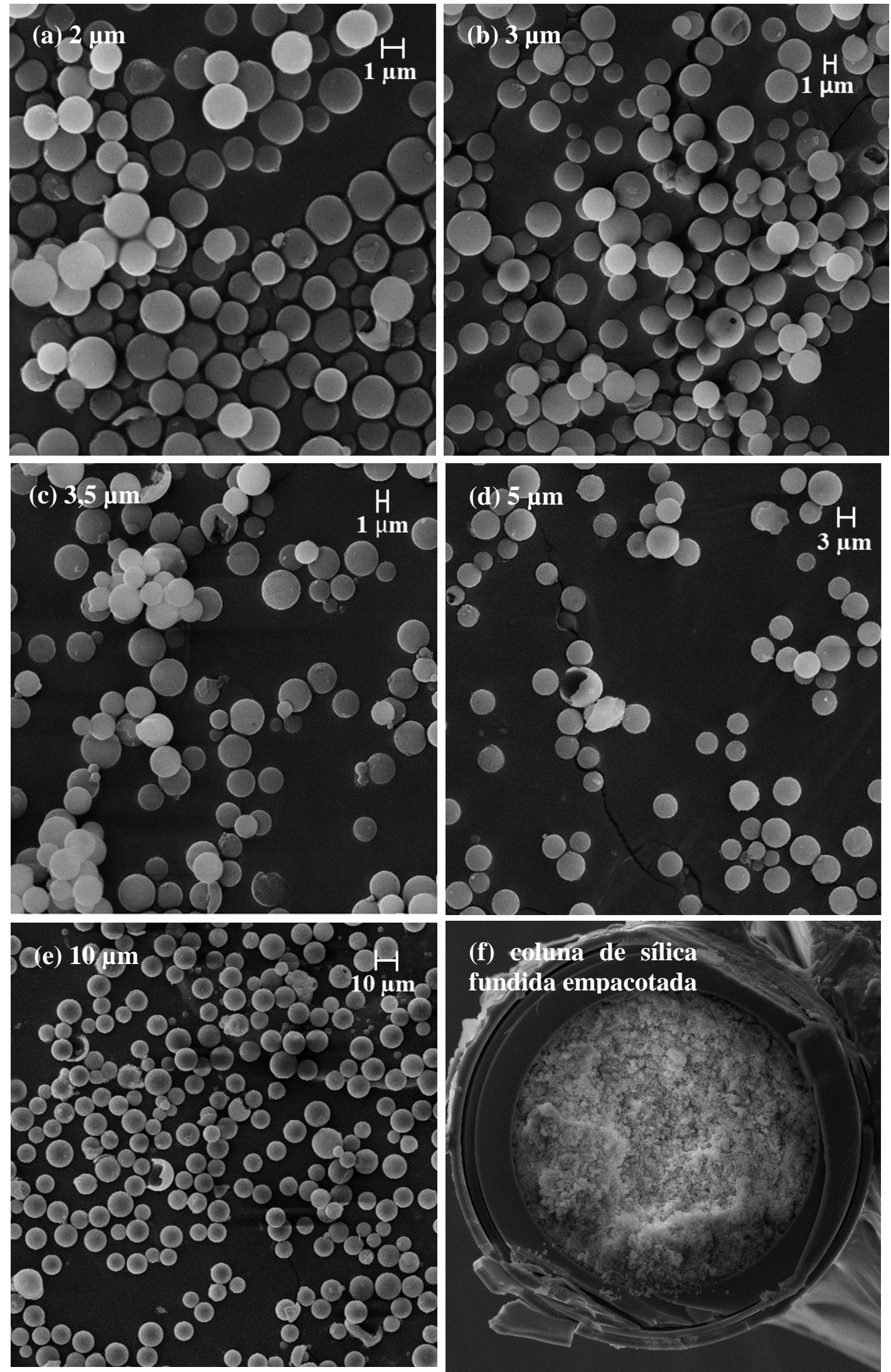

Figura 15 - MEV das F.E C18 com diâmetros de partículas indicados pelo fabricante, iguais a $2 \mu \mathrm{m}$ (a), $3 \mu \mathrm{m}$ (b), 3,5 $\mu \mathrm{m}$ (c), $5 \mu \mathrm{m}$ (d), $10 \mu \mathrm{m}$ (e) e coluna de sílica fundida de $250 \mu \mathrm{m}$ d.i. (f). O microscópio foi operado a $20 \mathrm{kV}$ e magnificação de 1000 a 12000x 


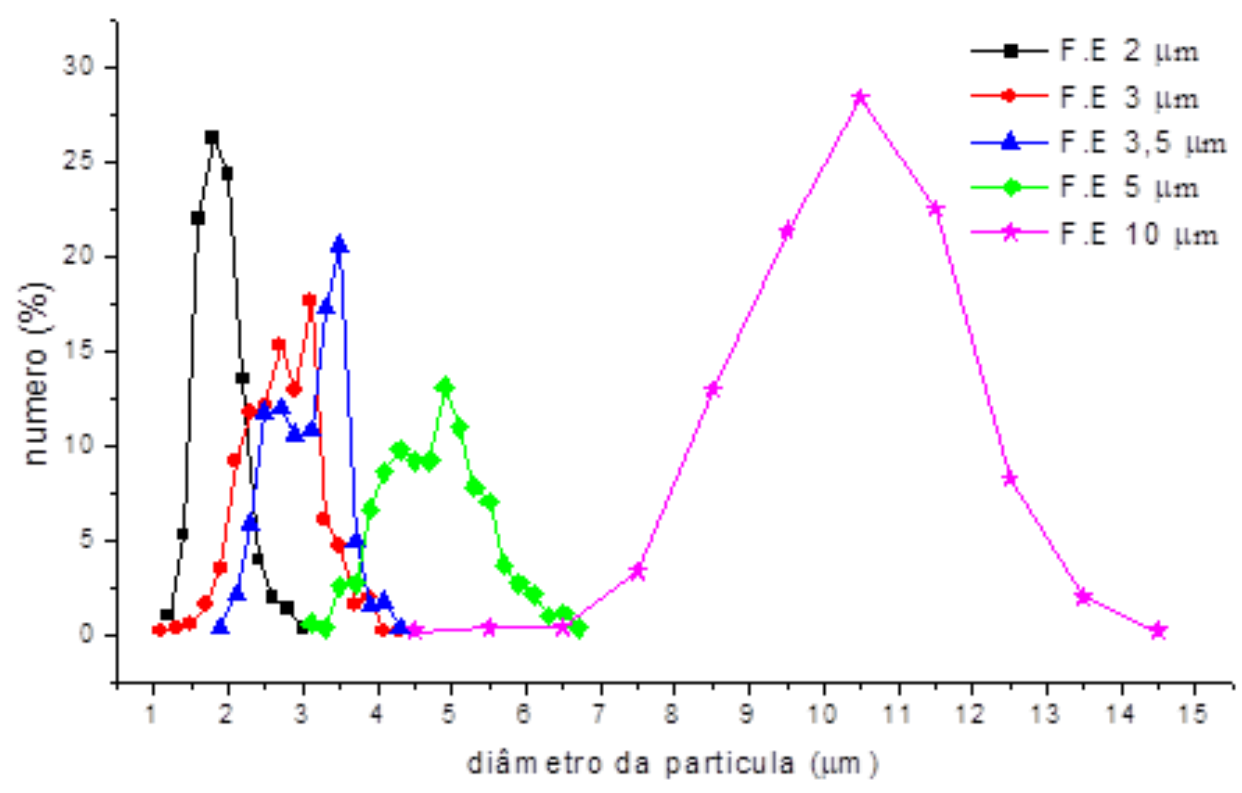

Figura 16 - Gráfico da distribuição do tamanho das partículas obtido através das medições realizadas nas imagens de MEV para cada uma das F.E empregadas

\begin{tabular}{llllll}
\hline Parâmetros & \multicolumn{5}{l}{ Fases estacionárias C18 } \\
d $\mathrm{d}_{\mathrm{p}}$ do fabricante & $2,0 \mu \mathrm{m}$ & $3,0 \mu \mathrm{m}$ & $3,5 \mu \mathrm{m}$ & $5 \mu \mathrm{m}$ & $10 \mu \mathrm{m}$ \\
$\mathrm{d}_{\text {Sauter }}$ & 1,98 & 2,9 & 3,19 & 4,96 & 10,68 \\
$\mathrm{~d}_{\mathrm{p}, \text { med }}$ & 1,77 & 2,62 & 3,03 & 4,72 & 9,90 \\
$\mathrm{~d}_{\mathrm{p} 90} / \mathrm{d}_{\mathrm{p} 10}$ & 1,51 & 1,64 & 1,50 & 1,47 & 1,46 \\
$\mathrm{~d}_{\mathrm{p}, \min }: \mathrm{d}_{\mathrm{p}, \max }$ & $1,1: 3,0$ & $1,0: 4,3$ & $1,8: 4,3$ & $3,1: 6,7$ & $4,8: 14,1$ \\
\hline
\end{tabular}

Tabela 10 - Diâmetros de partículas especificados pelo fabricante; diâmetro Sauter (dSauter); diâmetro médio (dp, med); diâmetro mínimo (dp,min) e máximo (dp,max); e razão dp90/dp10 obtidos a partir de imagens de MEV

Como o diâmetro nominal das partículas foi definido pelo valor $\mathrm{d}_{\text {sauter, }}$ foi possível notar que o tamanho das partículas que mais se distanciaram do valor informado pelo fabricante foram as de 3,5 e $10 \mu \mathrm{m}$ (com valores iguais a 3,19 e 10,68 $\mu \mathrm{m}$, respectivamente). Quando avaliado o diâmetro médio se observa que os valores diferem consideravelmente do valor do fabricante, com exceção da F.E de $10 \mu \mathrm{m}$. Destaque novamente, para F.E de 3,5 $\mu \mathrm{m}$ cuja diferença de tamanho é de aproximadamente $0,5 \mu \mathrm{m}^{73}$.

Com relação aos valores de $\mathrm{d}_{\mathrm{p} 90} / \mathrm{d}_{\mathrm{p} 10}$ quanto mais próximo da unidade mais estreita é a distribuição do tamanho das partículas; desta forma, a F.E contendo partículas de $10 \mu \mathrm{m}$ apresentou o menor valor $(1,46)$. O gráfico da Figura 16 mostrou para as partículas de $10 \mu \mathrm{m}$ 
uma maior largura de base com relação às demais, com a distribuição considerando desde o $\mathrm{d}_{\mathrm{p}, \min }(4,80)$ até o $\mathrm{d}_{\mathrm{p}, \max }(14,1)$ cujo $\Delta \mathrm{d}_{\mathrm{p}}$ foi a maior de todas $(9,3)$. No entanto, dentro da faixa de $10 \%$ a 90\%, as partículas apresentaram diâmetros próximos do valor nominal que foi de 10,68 $\mu \mathrm{m}$. Em seguida vem as partículas de 5, 3,5 e $2 \mu \mathrm{m}$ com valores iguais a 1,47, 1,50 e 1,51 , respectivamente. O maior valor para a razão $d_{p 90} / d_{p 10}$ foi para a F.E de $3 \mu \mathrm{m}$ cujo valor foi igual a 1,64. A literatura ${ }^{73}$ aborda que F.E.s C18 totalmente porosas comerciais nunca apresentam valores iguais a 1 , sendo um bom valor para a razão $d_{p 90} / d_{p 10}$ igual a 1,3 , este foi capaz de gerar colunas com alta eficiência e uma altura de prato reduzida igual a $1,7^{74}$. Sendo assim, acredita-se que dentre as partículas empregadas a que poderia gerar maior problema quanto a uniformidade do empacotamento e, consequentemente, da eficiência seriam as partículas de $3 \mu \mathrm{m}$, pois embora a distribuição do tamanho das demais partículas não estejam dentro do valor ótimo “ 1,3 ”, apresentaram valores próximo a ele.

Outro fator que afeta negativamente o desempenho das colunas é a presença de pequenos fragmentos resultantes da quebra das partículas ou pela presença de partículas esféricas ou irregulares muito pequenas (como pode ser observado na Figura 11). A presença desses tipos de materiais afeta mais negativamente o desempenho da coluna do que a presença de partículas muito maiores, influenciando principalmente o aumento da contrapressão da coluna. Estudos concluíram que "não é tanto a largura ou a amplitude da distribuição de tamanho de partícula, mas sim a presença de pequenos materiais que determinam grandemente o desempenho cromatográfico das colunas de partículas" $" 71$.

O desempenho das colunas empacotas com as F.E; aqui avaliadas, será discutido no próximo tópico.

\subsubsection{Avaliação da influência do tamanho da partícula da fase estacionária no desempenho das colunas}

Para avaliar o desempenho das colunas empacotadas com as fases estacionárias C18 de tamanhos de partículas iguais a 2,0;3,0;3,5;5,0 e 10,0 $\mu \mathrm{m}$, assim como, avaliar a influência do tamanho dessas partículas no desempenho da coluna, foram traçados o perfil da pressão em função do fluxo volumétrico e as curvas de Van Deemter assim como foram calculados os parâmetros cromatográficos. O comprimento de todas as colunas foram mantidos em $15 \mathrm{~cm}$ e os diâmetros internos em $250 \mu \mathrm{m}$ todos os experimentos realizados nesse tópico do trabalho foram feitos no cromatógrafo comercial Ultimate 3000 da Thermo, com volume fixo de injeção 
de $60 \mathrm{~nL}$, temperatura da coluna em $31{ }^{\circ} \mathrm{C}$, comprimento de onda em $254 \mathrm{~nm}$ e concentração dos analítos em 5 ppm.

No estudo da pressão empregou-se fluxos volumétricos correspondentes à escala capilar (de 1 a $10 \mu \mathrm{L} / \mathrm{min}$ ) e compatíveis com a pressão suportada pelo sistema. Em alguns casos foi possível empregar fluxos de $0,5 \mu \mathrm{L} / \mathrm{min}$, já que algumas colunas mostraram-se adequadas por permitirem a passagem de F.M. sem grandes variações da pressão e sem a formação de bolhas de ar. O gráfico da Figura 17 mostra o desempenho das colunas com relação a contrapressão em diferentes fluxos; para construção do gráfico empregou-se $\mathrm{ACN}_{2} \mathrm{H}_{2} \mathrm{O}(50: 50 \mathrm{v} / \mathrm{v})$ como fase móvel.

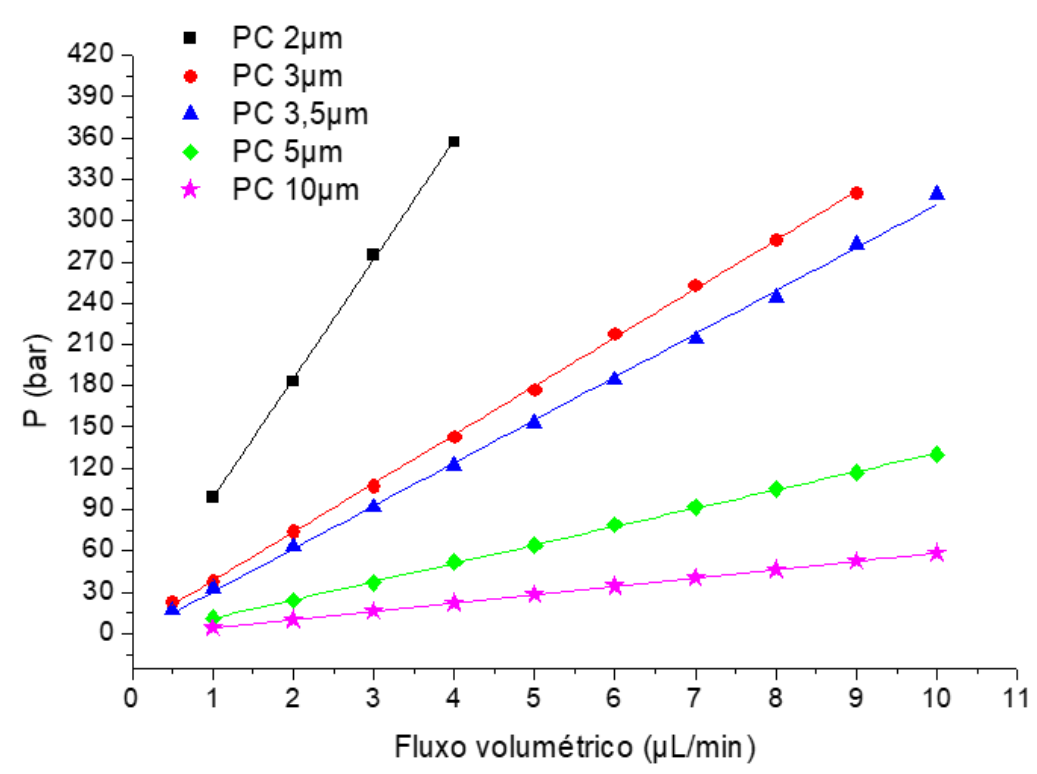

Figura 17- Efeito da variação de pressão em função do fluxo volumétrico (Fc) para as colunas empacotadas com F.E. C18 constituídas de partículas de 2,0; 3,0; 3,5; 5,0 e 10,0 $\mu \mathrm{m}$ de diâmetro

A pressão do sistema é um ponto bastante relevante nas separações cromatográficas pois, em alguns casos, pode existir a necessidade de se empregar vazões mais elevadas da fase móvel e, neste caso, as colunas com partículas muito pequenas podem tornar inviável essa prática uma vez que uma variação muito pequena do fluxo da F. M. pode ser suficiente para que se atinja a pressão limite suportada pelas tubulações do equipamento. Tal fato foi observado com as colunas de partículas de $2 \mu \mathrm{m}$, em que a utilização de um fluxo igual a $4 \mu \mathrm{L} / \mathrm{min}$, elevou a pressão do sistema para 357 bar, sendo a pressão máxima de trabalho recomendada pelo fabricante do equipamento igual a 400 bar. 
Era esperado que a pressão diminuísse conforme aumentasse os tamanhos das partículas, o que foi observado neste estudo, uma vez que as colunas com partículas de 5 e 10 $\mu \mathrm{m}$ apresentaram as menores variações de pressão tornando possível trabalhar com essas colunas em fluxos maiores que $10 \mu \mathrm{L} / \mathrm{min}$. Uma outra explicação para justificar as menores pressões destas colunas foi o menor intervalo de distribuição de tamanho de partículas apresentados por elas. A distribuição do tamanho das partículas também pode ter influenciado na contrapressão da coluna de $3 \mu \mathrm{m}$, de maior intervalo. Fluxos superiores a $9 \mu \mathrm{L} / \mathrm{min}$ provocavam um aumento abrupto da pressão, extrapolando o valor máximo suportado pelo cromatógrafo.

A coluna contendo partículas de 3,5 $\mu \mathrm{m}$, embora tenha apresentado uma grande variação de pressão foi capaz de trabalhar em vazão de $10 \mu \mathrm{L} / \mathrm{min}$ com pressão próxima à da coluna de $3 \mu \mathrm{m}$ operada à um fluxo de $9 \mu \mathrm{L} / \mathrm{min}$.

As F.E., contendo partículas de $2 \mu \mathrm{m}$ são geralmente empregadas na confecção de colunas convencionais com d.i. de $2,1 \mathrm{~mm}$ e comprimento máximo de $10 \mathrm{~cm}$. A coluna aqui avaliada com essas partículas apresentava comprimento significamente superior $(15 \mathrm{~cm})$; desta forma foi compreensível obter uma faixa de fluxo menor para esta coluna (de 1 a $4 \mu \mathrm{L} / \mathrm{min}$ ) em função da elevação da contrapressão.

A eficiência da coluna geralmente é avaliada em função da curva de Van Deemter, (Figura 18) na qual os valores da altura equivalentes a um prato teórico $(\mathrm{H})$ são empregados para comparar a eficiência de diferentes tipos de materiais de fases estacionárias e o mínimo da curva representa a velocidade ótima na qual ocorrerá a variância mínima por unidade de comprimento da coluna e, portanto, uma eficiência máxima.

Para construção das curvas foram empregadas as mesmas condições cromatográficas utilizadas no gráfico da pressão contra o fluxo. No entanto, a velocidade linear foi calculada em função do pico da uracila, ou seja, do composto não retido e os valores de $\mathrm{H}$ foram calculados em função do pico do composto retido, naftaleno. As curvas foram ajustadas usando o modelo de regressão clássica por mínimos quadrados.

Pela análise do gráfico fica evidente que a coluna de partículas de $2 \mu \mathrm{m}$ apresentou a maior eficiência (menor altura de prato $H=11,7$ ). Em seguida estão as colunas de 3, 3,5 e 5,0 $\mu \mathrm{m}$ com valores mínimos de $\mathrm{H}$ iguais a 13,5; 13,9 e 15,5 $\mu \mathrm{m}$, respectivamente. Como esperado, a coluna de partículas de 10,0 $\mu \mathrm{m}$ distingue-se por apresentar a menor eficiência dentre as demais, uma vez que, o valor mínimo para $\mathrm{H}$ foi igual a $38,8 \mu \mathrm{m}$. 


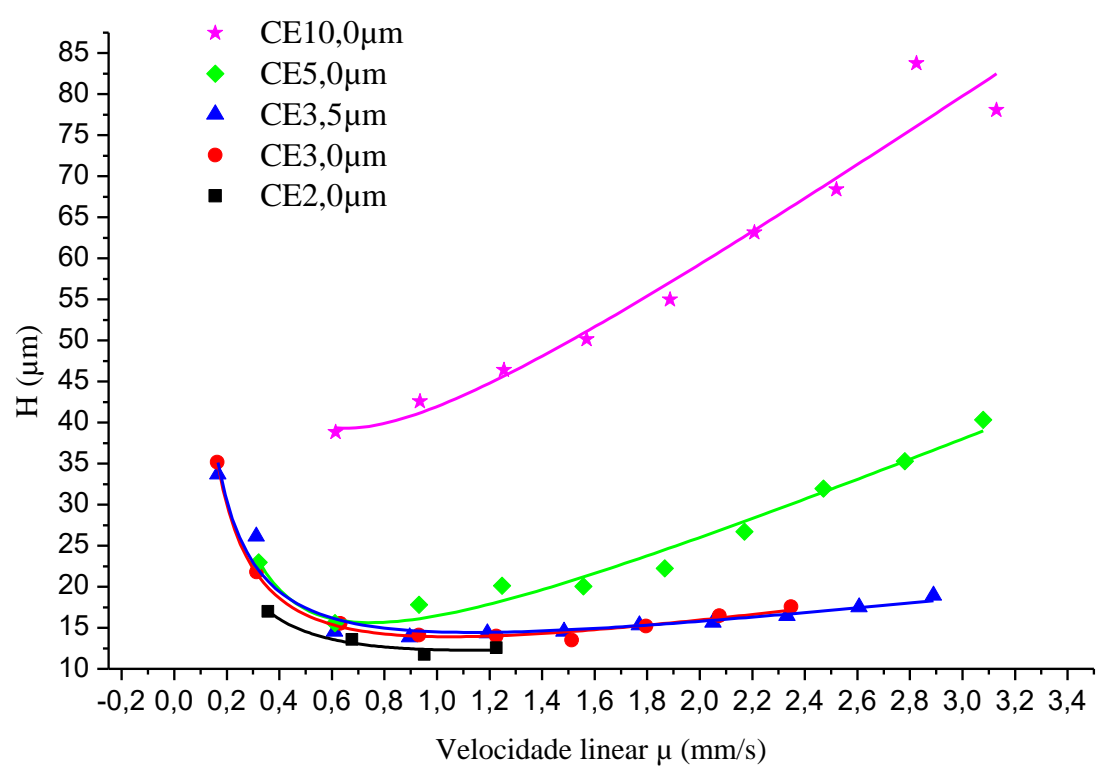

Figura 17 - Gráfico de Van Deemter para um composto não retido (naftaleno) empregando as colunas confeccionadas com fase C18 de partículas de 2,0;3,0; 3,$5 ; 5,0$ e $10,0 \mu \mathrm{m}$

Embora em alguns casos de forma sutil, pode-se observar uma dependência da eficiência com relação ao tamanho das partículas. Maiores eficiências foram obtidas com a redução do tamanho das partículas da F.E. As curvas das colunas de 3,0 e 3,5 $\mu \mathrm{m}$ se destacam pela similaridade, o que é compreensível, uma vez que a diferença entre os tamanhos das partículas (tamanhos nominais $=2,90$ e 3,19) foi pequena. Também se destacam pela acentuada inclinação das curvas na região de maiores taxas de fluxos (contribuição crescente da limitação de transferência de massa para $\mathrm{H}$ ) o que significa que essas duas colunas podem ser operadas em altas taxas de fluxo com menor perda de eficiência.

A coluna de 2,0 $\mu \mathrm{m}$ foi a mais eficiente, mas apresentou como inconveniente a restrição da faixa de fluxo linear de trabalho (1 a $4 \mu \mathrm{L} / \mathrm{min}$ ), ocasionado pela baixa permeabilidade da coluna, que resultou na elevação da contrapressão da mesma (Figura 17).

Com relação a coluna de partículas de 5,0 $\mu \mathrm{m}$, observou-se que o valor mínimo de $\mathrm{H}$ ficou mais próximo do valor de $\mathrm{H}$ mínimo das colunas de 3,5; 3 e $2 \mu \mathrm{m}$. Entretanto, a curva da coluna de $5 \mu \mathrm{m}$ apresentou uma maior inclinação em velocidades lineares mais elevadas, o que limita bastante a faixa de trabalho há alguns $\mathrm{mm} / \mathrm{s}$ sem que haja uma perda muito grande de eficiência.

O desempenho dessas colunas também foi avaliado a partir dos dados cromatográficos obtidos com a separação da mistura teste de PAH's. As concentrações dos analitos foram 
mantidas em 5 ppm; a F.M. empregada foi ACN/ $\mathrm{H}_{2} \mathrm{O}(60: 40 \nu / v)$; o fluxo foi igual a $3 \mu \mathrm{L} / \mathrm{min}$; comprimento de onda $254 \mathrm{~nm}$; e temperatura de $31{ }^{\circ} \mathrm{C}$.

A Figura 19 mostra a separação dos compostos uracila, naftaleno, fenanttreno, antraceno e pireno em cada uma das colunas avaliadas, sendo que as condições cromatográficas foram mantidas iguais em todas as separações.

Pela observação dos cromatogramas pode-se notar que todas as colunas apresentaram uma boa separação cromatográfica com os tempos de análise adequados; no entanto, os tempos de corrida em cada coluna diferem em função do tamanho da partícula da F.E. Desta forma, o tempo de análise aumenta conforme diminui o tamanho das partículas já que a área superficial de contato da F.E. aumenta, sendo que, o tempo total de análise para a coluna de partículas de $10 \mu \mathrm{m}$ foi cerca de $30 \%$ menor quando comparado ao tempo de análise da coluna de $2 \mu \mathrm{m}$.

Os dados cromatográficos calculados a partir da separação dos PAH's, (Tabela 11) mostram que, assim como observado nas curvas de Van Deenter (Figura 18), as maiores eficiências foram obtidas quando se fez uso de colunas com F.E de diâmetro pequenos. Desta forma a coluna de partículas de $2 \mu \mathrm{m}$ apresentou uma eficiência igual a 13.070 pratos, para as demais colunas $\mathrm{N}$ decresceu conforme o tamanho das partículas aumentaram. 


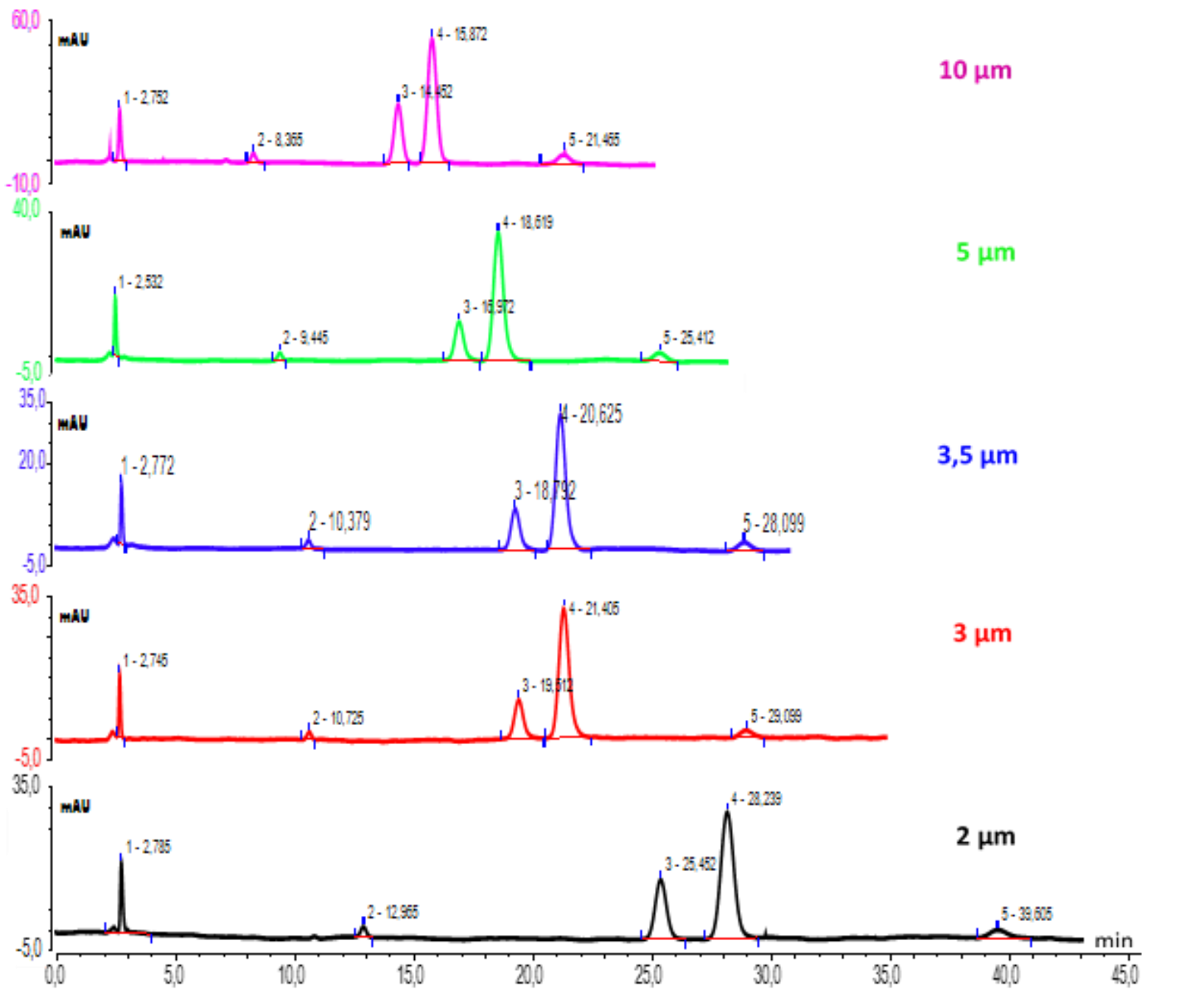

Figura 18 - Cromatogramas das separações de PAH's empregando as colunas C18 de $15 \mathrm{~cm}$, $250 \mu \mathrm{m}$ d.i. e partículas de $2 ; 3 ; 3,5 ; 5$ e $10 \mu \mathrm{m}$. Ordem de eluição: (1) uracila, (2) naftaleno, (3) fenantreno, (4) antraceno e (5) pireno

Uma observação deve ser feita com relação à coluna de 3,5 $\mu \mathrm{m}$, a qual apresentou eficiência levemente maior $(\mathrm{N}=12.350)$ do que a coluna de $3 \mu \mathrm{m}(\mathrm{N}=12,247)$. Tal fato pode estar relacionado com a proximidade dos tamanhos das partículas, e/ou função da maior distribuição do tamanho de partículas $\left(\mathrm{d}_{\mathrm{p} 90} / \mathrm{dp} 10=1,61\right)$ apresentada pela coluna de $3 \mu \mathrm{m}$; que pode ter contribuído na diminuição da eficiência desta coluna.

É sabido que colunas mais eficientes geram maiores resoluções; não diferente desta previsão, as resoluções das colunas avaliadas seguiram a mesma tendência que a eficiência. Desta forma, a coluna contendo partículas de $2 \mu \mathrm{m}$ apresentou a maior resolução e, por ser constituída de partículas bem pequenas, apresenta maior área superficial de contato, o que propicia uma maior interação analito/fase estacionária promovendo uma maior diferença entre os tempos de retenções dos compostos adjacentes. 


\begin{tabular}{|c|c|c|c|c|c|}
\hline \multirow[b]{2}{*}{ Parâmetros } & \multicolumn{4}{|c|}{ Colunas empacotadas com partículas de: } & \multirow[b]{2}{*}{$2 \mu \mathrm{m}$} \\
\hline & $10 \mu \mathrm{m}$ & $5 \mu \mathrm{m}$ & $3,5 \mu \mathrm{m}$ & $3 \mu \mathrm{m}$ & \\
\hline $\mathrm{t}_{\mathrm{M} \text { uracila }}(\mathrm{min})$ & 2,75 & 2,53 & 2,77 & 2,75 & 2,79 \\
\hline$t_{R}$ naftaleno $(\min )$ & 8,37 & 9,45 & 10,38 & 10,73 & 12,97 \\
\hline$t_{R}$ fenantreno $(\min )$ & 14,45 & 16,97 & 18,79 & 19,51 & 25,45 \\
\hline$t_{\mathrm{R} \text { antraceno }}(\mathrm{min})$ & 15,87 & 18,62 & 20,63 & 21,41 & 28,24 \\
\hline$t_{\mathrm{R} \text { pireno }}(\min )$ & 21,47 & 25,41 & 28,10 & 29,10 & 39,61 \\
\hline$w_{b}(50 \%)$ fenantreno $(\min )$ & 0,38 & 0,41 & 0,40 & 0,41 & 0,52 \\
\hline $\mathrm{N}$ & 7.847 & 9.493 & 12.350 & 12.247 & 13.070 \\
\hline $\mathrm{N} / \mathrm{m}$ & 52.313 & 63.287 & 82.338 & 81.644 & 87.136 \\
\hline $\mathrm{H}(\mu \mathrm{m})$ & 19,12 & 15,80 & 12,15 & 12,25 & 11,48 \\
\hline $\mathrm{R}_{\mathrm{s}}$ & 2,06 & 2,24 & 2,55 & 2,52 & 2,91 \\
\hline $\operatorname{As}_{(10 \%)}$ & 1,04 & 1,12 & 1,20 & 1,06 & 1,06 \\
\hline$\alpha$ & 1,12 & 1,11 & 1,11 & 1,11 & 1,12 \\
\hline $\mathrm{k}$ & 4,25 & 5,70 & 5,78 & 6,11 & 8,14 \\
\hline $\mathrm{v}$ & 5,45 & 2,78 & 1,62 & 1,50 & 1,00 \\
\hline $\mathrm{h}$ & 1,79 & 3,18 & 3,80 & 4,22 & 5,85 \\
\hline$\varnothing$ & 2.123 & 945 & 1.071 & 1.013 & 1.206 \\
\hline $\mathrm{E}$ & 6.803 & 9.596 & 15.278 & 18.077 & 41.365 \\
\hline$\Delta \mathrm{P}(\mathrm{bar})$ & 16,5 & 37,0 & 92,0 & 107,0 & 275,0 \\
\hline
\end{tabular}

Tabela 11 - Parâmetros das colunas obtidos a partir dos dados gerados nos cromatogramas apresentados na Figura 19

Outro parâmetro de grande importância para avaliar a qualidade das colunas é o fator de assimetria do pico $\left(\mathrm{A}_{\mathrm{s}}\right)$. Ao traçar uma reta do ponto mais alto do pico até $10 \%$ da altura de sua base é possível avaliar a similaridade entre as duas metades, pela razão entre os comprimentos das bases do pico. Assim, quando a $\mathrm{As}_{(10 \%)}$ for igual a 1, pode-se afirmar que o pico é perfeitamente simétrico; com relação a este parâmetro, foi possível observar que para todas as colunas os valores foram muito próximos à unidade $(1,04-1,20)$, indicando que todas as colunas promoveram separações com excelentes formatos de picos.

Os valores de $\alpha$ mantiveram-se praticamente constantes, o que era esperado, uma vez que o fator de separação é uma medida do potencial de separação do sistema cromatográfico para dois compostos, o que mostra que a separação dos analitos fenantreno e antraceno manteve-se constante nas três colunas, já que se trata da mesma F.E. (C18) e, portanto, apresentaram as mesmas características químicas. 
Com relação ao parâmetro fator de retenção (k), calculado empregando-se o fenantreno os valores para cada coluna foram diferentes, o que era esperado, pois, embora as colunas tenham as mesmas dimensões e a mesma fase estacionária (C18) o tamanho das partículas não foi o mesmo. Como esse parâmetro é diretamente proporcional ao volume ocupado pela fase estacionária e sua área superficial, era esperado que empregando partículas de diâmetros diferentes, as densidades de empacotamento também fossem diferentes. Assim, as colunas com partículas de $2 \mu \mathrm{m}(\mathrm{k}=8,14)$ possuem uma área superficial de contato maior que as de $3 \mu \mathrm{m}$ $(k=6,11)$, que por sua vez é maior que as de $3,5 \mu \mathrm{m}(\mathrm{k}=5,78)$, estas maiores que as de $5 \mu \mathrm{m}$ $(5,70)$ e as últimas maiores que as de $10,0 \mu \mathrm{m}(\mathrm{k}=4,25)$.

Com relação aos parâmetros reduzidos é importante ressaltar que eles se apresentam como uma das formas mais adequadas para comparar o desempenho cinético das colunas cromatográficas, pois permitem uma fácil comparação entre os resultados obtidos com colunas de diferentes características (diferentes comprimentos, diferentes diâmetros de partículas, diferentes eluentes, comparação entre colunas convencionais ou capilares, fase normal ou reversa e solutos com diferentes coeficientes de difusão).

Uma vez definido o valor nominal dos diâmetros de partícula de cada F.E foi possível calcular os valores dos parâmetros reduzidos. Quando comparados h e H observou-se uma inversão de valores em função dos tamanhos nominais das partículas; assim, as colunas de melhor desempenho foram aquelas constituídas com partículas de maiores diâmetros. Neste caso, a coluna de $10 \mu \mathrm{m}$ cujo valor de h foi de 1,79. Em ordem decrescente de tamanho de partícula a coluna menos eficiente foi a de $2 \mu \mathrm{m} \operatorname{com} \mathrm{h}=5,85$.

Essa inversão de valores ocorreu, provavelmente, porque a diferença entre os valores de $\mathrm{H}$ deveria ter sido maior entre as colunas, desta forma quando dividido pelo tamanho nominal das partículas os valores de h deveriam ter mantido a mesma tendência que a observada para H. Isso pode estar relacionado ao fato de que as F.E.s empregadas nas colunas capilares são as mesmas que foram desenvolvidas para as colunas de dimensões convencionais, sendo assim, esse tipo de partícula pode não ser o mais adequado para a escala miniaturizada, sugerindo que novas pesquisas poderão ser voltadas para o desenvolvimento de F.E exclusivas para a cLC. Outro ponto importante refere-se à distribuição do tamanho das partículas de cada F.E., que deve ser mais crítico em colunas capilares do que em colunas convencionais ${ }^{73}$.

A literatura ${ }^{66}$ aborda ainda que, quando $\mathrm{h}$ for menor que 5 as colunas podem ser consideradas de excelente desempenho, como no caso das colunas aqui investigadas onde o $\mathrm{h}$ variou de 1,79 a 5,85 . 
Como a velocidade reduzida está relacionada ao tamanho das partículas da F. E. já era esperado que mantendo as mesmas condições de análises para todas as colunas e diminuindo o tamanho das partículas, a velocidade reduzida também diminuiria, uma vez que a permeabilidade da coluna deve diminuir. Desta forma, a coluna de $10 \mu \mathrm{m}$ apresentou maior $\mathrm{v}$ $=5,45$, e a de $2 \mu \mathrm{m}$ o menor $\mathrm{v}=1,00$.

Para efeitos comparativos, com relação ao desempenho das colunas é importante entender a dependência de h com relação a velocidade de eluição, no caso v. Dessa forma, foi traçado o gráfico do h versus v (gráfico de Knox) conforme mostrado na Figura 20.

O gráfico de Knox mostrou que a coluna de partículas de $5 \mu \mathrm{m}$ apresentou a melhor eficiência medida por $\mathrm{h}(\mathrm{h}=3,10)$ seguida da coluna de $10 \mu \mathrm{m}(\mathrm{h}=3,65)$, o que implica em dizer que as partículas de $5 \mu \mathrm{m}$ foram mais adequadas para o empacotamento desse perfil de coluna (colunas capilares de sílica fundida de $250 \mu \mathrm{m}$ d.i.). No entanto, em taxas de fluxo maiores (onde o termo $\mathrm{C}$ é mais predominante), a perda de eficiência da coluna de $5 \mu \mathrm{m}$ é significativamente maior do que para a coluna de $10 \mu \mathrm{m}$. Uma possível explicação para o melhor desempenho da colona de $5 \mu$ m pode estar relacionado com a menor resistência ao fluxo (Ø) oferecida por esta coluna, como pode ser observado na Tabela 11

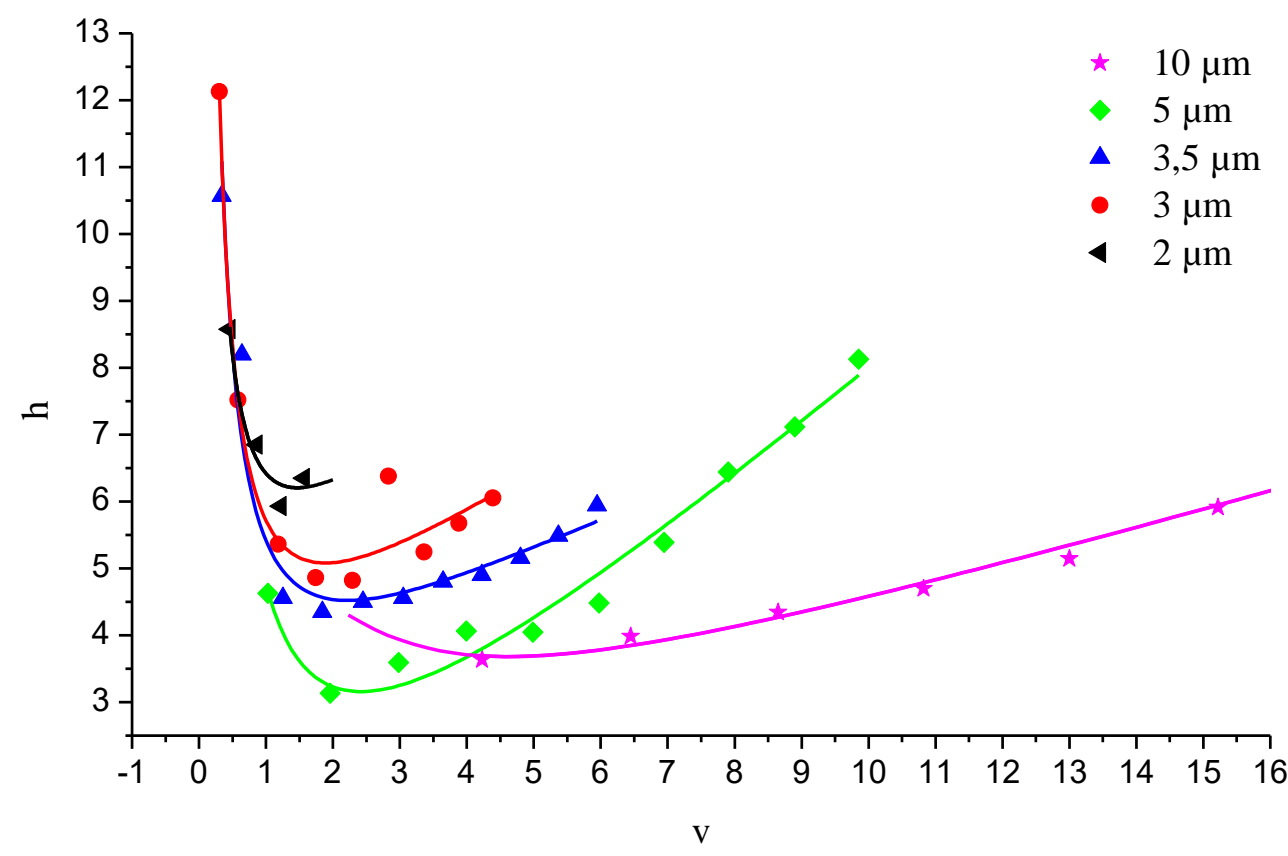

Figura 19 - Gráfico Knox (variação de h em função de v) para as colunas empacotadas com partículas $\mathrm{C} 18$ de $2 ; 3 ; 3,5 ; 5$ e $10 \mu \mathrm{m}$ de diâmetro 
Outra importante observação que pode ser feita a respeito da coluna de $10 \mu \mathrm{m}$ foi que ela não se mostrou adequada para trabalhar em taxas de fluxos igual ou menores que $1 \mu \mathrm{L} / \mathrm{min}$, já que foi observada uma instabilidade no perfil do fluxo que promove alargamento de banda e formação de bolhas na cela do detector. Sendo assim, a coluna de $10 \mu \mathrm{m}$ não foi capaz de cobrir toda a faixa de fluxo da escala capilar (que é de 1 a $10 \mu \mathrm{L} / \mathrm{min}$ ), sendo que fluxos acima de 4 $\mu \mathrm{L} / \mathrm{min}$ apresentaram-se mais adequados para se trabalhar com essa coluna devido as menores variações de pressão. Também foi possível trabalhar em fluxos superior ao da escala capilar, embora com menor eficiência.

Para as demais colunas o desempenho em geral melhorou conforme foi aumentando os tamanhos das partículas. Os valores de h mínimo para as colunas com partículas de 3,5; 3 e 2 $\mu \mathrm{m}$ foram iguais a 4,35; 4,82 e 5,93, respectivamente.

A Impedância de separação (E) é outro parâmetro reduzido que expressa a qualidade do empacotamento eliminando os efeitos causados pelo tamanho das partículas, comprimento das colunas e o coeficiente de difusão molecular. Este parâmetro relaciona o desempenho da coluna com a contrapressão do sistema e viscosidade da F.M e, sendo assim, o desempenho das colunas aumentou conforme aumentou o tamanho das partículas (Tabela 11). No geral pode-se afirmar que as colunas apresentaram bons resultados de E. A coluna de $2 \mu \mathrm{m}$ apresentou a maior E e, de acordo com este parâmetro o menor desempenho. Isso está relacionado sobretudo à alta contrapressão $(\Delta \mathrm{P}=275)$ da coluna de $2 \mu \mathrm{m}$ que foi praticamente o triplo da segunda maior contrapressão (coluna de $3 \mu \mathrm{m}, \Delta \mathrm{P}=107$ ).

Pode-se então concluir que, se desejada uma alta eficiência, a qual vem acompanhada de melhores resoluções, deve-se então usar partículas de menor tamanho nas colunas capilares. Mas isso, provavelmente, acarreta em um maior tempo de análise e maior contrapressão das colunas, assim como foi observado neste trabalho. Se o objetivo for aliar a eficiência com baixo tempo de eluição e menor queda de pressão, as partículas de $5 \mu \mathrm{m}$ apresentaram-se mais adequadas para a confecção das colunas capilares.

Embora as colunas aqui avaliadas apresentaram bons desempenhos é importante ressaltar que não foi descontado dos resultados obtidos as contribuições do ECV do equipamento. Acredita-se também que se empregadas outras F.E que apresentem menor distribuição de tamanhos de partículas, baixa quantidade de fragmentos e menor quantidade de partículas muito pequenas, seria possível obter colunas com desempenho ainda melhores. 


\subsubsection{Avaliação da influência do comprimento da coluna}

Para avaliar a influência do comprimento da coluna no desempenho cromatográfico foram confeccionadas três colunas empacotadas, empregando o primeiro modelo de hardware, tubo de sílica fundida com $250 \mu \mathrm{m}$ de d.i., e com comprimentos iguais a 5, 15 e $25 \mathrm{~cm}$. Tentouse reproduzir ao máximo as condições de empacotamento para todas as colunas. A F.E empregada foi a $\mathrm{C} 18$ de $3,5 \mu \mathrm{m}$ de diâmetro e a concentração das suspenções foram proporcionais ao comprimento das colunas. Foi empregada a bomba de volume fixo e pressão variável, sendo a pressão inicial de empacotamento mantida em 100 bar.

Os desempenhos foram avaliados a partir das separações dos compostos de PAH's, sendo empregado para isso $\mathrm{ACN} / \mathrm{H}_{2} \mathrm{O}(60: 40 \nu / v)$ como F.M. e fluxo volumétrico de $5 \mu \mathrm{L} / \mathrm{min}$. As demais condições de análises foram mantidas idênticas ao tópico anterior.

A Figura 21 exibe os cromantogramas de cada uma das colunas investigadas, desta forma, os desempenhos das colunas foram avaliados pela observação do perfil das separações e pela análise dos parâmetros cromatográficos.

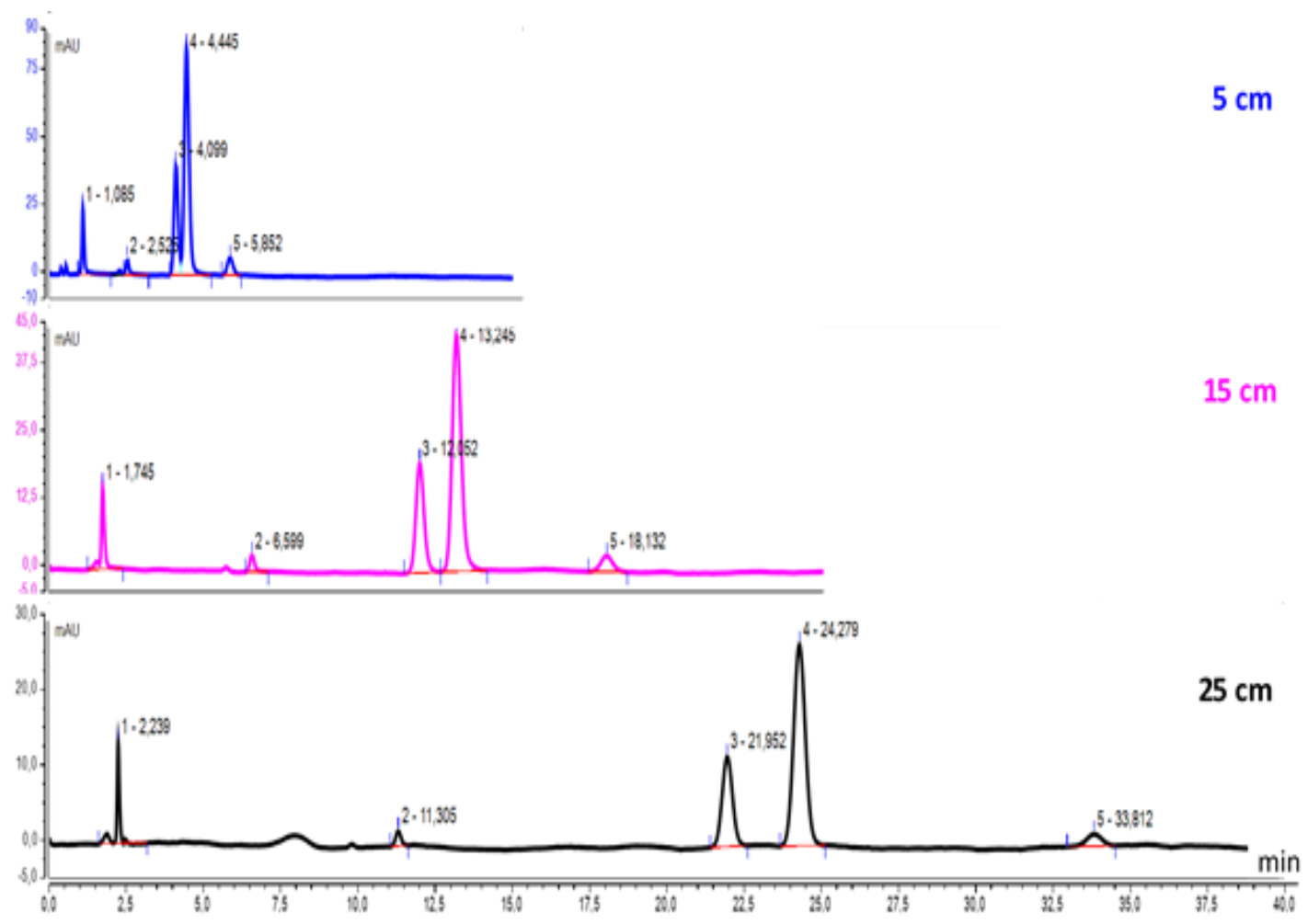

Figura 20 - Cromatogramas da separação da mistura de PAH's realizados em colunas C18 de $250 \mu \mathrm{m}$ d.i., partículas 3,5 $\mu \mathrm{m}$ e comprimentos de 5, 15 e $25 \mathrm{~cm}$. Ordem de eluição: (1) uracila, (2) naftaleno, (3) fenantreno, (4) antraceno e (5) pireno 
Pode-se observar na Figura 21 que os tempos de retenção dos compostos aumentaram significativamente com o aumento do comprimento da coluna, sendo que o tempo de retenção da coluna de $25 \mathrm{~cm}$ aumentou praticamente seis vezes quando comparado com a coluna de 5 $\mathrm{cm}$ e aproximadamente o dobro do tempo da coluna de $15 \mathrm{~cm}$. Como colunas mais longas possuem uma maior quantidade de F.E. era esperado que os tempos de eluições aumentassem devido ao maior tempo de interação analito/F.E. Também foi possível notar que as colunas de 15 e $25 \mathrm{~cm}$ resultaram em boas separações, diferentemente da coluna de $5 \mathrm{~cm}$, que não apresentou uma separação de linha de base para os compostos fenantreno e antraceno.

Para melhor entendimento do desempenho destas colunas os parâmetros cromatográficos são apresentados na Tabela 12

\begin{tabular}{|c|c|c|c|}
\hline \multirow{2}{*}{ Parâmetros } & \multicolumn{3}{|c|}{ Colunas empacotadas (comprimento) } \\
\hline & $5 \mathrm{~cm}$ & $15 \mathrm{~cm}$ & $25 \mathrm{~cm}$ \\
\hline $\mathrm{t}_{\mathrm{M}}$ uracila $(\mathrm{min})$ & 1,08 & 1,75 & 2,24 \\
\hline$t_{\mathrm{R} \text { naftaleno }}(\mathrm{min})$ & 2,52 & 6,60 & 11,31 \\
\hline$t_{R}$ fenantreno $(\min )$ & 4,10 & 12,05 & 21,95 \\
\hline$t_{R \text { antraceno }}(\min )$ & 4,45 & 13,25 & 24,28 \\
\hline $\mathrm{t}_{\mathrm{R} \text { pireno }}(\mathrm{min})$ & 5,85 & 18,13 & 33,81 \\
\hline$w_{b(50 \%)}$ fenantreno $(\mathrm{min})$ & 0,15 & 0,29 & 0,37 \\
\hline $\mathrm{N}$ & 3.976 & 9.701 & 19.086 \\
\hline $\mathrm{N} / \mathrm{m}$ & 79.527 & 64.677 & 76.344 \\
\hline $\mathrm{H}(\mu \mathrm{m})$ & 12,57 & 15,46 & 13,09 \\
\hline $\mathrm{R}_{\mathrm{s}}$ & 1,26 & 2,31 & 3,47 \\
\hline $\operatorname{As}_{(10 \%)}$ & Indefinido & 1,13 & 1,03 \\
\hline$\alpha$ & 1,11 & 1,12 & 1,12 \\
\hline $\mathrm{k}$ & 2,78 & 5,91 & 8,80 \\
\hline $\mathrm{v}$ & 1,40 & 2,60 & 3,38 \\
\hline h & 3,92 & 4,83 & 4,10 \\
\hline$\varnothing$ & 237 & 1062 & 2633 \\
\hline $\mathrm{E}$ & 4223 & 24815 & 44128 \\
\hline$\Delta \mathrm{P}$ (bar) & 60,0 & 145,0 & 280,0 \\
\hline
\end{tabular}

Tabela 12 - Parâmetros das colunas obtidos a partir dos dados gerados nos cromatogramas apresentados na Figura 19 
Observando a eficiência notou-se um aumento crescente com o aumento do comprimento da coluna, de 3.976 a 19.086 pratos teóricos. Este fato já esperado, uma vez que em colunas mais longas o tempo para atingir o equilíbrio entre analito, F.E e F.M é maior, resultando em maiores eficiências ${ }^{23}$. Mas, se avaliada a eficiência por metro a coluna de $5 \mathrm{~cm}$ apresentou a maior razão N/m (igual a 79.527), em seguida a coluna de $25 \mathrm{~cm}(\mathrm{~N} / \mathrm{m}=76.344)$ e por último a coluna de $15 \mathrm{~cm}(\mathrm{~N} / \mathrm{m}=64.677)$. Isso mostra que embora maiores eficiências sejam alcançadas com o aumento do comprimento da coluna, a eficiência não aumentou proporcionalmente por metro, já que os primeiros $5 \mathrm{~cm}$ da coluna foram capazes de alcançar maior eficiência que os 10 e $20 \mathrm{~cm}$ restantes. Tal fato pode estar relacionado à reologia do empacotamento, pois este pode ter apresentando uma maior homogeneidade do leito no empacotamento dos primeiros $5 \mathrm{~cm}$ da coluna e uma maior heterogeneidade nos centímetros restantes. No entanto, a reologia do leito ainda é um ponto bastante desconhecido pela dificuldade de se definir com maior exatidão a estruturação do leito dentro da coluna.

Como $\mathrm{H}$ também está relacionado com o comprimento da coluna foi observada a mesma tendência da razão $\mathrm{N} / \mathrm{m}$. No que diz respeito à resolução, a coluna de $25 \mathrm{~cm}$ apresentou a melhor separação $\left(R_{s}=3,47\right)$ seguida da coluna de $15 \mathrm{~cm}\left(R_{s}=2,31\right)$, já na coluna de $5 \mathrm{~cm}$ a vantagem do menor tempo de análise foi seguido pela menor resolução $\left(\mathrm{R}_{\mathrm{S}}=1,26\right)$. Estes dados estão de acordo com a literatura que mostra que a resolução deve aumentar proporcionalmente à raiz quadrada do comprimento da coluna, mas como visto na Figura 21, o tempo de análise para alcançar maiores resoluções foi proporcional ao comprimento da coluna ${ }^{23}$.

Como a assimetria do pico foi calculada em função do pico do fenantreno e a coluna de $5 \mathrm{~cm}$ não apresentou uma separação de linha de base para este composto não foi possível definila. Mas os picos referentes ao naftaleno e pireno apresentaram excelente valor para o fator de assimetria (1,4 e 1,1, respectivamente); as outras duas colunas também apresentaram valores para o fator de assimetria próximos da unidade.

Em se tratando das colunas com as mesmas características químicas e somente tamanhos diferentes, já era esperado que os fatores de separação se mantivessem constantes. Assim, como também eram esperados valores crescentes do fator de retenção com o aumento do comprimento da coluna, uma vez que aumenta o tempo em que os compostos ficam retidos na coluna.

Considerando os valores de $h$, as colunas apresentaram excelente desempenho $(h<5)$ e devido este parâmetro está relacionado com a altura equivalente a um prato teórico e ao diâmetro da partícula (que neste caso foi de 3,5 $\mu \mathrm{m}$ ), foi observada a mesma tendência do 
parâmetro $\mathrm{H}$, ou seja, a coluna com melhor desempenho foi a de $5 \mathrm{~cm} \operatorname{com~} \mathrm{h}=3,92$, depois a de $25 \mathrm{~cm}$ com $\mathrm{h}=4,10$ e, por último, a coluna de $15 \mathrm{~cm}$ com $\mathrm{h}=4,83$.

Os parâmetros $\varnothing$ e E são diretamente proporcionais a $\Delta \mathrm{P}$, o que explica o aumento conforme foi aumentado o comprimento da coluna. Como o $\Delta \mathrm{P}$ da coluna de $25 \mathrm{~cm}$ foi maior, os valores de $\varnothing$ e E também foram maiores.

De uma forma geral todas as colunas mostraram bom desempenho, mas cada uma tem seu próprio intervalo distinto de aplicação. A coluna de $5 \mathrm{~cm}$ pode ser usada quando se almeja análises rápidas, enquanto a coluna de $15 \mathrm{~cm}$ fornece suficiente poder de resolução para a mesma demanda de analitos. Já o uso da coluna de $25 \mathrm{~cm}$ fica restrito a uma menor faixa de fluxo, uma vez que, com um fluxo de $5 \mu \mathrm{L} / \mathrm{min}$ resultou em elevação da contrapressão da coluna e maior tempo de eluição. Sendo assim, o uso dessa coluna deve se restringir a aplicações que exigem um alto poder de resolução.

\subsubsection{Avaliação da influência do diâmetro interno no desempenho das colunas}

Para avaliar a influência do diâmetro interno dos tubos no desempenho das colunas foram confeccionadas colunas com quatro d.i. diferentes, $100 \mu \mathrm{m}, 250 \mu \mathrm{m}, 320 \mu \mathrm{m}$ e $500 \mu \mathrm{m}$. Essas dimensões foram escolhidas com o objetivo de abordar toda escala capilar conforme classificação proposta por Chervet et al. ${ }^{35}$, ou seja os d.i. das colunas capilares variam de 150 a $500 \mu \mathrm{m}$. Devido a indisponibilidade de material no nosso laboratório, não foi possível confeccionar colunas de $150 \mu \mathrm{m}$ de d.i. e, por isso, foi desenvolvida uma coluna de $100 \mu \mathrm{m}$ d.i.

Foi empregado o segundo modelo de hardware para confecção das colunas estudadas nessa parte do trabalho, em função deste modelo não fazer uso do tubo restritor. Caso contrário, seriam necessários tubos de sílica fundida de d.i. fixo e diâmetros externos variados, o que também não estava disponível no laboratório. Desta forma, foram utilizados como corpo das colunas tubos de sílica fundida com d.i. e d.e. iguais aos especificados na Tabela 7, o comprimento de todas as colunas foram mantidos em $15 \mathrm{~cm}$.

Tentou-se reproduzir ao máximo as condições de empacotamento para todas as colunas, sendo assim todas as colunas foram confeccionadas empregando a bomba Haskel com pressão fixa de empacotamento igual a 207 bar (este valor foi escolhido devido a pressão máxima suportada pelo tubo de sílica de $500 \mu \mathrm{m}$ de d.i. se restringir a 220 bar).

A concentração das suspenções de F.E C18 de partículas de 3,5 $\mu \mathrm{m}$ foram mantidas proporcionais aos diâmetros dos tubos, ou seja, iguais a 9,3;22,9; 29,3 e 45,8 mg/mL para os tubos de 100, 250, 320 e $500 \mu \mathrm{m}$ respectivamente. 
As condições cromatográficas de análise foram mantidas as mesmas para todas as colunas, e foram iguais as condições descritas nos itens anteriores, com exceção apenas na proporção de F.M empregada, pois a otimização do método para realizar as separações de PAH's na coluna de $500 \mu \mathrm{m}$ de d.i. requereu maior força de eluição, assim a F.M foi mantida em $70 \%$ ACN e $30 \% \mathrm{H}_{2} \mathrm{O}$ para minimizar o alargamento de banda dos picos.

Também foi necessário trabalhar em fluxos volumétricos maiores, pois, conforme discutido anteriormente, somente os fluxos empregados na escala capilar $(1 \mathrm{a} 10 \mu \mathrm{L} / \mathrm{min})^{33}$, não foram totalmente adequados para trabalhar com colunas de d.i. maiores que 250. Assim, para as curvas de pressão, de Van Deemter e de Knox foram empregados fluxos que variaram de 1 a $15 \mu \mathrm{L} / \mathrm{min}$.

A Figura 22 apresenta os dados do estudo na queda de pressão das colunas de 250, 320 e $500 \mu \mathrm{m}$ de d.i.. Era esperado que fixando-se o comprimento da coluna e variando-se o diâmetro interno a pressão aumentasse conforme diminuísse o d.i.. Tal fato foi observado para as colunas de 250 e $320 \mu \mathrm{m}$ de d.i.; já a coluna de $500 \mu \mathrm{m}$ essa tendência não é muito clara.

A coluna de $250 \mu \mathrm{m}$ se aproximou da pressão máxima suportada pelo equipamento em $10 \mu \mathrm{L} / \mathrm{min}$, enquanto a coluna de $320 \mu \mathrm{m}$ de d.i. em $12 \mu \mathrm{L} / \mathrm{min}$ não atingiu metade da pressão alcançada pela coluna de $250 \mu \mathrm{m}$ d.i. em $10 \mu \mathrm{L} / \mathrm{min}$. Também foi possível observar que todos os fluxos empregados na coluna de $320 \mu \mathrm{m}$ d.i. resultaram em pressões menores do que as obtidas para as colunas de $250 \mu \mathrm{m}$ de d.i., em fluxos correspondentes.

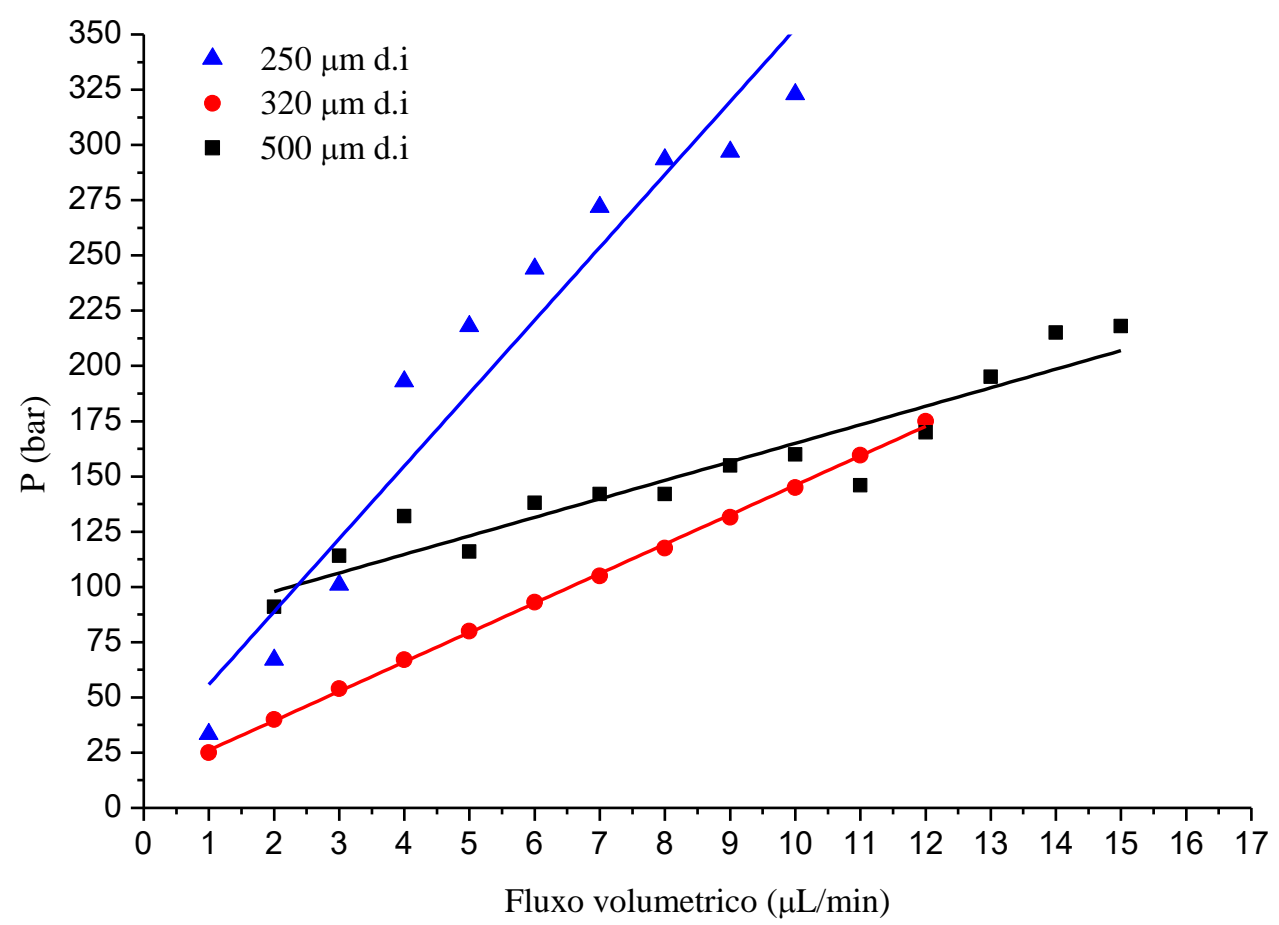

Figura 21 - Efeito da variação da Pressão em função do fluxo volumétrico para as colunas de $15 \mathrm{~cm}, \mathrm{~F}$. E. C18 com partículas de 3,5 $\mu \mathrm{m}$ e d.i. iguais a 250, 320 e $500 \mu \mathrm{m}$ 
Fato curioso foi observado na coluna de $500 \mu \mathrm{m}$ d.i., onde a queda de pressão em fluxos menores, até $3 \mu \mathrm{L} / \mathrm{min}$, foi maior do que os correspondentes nas demais colunas. De um modo geral esse comportamento se estendeu para a coluna de $320 \mu \mathrm{m}$ d.i., que apresentou menores pressões que a coluna de $500 \mu \mathrm{m}$ d.i., o que pode estar relacionado à qualidade do empacotamento dessas colunas. Esta última também apresentou menor inclinação na linha de pressão o que representa maior estabilidade em função da pressão.

Considerando o desempenho das colunas em função da velocidade linear ou velocidade reduzida, descritas pelas curvas de Van Deemter e de Knox, observou-se um comportamento semelhante entre os dois gráficos (Figura 23).

Pode-se afirmar então que a coluna de $250 \mu \mathrm{m}$ de d.i. apresentou o melhor desempenho, pois os valores de $\mathrm{H}$ e $\mathrm{h}$ foram os menores $(\mathrm{H}=25,15 \mathrm{e} h=7,86)$. Seguida pela coluna de 320 $\mu \mathrm{m}(\mathrm{H}=26,6 \mathrm{e} \mathrm{h}=8,32)$ e, por último, a coluna de $500 \mu \mathrm{m}(\mathrm{H}=27,52 \mu \mathrm{m} \mathrm{e} \mathrm{h}=8,60)$. No entanto, o melhor desempenho das colunas de 320 e $500 \mu \mathrm{m}$ foi alcançado em velocidade linear ou velocidade reduzida mais elevada.

Os valores ótimos de $\mu$ e v para a coluna de $320 \mu \mathrm{m}$ d.i. foram iguais a 2,68 e 7,73, respectivamente. Para a coluna de $500 \mu \mathrm{m}$ o valor ótimo de $\mu$ foi 1,32 e de $v$ foi 2,10 . Isso indica que além da coluna de $320 \mu \mathrm{m}$ d.i. apresentar maior eficiência do que a de $500 \mu \mathrm{m}$ d.i. ela consegue isto em um menor tempo de análise.

Através dos gráficos da Figura 23 pode-se observar que o declive da curva da coluna de $320 \mu \mathrm{m}$ d.i. foi o menor na região de predominância do termo C, o que indica que a resistência à transferência de massa entre a fase móvel e a estacionária foi muito menor nessa coluna que nas demais.
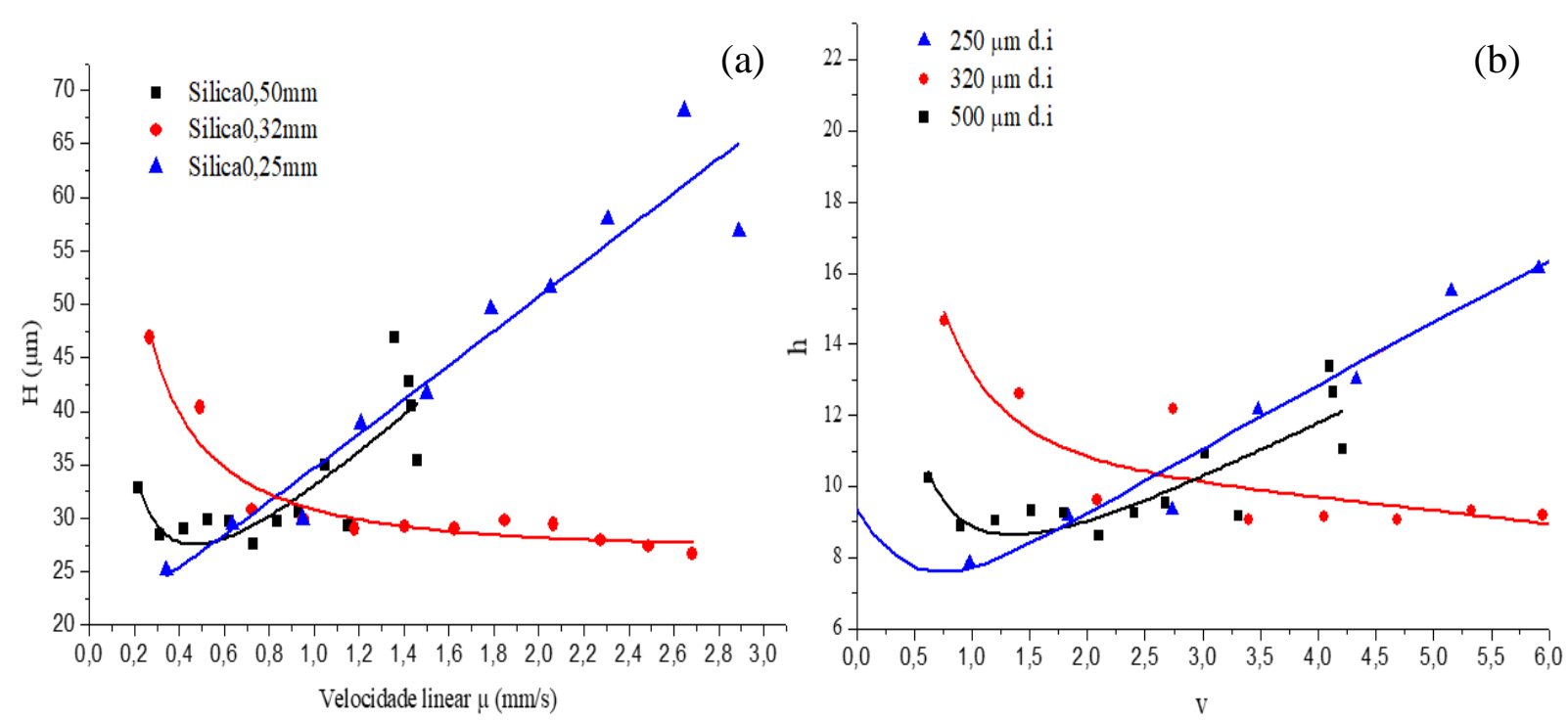

Figura 22 - Gráfico de Van Deemter (a) e Knox (b) para as colunas com d.i. iguais a 500, 320 e $250 \mu \mathrm{m}$ 
Embora a coluna de $250 \mu \mathrm{m}$ apresente o maior desempenho, isso é alcançado à custa de um maior tempo de análise $(\mu=0,34$ e $v=0,98)$.

Na Figura 24 estão os cromatogramas da separação dos PAH's nas três colunas aqui avaliadas. Como mencionado anteriormente, não foi possível realizar as separações em um mesmo fluxo, então para as colunas de 250, 320 e $500 \mu \mathrm{m}$ de d.i. foram empregados fluxos iguais a 3,4 e $10 \mu \mathrm{L} / \mathrm{min}$, respectivamente.

Mesmo operada em maior fluxo, o tempo de análise da coluna de $500 \mu \mathrm{m}$ de d.i. foi maior. Os parâmetros extraídos dos cromatogramas da Figura 24 estão descritos na Tabela 13.

Os valores de $\mathrm{N}, \mathrm{H}$, e h foram relativamente próximos para todas as colunas, mas os melhores valores foram obtidos para coluna de $250 \mu \mathrm{m}$ d.i.

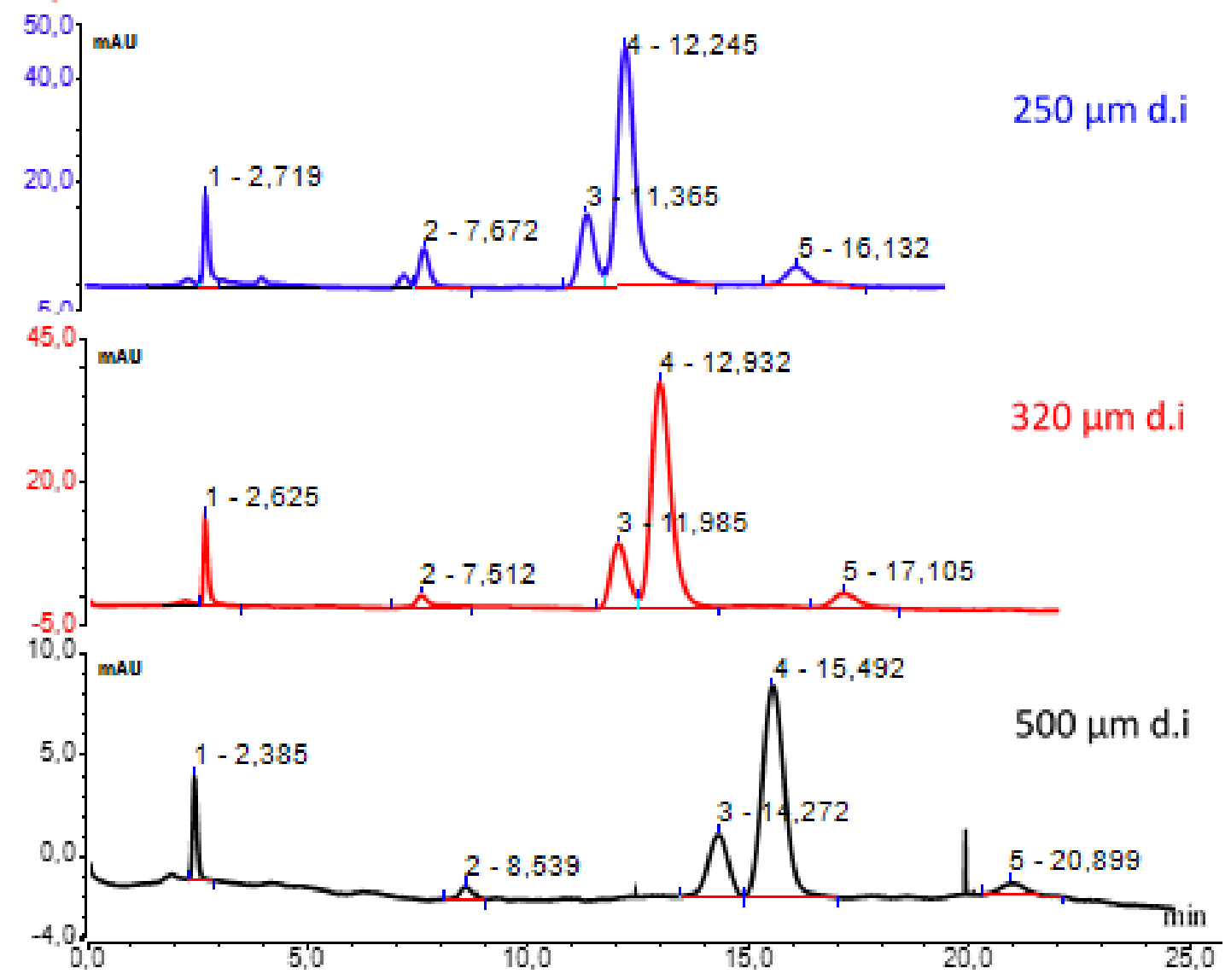

Figura 23 - Cromatogramas da separação dos PAH's realizadas em colunas C18, partículas 3,5 $\mu \mathrm{m}$, comprimento de $15 \mathrm{~cm}$ e d.i de 250, 320 e $500 \mu \mathrm{m}$. Ordem de eluição: (1) uracila, (2) naftaleno, (3) fenantreno, (4) antraceno e (5) pireno 
Como v foi calculada em função do composto uracila, e este composto elui praticamente sem nenhuma interação com a F.E, era esperado que v aumentasse em fluxos mais elevados, como observado na Tabela 13. O parâmetro $\alpha$ é uma propriedade inerente a F.E e manteve-se invariável em todas as separações.

Como, de um modo geral, a coluna de $320 \mu \mathrm{m}$ de d.i. apresentou um menor $\Delta \mathrm{P}$, os melhores resultados de $\emptyset$ e E foram obtidos para essa coluna.

Uma coluna de $100 \mu \mathrm{m}$ de diâmetro interno também foi confeccionada, mas, devido a incompatibilidade da coluna com as condições cromatográficas disponíveis, como por exemplo fluxo, tubulação e cela de detecção, não foi possível realizar os mesmos testes realizados nas demais colunas.

\begin{tabular}{llll}
\hline \multirow{2}{*}{ Parâmetros } & \multicolumn{3}{l}{ Colunas empacotadas (diâmetro interno) } \\
\cline { 2 - 4 } & $250 \mu \mathrm{m}$ & $320 \mu \mathrm{m}$ & $500 \mu \mathrm{m}$ \\
\hline $\mathrm{t}_{\mathrm{M} \text { uracila }(\mathrm{min})}$ & 2,72 & 2,63 & 2,39 \\
$\mathrm{t}_{\mathrm{R} \text { naftaleno }}(\mathrm{min})$ & 7,67 & 7,51 & 8,54 \\
$\mathrm{t}_{\mathrm{R} \text { fenantreno }}(\mathrm{min})$ & 11,37 & 11,99 & 14,27 \\
$\mathrm{t}_{\mathrm{R} \text { antraceno }}(\mathrm{min})$ & 12,25 & 12,93 & 15,49 \\
$\mathrm{t}_{\mathrm{R} \text { pireno }}(\mathrm{min})$ & 16,13 & 17,11 & 20,90 \\
$w_{b(50 \%) \text { fenantreno }}(\min )$ & 0,37 & 0,43 & 0,50 \\
$\mathrm{~N}$ & 5.171 & 4.406 & 4.460 \\
$\mathrm{~N} / \mathrm{m}$ & 34.472 & 29.371 & 29.734 \\
$\mathrm{H}(\mu \mathrm{m})$ & 29,01 & 34,05 & 33,63 \\
$\mathrm{R}_{\mathrm{S}}$ & 1,32 & 1,25 & 1,38 \\
$\mathrm{As}(10 \%)$ & Indefinido & Indefinido & 0,90 \\
$\alpha$ & 1,10 & 1,10 & 1,10 \\
$\mathrm{k}$ & 3,18 & 3,57 & 4,98 \\
$\mathrm{v}$ & 2,65 & 2,75 & 3,02 \\
$\mathrm{~h}$ & 9,06 & 10,64 & 10,51 \\
$\varnothing$ & 1.271 & 814 & 1.766 \\
$\mathrm{E}$ & 104.449 & 92.148 & 195.084 \\
$\Delta \mathrm{P}($ bar) & 107 & 67 & 160 \\
\hline
\end{tabular}

Tabela 13 - Parâmetros da coluna obtidos a partir dos dados gerados nos cromatogramas apresentados na Figura 24 
Para melhor entendimento é apresentado na Figura 25 um cromatograma da separação dos PAH's realizados em um fluxo de $1 \mu \mathrm{L} / \mathrm{min}, 40 \mathrm{~nL}$ de volume de injeção e concentração dos analitos de 1 ppm.

Ficou evidente durante os experimentos que fluxos menores que $1 \mu \mathrm{L} / \mathrm{mL}$ deveriam ser mais compatíveis com esta coluna, pois a um fluxo de $1 \mu \mathrm{L} / \mathrm{min}$ a pressão foi de 170 bar. Mas, devido às limitações instrumentais do equipamento, não podem ser testados fluxos menores. Isso mostra que colunas de $100 \mu \mathrm{m}$ de d.i. não foram empregadas adequadamente nos equipamentos projetados até o presente para colunas capilares. Por isso as classificações da escala capilar com relação ao diâmetro interno do tubo incluem colunas com diâmetros internos de 150 a $500 \mu \mathrm{m}$. As colunas de d.i. igual a $100 \mu \mathrm{m}$ ou menores estão sendo classificadas como nano LC (nLC)

Observa-se no cromatograma da Figura 25 que só não foi possível separar os analitos fenantreno e antraceno, como também os outros compostos separados com um tempo de retenção menor do que os obtidos pelas outras colunas. Mesmo nas separações realizadas anteriormente foi possível notar em alguns cromatogramas, a presença de contaminantes bem maiores na coluna de $100 \mu \mathrm{m}$ d.i. Pode-se então concluir que colunas com diâmetro interno igual ou inferiores a $100 \mu \mathrm{m}$ devem ser empregados na escala nano e em equipamentos projetados para a esta escala.

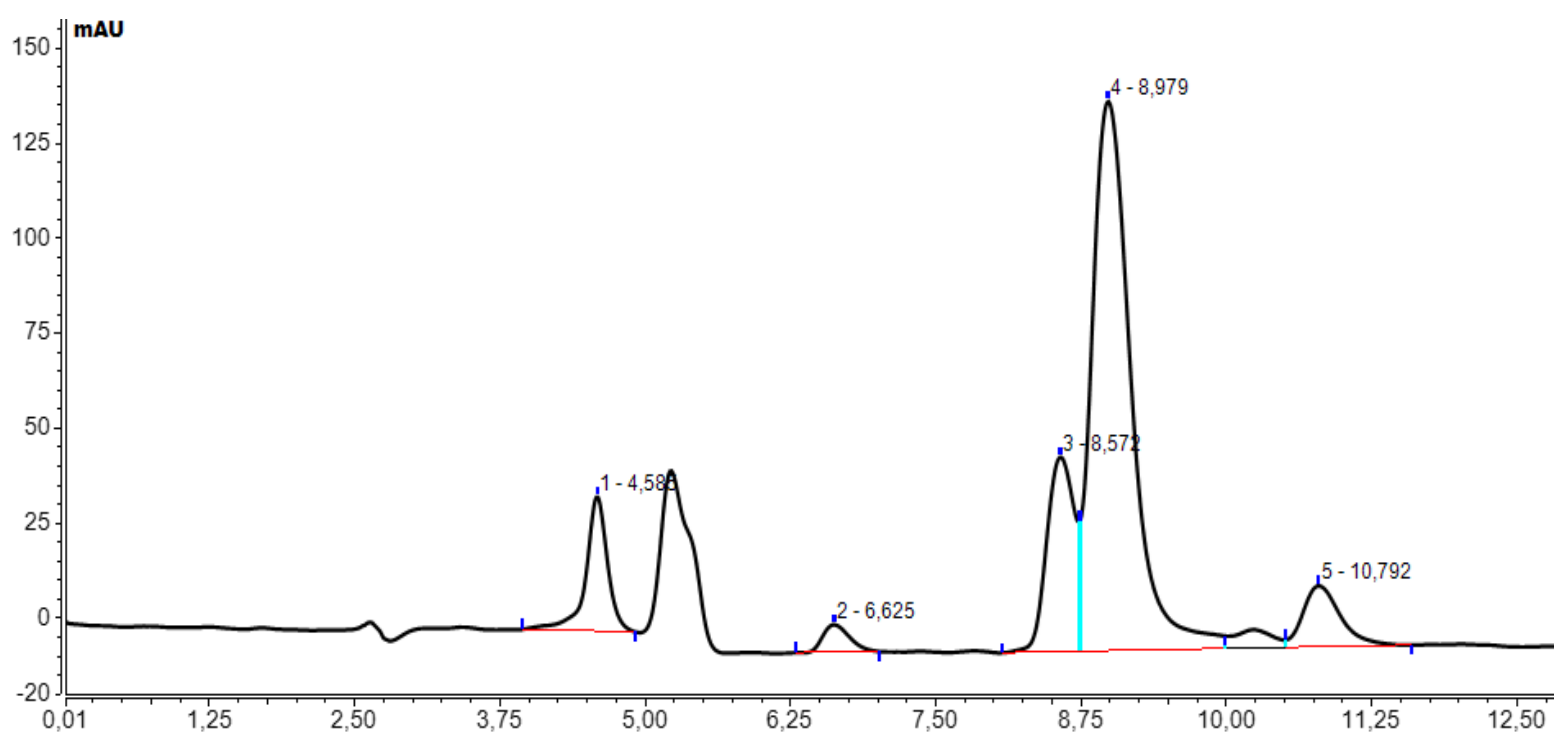

Figura 24 - Cromatogramas da separação dos PAH's realizadas em colunas C18 de partículas $3,5 \mu \mathrm{m}$, comprimento de $15 \mathrm{~cm}$ diâmetro interno de $100 \mu \mathrm{m}$. Ordem de eluição: (1) uracila, (2) naftaleno, (3) fenantreno, (4) antraceno e (5) pireno 


\subsubsection{Avaliação da influência do tipo de material empregado como suporte no desempenho da coluna}

As colunas cromatográficas podem ser construídas em diferentes tipos de materiais, sendo os mais comuns PEEK, aço inoxidável ou sílica revestida por PEEK ou aço inoxidável. Para verificar se o tipo de material apresenta influência no desempenho das colunas, foram confeccionadas colunas em tubos de PEEK, aço inoxidável, sílica revestida por aço inox (AçoSil) e, como neste trabalho foi proposto o emprego de colunas confeccionadas em tubos de sílica fundida, também foi produzida coluna nesse tipo de material.

Foi empregado o segundo modelo de hardware (o mesmo geralmente utilizado em colunas comerciais), sendo o comprimento da coluna foi mantido em $15 \mathrm{~cm}$ e o diâmetro interno igual a $500 \mu \mathrm{m}$. As condições de empacotamento foram mantidas as mesmas na confecção de todas as colunas. Foi empregada a bomba Haskel como empacotadora, a concentração da suspenção foi 45,8 mg/mL e pressão de empacotamento de 207 bar (pressão máxima suportado pelo tubo de sílica fundida de $500 \mu \mathrm{m}$ de d.i.).

Iniciou-se avaliando a queda de pressão da coluna em função do fluxo volumétrico (Figura 26). As colunas apresentaram comportamento diferentes sendo que as menores pressões foram registradas para a coluna de açosil. Desta forma, era esperado que a coluna de sílica fundida também apresentasse comportamento semelhante, já que teoricamente a F.E e F.M estariam em contato com o mesmo material e, assim, o perfil do leito cromatográfico e os efeitos de parede deveriam se assemelhar. No entanto, a procedência dos materiais empregados foi diferente e isso pode ter influenciado na pressão das colunas.

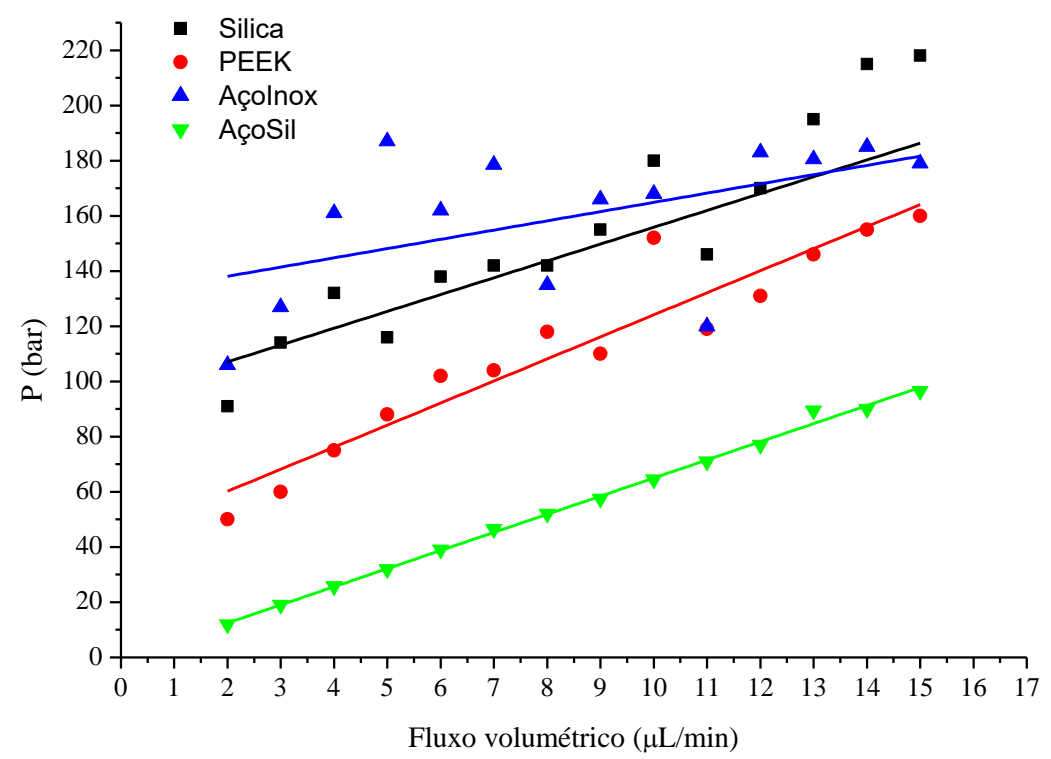

Figura 25 - Efeito da variação da pressão em função do fluxo volumétrico para as colunas C18 $(15 \mathrm{~cm}$ x $500 \mu \mathrm{m} \times 3,5 \mu \mathrm{m})$ confeccionadas em PEEK, aço inox, sílica fundida e açosil 
A coluna de PEEK apresentou a segunda menor variação de pressão, seguida da coluna de sílica fundida e por último a coluna de aço inox. Foi possível notar também que as duas últimas colunas apresentaram maior instabilidade da pressão.

Os gráficos de Van Deemter e Knox (Figura 27) apresentaram o mesmo perfil, isso porque são colunas com características físicas (mesmas dimensões) e químicas (mesma F.E) similares. De acordo com estes gráficos, a coluna de AçoSil também apresentou melhor desempenho $(\mathrm{H}=8,13 \mu \mathrm{m}$ e $\mathrm{h}=2,54)$ estando em conformidade com as menores pressões obtidas.

A coluna de AçoInox apresentou o segundo melhor desempenho $(\mathrm{H}=9,30 \mathrm{e} \mathrm{h}=2,91)$ e suas curvas se assemelharam bastante com as da coluna AçoSil, sendo que o melhor desempenho destas colunas foi atingido em velocidades lineares/ou reduzidas mais altas que para as demais colunas. As inclinações das curvas também foram mais acentuadas, indicando que as colunas de AçoSil e AçoInox podem operar em fluxos mais elevados, diminuindo então o tempo de eluição dos compostos, com menor perda de eficiência.

Diferentemente da coluna de AçoSil a coluna de AçoInox foi a que apresentou maior contrapressão, não sendo possível estabelecer uma relação entre a contrapressão da coluna e a qualidade do empacotamento.

O terceiro melhor desempenho foi registrado pela coluna confeccionada em tubo de PEEK $(\mathrm{H}=12,71 \mu \mathrm{m} \mathrm{e} \mathrm{h}=3,97)$, mas é possível notar, através da Figura 27, que a inclinação das curvas, para esta coluna, foi mais acentuada que as das colunas de aço. Esta coluna somente se destaca com relação a coluna de sílica fundida, que apresentou o pior desempenho $(\mathrm{H}=27,52$ $\mu \mathrm{me} \mathrm{h}=8,60)$.
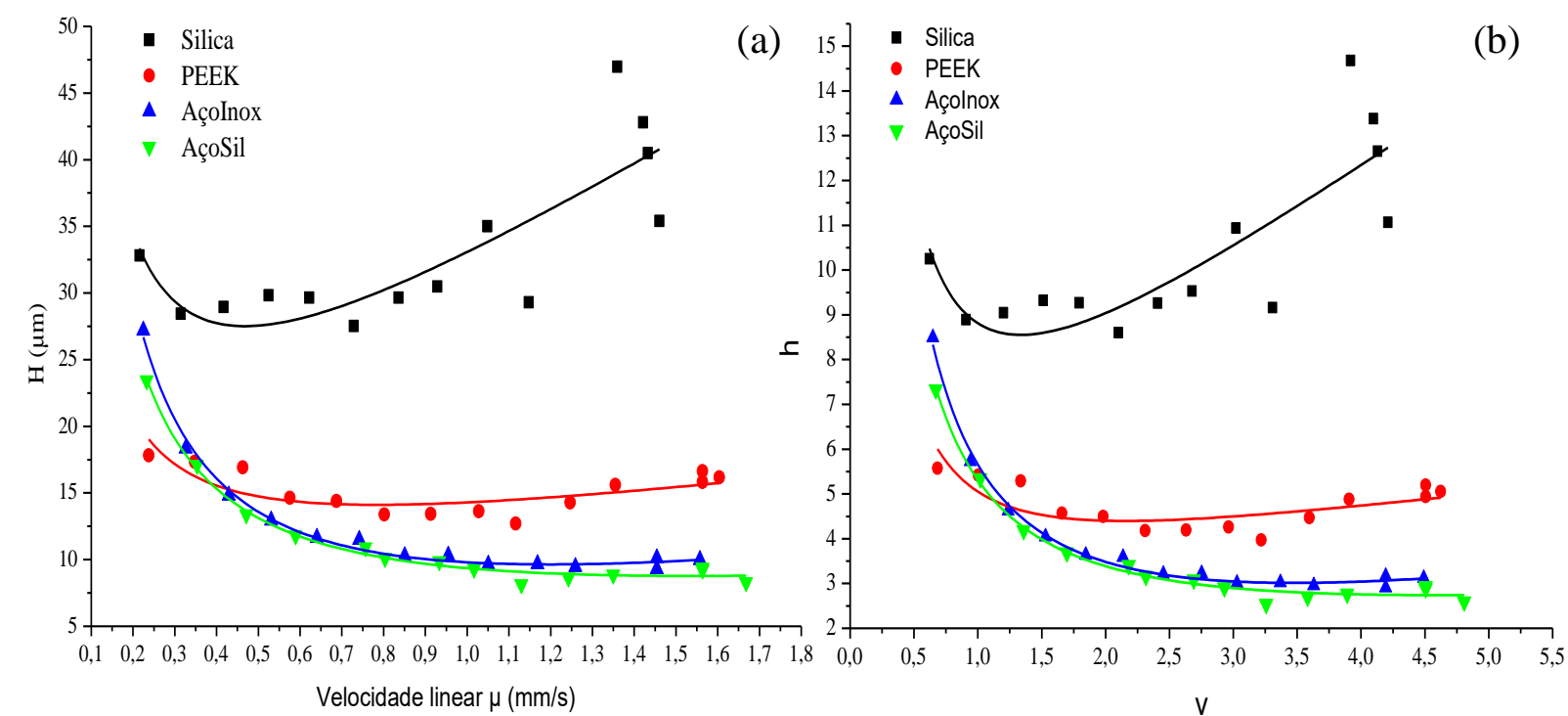

Figura 26 - Gráfico de Van Deemter (a) e Knox (b) para as colunas confeccionadas em PEEK, aço inox, sílica fundida e açosil 
Os cromatogramas da Figura 28 correspondem às separações dos compostos de PAH's em cada uma das colunas aqui estudadas. Foi empregado ACN/ $\mathrm{H}_{2} \mathrm{O}$ (70:30) com F.M a um fluxo de $10 \mu \mathrm{L} / \mathrm{min}$, sendo as demais condições cromatográficas iguais aos dos experimentos anteriores. Os parâmetros extraídos destes cromatogramas são apresentados na Tabela 14.

As colunas apresentaram tempos de retenção semelhantes, com exceção da coluna de AçoSil, que apresentou uma redução do tempo de análise de cerca de 2:30 min. Os valores de N, H, h e R apresentaram a mesma tendência mostrada pelos gráficos de Van Deente e Knox, as colunas mantiveram a mesma ordem de desempenho (AçoSil > AçoInox > PEEK > Sílica), lembrando que a coluna de sílica fundida apresentou desempenho muito inferior às demais.

O parâmetro As(10\%) revela excelente formato de pico para as colunas AçoSil $(1,03)$, AçoInox $(1,05)$ e PEEK $(1,04)$ enquanto o pico da coluna de Silíca apresentou-se menos simétrico $(0,90)$. Uma vez que se trata de colunas compostas pela mesma F.E o valor de $\alpha(1,10)$ se reproduziu para todas elas.
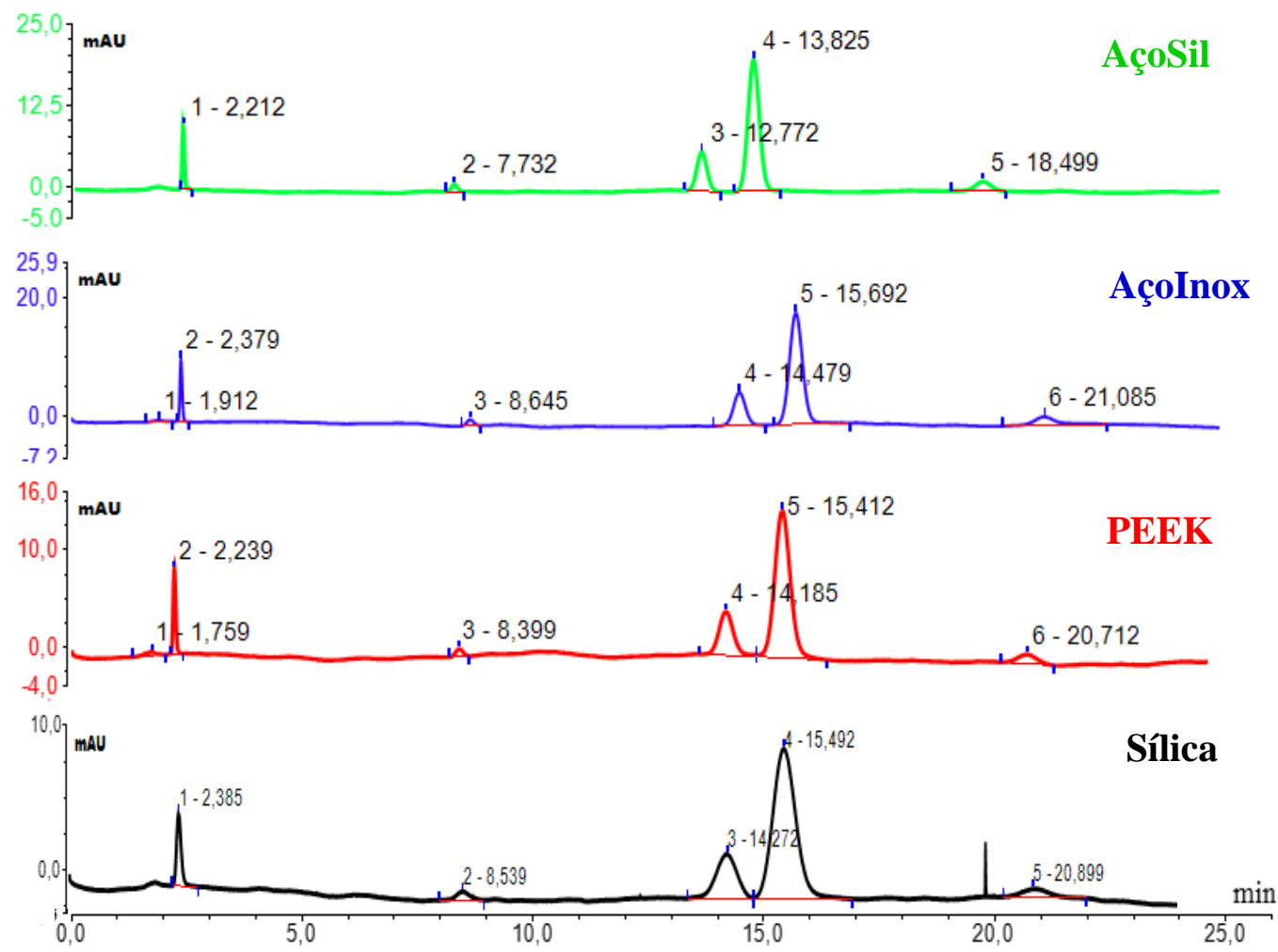

Figura 27 - Cromatogramas da separação dos PAH's realizadas em colunas C18 (15 cm x $500 \mu \mathrm{m}$ x 3,5 $\mu \mathrm{m}$ ) confeccionadas em tubos de Sílica, PEEK, AçoInox e AçoSil. Ordem de eluição: (1) uracila, (2) naftaleno, (3) fenantreno, (4) antraceno e (5) pireno 


\begin{tabular}{|c|c|c|c|c|}
\hline \multirow{2}{*}{ Parâmetros } & \multicolumn{4}{|c|}{ Colunas empacotadas (material empregado como suporte) } \\
\hline & Sílica & PEEK & AçoInox & AçoSil \\
\hline $\mathrm{t}_{\mathrm{M} \text { uracila }}(\mathrm{min})$ & 2,39 & 2,24 & 2,37 & 2,21 \\
\hline$t_{\mathrm{R} \text { naftaleno }}(\min )$ & 8,54 & 8,40 & 8,50 & 7,73 \\
\hline$t_{R}$ fenantreno $(\min )$ & 14,27 & 14,19 & 14,17 & 12,77 \\
\hline$t_{R}$ antraceno $(\min )$ & 15,49 & 15,41 & 15,35 & 13,83 \\
\hline $\mathrm{t}_{\mathrm{R} \text { pireno }}(\min )$ & 20,90 & 20,71 & 20,61 & 18,50 \\
\hline$w_{b}(50 \%)$ fenantreno $(\min )$ & 0,50 & 0,33 & 0,28 & 0,23 \\
\hline $\mathrm{N}$ & 4460 & 10.299 & 14.280 & 17.538 \\
\hline $\mathrm{N} / \mathrm{m}$ & 29734 & 68657 & 95201 & 116919 \\
\hline $\mathrm{H}(\mu \mathrm{m})$ & 33,63 & 14,57 & 10,50 & 8,55 \\
\hline $\mathrm{R}_{\mathrm{s}}$ & 1,38 & 2,10 & 2,37 & 2,56 \\
\hline $\operatorname{As}_{(10 \%)}$ & 0,90 & 1,04 & 1,05 & 1,03 \\
\hline$\alpha$ & 1,10 & 1,10 & 1,10 & 1,10 \\
\hline $\mathrm{k}$ & 4,98 & 5,34 & 4,99 & 4,77 \\
\hline $\mathrm{v}$ & 3,02 & 3,22 & 3,05 & 3,26 \\
\hline h & 10,51 & 4,55 & 3,28 & 2,67 \\
\hline$\varnothing$ & 1766 & 1575 & 1839 & 655 \\
\hline $\mathrm{E}$ & 195084 & 32632 & 19814 & 4681 \\
\hline$\Delta \mathrm{P}($ bar $)$ & 160 & 152 & 168 & 64 \\
\hline
\end{tabular}

Tabela 14 - Parâmetros da coluna obtidos a partir dos dados gerados nos cromatogramas apresentados na Figura 28

Embora fosse esperado também que os valores de $\mathrm{k}$ se mantivessem constantes para todas as colunas, pois foram mantidas as condições de análise e as características das colunas, foi observada uma variação do valor de k. Para coluna de AçoSil o valor de k, o menor registrado, comportou-se de acordo com o tempo de retenção, ou seja, quanto menor o $t_{R}$, menor o valor de k. Mesmo que o tempo de retenção nas outras colunas tenham sido parecidos, o valor de $\mathrm{k}$ variou consideravelmente para a coluna de PEEK, o que pode estar relacionado com a estruturação do leito de F.E, ou estar relacionado a variações de temperatura do ambiente no momento da análise, já que esta é uma variável difícil de ser controlada.

A coluna de AçoSil também apresentou excelente desempenho com relação aos parâmetros $\emptyset$ e E, pois, seus valores foram muito pequenos, mostrando que a coluna atingiu elevada eficiência combinada com uma baixa contrapressão. Já as colunas de AçoInox e PEEK apresentaram valores de $\Delta \mathrm{P}$ mais elevados, no entanto, devido às maiores eficiências 
apresentadas, os valores $\varnothing$ e $\mathrm{E}$ foram mais elevados do que o da coluna de AçoSil, mas considerados bons. Apenas a coluna de Sílica fundida apresentou desempenho ruim, considerando a impedância de separação $(\mathrm{E}=195.084)$.

De um modo geral os resultados obtidos mostraram que o material empregado como suporte da coluna influenciou no seu desempenho, sendo que o material que se mostrou mais adequado foi o AçoSil, pois resultou em colunas com alta eficiência e baixa contrapressão. A coluna de sílica, pelo menos no formato de hardware empregado aqui, apresentou-se como a menos adequada pois, além de menor eficiência deve-se levar em conta também que o tubo de sílica apresenta uma resistência mecânica baixa, com maior dificuldade para seu manuseio. Em se tratando do tubo de sílica de $500 \mu \mathrm{m}$ de d.i., cuja pressão máxima suportada é de 220 bar, fica-se impedido de trabalhar com a coluna em fluxos mais altas que $15 \mu \mathrm{L} / \mathrm{min}$.

\subsubsection{Avaliação da influência da pressão de empacotamento no desempenho da coluna}

A pressão de empacotamento é aquela empregada para empurrar, a um fluxo constante, a suspensão de partículas da F.E armazenada em uma coluna de empacotamento para dentro de um tubo cilíndrico vazio com um frit (filtro) na extremidade, formando um leito cromatográfico compactado. Acredita-se que a homogeneidade do leito pode ser influenciada pela pressão de empacotamento o que, por sua vez, influencia no desempenho da coluna.

O leito cromatográfico é um esqueleto formado por partículas compactadas e com pequenos espaços vazios entre as mesmas, o qual é preenchido com o solvente. As altas pressões empregadas são transmitidas para todo o leito na forma de gradiente de pressão. $\mathrm{O}$ fluxo do solvente utilizado no empacotamento promove uma intensa fricção entre as partículas ao longo da coluna, em direção ao fluxo. Devido a todas essas forças aplicadas ao leito cromatográfico durante o empacotamento, pode ocorrer uma reorganização do leito, causado pelo movimento de uma partícula ou a quebra dela ${ }^{71}$.

Os trabalhos científicos disponíveis relatam que para um melhor empacotamento das colunas capilares devem ser empregadas pressões elevadas, normalmente de 280 a 2800 bar $^{71}$. Desta forma, nesta parte do trabalho executamos experimentos para verificar se a pressão de empacotamento exerce influência no desempenho da coluna, já que a formação do leito está relacionada à pressão de empacotamento.

Desta forma, as colunas foram empacotadas sob as mesmas condições experimentais, empregando-se apenas pressões diferentes. O tubo para confecção da coluna foi o de AçoInox 
e utilizou-se o mesmo tubo para empacotamento das colunas nas três diferentes pressões estudadas, 220, 680 e 1034 bar.

O gráfico mostrando a influência da pressão versus o fluxo (Figura 29) mostra que a coluna empacotada sob a maior pressão (1034 bar) registrou as pressões mais elevadas e uma maior instabilidade de pressão ao elevar o fluxo. As colunas empacotadas a 220 e 680 bar apresentaram pressões semelhantes nos mesmos fluxos, sendo que a de 220 bar apresentou pressões um pouco menores que a de 680 em fluxos mais altos.

Como aumentando a pressão de empacotamento, supostamente as partículas ficam mais compactadas dentro da coluna, isso provavelmente pode aumentar a resistência ao fluxo da fase móvel, e com isso, aumentar a contrapressão das colunas conforme aumento da pressão de empacotamento.

Os desempenhos das colunas em relação aos gráficos de Van Deemter e Knox (Figura 30) apresentaram comportamento semelhante ao da pressão, embora de uma forma mais sutil. Sendo assim, a coluna empacotada a 220 bar apresentou melhores valores de $\mathrm{H}(8,13)$ e h $(2,54)$, em seguida encontra-se a coluna empacotada a 680 bar $(\mathrm{H}=8,25 \mathrm{e} \mathrm{h}=2,60)$ com desempenho muito próximo da coluna de 220 bar e, por último, a coluna empacotada a 1034 bar $(\mathrm{H}=9,54$ $\mathrm{e} h=2,98)$

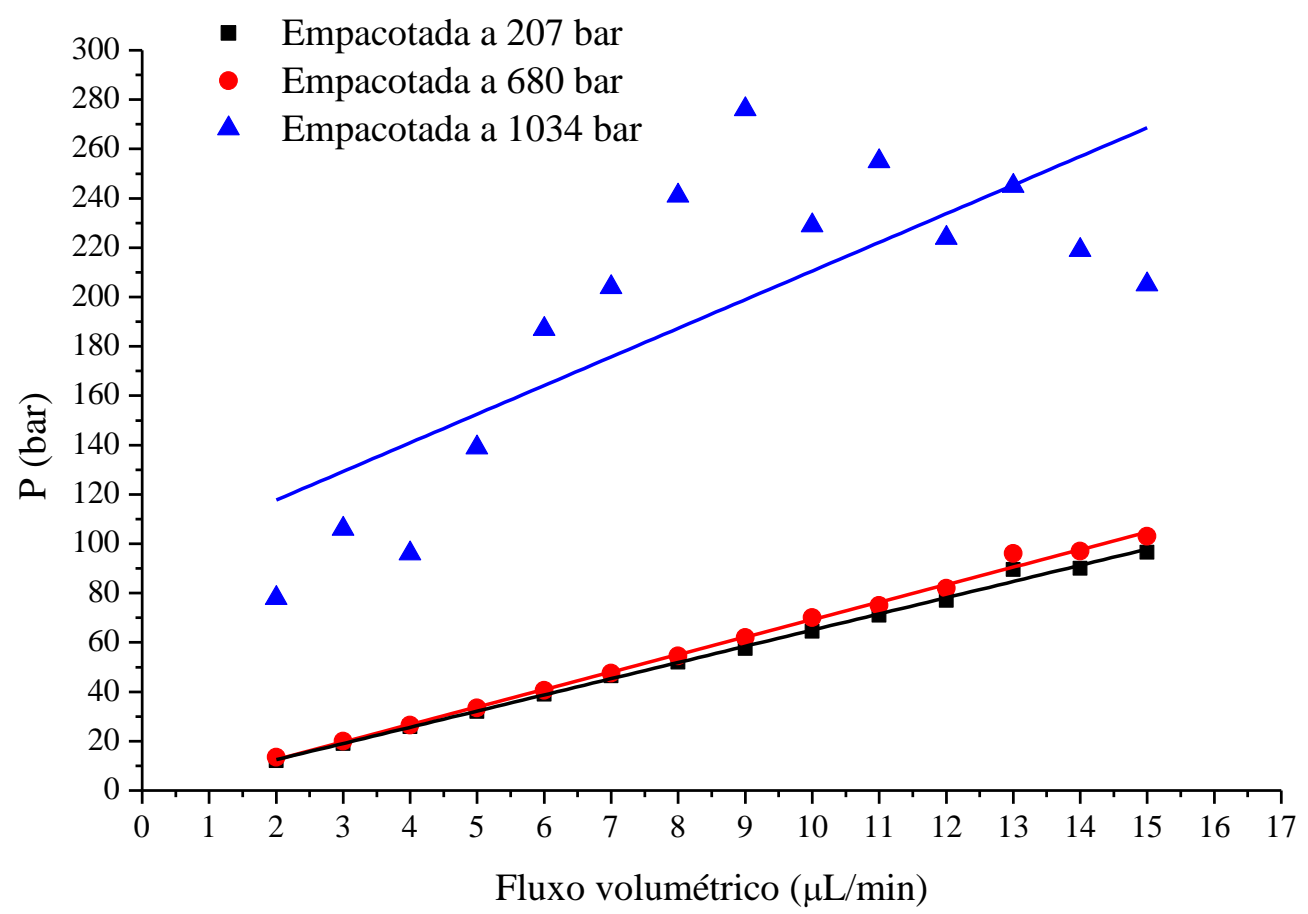

Figura 28 - Efeito da variação da pressão em função do fluxo volumétrico para as colunas C18 $(15 \mathrm{~cm}$ x $500 \mu \mathrm{m} \times 3,5 \mu \mathrm{m})$ empregando pressões de empacotamento iguais a 220, 680 e 1034 bar 

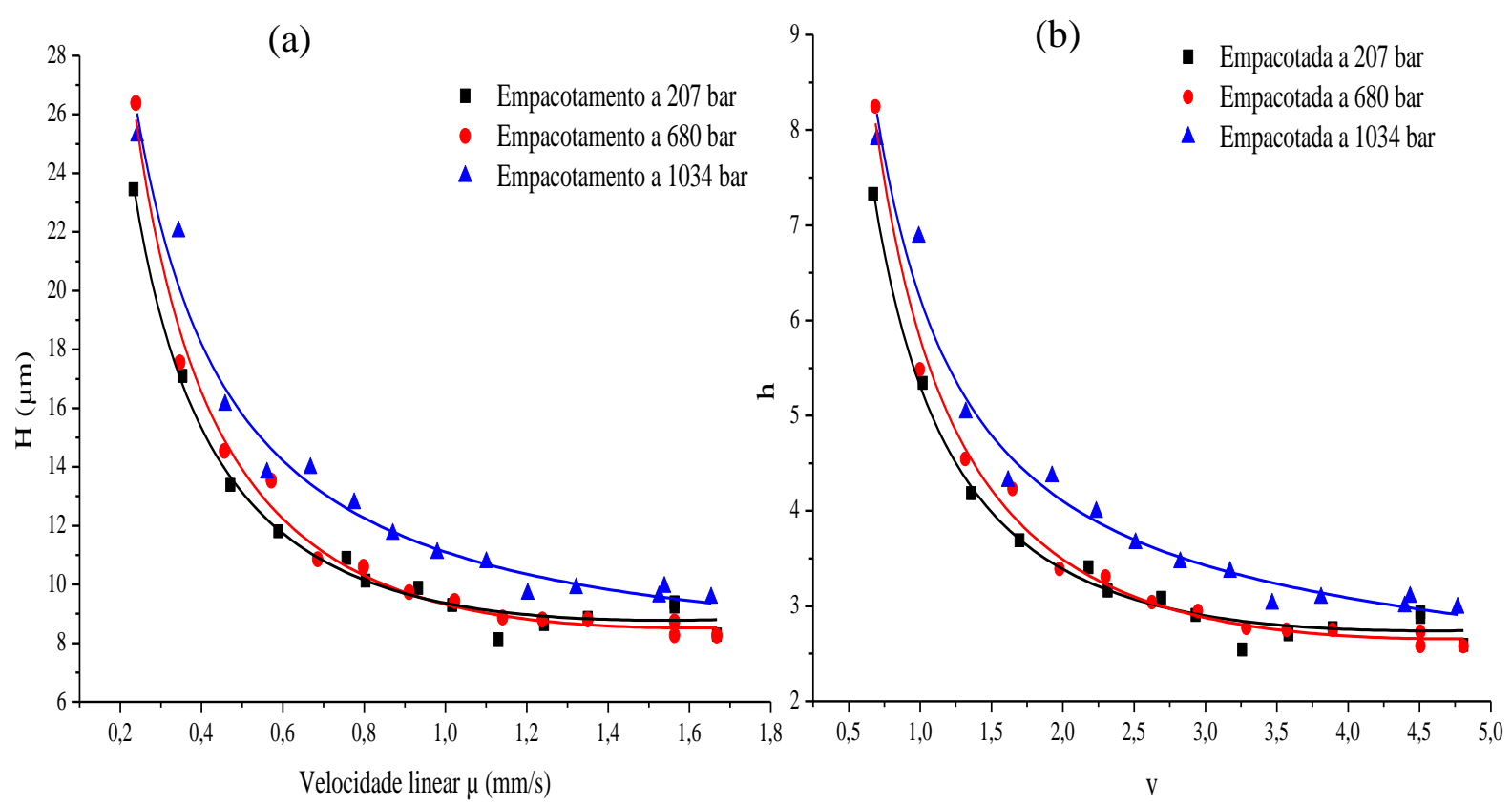

Figura 29 - Gráfico de Van Deemter (a) e Knox (b) para as colunas C18 (15 cm x $500 \mu \mathrm{m}$ x 3,5 $\mu \mathrm{m})$ empregando pressões de empacotamento iguais a 220, 680 e 1034 bar

A literatura ${ }^{71}$ aborda que as colunas que apresentaram maiores eficiências são aquelas cujas pressões de empacotamento são as mais elevadas. No entanto, para as colunas investigadas neste trabalho ficou evidente que mesmo usando uma pressão de 207 bar, pressão essa que está abaixo da mínima usualmente estimada pela literatura (280 bar) como adequada para empacotamento ${ }^{71}$, foi possível alcançar melhor eficiência que empregando pressões mais altas.

Para melhor entendimento do comportamento das colunas, também em função do tempo de análise, foram expostos na Figura 31 os cromatogramas das separações dos compostos de PAH's. As condições de análises cromatográficas foram as mesmas usadas nas separações da Figura 28.

Os tempos de retenção foram diferentes para as três colunas, mas especialmente para a coluna empacotada a 1034 bar, cujo o último pico eluido apresentou um aumento do $t_{R}$ de cerca de $3 \mathrm{~min}$, se comparado às outras colunas. Os resultados mostraram que, além de um pior desempenho essa coluna atinge o final da análise em um maior tempo; outro ponto negativo a ser ressaltado é que a intensidade dos picos desta coluna foi cerca da metade da intensidade dos picos das demais. No entanto, pode-se observar de um modo geral que todas as colunas foram capazes de separar perfeitamente todos os compostos com excelentes eficiências $(\mathrm{N})$, formatos de picos $\left(\mathrm{As}_{(10 \%)}\right)$ e boas resoluções $\left(\mathrm{R}_{\mathrm{s}}\right)$. A comprovação numérica disso está atestada através dos valores dos parâmetros cromatográficos na Tabela 15. 


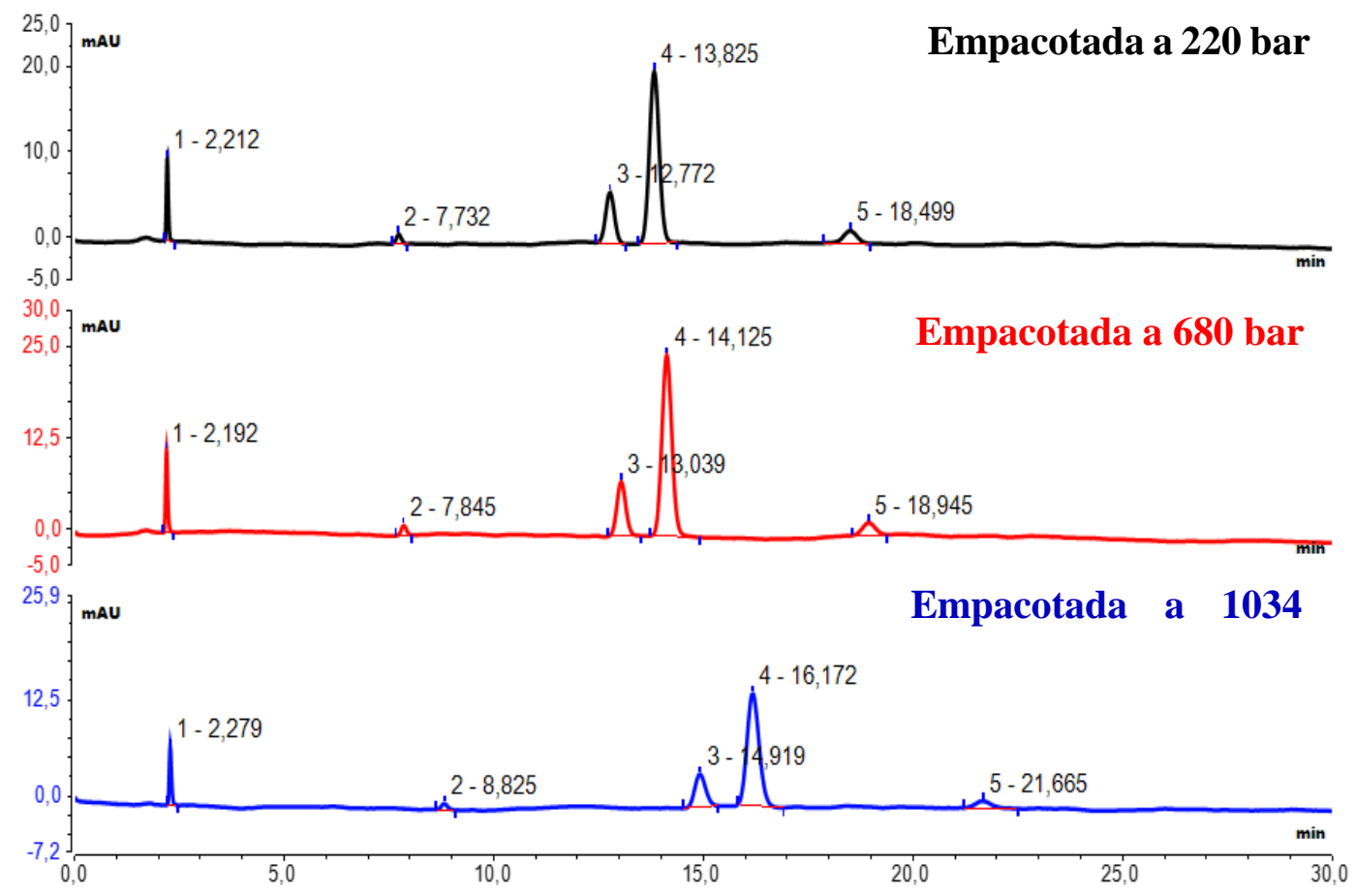

Figura 30 - Cromatogramas da separação dos PAH's empregando colunas C18 (15 $\mathrm{cm}$ x $500 \mu \mathrm{m}$ x 3,5 $\mu \mathrm{m}$ ) empacotadas a pressões iguais a 220, 680 e 1034 bar. Ordem de eluição: (1) uracila, (2) naftaleno, (3) fenantreno, (4) antraceno e (5) pireno

\begin{tabular}{|c|c|c|c|}
\hline \multirow{2}{*}{ Parâmetros } & \multicolumn{3}{|c|}{ Colunas com diferentes pressões de empacotamento } \\
\hline & 207 bar & 680 bar & 1034 bar \\
\hline $\mathrm{t}_{\mathrm{M} \text { uracila }}(\mathrm{min})$ & 2,21 & 2,19 & 2,28 \\
\hline $\mathrm{t}_{\mathrm{R} \text { naftaleno }}(\mathrm{min})$ & 7,73 & 7,85 & 8,83 \\
\hline$t_{\mathrm{R} \text { fenantreno }}(\mathrm{min})$ & 12,77 & 13,04 & 14,92 \\
\hline $\mathrm{t}_{\mathrm{R} \text { antraceno }}(\mathrm{min})$ & 13,83 & 14,13 & 16,17 \\
\hline $\mathrm{t}_{\mathrm{R} \text { pireno }}(\mathrm{min})$ & 18,50 & 18,95 & 21,67 \\
\hline$w_{b}(50 \%)$ fenantreno $(\mathrm{min})$ & 0,23 & 0,24 & 0,29 \\
\hline $\mathrm{N}$ & 17538 & 17055 & 14970 \\
\hline $\mathrm{N} / \mathrm{m}$ & 116919 & 113703 & 99801 \\
\hline $\mathrm{H}(\mu \mathrm{m})$ & 8,55 & 8,79 & 10,02 \\
\hline $\mathrm{R}_{\mathrm{s}}$ & 2,56 & 2,59 & 2,44 \\
\hline $\mathrm{As}_{(10 \%)}$ & 1,03 & 1,07 & 1,14 \\
\hline$\alpha$ & 1,10 & 1,10 & 1,10 \\
\hline $\mathrm{k}$ & 4,77 & 4,95 & 5,55 \\
\hline $\mathrm{v}$ & 3,26 & 3,29 & 3,16 \\
\hline h & 2,67 & 2,75 & 3,13 \\
\hline$\varnothing$ & 655 & 710 & 2373 \\
\hline $\mathrm{E}$ & 4681 & 5364 & 23269 \\
\hline$\Delta \mathrm{P}$ (bar) & 64 & 70 & 225 \\
\hline
\end{tabular}

Tabela 15 - Parâmetros da coluna obtidos a partir dos dados gerados nos cromatogramas apresentados na Figura 31 
De um modo geral os parâmetros cromatográficos resultantes da separação dos PAH's mostram, assim como os gráficos de Van Deemter e Knox, que o desempenho das colunas empacotadas a 207 e 680 bar foram muito próximos, sendo que o desempenho da coluna empacotada a 207 bar foi um pouco maior. Já a coluna empacotada a 1035 bar, comparativamente, apresentou um desempenho bem inferior às outras colunas.

Aqui, todos os parâmetros $\left(\mathrm{N}, \mathrm{H}, \mathrm{A}_{\mathrm{s}(10 \%)}, \mathrm{K}, \mathrm{v}, \mathrm{h}, \varnothing, \mathrm{E}\right.$ e $\left.\Delta \mathrm{P}\right)$ apresentaram excelentes resultados e melhores valores, primeiramente para a coluna empacotada a 220 bar, seguida da coluna empacotada a 680 bar e, por último, a coluna empacotada a 1034 bar. Isso mostra uma nítida relação do desempenho das colunas com as pressões de empacotamento empregadas. O único parâmetro que se manteve constante foi o $\alpha$, o que era esperado uma vez que se manteve a mesma fase estacionária e móvel em todas as separações, o que indica que as distâncias de separação entre os compostos fenantreno e antraceno mantiveram-se inalteradas.

A contrapressão da coluna empacotada a 1034 bar reproduziu o que foi observado no gráfico da pressão (Figura 25) ou seja, uma pressão bastante elevada se comparada às das outras colunas. Isso, consequentemente, reflete no valor da resistência ao fluxo ( $\varnothing$ ), que foi bastante elevada e na impedância de separação (E) que, embora tenha apresentado um bom resultado, quando comparado ao das demais colunas, foi muito maior.

Desta forma, pode-se concluir que a pressão de empacotamento exerceu grande influência no desempenho das colunas, tanto em termos de eficiência, quanto no tempo de análise e na contra- pressão da coluna. A pressão de empacotamento que se mostrou mais adequada para essa metodologia, foi a de 207 bar.

\subsubsection{Avaliação da influência do tipo de bomba empacotadora no desempenho da coluna}

Como neste trabalho foram empregados dois tipos de bombas para empacotamento das colunas, fez-se necessário avaliar se elas poderiam interferir no desempenho das colunas.

Foi utilizada uma bomba pneumática para líquidos Haskel de duplo cabeçote, relação nominal 122:1 e acionada por ar nitrogênio, com pressão inicial e máxima de saída de 100 a 1034 bar, respectivamente. Foi utilizada também uma bomba de pistão reciprocante de uso geral Shimadzu (CL-20AT), geralmente empregada nos sistemas de HPLC. Trata-se de uma bomba de duplo pistão reciprocante de fluxo constante, na qual podem ser empregadas taxas de fluxos de 0,1 a $5 \mathrm{~mL} / \mathrm{min}$ e pressão máxima de 400 bar.

Sendo assim, foi empacotada uma coluna empregando cada uma das bombas, para isso utilizou-se o segundo modelo de hardware com $15 \mathrm{~cm}$ de comprimento e F.E C18 com 
partículas de 3,5 $\mu \mathrm{m}$. Foram mantidas todas as condições experimentais de empacotamento e as pressões nas bombas foram fixadas em 200 bar.

As nomenclaturas das colunas empregadas, nesta parte do trabalho, fizeram menção às bombas utilizadas; assim, nos gráficos e figuras, os nomes das colunas foram substituídos pelas marcas das bombas empregadas no seu empacotamento.

A Figura 32 apresenta o estudo da pressão em função do fluxo da fase, realizados para as duas colunas investigadas.

Observou-se que os comportamentos da contrapressão das duas colunas em cada um dos fluxos empregados foram muito semelhantes, sendo a contrapressão da coluna empacotada na bomba Haskel um pouco mais elevada.

Através dos gráficos de Van Deemter e Knox (Figura 33) foi possível observar uma maior interferência do tipo de bomba empacotadora no desempenho das colunas. Nos dois gráficos a coluna empacotada com a bomba Haskel apresentou desempenho muito superior $(\mathrm{H}$ $=8,69 \mathrm{e} \mathrm{h}=2,71)$ ao da coluna empacotada na bomba Shimadzu $(\mathrm{H}=13,86 \mathrm{e} \mathrm{h}=4,33)$. Embora não existam relatos na literatura da comparação do desempenho das colunas com relação ao tipo de bomba empregada no empacotamento, os artigos que abordam o desenvolvimento de colunas, geralmente, fizeram uso de diferentes modelos de bombas Haskel ${ }^{71,72}$. Isso pode ter ocorrido, não só pelas altas pressões atingidas por essas bombas, mas também, porque provavelmente foi observado uma melhoria do desempenho das colunas devido a uma melhor compactação do leito cromatográfico.

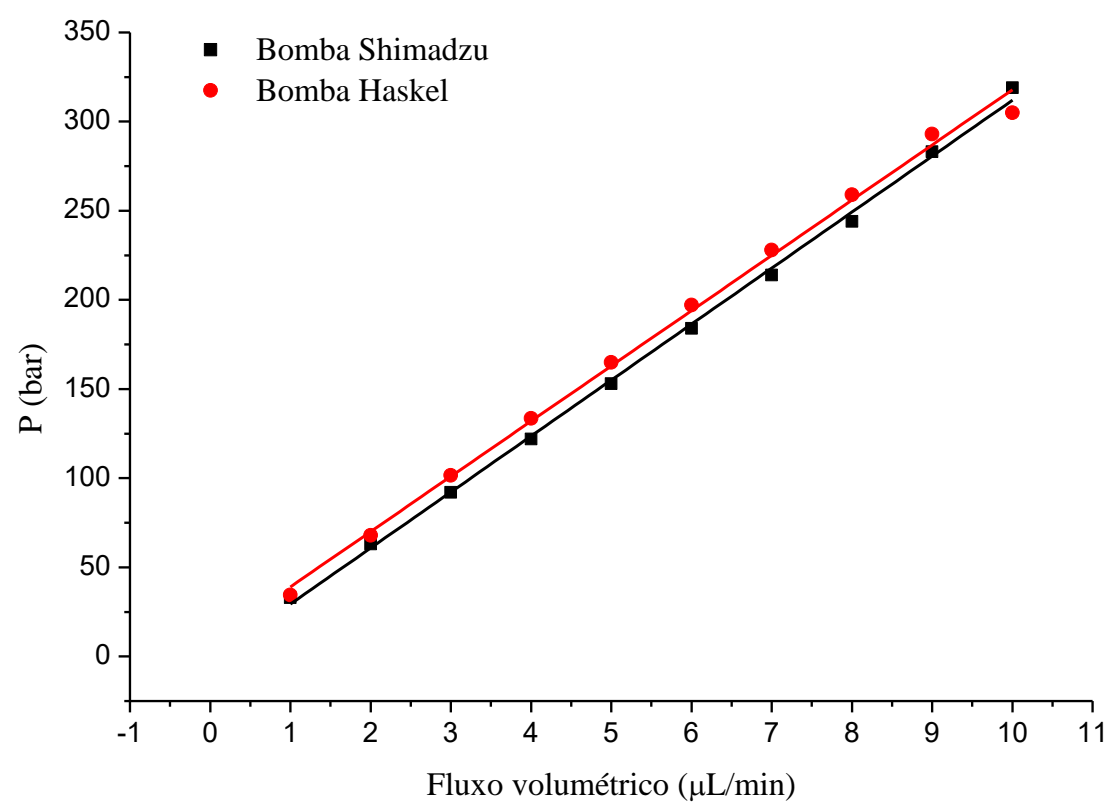

Figura 31 - Efeito da variação da pressão em função do fluxo volumétrico para as colunas $\mathrm{C} 18(15 \mathrm{~cm}$ x $250 \mu \mathrm{m}$ x $3,5 \mu \mathrm{m})$ empacotadas em uma bomba Haskel e uma bomba Shimadzu 

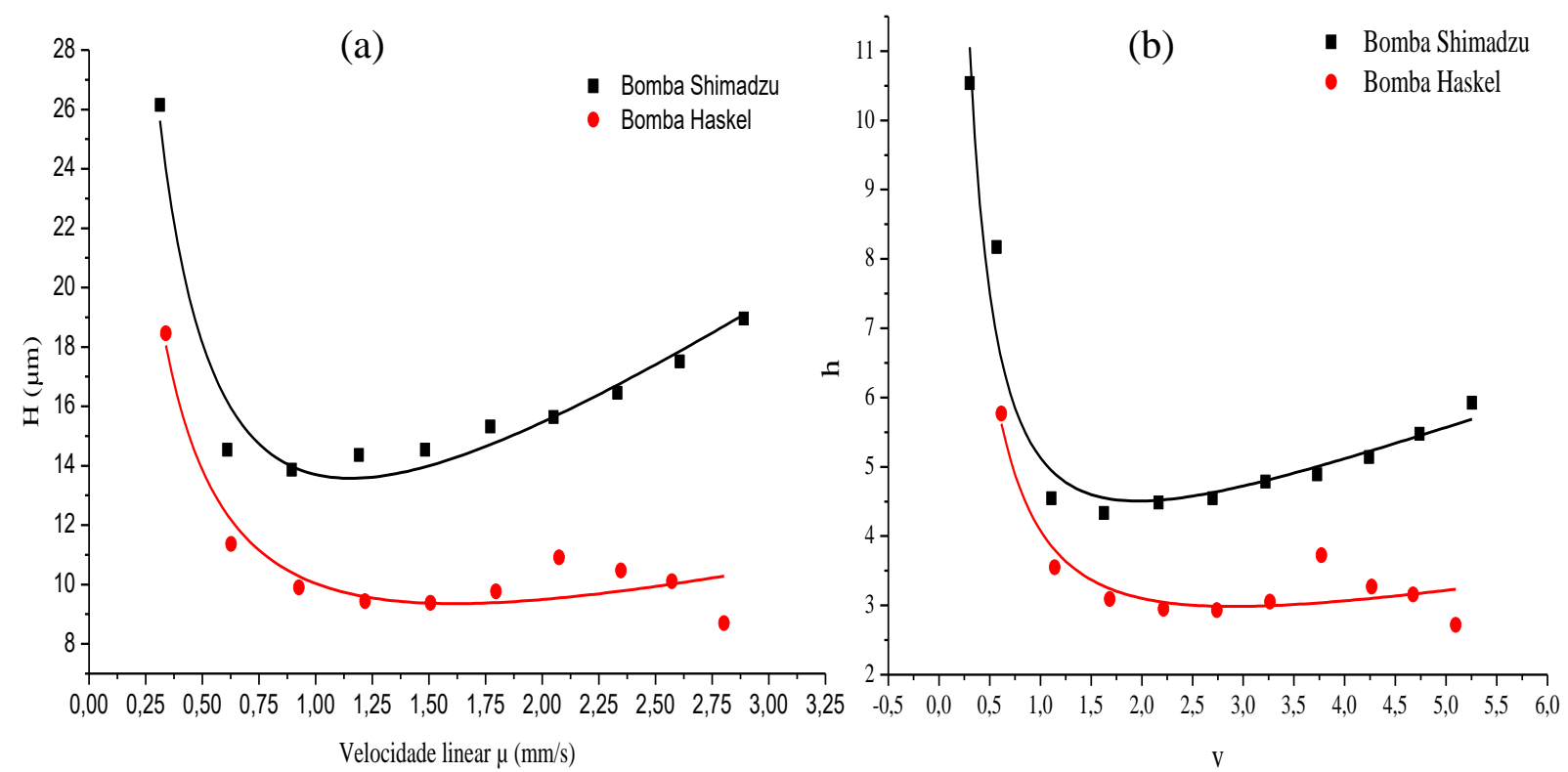

Figura 32 - Gráfico de Van Deemter (a) e Knox (b) para as colunas C18 (15 cm x $250 \mu \mathrm{m}$ x 3,5 $\mu \mathrm{m})$ empacotadas em uma bomba Haskel e uma bomba Shimadzu

Os cromatogramas da Figura 34 mostram as separações dos PAH's realizados sob as mesmas condições de análises. A F.M empregada foi $\mathrm{ACN}: \mathrm{H}_{2} \mathrm{O}(60: 40 v / v)$ a um fluxo linear igual a $3 \mu \mathrm{L} / \mathrm{min}$; as demais condições cromatográficas foram mantidas iguais aos experimentos anteriores.
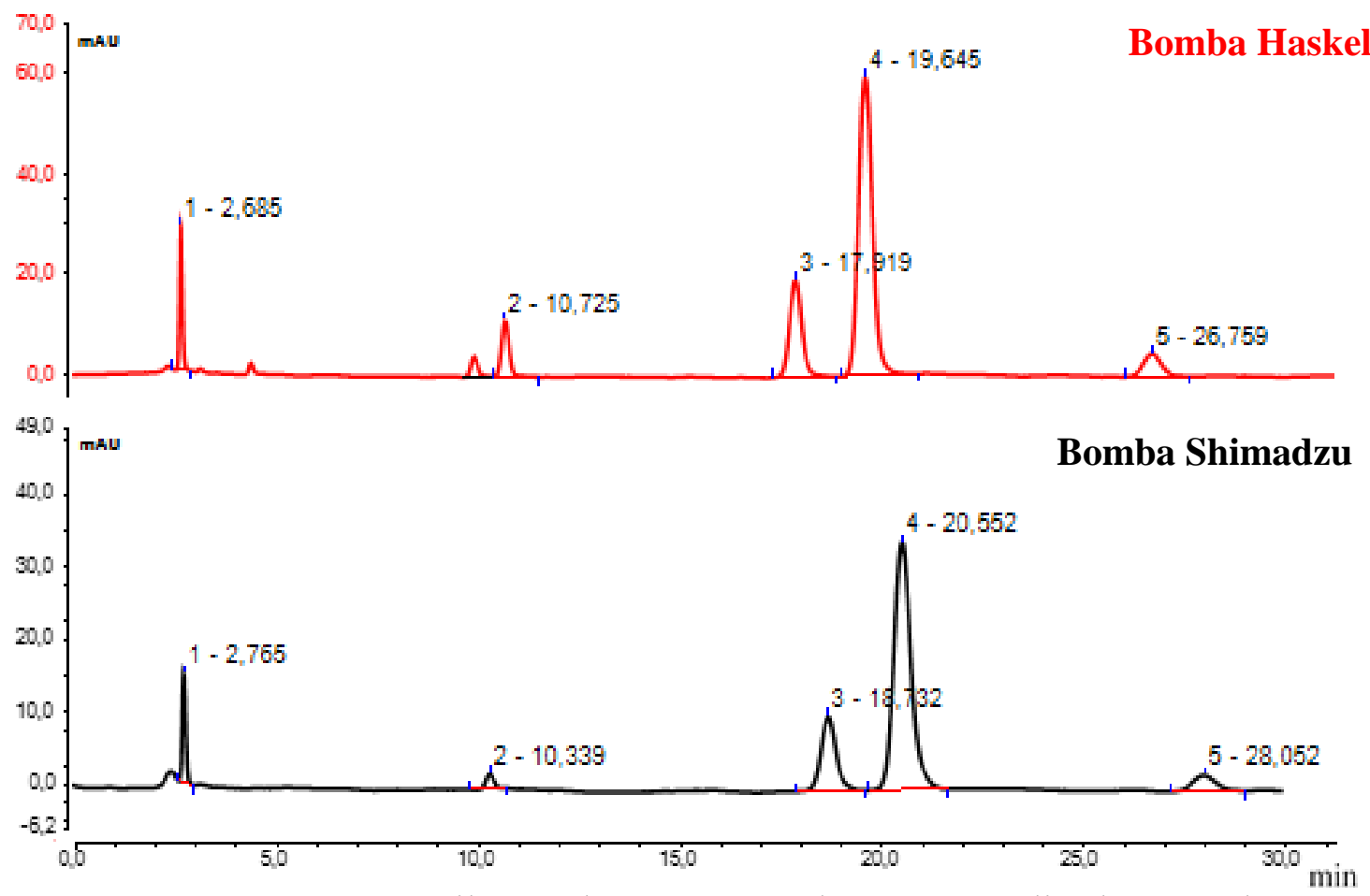

Figura 33 - Cromatogramas ilustrando a separação dos PAH's realizadas em colunas C18 (15 cm x $500 \mu \mathrm{m}$ x 3,5 $\mu \mathrm{m}$ ) empacotadas em uma bomba Haskel e em uma bomba Shimadzu. Ordem de eluição: (1) uracila, (2) naftaleno, (3) fenantreno, (4) antraceno e (5) pireno 
Pelos cromatogramas observa-se que os tempos de retenção também variaram para as duas colunas, embora essa variação não tenha sido tão grande, sendo que a bomba Haskel apresentou um tempo total de análise de 1:30 min mais curto que a coluna empacotada na bomba Shimadzu. As intensidades dos picos praticamente dobraram na coluna empacotada na bomba Shimadzu.

$\mathrm{Na}$ Tabela 16 estão descritos os parâmetros cromatográficos extraídos dos cromatogramas apresentados na Figura 34.

Os dados mostram que a coluna empacotada na bomba Haskel apresentou cerca de 4000 pratos teóricos a mais do que a coluna empacotada na bomba Shimadzu; consequentemente, os valores de $\mathrm{H}$ e h também foram menores para essa primeira coluna, confirmando seu melhor desempenho. Como era esperado, as colunas mais eficientes geraram melhores resoluções.

\begin{tabular}{|c|c|c|}
\hline \multirow{2}{*}{ Parâmetros } & \multicolumn{2}{|c|}{ Colunas empacotadas na: } \\
\hline & Bomba Shimadzu & Bomba Haskel \\
\hline $\mathrm{t}_{\mathrm{M}}$ uracila $(\min )$ & 2,77 & 2,69 \\
\hline$t_{\mathrm{R} \text { naftaleno }}(\min )$ & 10,34 & 10,73 \\
\hline$t_{R \text { fenantreno }}(\min )$ & 18,73 & 17,92 \\
\hline$t_{R \text { antraceno }}(\min )$ & 20,55 & 19,65 \\
\hline$t_{R \text { pireno }}(\min )$ & 28,05 & 26,76 \\
\hline$w_{b}(50 \%)$ fenantreno $(\min )$ & 0,39 & 0,33 \\
\hline $\mathrm{N}$ & 12522 & 16738 \\
\hline $\mathrm{N} / \mathrm{m}$ & 83482 & 111586 \\
\hline $\mathrm{H}(\mu \mathrm{m})$ & 11,98 & 8,96 \\
\hline $\mathrm{R}_{\mathrm{s}}$ & 2,55 & 2,92 \\
\hline $\operatorname{As}_{(10 \%)}$ & 1,16 & 1,11 \\
\hline$\alpha$ & 1,11 & 1,11 \\
\hline $\mathrm{k}$ & 5,77 & 5,67 \\
\hline $\mathrm{v}$ & 1,64 & 1,69 \\
\hline h & 3,74 & 2,80 \\
\hline$\varnothing$ & 1069 & 1139 \\
\hline $\mathrm{E}$ & 14974 & 8935 \\
\hline$\Delta \mathrm{P}$ (bar) & 92 & 101 \\
\hline
\end{tabular}

Tabela 16 - Parâmetros da coluna obtidos a partir dos dados gerados nos cromatogramas apresentados na Figura 34 
As colunas também apresentaram excelentes formatos de picos, ou seja, As(10\%) dos picos muito próximos de 1 . O valor de $\alpha$ permaneceu constante nas duas colunas, mostrando que a separação dos compostos adjacentes não variou nas duas colunas.

Os parâmetros k e v comportaram-se conforme os tempos de retenção. Uma vez que na coluna empacotada na bomba Haskel os $t_{R}$ foram um pouco menores, era esperada uma diminuição também nos valores destes parâmetros.

Diferente do que foi observado para algumas colunas estudadas em tópicos anteriores, as melhores eficiências também foram seguidas por menores contrapressões. Aqui a coluna empacotada na bomba Haskel apresentou um $\Delta \mathrm{P}$ um pouco superior e, em função disso, essa coluna apresentou uma maior resistência ao fluxo $(\varnothing)$. Mesmo assim, devido ao valor de $\mathrm{h}$ da coluna empacotada na bomba Haskel ter sido muito inferior, essa coluna também apresentou um melhor desempenho com relação ao parâmetro E.

Desta forma, pode-se concluir que o tipo de bomba empregada no empacotamento das colunas exerce influência em todos os parâmetros relacionados à eficiência da coluna, sendo que a bomba Haskel apresentou-se como uma alternativa muito melhor para o empacotamento das colunas capilares.

\subsubsection{Avaliação da influência dos modelos de hardware utilizados no desempenho da coluna}

Dois modelos de hardware foram propostos nesse tralho, o primeiro visando a aplicação de programação de temperatura e o segundo modelo foi importante para avaliar a influência do uso de diferentes condições no desempenho da coluna. Sendo assim, considerou-se importante avaliar se os modelos propostos poderiam influenciar no comportamento cromatográfico das colunas.

As mesmas análises realizadas nos tópicos anteriores foram aplicadas aqui, sendo as mesmas condições de empacotamento foram utilizadas para as duas colunas. As colunas foram empacotadas com F.E C18 de partículas de 3,5 $\mu \mathrm{m}$ e as dimensões das colunas foram mantidas em $15 \mathrm{~cm}$ de comprimento e 250 um de d.i. As condições cromatográficas de análise foram idênticas às empregadas no Tópico 2.1.3. A nomenclatura empregada para as colunas avaliadas nessa parte do trabalho fez menção aos tipos de modelos de hardware empregados: hardware 1 (corresponde ao $1^{\mathrm{o}}$ modelo de hardware que não utiliza tubo restritor, Figura 7) e hardware 2 (corresponde ao $2^{\circ}$ modelo de hardware que utiliza tubo restritor, Figura 8). 
Através da Figura 35, foi possível observar que o comportamento da contrapressão das colunas, em função do fluxo da F.M, foi melhor para a coluna com hardware 2, pois as pressões foram menores do que para a coluna com hardware 1

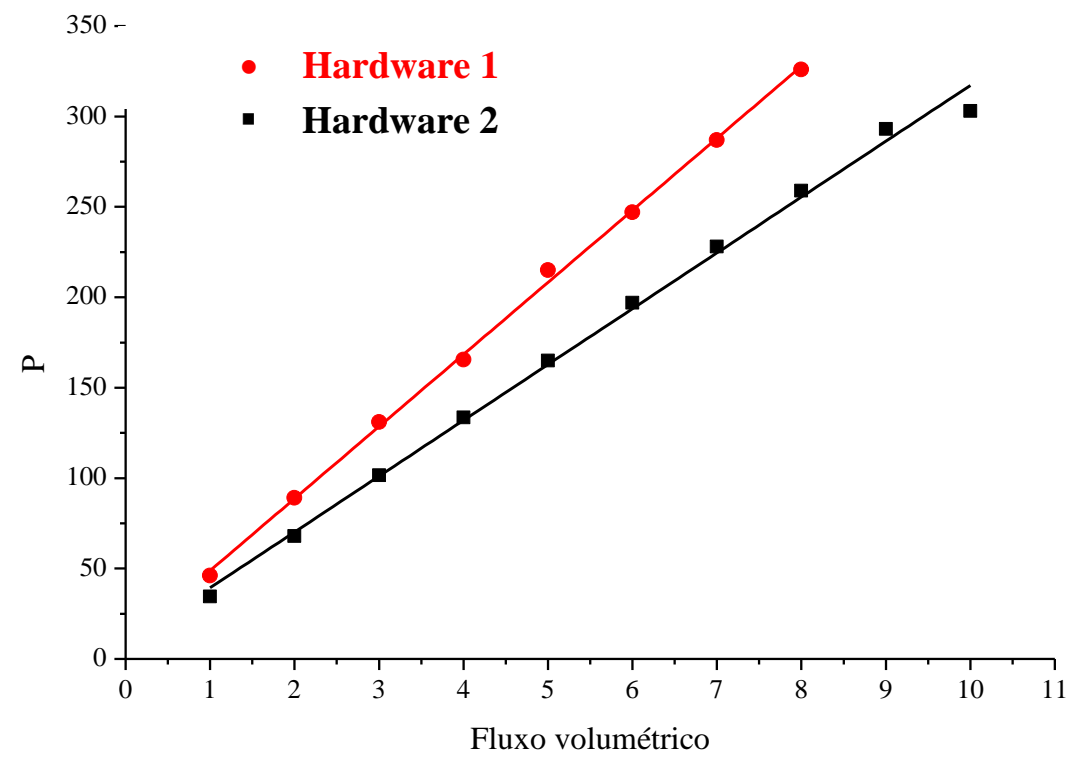

Figura 34 - Efeito da variação da pressão em função do fluxo volumétrico para as colunas $\mathrm{C} 18(15 \mathrm{~cm} \times 250 \mu \mathrm{m} \times 3,5 \mu \mathrm{m})$ confeccionadas empregando os hardwares 1 e 2

Os gráficos de Van Deemter e Knox (Figura 36) mostram a comparação das duas colunas em relação a eficiência.

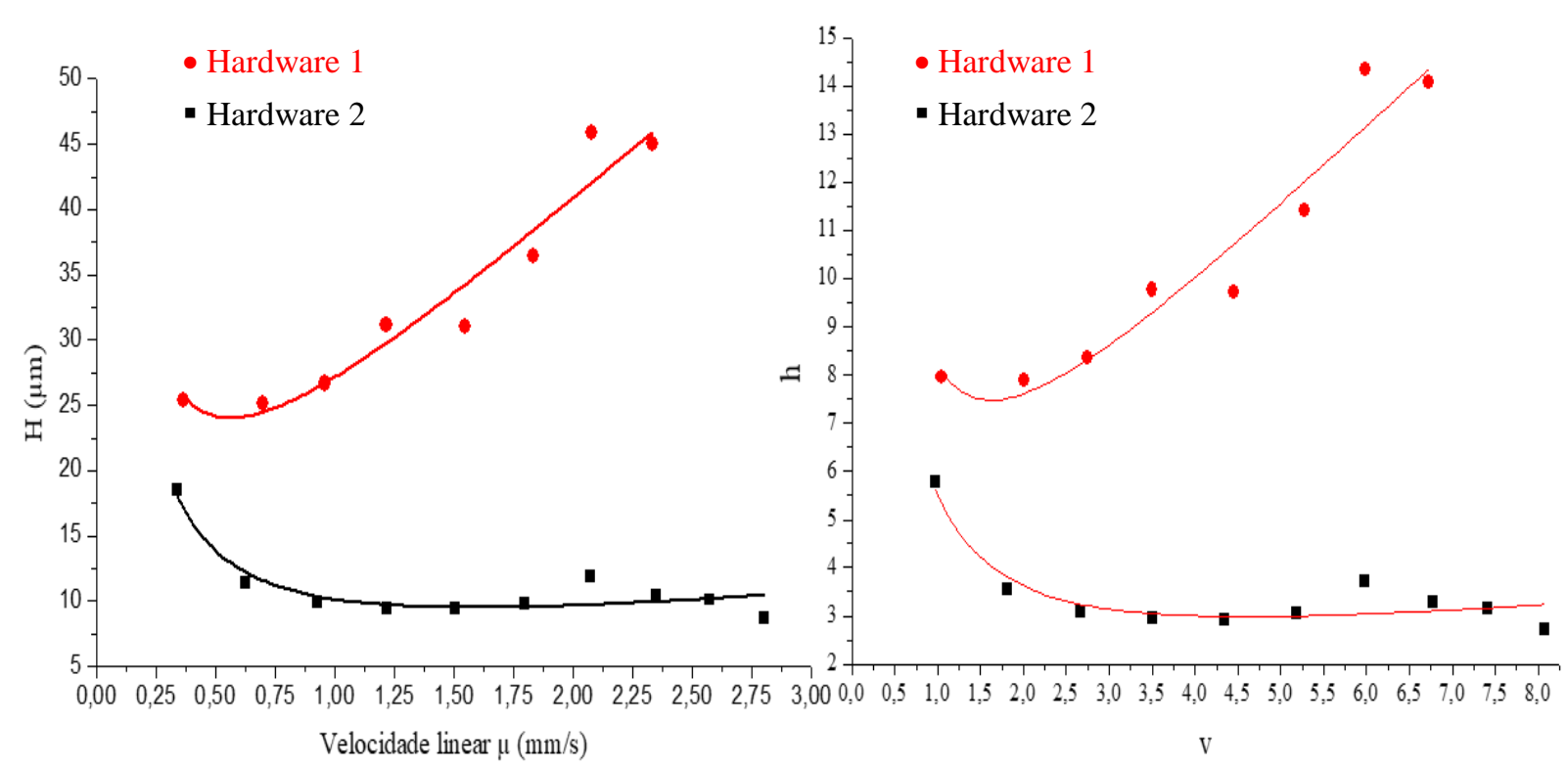

Figura 35 - Gráfico de Van Deemter (a) e Knox (b) para as colunas C18 (15 cm x $250 \mu \mathrm{m}$ x 3,5 $\mu \mathrm{m})$ confeccionadas empregando os hardwares 1 e 2 
Foi notável a diferença de desempenho apresentadas pelas duas colunas, sendo que a eficiência da coluna com hardware 2 , em termos de $\mathrm{H}$ e $\mathrm{h}$, foi cerca de duas vezes maior do que a eficiência da coluna com hardware 1.

A coluna com hardware 1 apresentou os valores mínimos da curva de Van Deemter (Figura 36) iguais a: $\mathrm{H}=25,22$ e $\mu=0,69$ e os valores mínimos das curvas de Knox iguais a $\mathrm{h}$ $=8,35$ e v $=2,75$. Já a coluna com hardware 2 os valores mínimos da curva de Van Deemter foram $\mathrm{H}=8,70$ e $\mu=2,80$ e os valores mínimos da curva de Knox foram iguais a $\mathrm{h}=2,71$ e $\mathrm{v}$ $=8,07$

Tamanha diferença no desempenho destas colunas pode estar relacionada ao tipo de "frit" empregado ou mesmo a presença do tubo restritor, uma vez que todas as demais características das colunas foram mantidas idênticas.

O frit empregado no modelo de hardware 1 é disponibilizado comercialmente e fabricado em aço inoxidável e o frit empregado no modelo de Hardware 2 consiste em pequenos pedaços de filtro de lã de vidro cortados sob molde da coluna.

Para melhor entender a estrutura dos dois materiais empregados como frits eles foram caracterizados por MEV e algumas das imagens obtidas são mostradas na Figura 37.

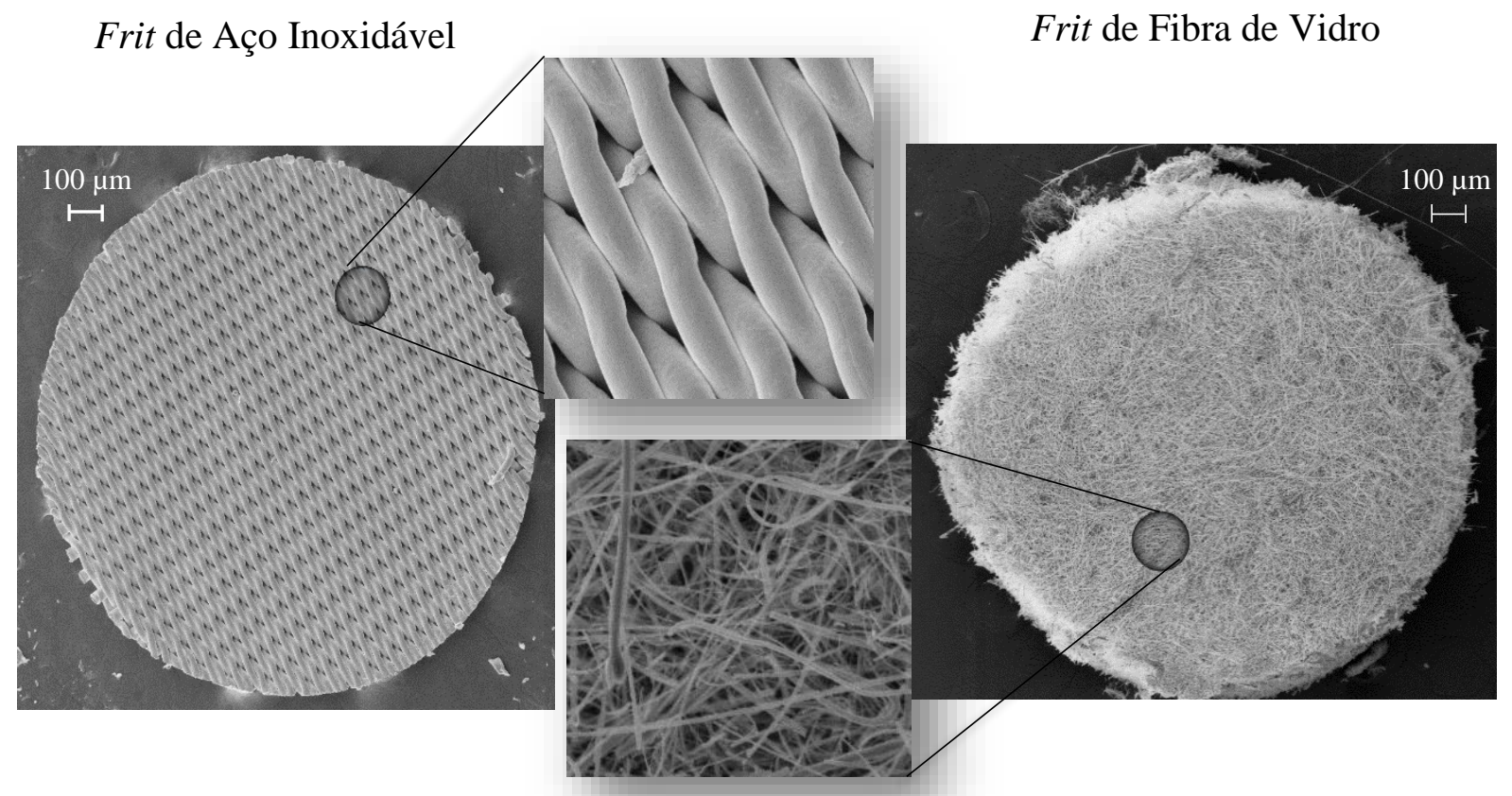

Figura 36 - MEV dos Frits de aço inoxidável e fibra de vidro empregados nestes trabalho. O microscópio foi operado a $20 \mathrm{kV}$ e magnificação de 1000 a 1500 x 
É possível observar que os poros do frit de aço são formados a partir do "entrecruzamento das fibras de aço" e, por isso, apresentam um espaçamento uniforme e regular. Na fibra de vidro os poros são formados de forma "aleatória" pela sobreposição de inúmeros fios bem finos de vibra de vidro. Isso deve conferir maior permeabilidade para o Frit de fibra de vidro, facilitando a passagem da F.M e dos analitos e contribuindo para a diminuição da contrapressão das colunas confeccionadas com esse tipo de frit.

Com relação ao frit de aço, aparentemente ele contribui com um impedimento físico a passagem do solvente e analitos, devido à disposição das suas fibras. Isso pode ser o motivo da elevação da pressão na coluna confeccionada com o hardware 1. A estrutura apresentada pelo frit de aço pode ter contribuído para a elevação do termo A da equação de Van Deemter, que corresponde à difusão turbulenta, ou seja, está relacionada aos diferentes caminhos que os analitos devem percorrer dentro da coluna. Aqui o frit pode ser colocado como uma pequena extensão da coluna que apresenta um novo caminho a ser percorrido pelos analitos e, portanto, contribuído com a elevação do termo A. De fato foi observada a elevação do termo A para a coluna confeccionada com hardware 1 (termo $A=5,70$ ), com relação ao valor apresentado pela coluna confeccionada com o hardware 2 (tremo $\mathrm{A}=0,90$ ).

Uma outra possível explicação para a diferença de desempenho apresentado pelas colunas, pode estar relacionada com os tipos de conexões empregadas em cada coluna. $\mathrm{Na}$ coluna feita com o hardware 2, foi colocada uma união de volume reduzido na extremidade superior e na extremidade inferior apenas o frit de fibra de vidro como tubo restritor. A união dos tubos foi feita com cola epóxi e embora, a cola possa não preencher toda a região de junção dos tubos e sobre um espaço vazio, que será preenchido pelo solvente, esse espaço deve ser bem pequeno e pode ser inferior aos espaços formados nas duas uniões colocadas nas extremidades da coluna, confeccionada com o hardware 1. Nessa última, emprega-se uma união de volume não reduzido para que o frit possa ser acomodado dentro dela; fora isso a interface tubo capilar/ frit e interface frit/união deve ser livre de qualquer tortuosidade ou ranhuras, que acarretam em um encaixe não perfeito e possam formar volume sobressalente. No entanto, esse foi um ponto que não foi investigado neste trabalho.

A Tabela 17 apresenta os valores dos parâmetros extraídos dos picos de cada um dos cromatogramas apresentados na Figura 38. 


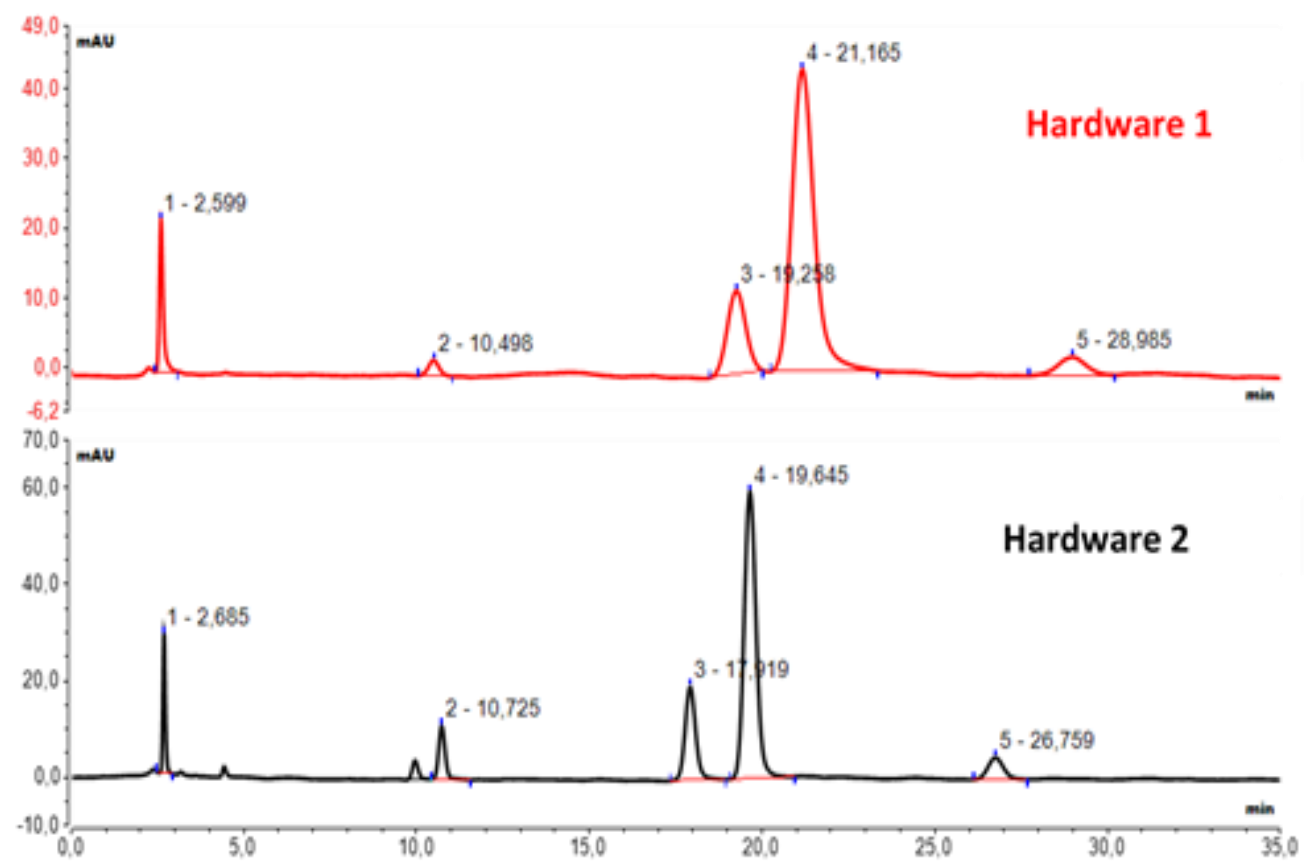

Figura 37 - Cromatogramas da separação dos PAH's realizadas em colunas C18 (15 cm x 500 $\mu \mathrm{m} \times 3,5 \mu \mathrm{m}$ ) confeccionadas empregando os hardwares 1 e 2. Ordem de eluição: (1) uracila, (2) naftaleno, (3) fenantreno, (4) antraceno e (5) pireno

\begin{tabular}{|c|c|c|}
\hline \multirow{2}{*}{ Parâmetros } & \multicolumn{2}{|c|}{ Colunas confeccionadas usando } \\
\hline & Hardware 1 & Hardware 2 \\
\hline $\mathrm{t}_{\mathrm{M} \text { uracila }}(\min )$ & 2,60 & 2,69 \\
\hline$t_{\mathrm{R} \text { naftaleno }}(\mathrm{min})$ & 10,50 & 10,73 \\
\hline$t_{R}$ fenantreno $(\min )$ & 19,26 & 17,92 \\
\hline$t_{R}$ antraceno $(\min )$ & 21,17 & 19,65 \\
\hline $\mathrm{t}_{\mathrm{R} \text { pireno }}(\mathrm{min})$ & 28,99 & 26,76 \\
\hline$w_{b}(50 \%)$ fenantreno $(\mathrm{min})$ & 0,62 & 0,33 \\
\hline $\mathrm{N}$ & 5397 & 16738 \\
\hline $\mathrm{N} / \mathrm{m}$ & 35981 & 111586 \\
\hline $\mathrm{H}(\mu \mathrm{m})$ & 27,79 & 8,96 \\
\hline $\mathrm{R}_{\mathrm{s}}$ & 1,72 & 2,92 \\
\hline $\operatorname{As}_{(10 \%)}$ & 1,18 & 1,11 \\
\hline$\alpha$ & 1,11 & 1,11 \\
\hline $\mathrm{k}$ & 6,41 & 5,67 \\
\hline $\mathrm{v}$ & 1,75 & 1,69 \\
\hline h & 8,69 & 2,80 \\
\hline$\varnothing$ & 1288 & 1139 \\
\hline $\mathrm{E}$ & 97186 & 8935 \\
\hline$\Delta \mathrm{P}$ (bar) & 118 & 101 \\
\hline
\end{tabular}

Tabela 17 - Parâmetros da coluna obtidos a partir dos dados gerados nos cromatogramas apresentados na Figura 38 
Foi possível observar que o tempo de análise empregando a coluna com hardware 2 foi um pouco menor, assim como as intensidades dos picos foram maiores do que os da coluna confeccionada no hardware 1.

Os valores dos parâmetros cromatográficos confirmam a superioridade da coluna com hardware 2, pois a eficiência foi cerca de 11 mil pratos teóricos a mais que o da coluna com hardware 1. Todos os demais parâmetros $(\mathrm{H}, \mathrm{R}, \mathrm{As}(10 \%), \mathrm{k}, \mathrm{v}, \mathrm{h}, \varnothing$ e E) apresentaram valores favoráveis à coluna confeccionada com o hardware 2. A impedância de separação da coluna com hardware 1 apresentou-se bastante elevada em função do maior valor de altura reduzida apresentada.

Portanto, os resultados mostraram que o tipo de hardware empregado como corpo da coluna exerceu influência no desempenho das colunas, sendo o segundo modelo de hardware investigado o mais indicado para confecção de colunas com elevado desempenho. É importante também ressaltar que como inconveniente esse hardware apresenta uma confecção mais trabalhosa e demorada.

\subsubsection{Efeitos do equipamento nas características das colunas}

Dois cromatógrafos líquidos capilares foram usados neste trabalho, sendo um desenvolvido no próprio grupo de cromatografia e outro foi o sistema capilar comercial UltiMate $^{\mathrm{TM}} 3000$ RSLCnano da Termo Scientific Dionex. Como mostrado anteriormente, o cromatógrafo comercial apresentou um volume extra coluna que interfere negativamente no desempenho da coluna enquanto o equipamento homemade não apresentou. Desta forma, para melhor entendimento do efeito do equipamento no desempenho das colunas, uma coluna C18 (14 $\mathrm{cm} \times 250 \mu \mathrm{m} \times 3,5 \mu \mathrm{m})$ foi avaliada nos dois sistemas. O desempenho dessa coluna também foi comparado com o desempenho de uma coluna empacotada comercial C18 (150 mm x 0,50 mm x 2,7 $\mu \mathrm{m})$ da Ascentis ${ }^{\circledR}$ Express.

Tentou-se operar o sistema cromatográfico comercial sob as mesmas condições empregadas no cromatógrafo capilar homemade. Para tal, fez-se uso de acetonitrila/agua (70:30, $v / v$ ) como F.M a uma vazão de $5 \mu \mathrm{L} / \mathrm{min}$. Injetou-se $60 \mathrm{~nL}$ da amostra e a detecção foi realizada em $254 \mathrm{~nm}$. Os cromatogramas com as separações dos compostos de PAH's empregando a coluna homemade (no cLC comercial e no cLc homemade) e a coluna comercial, estão ilustrados na Figura 39. 


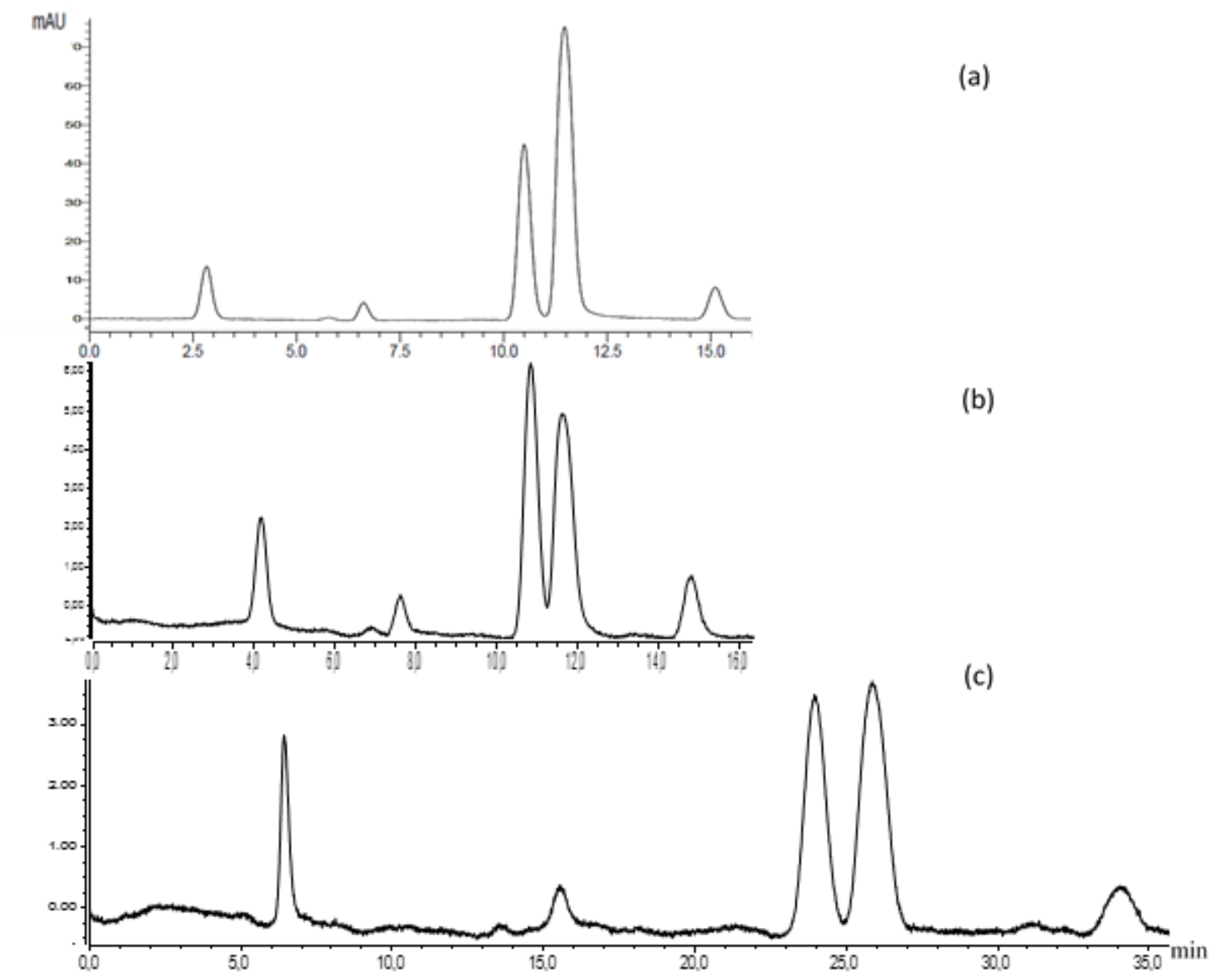

Figura 38 - Cromatogramas da separação de PAH's usando a coluna e o cLC homemade (a) a coluna homemade e o cLC comercial (b) e a coluna comercial e o cLC comercial (c) Ordem de eluição: (1) uracila, (2) naftaleno, (3) fenantreno, (4) antraceno e (5) pireno

Na Tabela 18, estão expostos os valores dos parâmetros calculados a partir dos cromatogramas apresentados nas Figuras 39.

Comparando o desempeno da coluna homemade em sistemas cromatográficos distintos, percebe-se que o desempenho da mesma foi melhor no sistema homemade; nele o número de pratos teóricos da coluna aumentou em torno de 1200 pratos e os valores de $\mathrm{H}$, h, e E foram menores. A impedância de separação para a coluna avaliada no sistema cromatográfico comercial foi muito elevada devido sobretudo ao maior valor do $\Delta \mathrm{P}$. 


\begin{tabular}{|c|c|c|c|}
\hline \multirow{2}{*}{ Parâmetros } & \multicolumn{2}{|c|}{ Colunas homemade avaliadas no: } & \multirow{2}{*}{$\begin{array}{l}\text { Coluna } \\
\text { Comercial }\end{array}$} \\
\hline & cLC homemade & cLC comercial & \\
\hline $\mathrm{t}_{\mathrm{M} \text { uracila }}(\mathrm{min})$ & 2,83 & 4,19 & 6,43 \\
\hline $\mathrm{t}_{\mathrm{R} \text { naftaleno }}(\mathrm{min})$ & 6,61 & 7,61 & 15,52 \\
\hline$t_{R \text { fenantreno }}(\min )$ & 10,49 & 10,81 & 23,95 \\
\hline$t_{R}$ antraceno $(\min )$ & 11,46 & 11,59 & 25,85 \\
\hline $\mathrm{t}_{\mathrm{R} \text { pireno }}(\min )$ & 15,10 & 14,78 & 34,05 \\
\hline$w_{b}(50 \%)$ fenantreno $(\min )$ & 0,29 & 0,32 & 0,79 \\
\hline $\mathrm{N}$ & 7.453 & 6.208 & 5.118 \\
\hline $\mathrm{N} / \mathrm{m}$ & 53.235 & 44.339 & 34.123 \\
\hline $\mathrm{H}(\mu \mathrm{m})$ & 18,78 & 22,55 & 29,31 \\
\hline $\mathrm{R}_{\mathrm{s}}$ & 1,74 & 1,18 & 1,27 \\
\hline $\mathrm{As}_{(10 \%)}$ & 1,13 & 1,16 & 1,10 \\
\hline$\alpha$ & 1,11 & 1,12 & 1,11 \\
\hline $\mathrm{k}$ & 2,71 & 1,58 & 2,73 \\
\hline $\mathrm{v}$ & 1,61 & 1,09 & 0,71 \\
\hline h & 5,87 & 7,05 & 9,16 \\
\hline$\varnothing$ & 463 & 1.211 & 702 \\
\hline $\mathrm{E}$ & 15.962 & 60.152 & 58.858 \\
\hline$\Delta \mathrm{P}($ bar $)$ & 34 & 60 & 26 \\
\hline
\end{tabular}

Tabela 18 - Comparação entre os parâmetros obtidos com a coluna 1 no cromatógrafo homemade e comercial, e comparação entre os parâmetros obtidos com a coluna produzida em laboratório e coluna comercial, operadas no cromatógrafo comercial

Com relação à resolução, percebe-se, através das Figuras 39 (a) e (b), que os picos foram melhor separados quando a coluna foi operada no cLC homemade, ou seja, maior valor de R. Como o cálculo de $\mathrm{R}$ envolve o parâmetro k, esperava-se que este também fosse maior no homemade, o que foi observado na prática, pois quanto maior for o valor de $\mathrm{k}$ maior será a resolução. No entanto, valores de k muito grandes não são desejáveis porque podem elevar bastante o tempo de análise. O principal fator que contribuiu na diferenciação dos valores de $\mathrm{k}$ foi o tempo de retenção da uracila (a qual mede o tempo morto, $\mathrm{t}_{\mathrm{M}}$ ), que entre os sistemas mudou muito. O tempo de retenção do tolueno também foi diferente e os demais compostos apresentaram $t_{R}$ muito próximos. 
Como se trata de uma mesma coluna, empregando os mesmos compostos e a mesma F.M, era previsto que os valores de $\alpha$, mesmo quando utilizado sistemas cromatográficos capilares distintos, fossem praticamente iguais. Isto foi observado nos valores determinados.

Além do ECV apresentado pelo cromatógrafo comercial, outros fatores podem ter contribuído para a diferença de desempenho da coluna nos dois equipamentos capilares, como por exemplo, as diferenças instrumentais, incluindo a bomba (que impulsiona a F.M) e o sistema de aquecimento da coluna analítica. A bomba do cromatógrafo homemade é do tipo seringa e apresenta como principal vantagem a ausência de pulsação fornecendo fluxo de F.M uniforme, diferente da bomba de pistão reciprocante utilizada no cromatógrafo comercial, que devido à movimentação dos pistões da bomba gera um fluxo pulsado, o qual necessita ser atenuado. A fase móvel na bomba seringa, quando composta por mais de um solvente, deve ser misturada manualmente, enquanto na bomba de pistão reciprocante a mistura é feita pelo próprio sistema de bombeamento. A F.M acetonitrila/água 70:30 $(v / v)$ foi preparada medindose o volume de água deionizada e, em seguida, completando-se o volume com acetonitrila, pois quando se mistura água com solvente orgânico ocorre contração do volume e a quantidade do volume adicionado por último vai ser maior que o desejado.

Nos dois sistemas cromatográficos, a coluna é mantida em um compartimento aquecido; no homemade foi construído um forno dedicado a colunas capilares com um rigoroso sistema de controle de temperatura e com isolamento térmico apropriado. No sistema comercial o compartimento da coluna não possui isolamento térmico, podendo ter sofrido influência da temperatura externa. Tais fatores podem ser responsáveis por provocar alterações na difusão molecular, na viscosidade, no coeficiente de difusão entre outros. Esses parâmetros podem, consequentemente, alterar o tempo de retenção, a seletividade, a eficiência e várias outras propriedades da fase estacionária. Como as colunas capilares foram confeccionadas com finos tubos de sílica fundida, elas estão mais propícias à transferência rápida de temperatura do que as colunas confeccionadas em tubos de aço.

Comparando-se o desempenho da coluna confeccionada no laboratório com a coluna comercial utilizada, percebe-se que o desempenho da coluna homemade foi superior e com tempo de análise mais curto, demonstrando que colunas com boa eficiência podem ser preparadas sem grandes inconveniências. 


\subsection{CONCLUSÕES DO CAPÍTULO}

A metodologia utilizada no empacotamento das colunas foi capaz de fornecer colunas capilares com boa eficiência, mostrando que colunas de alta qualidade e menor custo podem ser desenvolvidas em laboratório de forma simples e rápida;

A metodologia de empacotamento desenvolvida mostrou-se bastante reprodutível, uma vez que as colunas apresentaram boa repetitividade;

Dentre os vários fatores estudados, e nas condições experimentais empregadas, podem influenciar no desempenho das colunas:

* Tamanho das partículas da F.E: As colunas com partículas de $2 \mu \mathrm{m}$ geram a maior eficiência. Porém, colunas confeccionadas com partículas de $5 \mu \mathrm{m}$ conseguiram aliar boa eficiência, com menor tempo total de análise e menor contrapressão. Por isso, apresentou-se como o tamanho de partícula totalmente porosa mais adequado para confecção das colunas capilares;

* Comprimento da coluna: colunas de maiores comprimentos geraram maiores eficiências, sendo o comprimento de $15 \mathrm{~cm}$ o mais recomendado por aliar bons valores dos parâmetros cromatográficos com o tempo de análise e contrapressão da coluna;

* Diâmetro interno da coluna: $O$ diâmetro interno que resultou em colunas mais eficientes foi o de $250 \mu \mathrm{m}$;

* Material de suporte da coluna: O material que se mostrou mais adequado para confecção das colunas capilares foi o AçoSil;

* Pressão de empacotamento: a pressão de empacotamento influenciou no desempenho das colunas, sendo 207 bar a melhor pressão para empacotamento. Isso revelou que o preparo das colunas empacotadas capilares pode ser simples e sem necessidade de utilizar pressões muito elevadas;

* Bomba empregada no empacotamento: A bomba Haskel mostrou-se mais adequada para o empacotamentos das colunas empregadas neste trabalho;

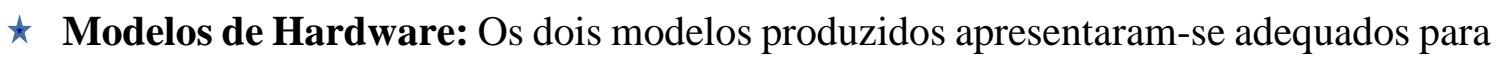
a confecção das colunas capilares, mas o modelo que faz uso do tubo restritor apresentou-se como melhor alternativa, por gerar colunas mais eficientes.

A análise realizada no LC capilar apresentou baixo consumo de solvente quando comparado ao LC convencional. 
Gapitula 3: Desenuolvimento e avaliasãa de colunas Tibulares Abentas para cromatografia liquida capilase 


\section{.CAPÍTULO 3: Desenvolvimento e avaliação de colunas Tubulares Abertas para cromatografia líquida capilar}

As colunas tubulares abertas são amplamente utilizadas em GC, elas também vêm sendo bastante exploradas na eletroforese capilar (CE, Capillary Electrophoresis) e na eletrocromatografia capilar (CEC, Capillary Electrochromatography). Esta última técnica compreende uma combinação dos princípios eletroforético e cromatográfico. A utilização de colunas OT em CEC se destaca por permitir a formação de fluxo com um perfil de velocidade linear praticamente plana; assim, os componentes da velocidade eletrosmótica dos analítos, em diferentes regiões do capilar, são iguais. Já na LC o perfil do fluxo é parabólico ou laminar e os analítos, no centro do capilar, migram mais rapidamente que aqueles próximos à parede do tubo, causando, assim, uma diminuição na eficiência da separação. Este fato, aliado à falta de instrumentação adequada para se empregar colunas OT, contribuiu para que as colunas OT fossem pouco investigadas em LC e só recentemente a comunidade científica tem voltado atenção para pesquisas nesta área, pois embora o perfil do fluxo possa afetar a eficiência, a teoria a respeito das colunas OT indica a possibilidade de se conseguir colunas mais eficientes, ou no mínimo comparáveis com as colunas empacotadas utilizadas em LC.

Desta forma, este capítulo descreve os resultados dos estudos visando o desenvolvimento de colunas tubulares abertas de alta eficiência, para uso em cromatografia líquida capilar. A teoria relacionada a este assunto foi apresentada no capítulo 1.

\subsection{PARTE EXPERIMENTAL}

\subsubsection{Materiais e reagentes}

Os solventes utilizados foram: Metanol $(\mathrm{MeOH})$ e Acetonitrila $(\mathrm{ACN})$ grau HPLC fornecidos pela Tedia, Tetrahidrofurano (THF 99\%), Etanol (EtOH), acetona e ácido acético P.A. obtidos da J. T Baker. Água deionizada de alta pureza foi obtida pelo sistema de purificação Milli-Q (Millipore).

O hidróxido de sódio utilizado foi obtido da Mallinckrodt (Xalostoc). Polietileno glicol (PEG) da Alfa Aesar; clorodimetiloctadecilsilano, tetrametil ortosilicato (TMOS), 2,2' azobis(2-metil-propionitrila) (AIBN), e estireno, divenilbenzeno, xileno e $\gamma$ methacryloyloxypropyl)trimethoxysilane ( $\gamma$-MAP) foram obtidos da Sigma Aldrich. 
A usabilidade e eficiência das colunas foram testadas com padrões de alquilbenzenos (tolueno, etilbenzeno, butilbenzeno e pentilbenzeno) adquiridos da Sigma Aldrich. Devido à volatilidade, as soluções dos padrões foram constantemente substituídas por novas soluções.

No preparo das colunas utilizou-se tubos de sílica fundida de 100, 75, 50 e $25 \mu \mathrm{m}$ de diâmetros interno adquiridos da Polymicro Technologies Inc. e MicroQuartz. Os conectores e as luvas de teflon utilizadas para conexão das colunas ao sistema de recobrimento do filme e ao sistema cromatográfico foram adquiridos pela Upchurch Scientific $®$

\subsubsection{Preparo das colunas WCOT}

Quatro colunas, preparadas com a técnica de recobrimento estático de acordo com o descrito por Fonseca (2009) ${ }^{35}$, sem modificações, foram testadas e denominadas neste trabalho por OTLC-1, OTLC-2, OTLC-3 e OTLC-4. As colunas OTLC-1, e OTLC-3 são colunas revestidas com fase líquida compostas por $5 \%$ fenil e $95 \%$ dimetilpolisiloxano entrecruzado e as colunas OTLC-2 e OTLC-4 correspondem a um silicone composto por $50 \%$ metil e $50 \%$ fenilpolisiloxano entrecruzado. As mesmas também diferem quanto a espessura, diâmetro interno e o comprimento (Tabela 19).

\begin{tabular}{lllcc}
\hline Colunas & Fase Estacionária & $\begin{array}{l}\text { Espessura do } \\
\text { Filme }(\mu \mathrm{m})\end{array}$ & $\begin{array}{l}\text { Diâmetro } \\
\text { Interno }(\mu \mathrm{m})\end{array}$ & Comprimento $(\mathrm{m})$ \\
\hline OTLC-1 & $\begin{array}{l}5 \% \text { fenil e 95 \% } \\
\text { dimetilpolisiloxano }\end{array}$ & 0,20 & 70 & 7,00 \\
OTLC-2 & $\begin{array}{l}50 \% \text { metil e 50\% } \\
\text { fenilpolisiloxano }\end{array}$ & 0,20 & 70 & 5,00 \\
OTLC-3 & $\begin{array}{l}5 \% \text { fenil e 95 \% } \\
\text { dimetilpolisiloxano }\end{array}$ & 0,25 & 50 & 6,00 \\
\hline OTLC-4 & $\begin{array}{l}50 \% \text { metil e 50\% } \\
\text { fenilpolisiloxano }\end{array}$ & 0,25 & 50 & 2,30 \\
\hline
\end{tabular}

Tabela 19 - Característica das colunas WCOT utilizadas

\subsubsection{Preparo das colunas PLOT}

\subsubsection{Preparo das colunas OT-PS-DVB}

Foram utilizados tubos de sílica fundida de 100, 75, 50 e $25 \mu \mathrm{m}$ de diâmetro interno e comprimentos iguais a $5 \mathrm{~m}$. Inicialmente foi necessário realizar um pré-tratamento dos tubos 
para aumentar e ativar os grupos silanois dos tubos, garantindo melhor adesão da F.E à parede do tubo de sílica fundida. O pré-tratamento do tubo foi feito seguindo metodologia de Yue et al (2007) com algumas modificações ${ }^{75}$. Primeiramente preencheu-se o tubo de sílica com uma solução de $\mathrm{NaOH} 1 \mathrm{~mol} / \mathrm{L}$ e, em seguida, as pontas foram seladas com um septo e feita uma inspeção visual para garantir que toda a extensão do tubo tinha sido preenchida com a solução. Os tubos foram então levados para um forno de HPLC, onde foram mantidos por 20 horas a 60 ${ }^{\circ} \mathrm{C}$. Passado esse tempo, os tubos foram lavados com agua e ACN durante 30 min cada. Posteriormente os tubos foram secos com $\mathrm{N}_{2}$ durante $30 \mathrm{~min}$. Em seguida, iniciou-se a etapa de silanização: foi preparada uma solução com $40 \mu \mathrm{L}$ de $\gamma$-MAPS e $10 \mathrm{~mL}$ de ácido acético 6 mol/L, a mistura foi sonicada por 5 min, em seguida os tubos capilares foram preenchidos com essa solução, as extremidades dos tubos foram seladas com septos e levadas ao forno de HPLC durante 20 horas a $60^{\circ} \mathrm{C}$. Posteriormente, o tubo de sílica fundida foi lavado com $\mathrm{H}_{2} \mathrm{O}$ e $\mathrm{ACN}$ durante 30 min cada, por último o tubo é seco com gás $\mathrm{N}_{2}$. Terminada a etapa de tratamento do tubo, foi preparada a solução de polimerização, empregando 5 mg de AIBN, $200 \mu \mathrm{L}$ de estireno, $200 \mu \mathrm{L}$ de divinilbenzeno e $600 \mu \mathrm{L}$ de etanol, os reagentes foram misturados em um eppendorf e levados para sonicar em ultrason durante, no mínimo, 5 min. Feito isso, os capilares foram preenchidos com a solução de polimerização, empregando um sistema desenvolvido no nosso laboratório, adaptado do trabalho de Berg et al. ${ }^{76}$. O esquema desse sistema foi apresentado na Figura 40.

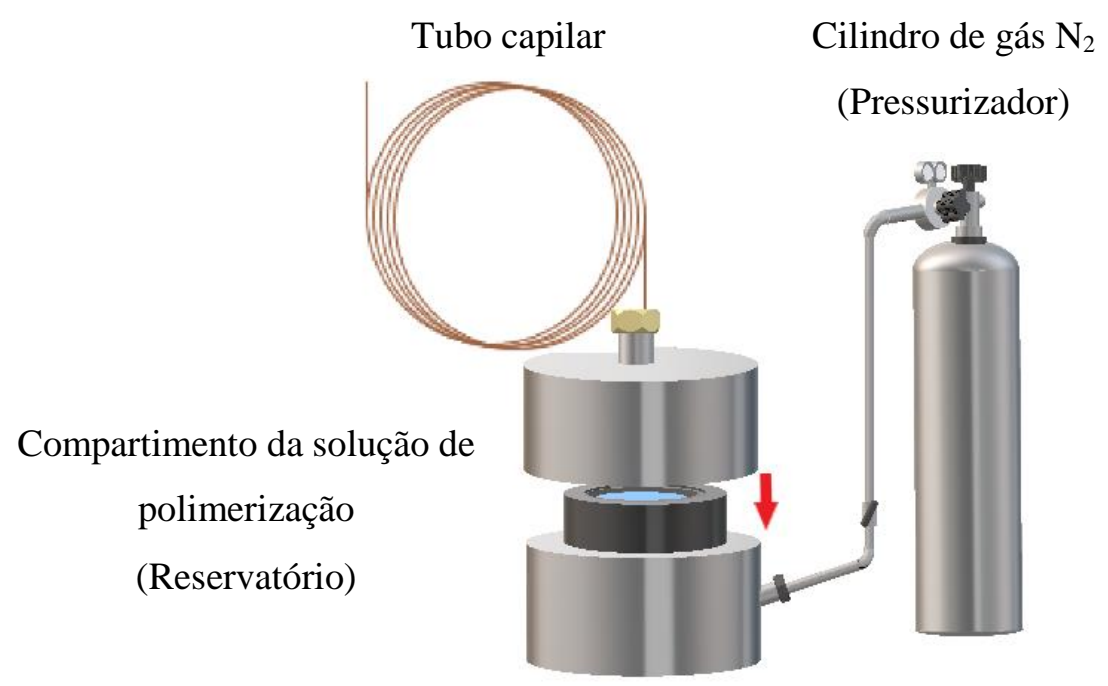

Figura 39 - Diagrama esquemático do sistema empregado para confecção das colunas PLOT 
Após preenchimento, as extremidades dos tubos foram vedadas com septo e imediatamente levadas para o banho térmico a $74{ }^{\circ} \mathrm{C}$, variando-se o tempo de polimerização. Por fim, as colunas foram lavadas com $\mathrm{H}_{2} \mathrm{O}$ e ACN por 30 min cada e secas com gás $\mathrm{N}_{2}$ por no mínimo $1 \mathrm{~h}$.

\subsubsection{Preparo das colunas OT-ODS}

A coluna denominada de ODS refere-se a um tipo de coluna que apresenta grupos funcionais octadecilsilano (ODS, isto é, C18) ligados a um esqueleto de sílica que reveste a parede das colunas. Para confecção dessas colunas foi seguida a metodologia proposta por Vehus et al. ${ }^{77}$ com adaptações. Inicialmente, foi realizado um pré-tratamento do tubo, para tal o tubo foi preenchimento com $\mathrm{NaOH}(1 \mathrm{~mol} / \mathrm{L})$, as extremidades foram seladas com septo e colocadas em uma estufa a $110^{\circ} \mathrm{C}$ por 2 horas. Em seguida, o tubo foi lavado com $\mathrm{H}_{2} \mathrm{O}, \mathrm{HCl}$ (0,01 $\mathrm{mol} / \mathrm{L})$ e acetona por no mínimo $15 \mathrm{~min}$ cada, posteriormente foi seco com gás $\mathrm{N}_{2}$ por 1 hora.

A solução de polimerização foi preparada pela dissolução de $90 \mathrm{mg}$ de PEG em ácido acético $(0,01 \mathrm{~mol} / \mathrm{L})$ a $4{ }^{\circ} \mathrm{C}$ e sob agitação constante durante $30 \mathrm{~min}$, a solução foi filtrada em um filtro de celulose regenerada com microporos de $0,45 \mu \mathrm{m}$. Foi então adicionada a essa solução $170 \mu \mathrm{L}$ de TMOS. Essa mistura foi sonicada por 5 min e homogeneizada em vortex por 1 min. Preencheu-se o tubo capitalar de sílica fundida com a solução de polimerização empregando o sistema mostrado da Figura 40. As pontas do tubo capilar foram vedadas com septo e, em seguida, o tubo foi levado ao forno de HPLC a $40{ }^{\circ} \mathrm{C}$ durante 48 horas e depois levado para uma estufa, onde permaneceu durante 24 horas a $200{ }^{\circ} \mathrm{C}$. Passado esse tempo a temperatura foi gradativamente reduzida e, em seguida, o tubo foi lavado com etanol por 2 horas e seco com gás $\mathrm{N}_{2}$.

A funcionalização do tubo com C18 foi feita através da passagem de uma solução contendo $50 \%$ clorodimetiloctadecilsilano e $50 \%$ p-xileno durante 1 hora. As extremidades do tubo foram seladas com septo e o tubo foi levado para a estufa onde permaneceu 15 horas a 110 ${ }^{\circ} \mathrm{C}$.

Por fim, o tubo foi lavado com THF, $\mathrm{MeOH}, \mathrm{MeOH} / \mathrm{H}_{2} \mathrm{O}(50: 50 \mathrm{v} / \mathrm{v})$ e $\mathrm{MeOH}$ por no mínimo 15 min cada e secos com gás $\mathrm{N}_{2}$. 


\subsubsection{Instrumentação}

Quando se trabalha com colunas tubulares abertas (OT), pequenas variações apresentadas no equipamento e fora dele tornam-se críticas para o desempenho da coluna OT, mais do que seria para as colunas capilares empacotadas. Sendo assim, optou-se por empregar o cromatógrafo capilar desenvolvido no nosso grupo de pesquisa, o qual consta de uma bomba do tipo seringa para evitar dispersão da banda cromatográfica, sistema de injeção equipado com um rotor apropriado à técnica com volume de circuito interno igual a $60 \mathrm{~nL}$ (Valco Instruments, Houston, USA), um detector de Arranjo de Diodos (DAD), modelo SPD-M10AVP conectado a uma controladora modelo CBM-20AD da Shimadzu (Kyoto, Japão) e uma cela capilar confeccionado no grupo com configuração em U e volume de $35 \mathrm{~nL}$.

A caracterização das colunas foi realizada através da Microscopia Eletrônica de Varredura (MEV). Utilisou-se o equipamento ZEISS LEO modelo 440 da Electron Microscopy Inc. (Canbridge, Inglaterra) com detector OXFORD modelo 7060, operado com feixe de elétrons de $20 \mathrm{kV}$. 


\subsection{RESULTADOS E DISCUSSÃO}

\subsubsection{Resultados obtidos com as colunas WCOT}

Nessa parte do trabalho foram avaliadas colunas tubulares abertas (OT) do tipo WCOT de 50 e $70 \mu \mathrm{m}$ de d.i., As colunas OTLC-1 e OTLC-3 são apolares, enquanto as colunas OTLC2 e OTLC-4 apresentam polaridade intermediária. As mesmas são revestidas com um filme e, por isso, permitem um maior fluxo através da coluna sem gerar pressões muito altas (em comparação às colunas empacotadas). Desta forma, colunas de comprimento na ordem de alguns metros podem ser utilizadas, consistindo em uma das principais vantagens de se empregar colunas OT em LC.

Poucos são os trabalhos descritos na literatura que abordam a utilização das colunas OT em cromatografia líquida. Isso ocorria, principalmente, devido às limitações instrumentais, pois fluxos muito baixos são requeridos, assim como um sistema de detecção apropriado a esses fluxos. Mesmo atualmente, com o desenvolvimento de instrumentação mais adequada para operar em nano fluxos, não se tem ainda dedicado muitos esforços à utilização das colunas tubulares abertas em LC.

Nessa parte do trabalho todos os testes realizados foram feitos utilizando o cromatógrafo líquido capilar (cLC) desenvolvido no laboratório de cromatografia ${ }^{69}$, sendo as colunas analíticas mantidas à temperatura ambiente $\left(25^{\circ} \mathrm{C}\right)$.

Colunas com diferentes tamanhos (7, 6, 5 e $5 \mathrm{~m})$ foram empregadas, para que pudessem ser obtidas informações a respeito da influência do comprimento das colunas na eficiência cromatográfica. Inicialmente foi avaliada a permeabilidade da coluna (calculada a partir da divisão da pressão do sistema pela velocidade linear média), experimentos estes realizados com todas as colunas sob as mesmas condições. Utilizou-se como fase móvel $60 \%$ de acetonitrila e $40 \%$ de água; o fluxo volumétrico empregado foi de $6 \mu \mathrm{L} / \mathrm{min}^{-1}$ e comprimento de onda de detecção de $210 \mathrm{~nm}$. Os cálculos da velocidade linear média $(\mu)$ foram feitos com base no tempo de eluição da uracila (composto não retido). Para fins comparativos, realizou-se os mesmos experimentos em uma das colunas contendo partículas de $\mathrm{C} 18(14 \mathrm{~cm} \times 250 \mu \mathrm{m} \times 3,5 \mu \mathrm{m})$ confeccionadas neste trabalho e descrito no capítulo anterior. Os valores obtidos para permeabilidade das colunas tubulares abertas foram pequenos 1,88 (OTLC-1), 1,32 (OTLC-2),

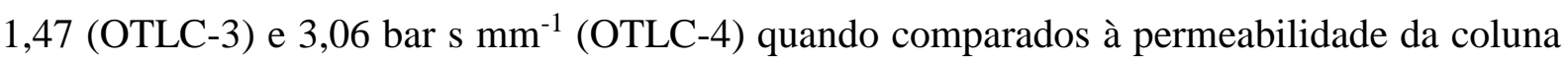
empacotada, igual a 101,01 bar s $\mathrm{mm}^{-1}$, revelando a baixa contrapressão das colunas OTLC. A pressão das mesmas é basicamente dependente do diâmetro interno, diferentemente das colunas 
com partículas, onde a contrapressão, quando se utiliza taxas de fluxo linear constante, não é afetada pelo d.i. da coluna e sim pelo tamanho das partículas.

Para avaliar o comportamento da pressão do sistema cromatográfico com as colunas OTLC, injetou-se uracila em diferentes fluxos volumétricos. O menor fluxo utilizado foi 0,2 $\mu \mathrm{L} \min ^{-1} \mathrm{e}$, devido a limitações no volume do pistão da bomba, o fluxo máximo empregado foi de $34 \mu \mathrm{L} \mathrm{min}^{-1}$. A fase móvel empregada foi $60 \%$ de acetonitrila e $40 \%$ de água e comprimento de onda $254 \mathrm{~nm}$. A partir dos dados obtidos calculou-se a velocidade linear $(\mu)$ correspondente a cada taxa de fluxo e, então, as curvas de pressão (P) versus $\mu$ foram plotadas conforme apresentadas na Figura 41.

Observa-se que as colunas OTLC podem operar com uma grande variedade de taxas de fluxos em função da melhor permeabilidade da coluna pois, uma vez que não possui partículas, o solvente da fase móvel pode passar através da mesma sem gerar pressões muito elevadas. Embora o sistema possa operar em velocidades lineares mais altas, deve-se ter cuidado para que a vazão da fase móvel não ultrapasse a capacidade dos conectores e da cela de detecção.

Para avaliar a eficiência das colunas, geralmente, é utilizada a curva de van Deemter que é plotada a partir dos valores da altura equivalente a um prato teórico, gerados em diferentes velocidades lineares. Na Figura 42 são apresentados os gráficos da curva de van Deemter empregando as colunas OTLC.

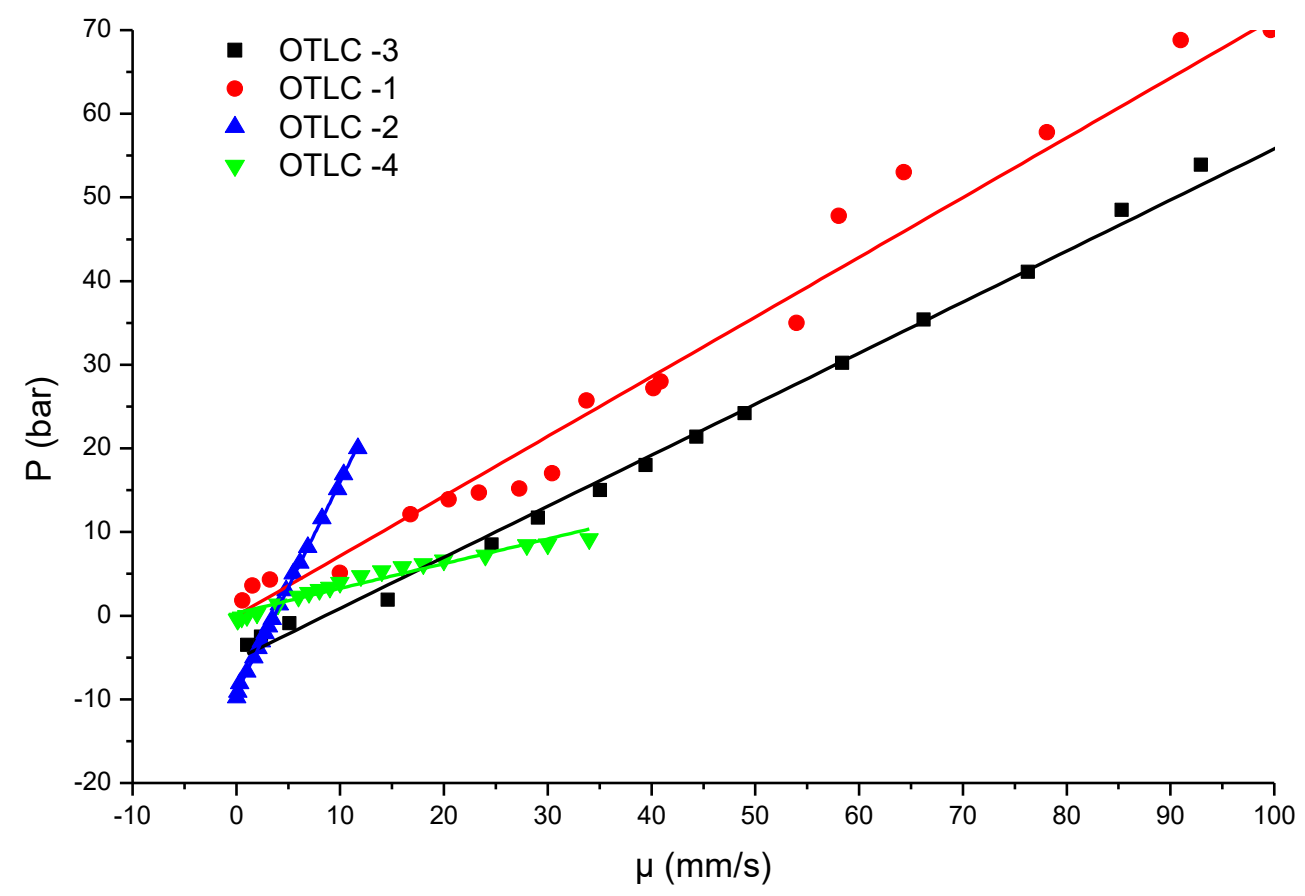

Figura 40 - Efeito da variação da pressão $(\mathrm{P})$ em função da velocidade linear aplicada $(\mu)$ para as colunas OTLC-1, OTLC-2, OTLC-3 e OTLC-4 


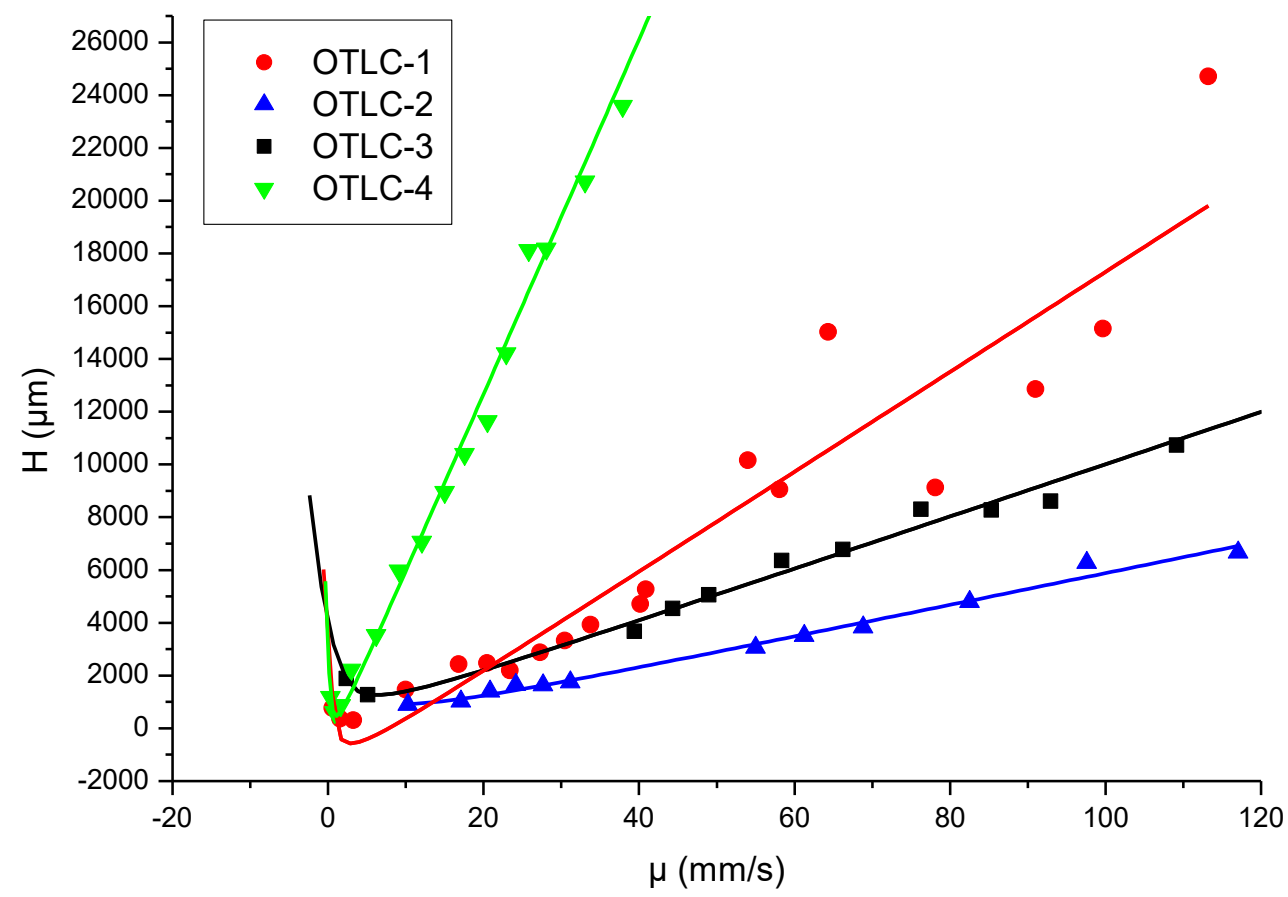

Figura 41 - Gráfico de Van Deemter para um composto retido (butilbenzeno) empregando as quatro colunas OTLC estudadas. As curvas foram plotadas usando regressão clássica dos mínimos quadrados

O ponto mais baixo da curva indica as condições ótimas para realizar as separações cromatográficas. Os menores valores de $\mathrm{H}$ determinados para as colunas OTLC-1, OTLC-2, OTLC-3 e OTLC-4 foram iguais a 77, 667, 48 e 118,0 $\mu \mathrm{m}$ respectivamente. Esses valores ainda são considerados altos para se obter eficiência adequada, embora seja possível realizar separações, quando empregados os padrões de alquilbenzenos. Os valores mínimos de H nas colunas OTLC-1, 3 e 4, foram obtidos com fluxo volumétrico de $1 \mu \mathrm{L} / \mathrm{min}$ e na coluna OTLC2 o fluxo foi de $3 \mu \mathrm{L} / \mathrm{min}$. No entanto, como a utilização desses fluxos implica em tempos de análise muito demorados, optou-se por trabalhar com fluxo volumétrico de $6 \mu \mathrm{L} / \mathrm{min}$, que resulta em análises mais rápidas e os valores de $\mathrm{H}$ não diferem muito dos valores mínimos.

Os parâmetros reduzidos são utilizados para comparar colunas de diferentes características. Para realizar a comparação entre as colunas OTLC estudadas, foi injetado um padrão de butilbenzeno em diferentes fluxos de F.M (60\% ACN/ $\left.40 \% \mathrm{H}_{2} \mathrm{O}\right)$, com os dados obtidos determinou-se os valores de $\mathrm{h}$ e $\mathrm{v}$, os mesmos foram relacionados através da curva de Knox $^{64}$. Os gráficos obtidos estão expostos na Figura 43. 


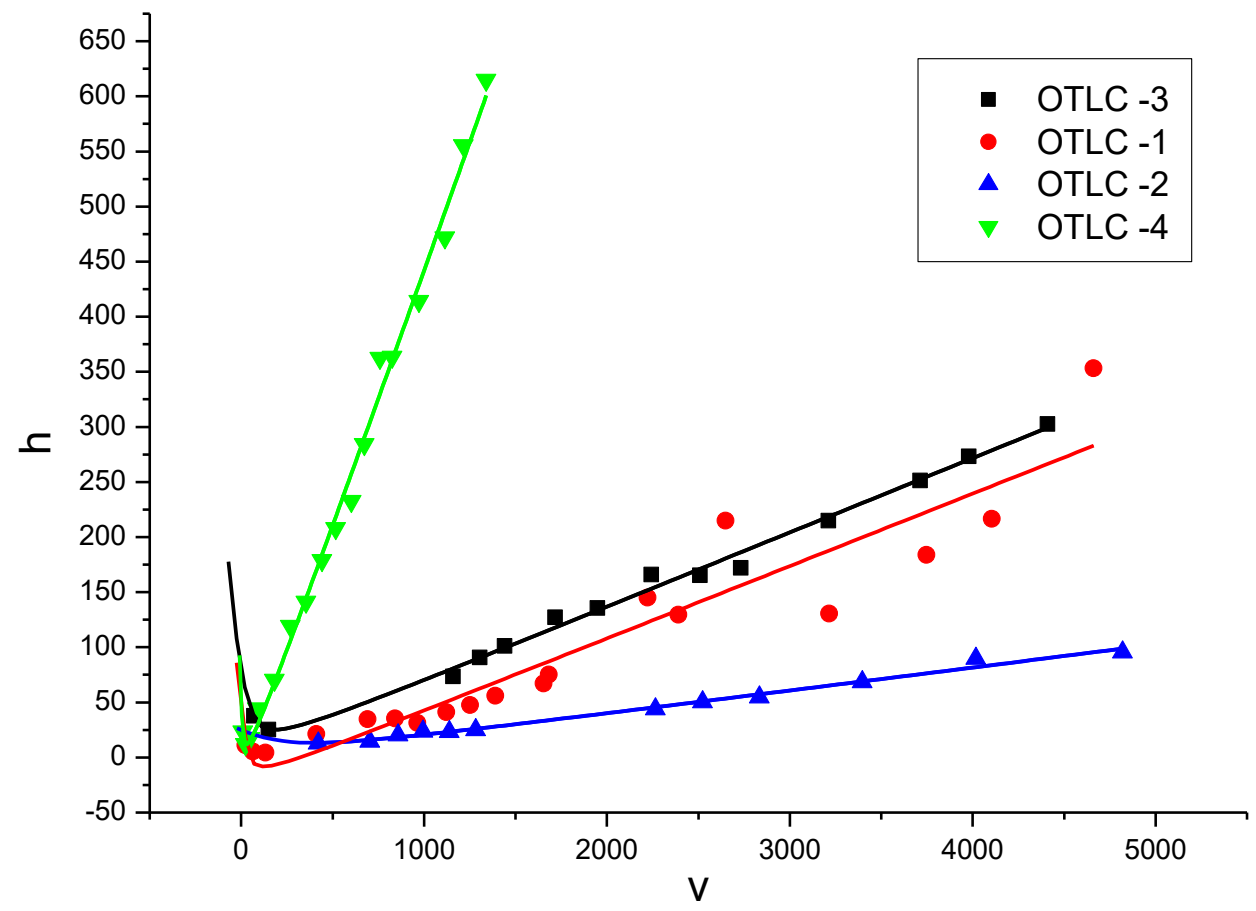

Figura 42 - Curva de Knox (log h x log v) para as coluna OTLC-1, OTLC-2, OTLC-3 e OTLC-4

Observa-se na Figura 43 que o perfil da curva de Konx foi semelhante para todas as colunas. A maior variação de $\mathrm{h}$ em função de $\mathrm{v}$ foi da coluna OTLC-4 ( $\mathrm{h}_{\text {mínimo }} \sim 12$ e $\mathrm{h}_{\text {máximo }}$ 600 ) e a coluna que apresentou as menores variações foi a OTLC-2 ( $h_{\text {mínimo }} \sim 12$ e $h_{\text {máximo }} \sim 95$ ). Essas duas colunas são constituídas com a mesma fase estacionária, mas apresentam tamanhos e diâmetros diferentes. O comprimento da coluna pode ter sido a causa principal para maior variação de h, pois a coluna OTLC-4 tem praticamente a metade do tamanho da coluna OTLC2, embora possua menor diâmetro interno.

Considerando os valores mínimos de $\mathrm{h}$ de todas as colunas, o menor $\mathrm{h}$ encontrado foi

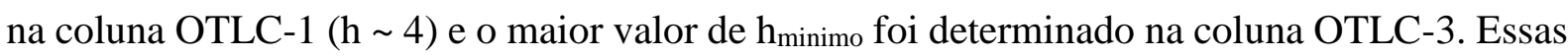
duas colunas apresentam a mesma fase estacionária e, novamente, a característica da coluna que pode ter influenciando para o menor h é o comprimento, pois a coluna OTLC-1 possui d.i. de $70 \mu \mathrm{m}$ e comprimento de $7 \mathrm{~m}$. Já a coluna OTLC-3 possui $50 \mu \mathrm{m}$ de d.i. e $6 \mathrm{~m}$ de comprimento. Assim, pode-se afirmar que os dois d.i. utilizados não atribuem às colunas características responsáveis por provocar melhoras na eficiência.

O desempenho das colunas OTLC também foi avaliado pela separação de quatro padrões de alquilbenzenos: tolueno, etilbenzeno, butilbenzeno e propilbenzeno $(1,4 \mu \mathrm{L} / \mathrm{mL})$, além da uracila (50 ppm). Antes de se realizar as separações, foram avaliados os efeitos da composição da fase móvel na separação da mistura de alquilbenzenos. Para isso, injetou-se 
individualmente cada padrão de aquilbenzeno, empregando-se fase móvel que variava a composição de $20 \%$ a $80 \%$ de acetonitrila em água, e calculou-se o fator de retenção para cada composto em função da composição da fase móvel. Esse procedimento foi realizado nas quatro colunas estudadas e os resultados são apresentados na forma de gráficos na Figura 44.

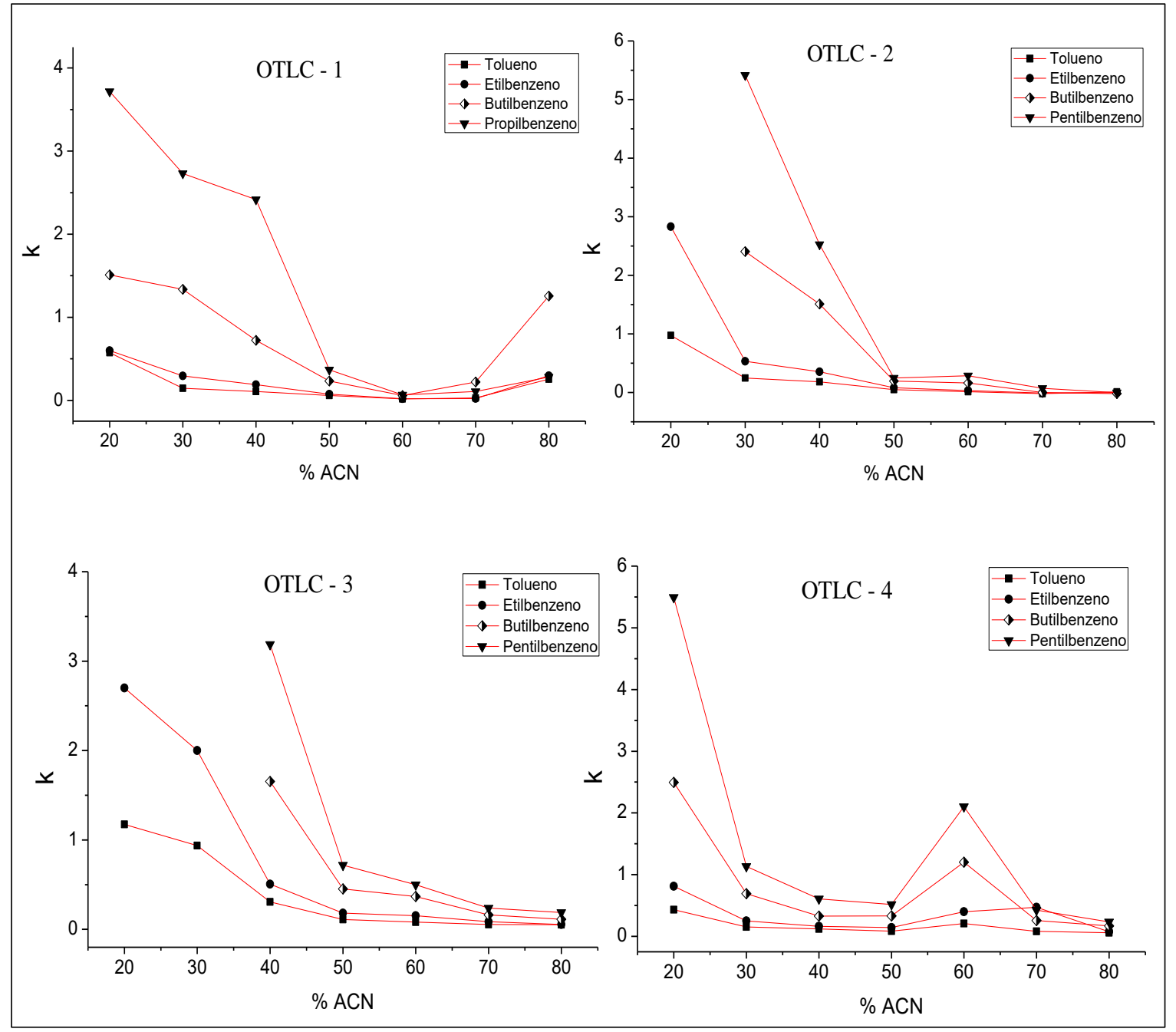

Figura 43 - Comportamento de $\mathrm{k}$ em função da quantidade de solvente orgânico na fase móvel. A vazão empregada foi de $6 \mu \mathrm{L} / \mathrm{min}$

Observa-se que a partir de $50 \%$ de acetonitrila na F.M os analitos começam a apresentar valores de k semelhantes, indicando que os mesmos não são totalmente separados, com exceção da coluna OTLC-4 que apresentou valores de $\mathrm{k}$ distintos em F.M composta por $60 \%$ de acetonitrila. Nas colunas OTLC-2 e OTLC-3 o solvente sobressai o sinal dos analitos butilbenzeno e pentilbenzeno empregando F.M contendo menos de $40 \%$ de acetonitrila. Desta forma, a F.M composta por $40 \%$ de acetonitrila foi considerada a mais adequada para realizar 
as separações da mistura de alquilbenzenos, considerando que uma mesma F.M deveria ser usada com todas as colunas OTLC avaliadas.

A Figura 45 apresenta os cromatogramas das separações de aquilbenzenos. Utilizou-se as mesmas condições cromatográficas em todas as injeções; o fluxo de fase móvel (acetonitrila/água (40:60)) empregado foi de $6 \mu \mathrm{L} / \mathrm{min}$ e a detecção realizada em $210 \mathrm{~nm}$. A Tabela 20 apresenta os parâmetros cromatográficos para todas as colunas. Os valores de N, k, h, $\varnothing$ e E foram calculados em relação ao analito etilbenzeno, o valor de $\eta$ utilizado nos cálculos foi de 1,03 mPa.s. O fator de separação e a resolução foram calculados em relação aos analitos etilbenzeno e butilbenzeno.

Utilizando a coluna OTLC-4 não foi possível realizar a separação dos compostos injetados. Como não é possível definir os tempos de retenção, e nem as larguras da base dos picos dos analitos, não foi possível calcular os parâmetros dessa coluna. Embora os compostos tenham sido separados nas colunas OTLC 1,2 e 3 os valores de $\mathrm{h}$ foram muito elevados. Como as colunas são tubulares abertas, esperavam-se valores menores que 6, revelando a baixa eficiência dessas colunas, mesmo apresentando bons resultados para resistência ao fluxo (Ø).

Considerando a separação dos alquilbenzenos o melhor desempenho foi observado na coluna OTLC-2, onde percebem-se os menores valores dos parâmetros reduzidos e maior valor de N.
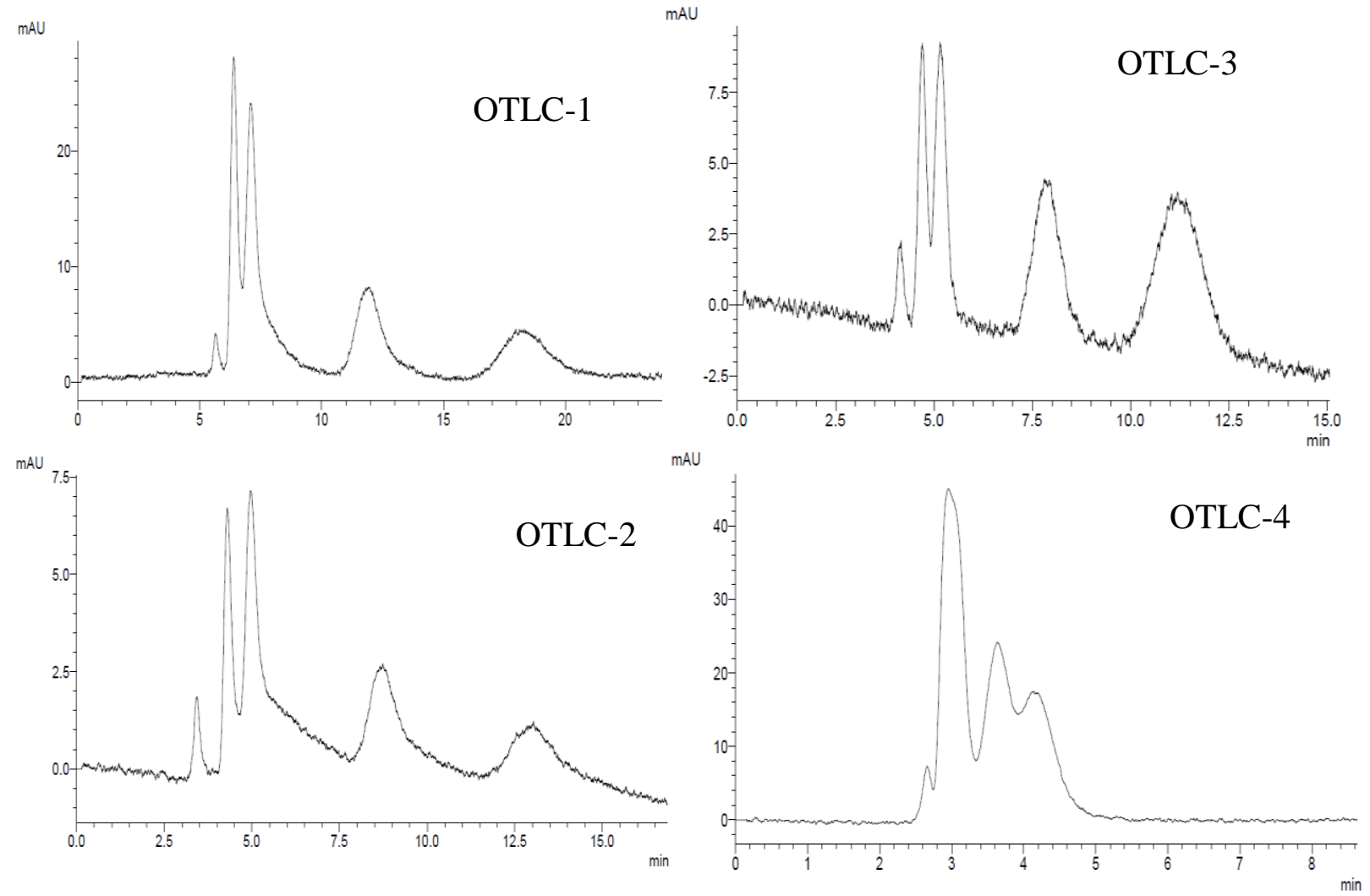

Figura 44 - Cromatogramas obtidos com as colunas capilares OTLC. Ordem de eluição: uracila, tolueno, etilbenzeno, butilbenzeno e propilbenzeno 


\begin{tabular}{|c|c|c|c|c|}
\hline \multirow{2}{*}{ Parâmetros } & \multicolumn{4}{|c|}{ Colunas WCOT } \\
\hline & OTLC-1 & OTLC-2 & OTLC-3 & OTLC-4 \\
\hline$t_{\mathrm{R}-\text { uracila }}(\min )$ & 5,63 & 4,16 & 3,43 & - \\
\hline $\mathrm{t}_{\mathrm{R}}-$ tolueno $(\mathrm{min})$ & 6,39 & 4,70 & 4,30 & - \\
\hline$t_{\mathrm{R}-\text { etilbenzeno }}(\mathrm{min})$ & 7,07 & 5,15 & 4,95 & - \\
\hline $\mathrm{t}_{\mathrm{R} \text {-butilbenzeno }}(\mathrm{min})$ & 11,96 & 7,80 & 8,73 & - \\
\hline $\begin{array}{l}t_{R} \text { - propilbenzeno } \\
(\min )\end{array}$ & 18,31 & 11,19 & 13,03 & - \\
\hline $\mathrm{L}(\mathrm{m})$ & 7,0 & 5,0 & 6,0 & 2,3 \\
\hline $\mathrm{N} / \mathrm{m}$ & 300 & 396 & 256 & - \\
\hline $\mathrm{k}$ & 0,11 & 0,24 & 0,446 & - \\
\hline$\alpha$ & 4,39 & 3,67 & 3,47 & - \\
\hline $\mathrm{R}_{\mathrm{s}}$ & 3,93 & 2,63 & 4,430 & - \\
\hline h & 40,74 & 36,07 & 77,93 & - \\
\hline$\varnothing$ & 22,34 & 4,75 & 34,65 & - \\
\hline $\mathrm{E}$ & 37.082 & 6.176 & 210.447 & - \\
\hline
\end{tabular}

Tabela 20 - Diagrama esquemático do sistema empregado para confecção das colunas PLOT

A partir dos resultados obtidos com os testes realizados com as colunas tubulares abertas, constatou-se que as colunas de diâmetro de 50 e $70 \mu \mathrm{m}$ de d. i. ainda não estão totalmente adequadas para serem utilizadas nos sistemas capilares. Isto pode ser explicado devido ao fato dos diâmetros internos empregados nas colunas ainda serem considerados elevados para as OTLC. Para esta técnica, admite-se hoje que o diâmetro interno seja inferior a $15 \mu \mathrm{m}$, o que representa um limite rigoroso para os equipamentos existentes no momento ${ }^{27}$. Assim, os resultados obtidos com as colunas WCOT estudados sugerem uma forte diminuição no diâmetro interno das mesmas (inferior a $20 \mu \mathrm{m}$ ) para que se possa obter colunas com qualidade similares as empacotadas descritas no capítulo anterior. 


\subsubsection{Resultados obtidos com as colunas PLOT}

As colunas tubulares abertas totalmente porosas, como o próprio nome diz, apresentam como principal característica uma camada de F.E porosa e mais espessa, que melhora a área de superfície de fases estacionárias e aumenta a capacidade de carga da coluna, pois a microestrutura porosa aumenta a área superficial efetiva e, assim, aumenta consideravelmente a capacidade.

As estruturas de camada porosa podem proporcionar uma capacidade melhorada devido à sua área superficial ser maior do que a dos revestimentos poliméricos não porosos, como no caso das F.E das colunas WCOT. Diante deste fato, decidimos produzir colunas tubulares abertas do tipo PLOT, para serem empregadas em cromatografia líquida, com o intuito de investigar se as mesmas produziriam melhores resultados do que os obtidos com as colunas do tipo WCOT. Para isso, foram estudados dois tipos de colunas PLOT, sendo uma baseada no polímero estireno-divenilbenzeno (PS-DVB) e outra com octadecilsilano ancorado à parede do tubo com auxílio do polietilenoglicol (ODS-PEG).

\subsubsection{Avaliação das colunas OT-PS-DVB}

As colunas OT-PS-DVB foram confeccionadas seguindo a metodologia descrita no Tópico 3.1.3.1. Foram empregados quatro tubos de sílica fundida de diâmetros internos iguais a 100, 75, 50 e $25 \mu \mathrm{m}$ sendo o comprimento mantido em $5 \mathrm{~m}$. Foi realizada a otimização do tempo de polimerização avaliando-se a polimerização de uma em uma hora durante 24 horas. Esta etapa era importante, primeiramente para se ter certeza de que o filme seria formado, para observar a uniformidade do filme e se ele estaria apenas na borda da coluna e não no centro também. Sendo assim, foram feitas as imagens por MEV e, com base nos resultados, os tempos de polimerização escolhidos foram 6 horas para coluna de $25 \mu \mathrm{m}$ d.i., 7 horas para a coluna de $50 \mu \mathrm{m}$ de d.i. e 8 horas para a coluna de 75 e $100 \mu \mathrm{m}$ de d.i., conforme critérios já citados. A Figura 46 apresenta as imagens obtidas por MEV para cada uma das colunas confeccionas.

Para melhor visualização da F.E nas colunas, a Figura 47 apresenta um tubo de sílica fundida vazio, no qual foi realizada apenas a etapa de silanização (a) e um tubo de sílica fundida contendo a F.E (b). 

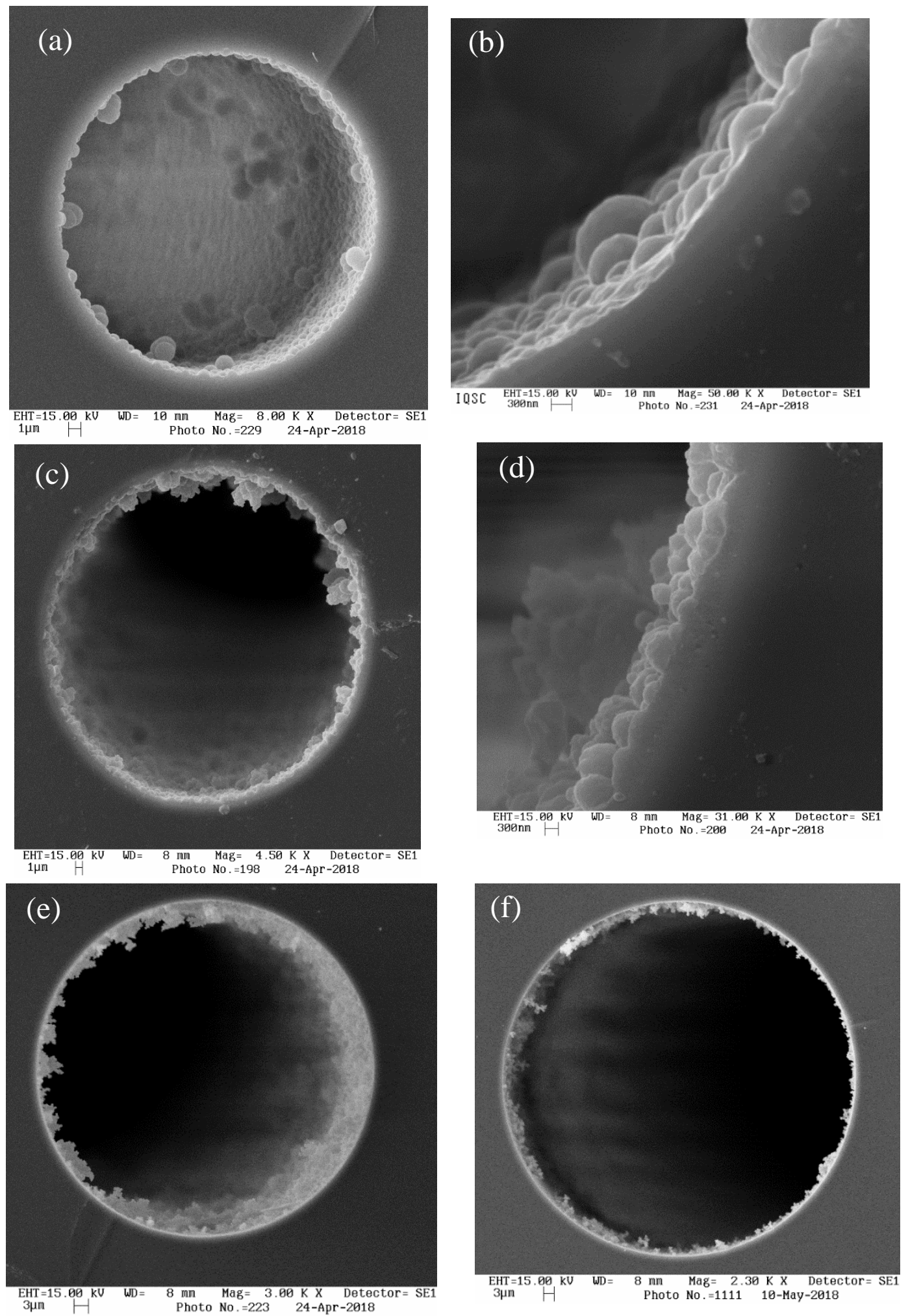

Figura 45 - Imagens de microscopia eletrônica de varredura (MEV) de várias colunas OT-PS-DVB sintetizadas (a) PS-DVB $25 \mu \mathrm{m}$ d.i (b) PS-DVB $25 \mu \mathrm{m}$ d.i. detalhada (c) PS-DVB $50 \mu \mathrm{m}$ d.i. (d) PS-DVB $50 \mu \mathrm{m}$ d.i. detalhada (e) PS-DVB $75 \mu \mathrm{m}$ d.i. (f) PS-DVB $100 \mu \mathrm{m}$ d.i. 


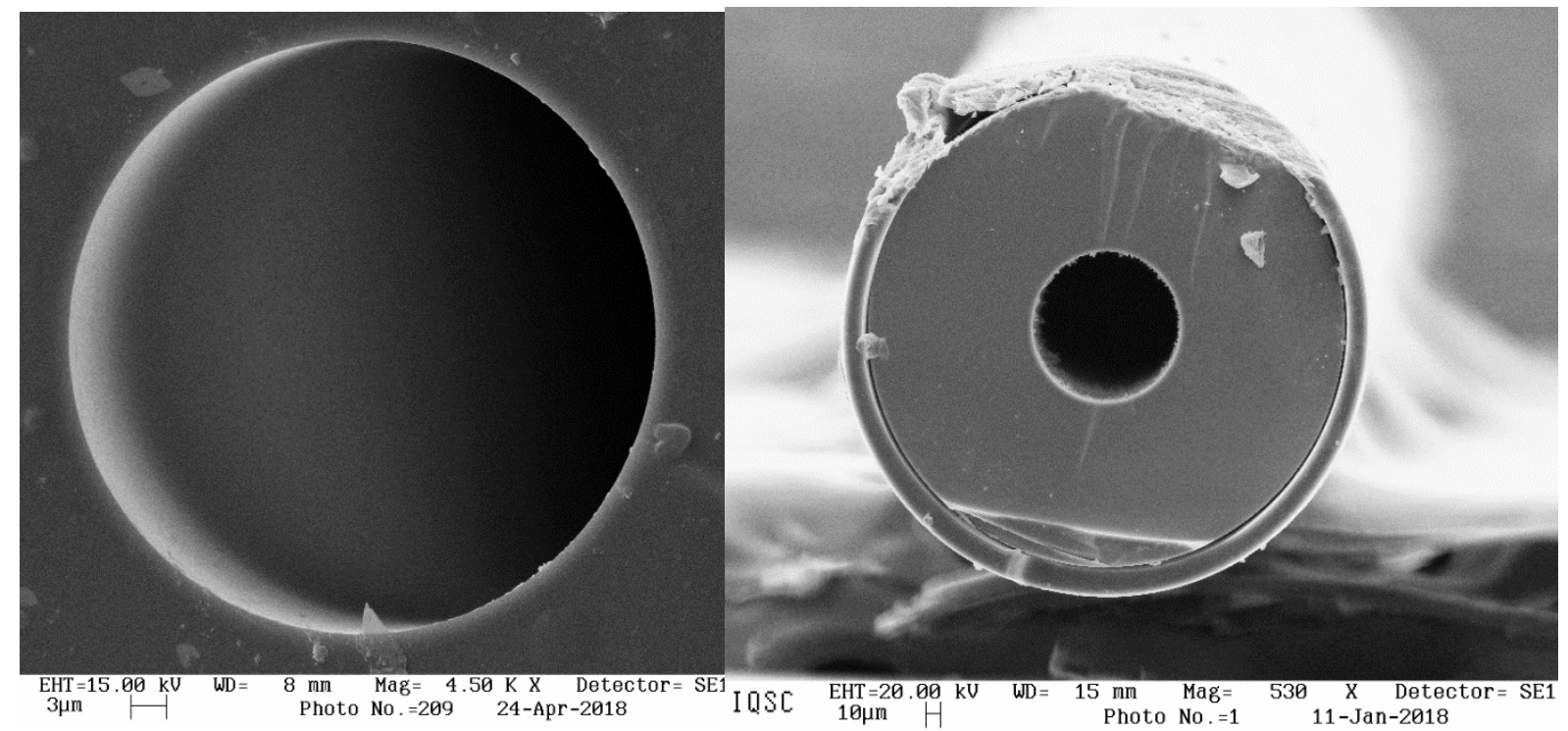

Figura 46 - Imagens de MEV de (a) tubo de sílica fundida vazio e (b) Coluna OT-PS-DVB

A partir das imagens de MEV, foi possível perceber que ouve a formação de F.E na parede dos tubos dando origem, então, às colunas PLOT. Observou-se que houve a formação de F.E em todos os tempos testados, com exceção do tempo de uma hora; no entanto, a quantidade de F.E formada dependeu estritamente do tempo de polimerização. Depois de 8 horas polimerizando, houve a formação de uma camada mais espessa em apenas um lado do tubo; esse fato apresentou-se mais crítico para os tubos de 75 e $100 \mu \mathrm{m}$. Por isso, os tempos de polimerização escolhidos foram rigorosamente executados.

Além dos tempos de polimerização foi investigada a temperatura da reação de polimerização e notou-se que nas temperaturas de 50 e $60^{\circ} \mathrm{C}$ a reação de polimerização ocorre lentamente, gerando tempos demasiadamente longos. Já, empregando a temperatura de $80^{\circ} \mathrm{C}$ a polimerização ocorreu rapidamente, mas formando um filme muito irregular e, aparentemente, apresentando um aspecto menos poroso.

Também tentou-se realizar a polimerização em estufa com temperatura controlada e através da foto polimerização, além de banho de água, mas as duas primeiras sem êxito.

As colunas obtidas foram analisadas no cromatógrafo "homemade", através da separação da mistura de alquibenzenos, empregando-se $\mathrm{ACN}: \mathrm{H}_{2} \mathrm{O}$ como F.M, comprimento de onda de $210 \mathrm{~nm}$ e temperatura da coluna de $30^{\circ} \mathrm{C}$. As colunas foram condicionadas durante, no mínimo, 12 horas antes de se realizar as análises.

Os cromatogramas da separação dos alquibenzenos empregando as colonas PLOT do tipo PS-DVB são apresentados na Figura 48. 

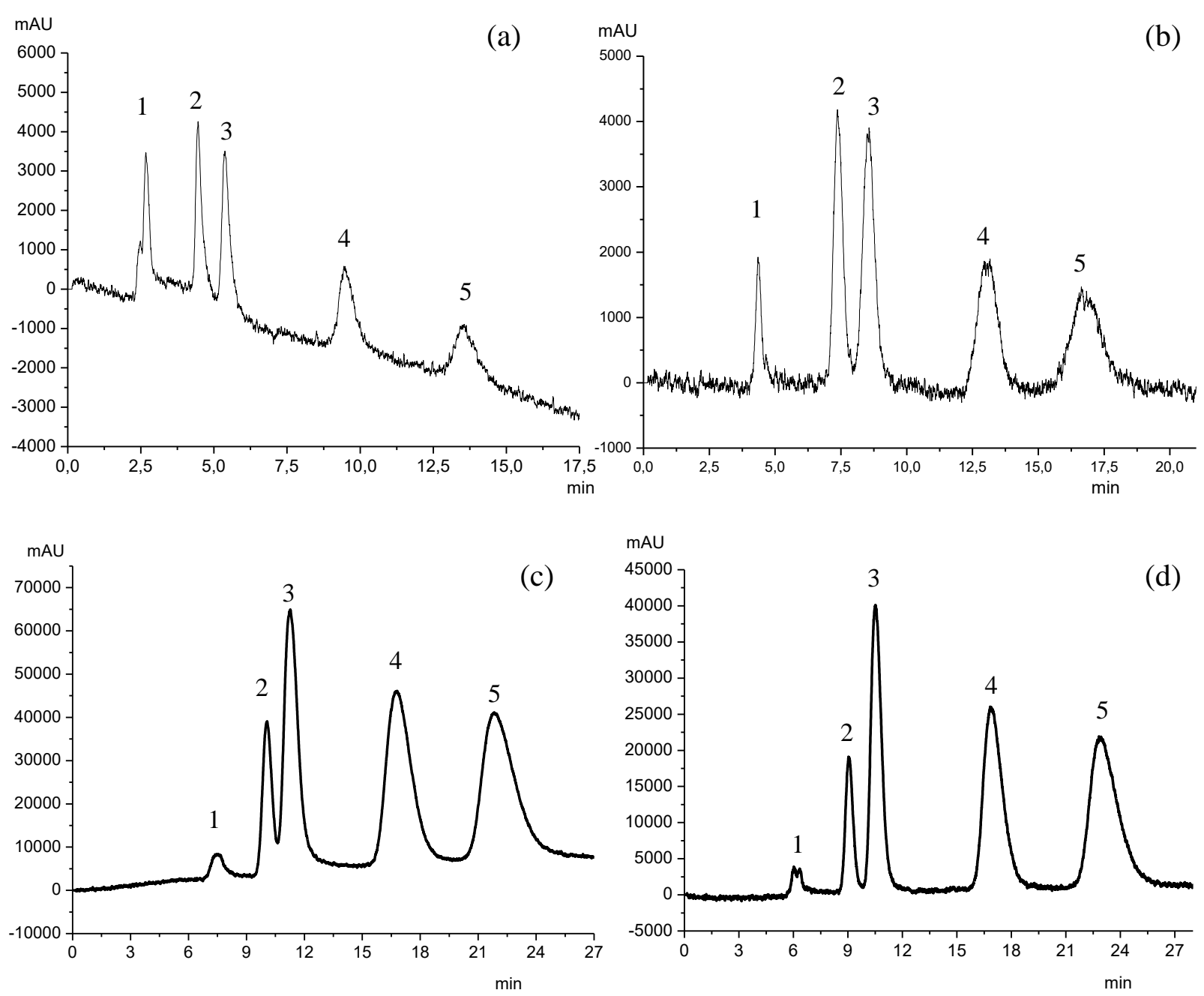

Figura 47 - - Cromatogramas da separação dos alquibenzenos usando as colunas PLOT (a) PSDVB $25 \mu \mathrm{m}$ d.i., (b) PS-DVB $50 \mu \mathrm{m}$ d.i., (c) PS-DVB $75 \mu \mathrm{m}$ d.i. e (d) PS-DVB $100 \mu \mathrm{m}$ d.i. Ordem de eluição: uracila, tolueno, etilbenzeno, butilbenzeno e propilbenzeno

As melhores condições cromatográficas de separação foram investigadas e utilizadas nas separações acima. Para as colunas PS-BVB de 75 e $100 \mu \mathrm{m}$ foi utilizada proporção de 60 $\%$ de $\mathrm{ACN}$ e $40 \%$ de $\mathrm{H}_{2} \mathrm{O}$, com F.M a um fluxo de 7 e $10 \mu \mathrm{L} / \mathrm{min}$. Para as colunas PS-DVB de 25 e $50 \mu \mathrm{m}$ de d.i. empregou-se como F.M uma proporção de $60 \%$ de $\mathrm{ACN}$ e $40 \%$ de $\mathrm{H}_{2} \mathrm{O}$ a um fluxo de 3 e $5 \mu \mathrm{L} / \mathrm{min}$ para as duas colunas PS-BVB de 25 e $50 \mu \mathrm{m}$ de d.i., respectivamente.

Houve a necessidade de diminuir 10 vezes a concentração dos padrões analíticos com relação à concentração empregada com as colunas WCOT, mostrando uma melhoria da capacidade dessas colunas. Os cromatogramas mostram que todas as colunas foram capazes de realizar a separação dos analitos e com tempos de análise adequados. No entanto, a coluna PSDVB de $75 \mu \mathrm{m}$ de d.i. não mostrou uma separação total dos analitos tolueno e etilbenzeno. 
Através dos parâmetros da Tabela 21 é possível analisar com maior clareza as diferenças entre as colunas. Para calcular $\emptyset$, empregou-se um valor de $\eta$ igual a $0,65 \mathrm{mPa}$.s quando a composição da F.M foi ACN/ $\mathrm{H}_{2} \mathrm{O}\left(60: 40\right.$, v/v) e $0,59 \mathrm{mPa} . \mathrm{s}$ quando a F.M foi $\mathrm{ACN} / \mathrm{H}_{2} \mathrm{O}$ (70:30, v/v). Os valores de R e $\alpha$ na tabela são referentes aos analitos tolueno e etilbenzeno; e os valores de $\mathrm{N}, \mathrm{k}$, h e E são referentes ao composto etilbenzeno.

\begin{tabular}{lllll}
\hline \multirow{2}{*}{ Parâmetros } & \multicolumn{4}{c}{ Diâmetro interno das colunas PS-DVB } \\
& $25 \mu \mathrm{m}$ & $50 \mu \mathrm{m}$ & $75 \mu \mathrm{m}$ & $100 \mu \mathrm{m}$ \\
\hline $\mathrm{t}_{\mathrm{R} \text { - uracila }(\mathrm{min})}$ & 2,666 & 4,345 & 7,46 & 6,03 \\
$\mathrm{t}_{\mathrm{R}}$ - tolueno $(\mathrm{min})$ & 4,456 & 7,365 & 10,07 & 9,03 \\
$\mathrm{t}_{\mathrm{R} \text { - etilbenzeno }}(\mathrm{min})$ & 5,372 & 8,569 & 11,27 & 10,51 \\
$\mathrm{t}_{\mathrm{R} \text {-butilbenzeno }}(\mathrm{min})$ & 9,445 & 13,162 & 16,81 & 16,83 \\
$\mathrm{t}_{\mathrm{R} \text { - propilbenzeno }}(\mathrm{min})$ & 13,560 & 16,632 & 21,82 & 22,82 \\
$\mathrm{~W}_{(50 \%)}(\min )$ & 0,28 & 0,49 & 0,79 & 0,65 \\
$\mathrm{~L}$ (m) & 5 & 5 & 5 & 5 \\
$\mathrm{~N}$ & 2.438 & 1.909 & 1141 & 1.529 \\
$\mathrm{k}$ & 1,02 & 0,97 & 0,51 & 0,74 \\
$\alpha$ & 1,51 & 1,40 & 1,46 & 1,49 \\
$\mathrm{R}$ & 3,65 & 2,73 & 1,78 & 2,67 \\
$\mathrm{~h}$ & 82 & 52 & 58 & 32 \\
$\varnothing$ & 63 & 124 & 263 & 200 \\
$\mathrm{E}$ & 424.204 & 569.869 & 899.317 & 35.683 \\
\hline
\end{tabular}

Tabela 21 - Parâmetros obtidos a partir dos dados dos cromatogramas gerados com as colunas OT-PS-DVB de 25, 50, 75 e $100 \mu \mathrm{m}$ de d.i.

Foi possível perceber que a coluna com menor diâmetro interno (PS-DVB $25 \mu \mathrm{m}$ de d.i.) apresentou a maior eficiência; a segunda e terceira maiores eficiências foram a das colunas 50 e $100 \mu \mathrm{m}$ de d.i., respectivamente. Devido à ordem de eficiência apresentada e aos relatos da literatura, esperava-se que a eficiência da coluna de $75 \mu \mathrm{m}$ de d.i. fosse maior do que a da coluna de $100 \mu \mathrm{m}$ de d.i., o que não ocorreu. Isto pode estar relacionado a F.E. pois, a sua não uniformidade em toda extensão do tubo, ou a presença de falhas, podem resultar em uma queda de eficiência. No entanto, isto não se pode ser afirmado, com certeza, devido a impossibilidade de inspecionar a F.E dentro do tubo. 
Como o fluxo e a composição da fase móvel não foram iguais, era esperada a variação dos parâmetros $\mathrm{k} \mathrm{e} \alpha$, como foi observado. Com exceção da coluna PS-DVB de $75 \mu \mathrm{m}$ de d.i., os valores de $\mathrm{R}$ para os picos do tolueno e fenatreno foram muito bons. O desempenho das colunas avaliadas, através do parâmetro h, mostra uma inversão de valores, se comparado aos valores de $\mathrm{N}$, pois a equação para o cálculo de h mostra uma relação inversamente proporcional ao tamanho do diâmetro interno do tubo $\left(h=H / d_{c}\right)$, o que explica o desempenho das colunas aumentarem (menor valor de h) com o aumento do d.i.

Os parâmetros $\varnothing$ e E possuem relação direta com o diâmetro interno das colunas e devido às colunas estudadas apresentarem d.i. muito grandes para o formato PLOT, ainda que tenham apresentado contrapressão muito baixa, não foi suficiente para que esses parâmetros apresentassem valores adequados.

$$
\emptyset=\frac{\Delta \mathrm{Pt}_{\mathrm{m}} \mathrm{d}_{\mathrm{c}}^{2}}{\eta \mathrm{L}^{2}} \quad \text { e } \quad \mathrm{E}=\frac{\mathrm{t}_{\mathrm{M}} \Delta \mathrm{P}}{\mathrm{N}^{2} \eta(1+\mathrm{k})}
$$

O comportamento das colunas, com relação a pressão, pode ser observado na Figura 49. Devido à eficiência das colunas com diâmetros internos maiores que $50 \mu \mathrm{m}$ terem sido muito baixas, elas foram consideradas inapropriadas para serem empregadas em cLC, e os estudos seguintes foram realizados somente com as colunas PS-DVB de 25 e $50 \mu \mathrm{m}$ de d.i.

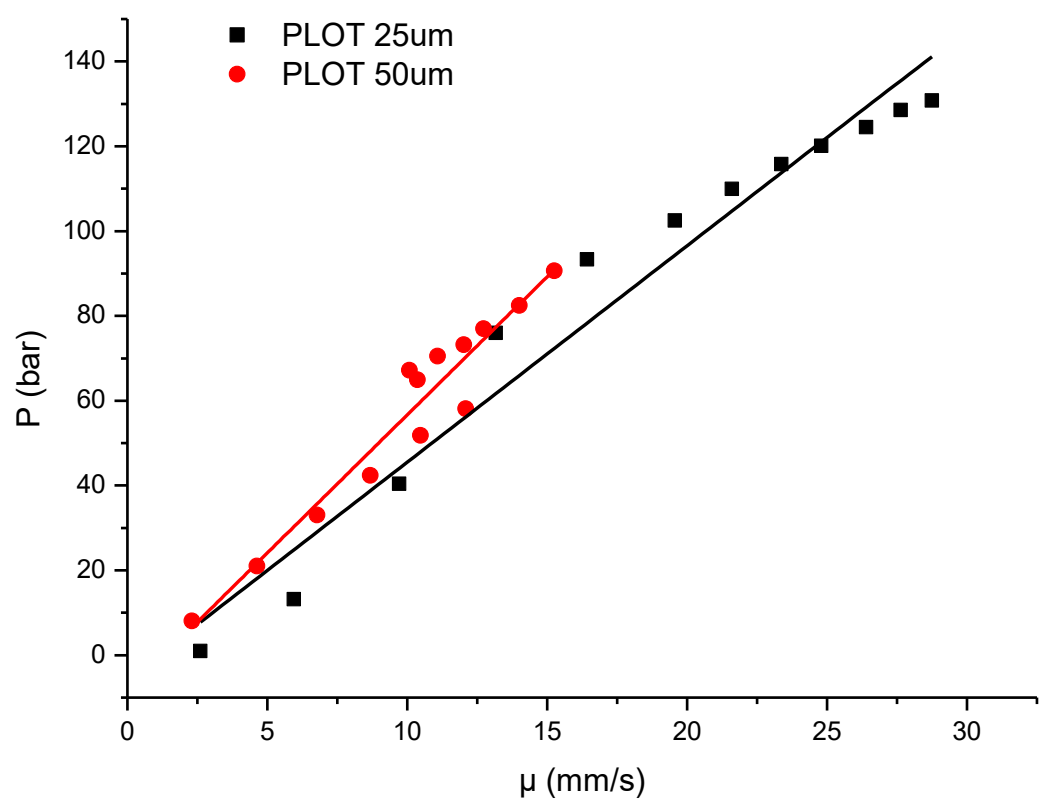

Figura 48 - Gráfico da Pressão em função do fluxo volumétrico para as colunas OT-PS-DVB de 50 e $25 \mu \mathrm{m}$ de d.i. 
Como esperado, a coluna de d.i. de $25 \mu \mathrm{m}$ apresentou contrapressão mais elevada do que a coluna de $75 \mu \mathrm{m}$ de d.i.; no entanto, mesmo em velocidade linear mais elevada, as pressões podem ser consideradas baixas, mostrando que as PLOT PS-DVB apresentaram uma alta permeabilidade, o que consistiu na principal vantagem dessas colunas. Os gráficos de Van Demter e Knox, Figura 50, apresentaram uma tendência mais linear, sendo que o ponto mínimo do gráfico para a coluna de PS-DVB de $50 \mu \mathrm{m}$ de d.i. foi menor do que o da coluna de $25 \mu \mathrm{m}$ de d.i. Isso indica que, operando nas condições ideais de fluxo, a coluna de $50 \mu \mathrm{m}$ de d.i. apresentou um melhor desempenho.
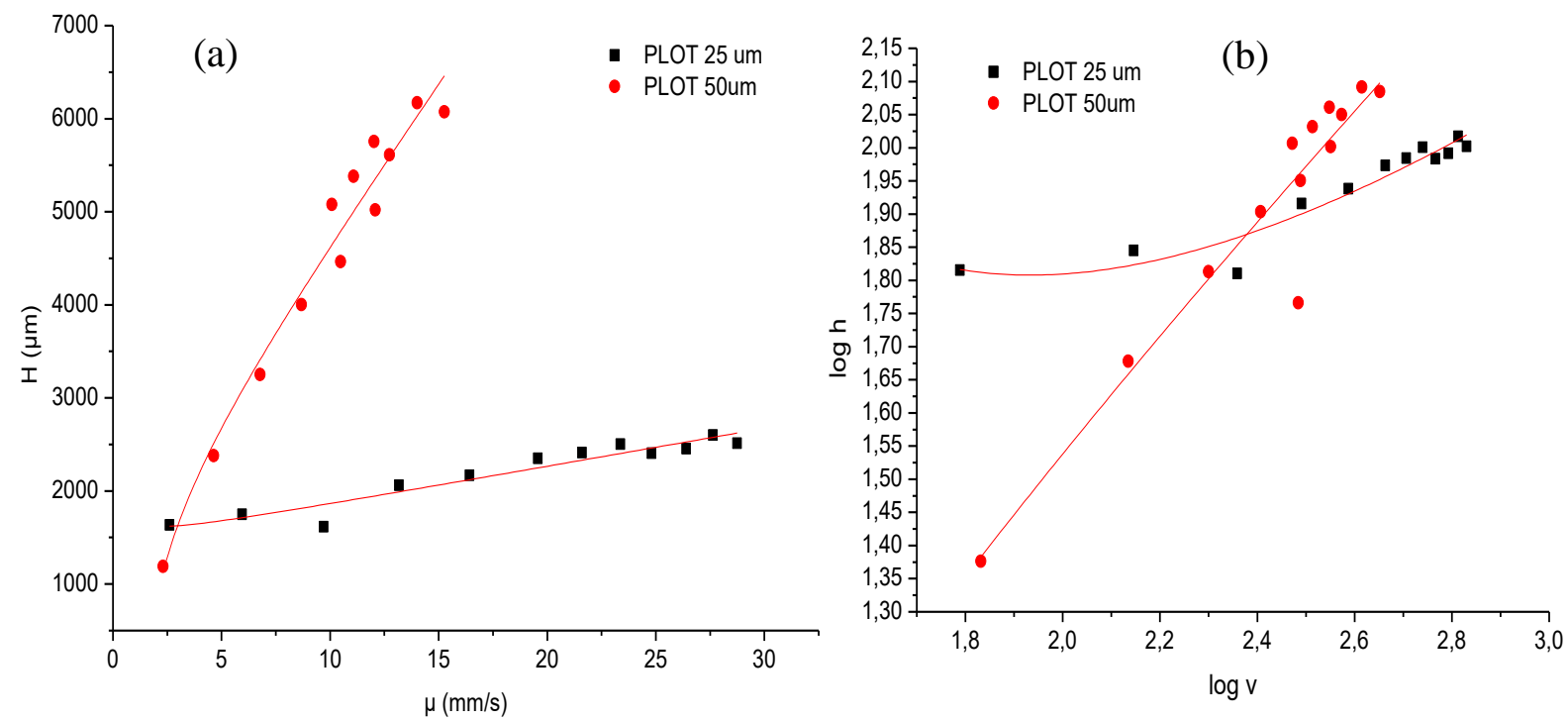

Figura 49 - Gráfico de Van Deemter (a) e Knox (log h x $\log$ v) (b) para as colunas OT-PSDVB de 50 e $25 \mu \mathrm{m}$ de d.i.

Tal fato pode estar relacionado à F.E, pois são vários os fatores que interferem na síntese do polímero. Durante os experimentos, notou-se que as colunas com d.i. maiores apresentaram uma polimerização mais crítica, no que se refere ao formato da F.E dentro do tubo, pois, dentre as várias colunas sintetizadas, as imagens de MEV, aparentemente, mostraram espessuras diferentes da F.E para um mesmo tempo de polimerização. Por outro lado, nas colunas com 25 $\mu \mathrm{m}$ de d.i. a espessura da F.E pareceu não mudar, considerando outras colunas sintetizadas e considerando os tempos de polimerização acima de 7 horas.

Não foi possível medir a espessuras das F.E, pois, pelas imagens de MEV obtidas, não foi possível distinguir a interface F.E/tubo de sílica, com exatidão. Mas, pela observação das imagens, foi possível notar que para algumas colunas a espessura da F.E variou, sendo esse um ponto importante para ser melhor estudado visando obter maior eficiência das colunas tubulares abertas. 


\subsubsection{Avaliação das colunas OT-ODS-PEG}

Na síntese das colunas OT-ODS tentou-se reproduzir ao máximo as condições de polimerização empregadas por Vehus et $\mathrm{al}^{77}$. Assim, foi utilizado um forno com temperatura controlada e o tempo total de polimerização de 87 horas foi seguido à risca. A síntese da F.E foi avaliada em tubos de 25 e $10 \mu \mathrm{m}$ de diâmetro interno e comprimentos de 5 e 1 metro. A Figura 51 apresenta algumas das imagens obtidas por MEV para estes tubos.
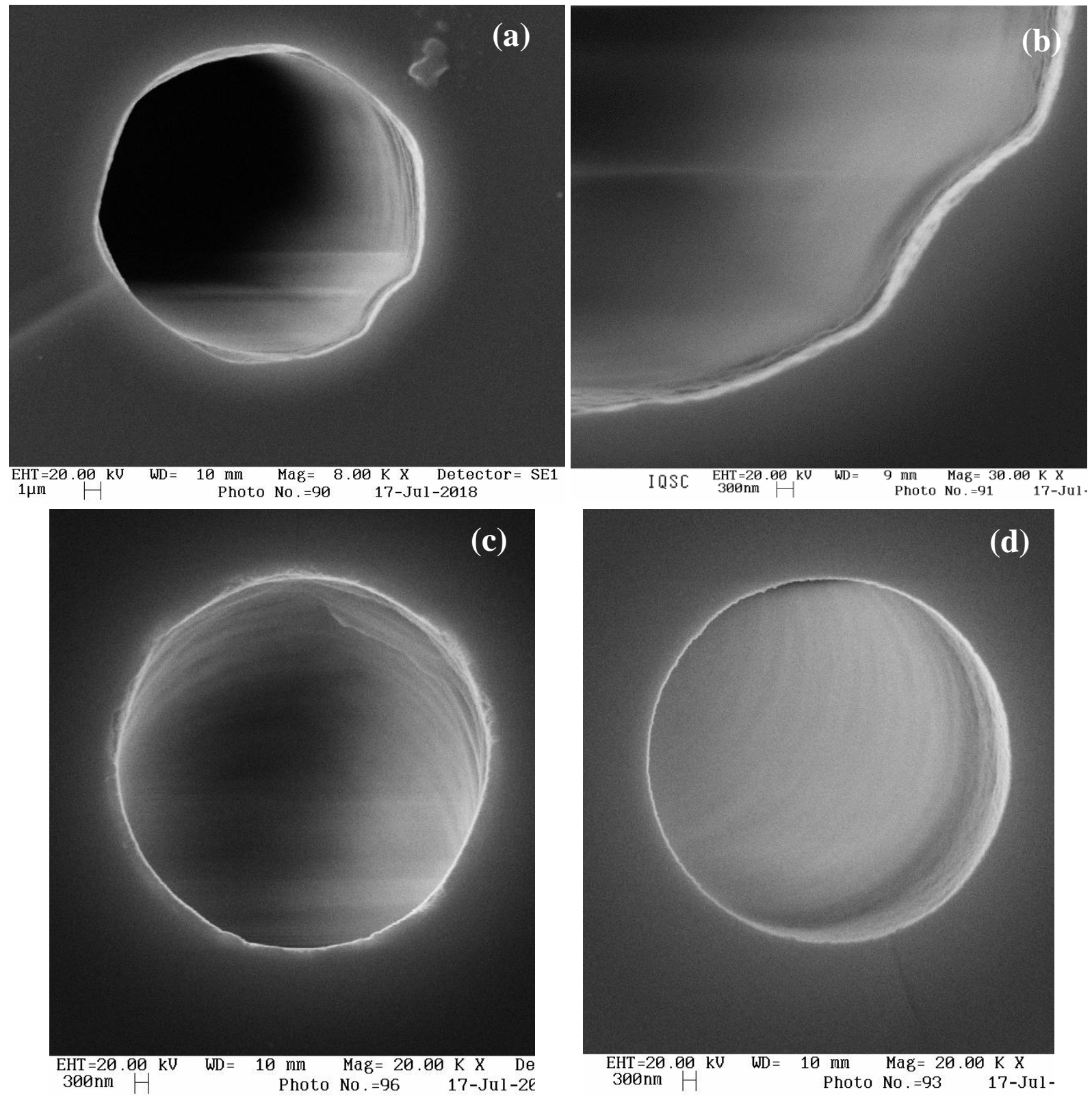

Figura 50 - Imagens de microscopia eletrônica de varredura (MEV) das colunas OT-ODS (a) ODS de $25 \mu \mathrm{m}$ d.i. (b) ODS de $25 \mu \mathrm{m}$ d.i. detalhada (c) e (d) ODS de $10 \mu \mathrm{m}$ de d.i. 
Foi possível observar a formação de F.E em todos os tubos avaliados. No tubo de $25 \mu \mathrm{m}$ de diâmetro interno observou-se que, após a síntese da F.E, a coluna apresentou ondulações na parede interna do tubo, o que mostra que, em algumas partes do tubo, a espessura da fase estacionária foi maior do que em outras partes. Já nos tubos de $10 \mu \mathrm{m}$ de d.i. a distribuição da F.E se apresentou mais uniforme; tais resultados mostraram o sucesso da síntese das colunas OT-ODS.

Um dos principais inconvenientes da síntese destas colunas foi o pré-tratamento com hidróxido de sódio $1 \mathrm{~mol} / \mathrm{L}$, que deixou os tubos de sílica mais frágeis e com menos resistência mecânica, principalmente os tubos de $25 \mu \mathrm{m}$ de d.i. que possuem uma menor camada de sílica fundida. Outro fator que pode ter contribuído para diminuição da resistência mecânica dos tubos foram os cortes realizados para se obter os tamanhos desejados, pois, dependendo da forma que são cortados, podem entrar pequenas fagulhas de vidro dentro do tubo e, ao passar o solvente, essas fagulhas podem ser arrastadas ao longo do tubo provocando algumas fissuras, que os tornam mais susceptíveis à quebra.

Devido ao diâmetro interno do tubo de $10 \mu \mathrm{m}$ ser muito pequeno, não foi possível avaliar o desempenho da coluna sintetizada, pois demanda equipamento que opere na escala nano, o que não tínhamos disponível em nosso laboratório à época. Já a coluna OT-ODS de $25 \mu \mathrm{m}$ de d.i., devido à maior fragilidade apresentada, acabou quebrando ao ser manuseada e apenas 2 metros restantes foram usados para análise cromatográfica.

A separação dos compostos de alquilbenzeno, apresentada na Figura 52, foi realizada empregando $40 \%$ de $\mathrm{ACN}$ e $60 \%$ de $\mathrm{H}_{2} \mathrm{O}$ como F.M a uma vazão de $2 \mu \mathrm{L} / \mathrm{min}$. A concentração da solução dos padrões analíticos foi de $0,14 \mu \mathrm{L} / \mathrm{mL}$. Foi possível observar que a coluna foi capaz de separar os compostos de alquilbenzeno, mas com formação de calda em todos os picos. O cromatograma também revela uma boa intensidade dos picos, provavelmente, devido ao comprimento da coluna ter sido pequeno, o que pode ter resultado no alargamento da banda dos compostos.

Mesmo não tendo conseguido uma boa separação com a coluna OT-ODS, os resultados obtidos indicam a possibilidade de se conseguir boas separações com boas eficiências em cromatografia líquida capilar, através da variação de algumas características da coluna, tais como, o comprimento e o diâmetro interno. 


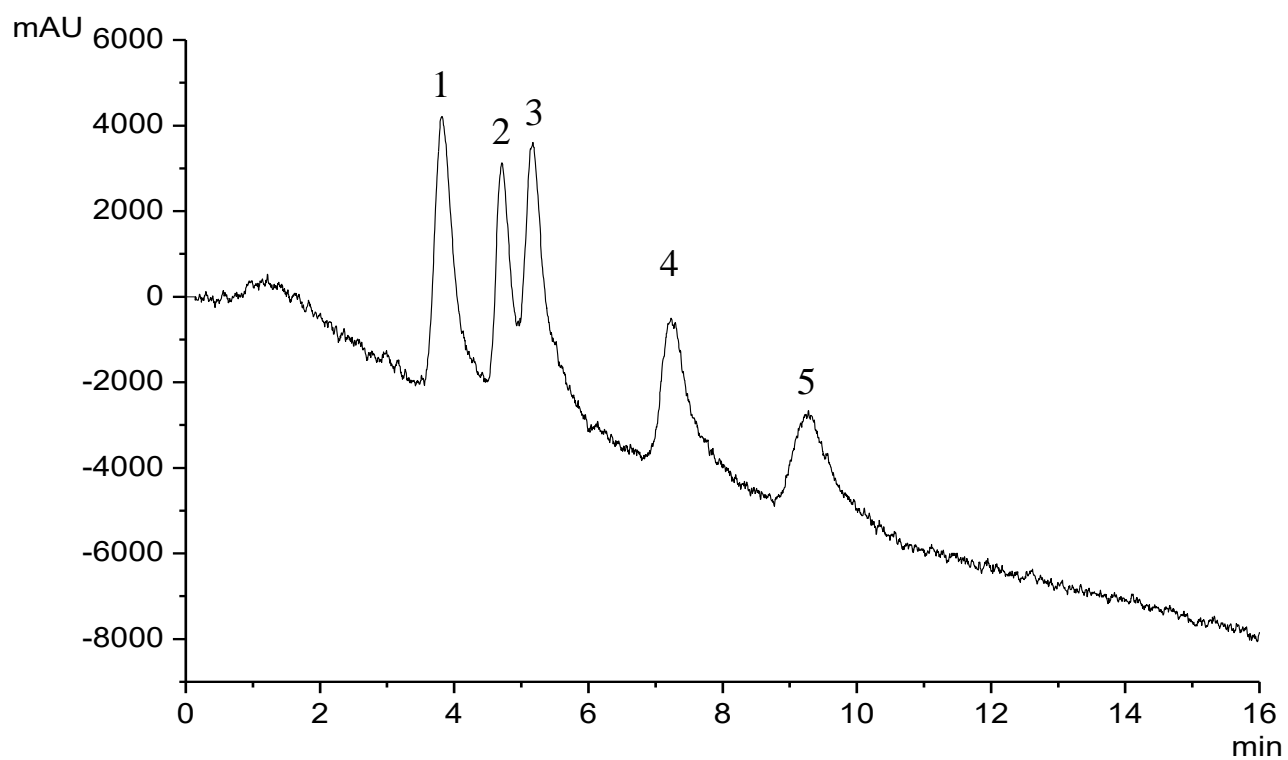

Figura 51 - Cromatogramas da separação de uma mistura de alquilbenzenos empregando a coluna OT-ODS de $25 \mu \mathrm{m}$ d.i. e 2 metros de comprimento. Ordem de eluição: uracila, tolueno, etilbenzeno, butilbenzeno e propilbenzeno 


\subsection{CONCLUSÕES DO CAPÍTULO}

$\checkmark$ Colunas tubulares abertas do tipo WCOT e PLOT, com diâmetros internos de 100 a 25 $\mu \mathrm{m}$, para aplicação em cromatografia líquida capilar foram produzidas com sucesso;

$\checkmark \quad$ Os estudos de desempenho realizados com as colunas OT, mostraram inadequabilidade das colunas de 75 e $100 \mu \mathrm{m}$ de d.i. para cLC. As colunas de 50 e $25 \mu \mathrm{m}$ de d.i., embora não tenham apresentado eficiência elevada, foram capazes de realizar a separação da mistura de alquilbenzenos com bons tempos de separação e com menor alargamento de banda;

As colunas WCOT, OT-PS-DVB e OT-ODS apresentaram-se como uma boa alternativa para aplicação em cromatografia líquida, mas otimizações nas características das colunas, especialmente na diminuição do diâmetro interno, ainda devem ser feitas para total adequabilidade dessas colunas a cLC e nLC;

$\checkmark \quad$ A alta permeabilidade apresentada pelas colunas OT garantem que os diâmetros internos das colunas podem ser diminuídos, provavelmente, assegurando a compatibilidade da contrapressão das colunas com a pressão suportada pelo equipamento;

$\checkmark \quad$ É de suma importância ressaltar que um volume muito grande de testes foi realizado empregando as colunas OT nos cromatógrafos líquido capilar com um consumo muito pequeno de solvente, já que microfluxos foram empregados, estando de acordo com os preceitos da química verde. 
Oapitula 4. OProgramasãa

de Temperatura em e@6 


\section{CAPÍTULO 4: Programação de Temperatura em cLC}

A programação de temperatura, do inglês "temperature programming" (TP) em cromatografia líquida só se tornou viável devido à miniaturização da técnica, pois com as colunas capilares o efeito do gradiente radial de temperatura, comum em colunas com diâmetro interno maior, é minimizado ou até desprezível. Isso porque em HPLC tradicional o gradiente é formado principalmente pelo alto fluxo de fase móvel, pelo diâmetro interno relativamente grande da coluna e a sua alta capacidade térmica, fatores estes contrários às características das colunas capilares.

As colunas de sílica fundida capilares permitem que variações de temperatura sejam aplicadas com uma distribuição de calor rápida e uniforme. Em função disso, nessa parte do trabalho será avaliado o emprego de programação de temperatura em cromatografia líquida capilar utilizando tanto microcolunas empacotadas quanto tubulares abertas do tipo WCOT e PLOT.

\subsection{PARTE EXPERIMENTAL}

\subsubsection{Materiais e reagentes}

Para estudo da aplicação de programação de temperatura foram utilizados padrões analíticos de sulfonamidas: sulfatiazol, sulfacetamida, sulfametizol, sulfamerazina, sulfadiazina, sulfametazina, sulfacloropiridazina, sulfametoxazol, fulfametoxina, e sulfaquinoxalina) grau UPS, adquiridos da USP. Os padrões de parabenos: metilparabeno, propilparabeno e butilparabeno foram adquiridos da Fluka e os padrões de etilparabeno e benzilparabeno foram fornecidos pela Sigma Aldrich. Os padrões de PAH's: naftaleno, acenaftileno, acenafteno, fluoreno, fenantreno, antraceno, criseno e dibenzo (a,h) antraceno foram disponibilizados pela Sulpeco. Já os padrões de alquilbenzenos (tolueno, etilbenzeno, butilbenzeno, pentilbenzeno e heptilbenzeno) foram adquiridos da Sigma Aldrich. As soluções estoques com concentração de $500 \mathrm{mg} / \mathrm{mL}$ de cada padrão foram preparadas e armazenadas a $18{ }^{\circ} \mathrm{C}$; e as soluções intermediarias foram preparadas pela diluição das soluções estoque, em concentrações que dependiam da resposta dos instrumentos de análise.

Os solventes Metanol (MeOH) e Acetonitrila (ACN), grau HPLC, foram fornecidos pela Tedia. O ácido fórmico P.A. foi adquirido da Sigma Aldrich, o ácido acético P.A e o 
tetrahidrofurano (THF 99 \%), pela J.T. Baker. O álcool isopropílico (IPA) foi disponibilizado pela Merck. Água de alta pureza foi obtida pelo sistema de purificação Milli-Q da Millipore.

\subsubsection{Instrumentação}

Para aplicação da programação de temperatura, foi empregado o sistema cromatógrafico líquido capilar desenvolvido no grupo de cromatografia. O cLC foi dotado com um forno que apresenta um sistema de isolamento térmico, para evitar a influência da temperatura externa e impedir perda de calor. O sistema de aquecimento do forno foi projetado para que a distribuição de calor fosse rápida e uniforme ao longo da coluna. Consta, também, um sistema de refrigeração e um sistema para realização de programação de temperatura, capazes de controlar rampa de temperatura, assim como gradiente isotérmico, durante uma corrida, com excelente precisão.

\subsubsection{Colunas Analíticas}

Foi utilizada uma coluna capilar C18 $(14 \mathrm{~cm}$ x $250 \mu \mathrm{m}$ x 3,5 $\mu \mathrm{m})$ confeccionada no laboratório, com a técnica de partícula em suspenção. Foi preparada uma suspenção com $16 \mathrm{mg}$ de F.E C18, com 3,5 $\mu \mathrm{m}$ de diâmetro (Cromatorex) e $0,7 \mathrm{~mL}$ da solução THF/IPA (1:6 v/v), sendo posteriormente agitada, transferida para a coluna de empacotamento e acoplada ao sistema de bombeamento Shimadzu. O bombeamento de $\mathrm{MeOH}$ foi iniciado a uma pressão de 200 bar e permaneceu por uma hora ligado. Passado esse tempo, a bomba foi desligada e a coluna foi removida, depois de decorrida mais $1 \mathrm{~h}$, para garantir total despressurização do sistema de empacotamento.

A coluna foi então lavada com $\mathrm{H}_{2} \mathrm{O}$ e $\mathrm{ACN}$, por 30 min cada. Finalmente, foi acoplada ao sistema cromatográfico, onde foi condicionada pela passagem de F.M. ACN/ $\mathrm{H}_{2} \mathrm{O}$ (70:30 v/v) por, no mínimo, 2 horas.

Também foram empregadas as colunas OTLC-4, descrita na seção 3.2-Capítulo 3, e a tubular abular totalmente porosa OT-PS-DVB, de $25 \mu \mathrm{m}$ de diâmetro interno. 


\subsection{RESULTADOS E DISCUSSÃO}

\subsubsection{Efeitos da programação de temperatura nas colunas empacotadas}

Para avaliação da utilização da programação de temperatura, foram realizadas separações testes de uma mistura de padrões de PAHs, sulfonamidas e parabenos, empregando a coluna capilar empacotada C18 $(14 \mathrm{~cm} \times 250 \mu \mathrm{m} \times 3,5 \mu \mathrm{m})$. A rampa de temperatura para determinada de cada classe de composto foi selecionada após realizar injeções dos analitos em diferentes temperaturas. Isso também foi importante para a escolha da temperatura que foi empregada em modo isotermico, sendo escolhida aquela que resultou em uma melhor separação

O cromatógrafo liquido capilar empregado nessa parte do trabalho só opera em modo isocrático, desta forma, a separação dos compostos de $\mathrm{PAH}$ 's foi empregado $\mathrm{ACN} / \mathrm{H}_{2} \mathrm{O}$ na proporção 70:30 v/v como F.M. Um fluxo de $5 \mu \mathrm{L} / \mathrm{min}$ foi utilizado, o comprimento de onda fixado em $254 \mathrm{~nm}$ e a concentração dos analitos foi de $50 \mathrm{mg} / \mathrm{mL}$. A Figura 53 apresenta os cromatogramas da separação dos 8 PAH's em modo isotérmico e com gradiente de temperatura.

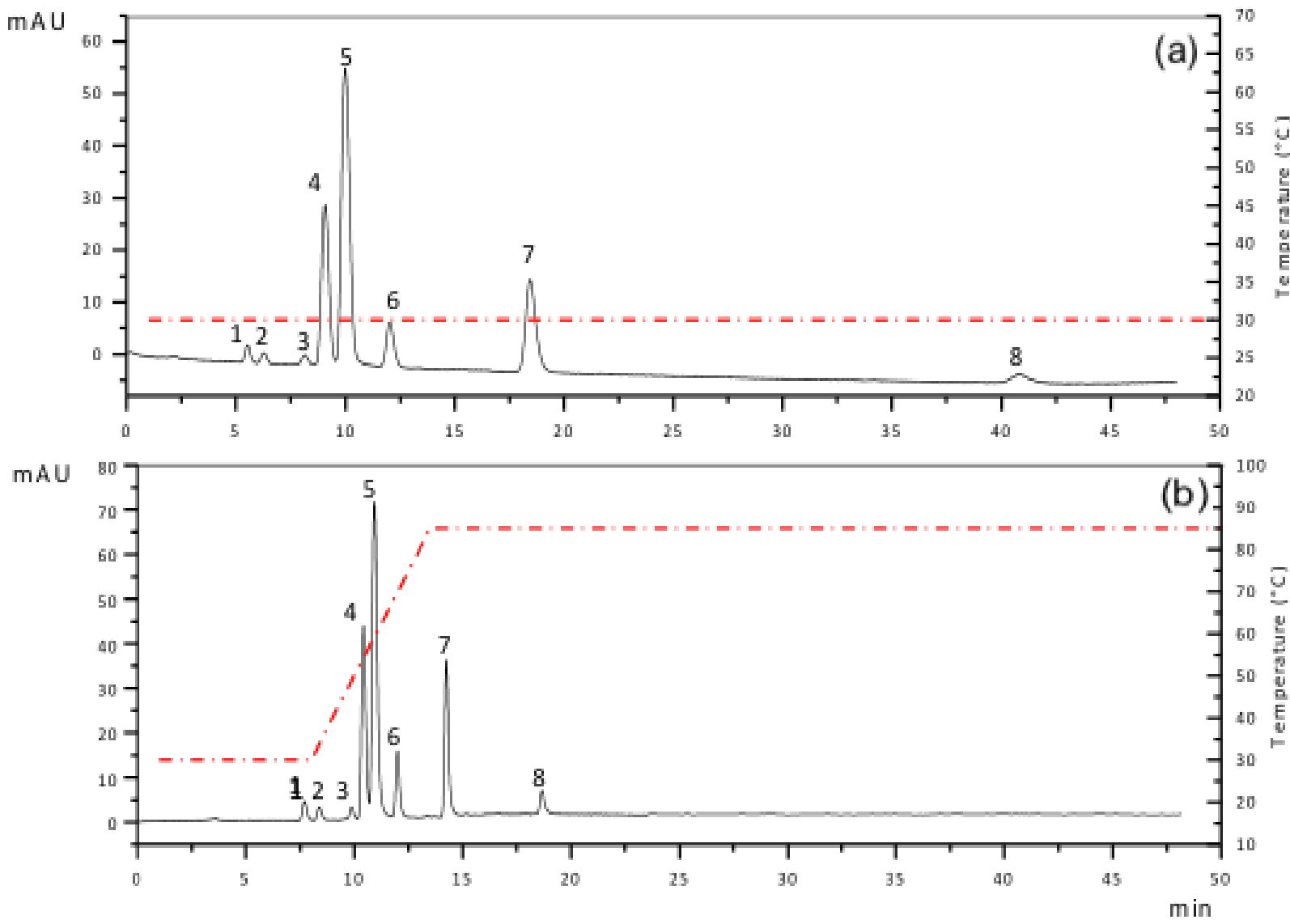

Figura 52 - Separação de PAHs em coluna capilare empacotada C18 (14 cm x $250 \mu \mathrm{m}$ x $3,5 \mu \mathrm{m}$ ) (a) sem programação de temperatura e (b) com programação de temperatura. Naftaleno (1), acenaftileno (2), acenafteno (3), fluoreno (4), fenantreno (5), antraceno (6), crisen 
A parte (a) da Figura 53 mostra a separação dos analítos realizada em temperatura fixa de $30{ }^{\circ} \mathrm{C}$, e a parte (b), a separação realizada com gradiente de temperatura, que variou de 30 ${ }^{\circ} \mathrm{C}$ a $85^{\circ} \mathrm{C}$. A partir da visualização dos cromatogramas ficou nítida a diferença da separação dos compostos em modo isotérmico e com a aplicação de TP. No primeiro caso, o tempo de retenção dos compostos foram muito maiores e a intensidade dos picos foi menor.

Para melhor entendimento dos efeitos da programação de temperatura no desempenho das colunas, foram calculados os parâmetros cromatográficos das separações dos PAH's, realizadas em modo isotérmico e com TP. Os dados obtidos estão apresentados na Tabela 22.

\begin{tabular}{|c|c|c|}
\hline Parâmetros & Isotérmica & $\begin{array}{l}\text { Programação de } \\
\text { temperatura }\end{array}$ \\
\hline $\mathrm{t}_{\mathrm{M} \text { naftaleno }}(\mathrm{min})$ & 5,55 & 7,70 \\
\hline$t_{R}$ acenaftileno $(\min )$ & 6,26 & 8,37 \\
\hline $\mathrm{t}_{\mathrm{R}}$ acenafteno $(\min )$ & 8,16 & 9,88 \\
\hline$t_{R}$ fluoreno $(\min )$ & 9,06 & 10,42 \\
\hline$t_{R}$ fenantreno $(\min )$ & 9,97 & 10,93 \\
\hline $\mathrm{t}_{\mathrm{R}}$ antraceno & 12,02 & 11,98 \\
\hline$t_{R}$ criseno & 18,43 & 14,25 \\
\hline$t_{R}$ dibenzo (a,h) antraceno & 40,76 & 18,67 \\
\hline$w_{b}(50 \%)$ fenantreno $(\mathrm{min})$ & 0,817 & 0,20 \\
\hline $\mathrm{N}$ & 14439 & 48554 \\
\hline $\mathrm{N} / \mathrm{m}$ & 103136 & 346813 \\
\hline $\mathrm{H}(\mu \mathrm{m})$ & 9,70 & 2,88 \\
\hline $\mathrm{R}$ & 1,59 & 1,56 \\
\hline$\alpha$ & 1,35 & 1,25 \\
\hline $\mathrm{k}$ & 13,56 & 5,67 \\
\hline $\mathrm{v}$ & 1,42 & 2,82 \\
\hline h & 2,82 & 0,82 \\
\hline$\varnothing$ & 1785 & 1488 \\
\hline $\mathrm{E}$ & 13700 & 1010 \\
\hline$\Delta \mathrm{P}($ bar $)$ & 120 & 100 \\
\hline
\end{tabular}

Tabela 22 - Parâmetros extraídos dos cromatogramas da Figura 53, onde foram realizadas separações no modo isotérmico e com programação de temperatura 
Para efeitos comparativos, os parâmetros N, N/m, H, k, h e E foram calculados com base no último pico retido (dibenzo $(\mathrm{a}, \mathrm{h})$ antraceno) e os parâmetros Rs e $\alpha$ foram calculados considerando o pico do acenafteno e fluoreno. Os $t_{R}$ dos analitos mostraram que nas duas condições foi possível separar todos os compostos, no entanto, com um tempo total de análise muito maior no modo isotérmico. $\mathrm{O} \mathrm{t}_{\mathrm{R}}$ do último pico eluido apresentou uma redução de, aproximadamente, 22 min com relação ao mesmo pico no modo isotérmico. Isso corresponde à diminuição pela metade do tempo de análise.

Comparando a eficiência, foi observado um aumento de cerca de 34 mil pratos teóricos, quando empregada a programação de temperatura. Já para a eficiência por metro, o aumento foi de aproximadamente 243 mil. Desta forma, houve um acréscimo de mais de três vezes na eficiência da coluna, quando empregada TP.

A variação da temperatura afetou os parâmetros $\mathrm{k}$ e $\alpha$, uma vez que foi observado uma diminuição dos valores destes parametros ao fazer uso do gradiente de temperatura.

A altura equivalente a um prato teórico apresentou excelentes valores nos dois casos, sendo que, com o gradiente de temperatura o valor de $\mathrm{H}$ foi ainda melhor, alcançando um valor muito baixo $(2,88)$. Esta redução ocorre também para o h $(2,82$ no caso isotérmico e 0,82 com programação de temperatura. Com ocorreu uma redução nos tempos de retenções, era esperada uma diminuição da resolução. Assim, para os compostos homólogos acenafteno e fluoreno, foi possível observar que a redução da resolução (de 1,59 a 1,56), foi praticamente desprezível pois manteve-se quase igual nas duas separações. Isso consta como um fator positivo para o emprego de TP em cLC, pois a diminuição do tempo de análise ocorre com uma perda mínima de resolução.

Através dos parâmetros reduzidos, também foi possível verificar a influência da temperatura no desempenho da coluna. O tempo de retenção diminuiu com a elevação da temperatura, consequentemente, aumentou a velocidade linear reduzida (v). Também foi observada uma drástica redução do valor de h, que variou de 2,82 a 0,82 com a aplicação de TP. A temperatura também exerce influência na pressão, por isso foi observada uma diminuição de 20 bar na contrapressão da coluna, o que afeta diretamente a resistência ao fluxo (Ø) e a impedância de separação (E). Assim, uma redução com um valor igual a 291 foi observada para o parâmetro Ø, enquanto para o parâmetro E a redução foi de 12.690, o que consiste em um excelente valor para colunas capilares empacotadas. 
Os resultados dos parâmetros reduzidos mostraram que a coluna apresentou um alto desempenho, no entanto, com o emprego da programação de temperatura foi possível atingir um desempenho ainda melhor.

Ainda para observar os efeitos da programação de temperatura, no desempenho das separações cromatográficas, foram realizadas separações empregando uma mistura de 10 compostos pertencente a classe dos antibióticos sulfonamidas, e separações de uma mistura contendo 5 compostos da classe dos parabenos, Figuras 54 e figura 55, respectivamente.

Para separação da mistura de sulfonamidas foi empregada uma concentração de $5 \mathrm{mg} / \mathrm{L}$ dos compostos. Foi empregada uma F.E acidificada com $1 \%$ de ácido fórmico, composta por $15 \%$ de $\mathrm{ACN}$ e $85 \%$ de $\mathrm{H}_{2} \mathrm{O}$ e um fluxo de $7 \mu \mathrm{L} / \mathrm{min}$. O comprimento de onda foi de $270 \mathrm{~nm}$, e a temperatura da coluna em modo isotérmico foi de $40{ }^{\circ} \mathrm{C}$. No gradiente de temperatura o primeiro minuto foi mantido em $40{ }^{\circ} \mathrm{C}$; de 1 a 3 minutos a temperatura foi elevada para $60{ }^{\circ} \mathrm{C}$, com uma rampa de $10{ }^{\circ} \mathrm{C} / \mathrm{min}$; de 8 a $11 \mathrm{~min}$ a temperatura foi elevada para $90^{\circ}$ a uma rampa de $10{ }^{\circ} \mathrm{C} / \mathrm{min}$; e de 16 a 18 min a temperatura foi elevada para $120{ }^{\circ} \mathrm{C}$, permanecendo neste patamar até o final da corrida.

Para a realização da separação dos parabenos foi empregado $\mathrm{MeOH}: \mathrm{H}_{2} \mathrm{O}$ como F.M na proporção 60:40 (v/v) e um fluxo de $5 \mu \mathrm{L} / \mathrm{min}$. O comprimento de onda foi fixado em $254 \mathrm{~nm}$, a concentração dos padrões analíticos foi de $50 \mathrm{mg} / \mathrm{mL}$. A temperatura da coluna em modo isotérmico foi mantida em $40{ }^{\circ} \mathrm{C}$. No gradiente de temperatura a coluna nos 3 primeiros minutos foi mantida a $40^{\circ} \mathrm{C}$, de 3 a 8 min a temperatura foi elevada a $70{ }^{\circ} \mathrm{C}$ com uma rampa de 6 ${ }^{\circ} \mathrm{C} / \mathrm{min}$, e de 8 a $10 \mathrm{~min}$ foi elevada a $80{ }^{\circ} \mathrm{C}$ com uma rampa de $5{ }^{\circ} \mathrm{C} / \mathrm{min}$, permanecendo nesta temperatura até o final da corrida cromatográfica.

Pela observação dos cromatogramas 54 e 55, foi possível notar que mesmo utilizando uma mistura mais complexa como as sulfonamidas, a coluna apresentou um desempenho suficiente para realizar a separação dos compostos; no entanto, ao empregar uma temperatura fixa, não foi possível observar os picos dos dois últimos compostos eluidos (sulfadimetoxina e sulfaquinoxalina).

Quando empregada a programação de temperatura, observou-se que, além do cromatograma ter apresentado os picos dos 10 compostos eluídos, este também apresentou uma redução do tempo total de análise, pela metade do observado em condição isotérmica. Isso considerando o tempo de retenção do último pico observável do cromatograma (a)-Figura 54.

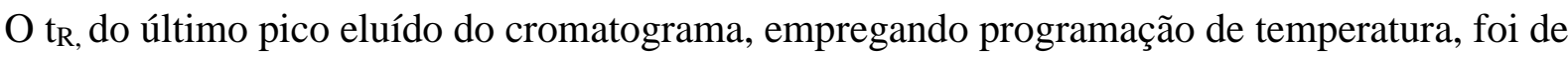
40,27 minutos. 

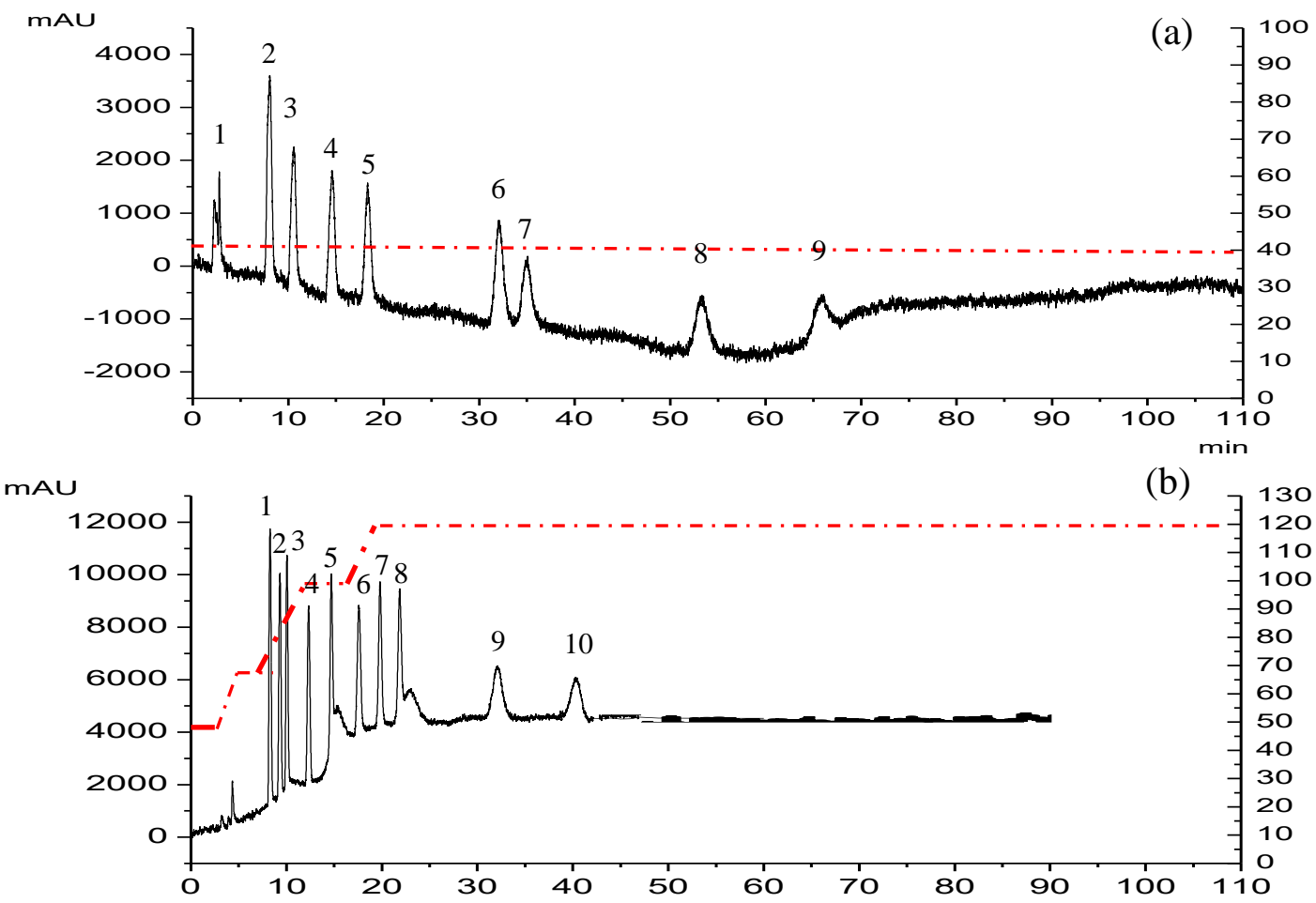

Figura 53 - Separação de sulfonamidas em coluna capilare empacotada C18 (14 $\tilde{\mathrm{cm} x}$ $250 \mu \mathrm{m} \times 3,5 \mu \mathrm{m}$ ), (a) sem programação de temperatura e (b) com programação de temperatura. (1) Sulfatiazol, (2) sulfacetamida, (3) sulfametizol, (4) sulfamerazina, (5) sulfadiazina (6) sulfametazina, (7) sulfacloropiridazina, (8) sulfametazol, (9)

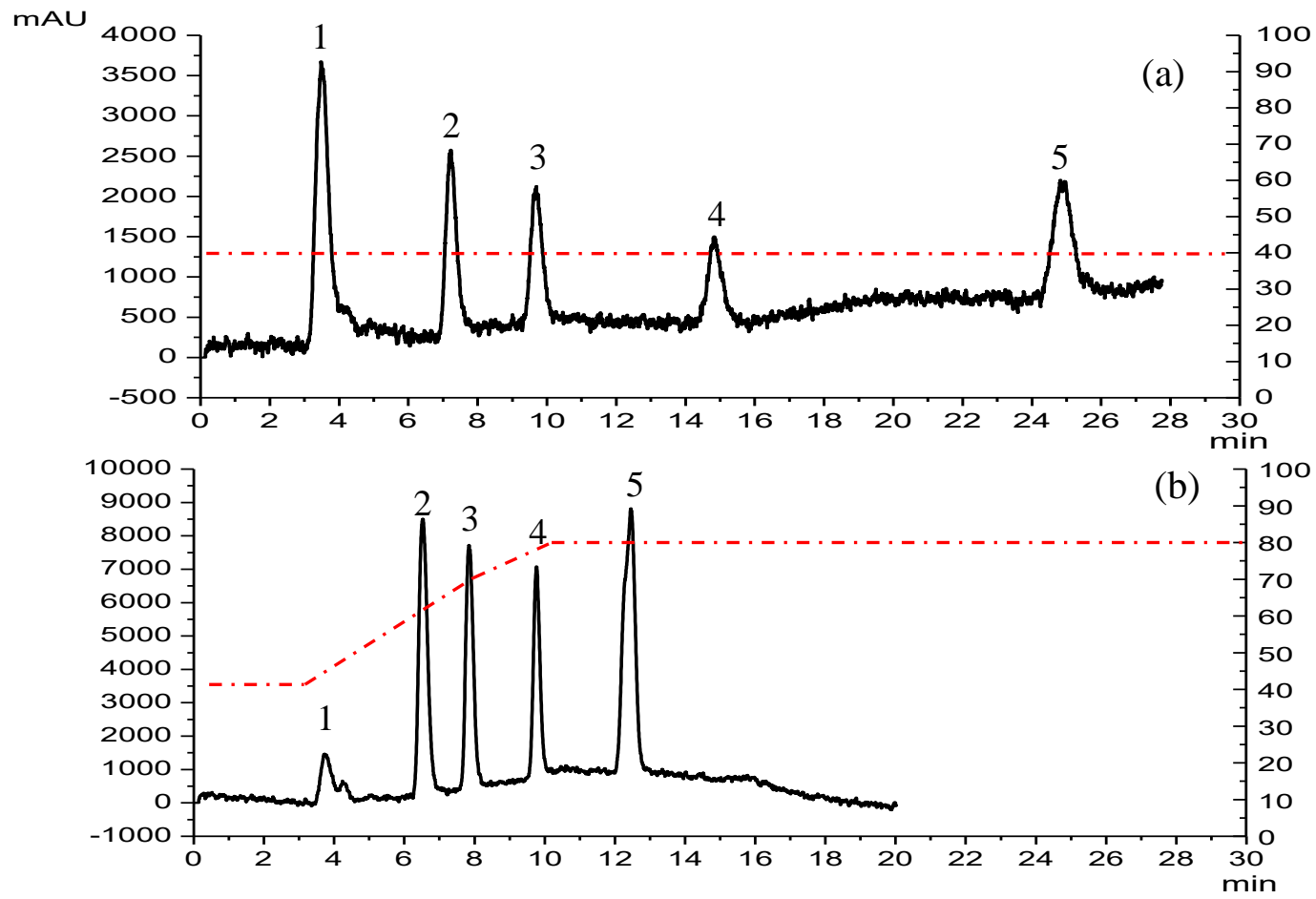

Figura 54 - Separação dos compostos de parabeno em coluna capilare empacotada C18 (14 cm x $250 \mu \mathrm{m} \times 3,5 \mu \mathrm{m}$ ), (a) sem programação de temperatura e (b) com programação de temperatura. (1) metilparabeno, (2) propilparabeno, (3) butilparabeno, (4) etilparabeno, e (5) benzilparabeno 
Na Figura 55 também foi possível observar a influência da utilização de programação de temperatura na separação dos compostos de parabenos. Novamente a utilização da PT resultou em uma redução do tempo de análise em 2,3 vezes, quando comparada à mesma análise sem programação de temperatura.

$\mathrm{Na}$ separação das duas classes de compostos, também foi possível perceber que as intensidades dos picos praticamente triplicaram quando empregada a programação de temperatura. Somente o pico do metilparabeno apresentou uma redução da intensidade, que pode estar relacionada a sensibilidade deste analito a temperaturas maiores que $40^{\circ} \mathrm{C}$.

A demonstração da aplicação de programação de temperatura também foi realizada em colunas tubulares abertas do tipo WCOT e PLOT. Para isso, foi empregada a coluna WCOT OTLC-4 de $50 \mu \mathrm{m}$ de d.i. e a coluna polimérica OT- PS-DVB de $25 \mu \mathrm{m}$ de d.i. Foi utilizada uma mistura contendo cinco alquilbenzenos mais a uracila (marcador de tempo morto).

Nas separações realizadas na coluna WCOT (Figura 56) foi empregada $\mathrm{ACN} / \mathrm{H}_{2} \mathrm{O}$ 60:40 (v/v) com F.M a uma taxa de fluxo de $5 \mu \mathrm{L} / \mathrm{min}$. A concentração dos padrões analíticos foi de $1,4 \mu \mathrm{L} / \mathrm{mL}$, e $\lambda=210 \mathrm{~nm}$. Na separação em modo isotérmico [Figura 56 (a)] a temperatura da coluna foi mantida em $30^{\circ} \mathrm{C}$. Já realizando $\mathrm{TP}$ o forno foi programado para elevar a temperatura de 30 a $100{ }^{\circ} \mathrm{C}$ em $14 \mathrm{~min}$, com uma rampa de $5{ }^{\circ} \mathrm{C} / \mathrm{min}$.

Quando empregada a coluna PLOT, foi utilizado $\mathrm{ACN} / \mathrm{H}_{2} \mathrm{O}(40: 60$ v/v) com F.M com fluxo de $3 \mu \mathrm{L} / \mathrm{min}$. A concentração dos padrões analíticos foi de $0,14 \mu \mathrm{L} / \mathrm{mL}$ e $\lambda=210 \mathrm{~nm}$. A separação em modo isotérmico foi realizada a $30{ }^{\circ} \mathrm{C}$. Já empregando $\mathrm{TP}$, a temperatura da coluna foi mantida em $30{ }^{\circ} \mathrm{C}$, e então foi elevada a $80{ }^{\circ} \mathrm{C}$ durante os 10 primeiros minutos de corrida com rapa de $5{ }^{\circ} \mathrm{C} / \mathrm{min}$. Os cromatogramas com a separação dos alquilbenzenos em coluna PLOT em modo isotérmico e com TP são apresentados na Figura 57.

As Figuras 56 e 57 mostraram que a programação de temperatura utilizando as colunas tubulares abertas foi empregada com sucesso, uma vez que foi nítida a redução do tempo de análise para as duas colunas. As intensidades dos picos, de um modo geral, melhoraram com a programação de temperatura; no entanto, o aumento da intensidade foi muito menor que os obtidos com as colunas empacotadas. 


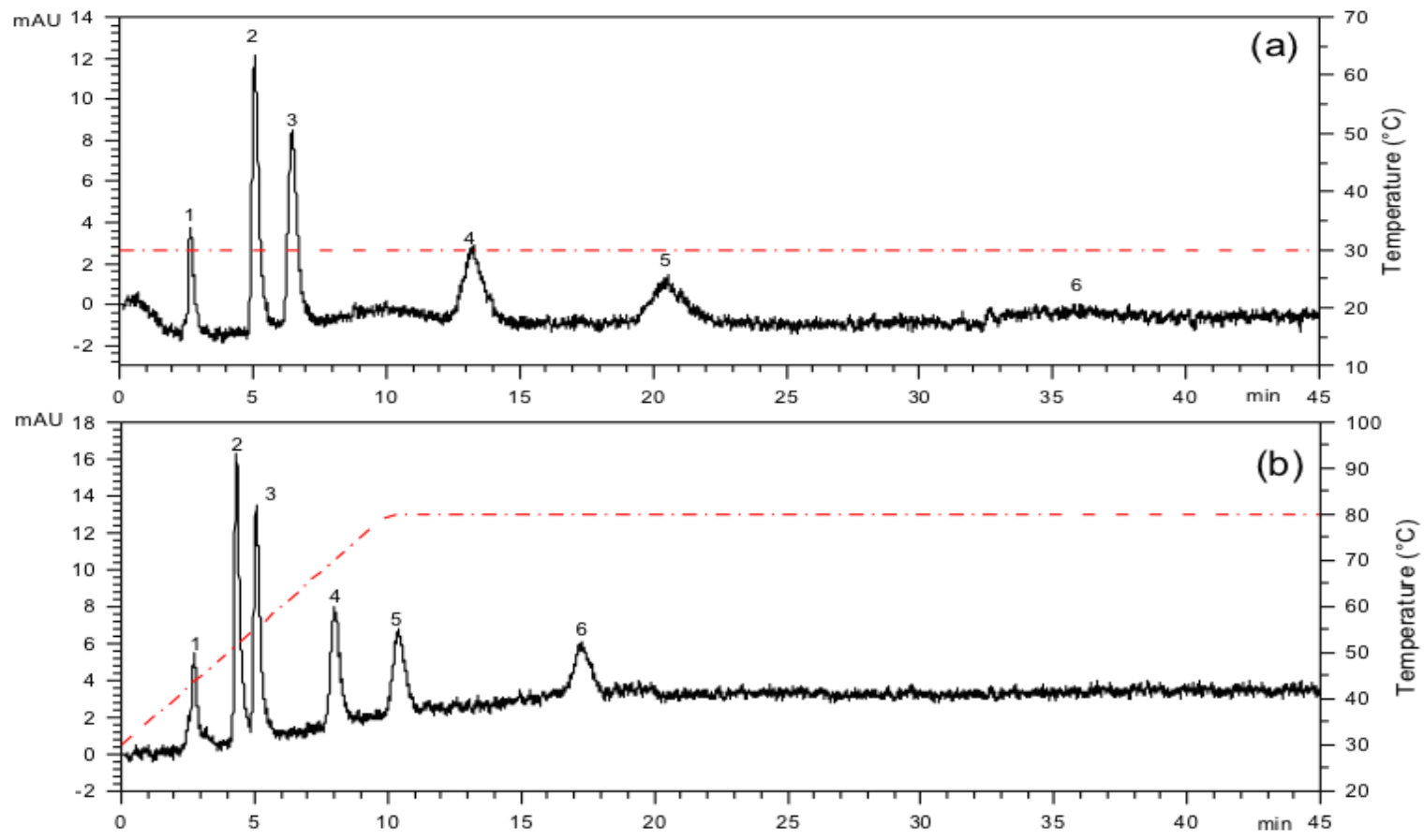

Figura 55 - Separação dos compostos de Alquibenzeno utilizando coluna WCOT (5 m x 50 $\mu \mathrm{m}$ de d.i.) (a) sem programação de temperatura e (b) com programação de temperatura. Uracila (1), tolueno (2), etilbenzeno (3), butilbenzeno (4), pentilbenzeno e (5) heptilbenzeno
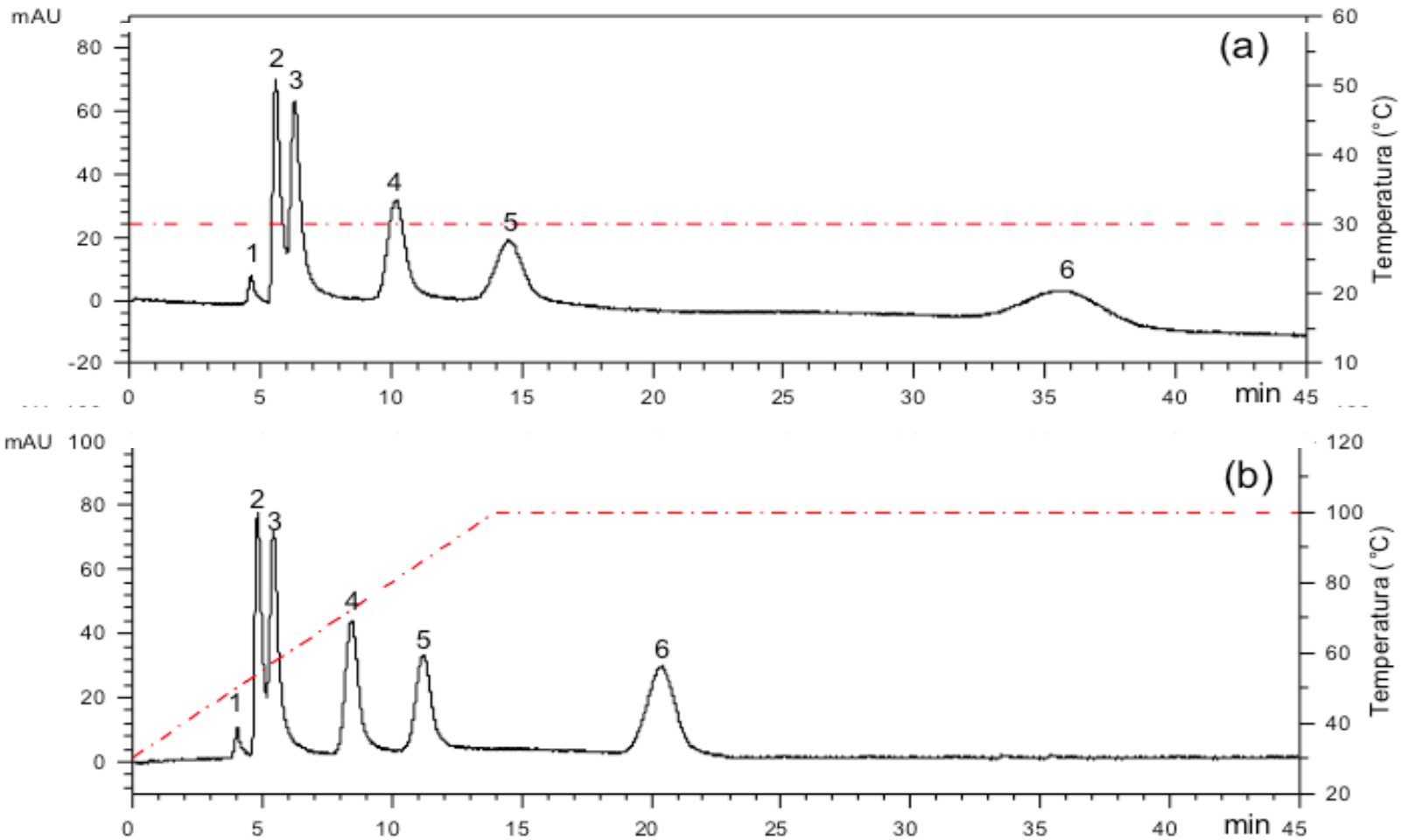

Figura 56 - Separação dos compostos de Alquibenzeno utilizando coluna PLOT (5 m x 50 $\mu \mathrm{m}$ de d.i.) (a) sem programação de temperatura e (b) com programação de temperatura. Uracila (1), tolueno (2), etilbenzeno (3), butilbenzeno (4), pentilbenzeno e (5) heptilbenzeno 
Empregando a coluna WCOT em modo isotérmico, não foi possível visualizar a forma do último pico eluído, mas com a TP a forma de todos os picos dos 6 padrões analíticos de alquilbenzenos foram bem observados. A redução do $t_{R}$ dos analitos foi acompanhada também pela redução da largura dos picos, de tal forma que a eficiência da coluna WCOT (considerando o pico do heptilbenzeno) foi elevada de 972 pratos teóricos para 2442 pratos teóricos. Ou seja, houve um aumento de 2,5 vezes na eficiência da coluna, o que mostra que a TP pode ser um forte aliada na utilização das colunas OT em cromatografia líquida.

A tendência observada nas colunas WCOT foi também observada para as colunas PLOT, ou seja, a redução do tempo de retenção dos analitos foi acompanhada pela formação de picos mais estreitos e a intensidade do o último composto eluído foi muito maior com a aplicação de programação de temperatura. Considerando o pico do pentilbenzeno, a eficiência da coluna aumentou 2 vezes com programação de temperatura, quando comparada à mesma análise em modo isotérmico.

Devido ao sucesso, aqui mostrado, da aplicação de programação de temperatura em cromatografia líquida capilar, ficou evidente que ela pode ser empregada em substituição ao gradiente de solvente, pois resultou na redução do tempo de análise e no aumento de desempenho das colunas, com simplificação significativa na instrumentação (uso de apenas uma bomba, eliminação de formato de gradiente de solvente e outros acessórios) 


\subsection{CONCLUSÕES DO CAPÍTULO}

$\checkmark \quad$ A aplicação de programação de temperatura em cromatografia líquida capilar (tanto em coluna empacotada quanto em tubular aberta) foi realizada com sucesso;

$\checkmark$ Quando empregada a coluna capilar empacotada, foi observada a redução do tempo de análise pela metade, e um aumento de 3 vezes na eficiência da coluna aplicando TP;

$\checkmark \quad$ Os efeitos positivos da aplicação de TP foram reproduzidos na separação de diferentes classes de compostos analíticos;

$\checkmark \quad$ A programação de temperatura também foi aplicada às colunas tubulares abertas, do tipo WCOT e PLOT, com sucesso, e resultou na redução do tempo de análise pela metade e no dobro da eficiência da coluna;

$\checkmark \quad$ A programação de temperatura apresentou-se como uma boa alternativa à substituição de gradiente de fase móvel; 
Tapitula 5 - Gonclusães gexais e perspectivas futuras 


\subsection{CONCLUSÕES GERAIS}

O emprego do cromatógrafo líquido capilar, neste trabalho, se mostrou uma excelente alternativa ao uso do HPLC, pois, atualmente, busca-se desenvolver pesquisas que resultem em um menor consumo de recursos naturais e preservação do meio ambiente, desta forma, a pesquisa científica tem inovado cada vez mais, a fim de atender aos apelos ambientais. Assim, a miniaturização da cromatografia líquida surgiu como um recurso que atende melhor a esta demanda, quando comparada à cromatografia líquida convencional. Uma vez que, quanto menor a quantidade de amostra necessária, menor será a quantidade de reagentes e solvente empregados no preparo dessa amostra. A quantidade de solvente empregado como fase móvel em cLC também é muito menor e, na maioria das vezes, faz-se uso de solventes tóxicos, tanto para o meio ambiente, como para quem os manipula.

Para efeitos comparativos do consumo de solvente no LC capilar, com o do LC convencional, considerando que o equipamento cLC opere oito horas por dia, a uma taxa de fluxo de $5 \mu \mathrm{L} / \mathrm{min}$ (fluxo geralmente mais empregado), o consumo diário de solvente será de 2,4 mL. Já em um HPLC operando a um fluxo de 0,2 mL/min, o consumo diário seria de 96 $\mathrm{mL}$. Em um ano (52 semanas), operando 5 dias por semana, o consumo de solvente no cLC será de apenas $624 \mathrm{~mL}$ contra 24,96 L no HPLC. Desta forma, além de gerar menos resíduos, o custo das análises no sistema miniaturizado, em termos econômicos, torna-se inferior ao do HPLC.

Também foi demostrado, neste trabalho, que colunas empacotadas e tubulares abertas podem ser produzidas em laboratório e, no caso das colunas microempacotadas, de forma relativamente simples, com grande eficiência e boa repetitividade, empregando diferentes materiais e com o custo inferior ao das colunas disponíveis comercialmente. Embora as colunas tubulares abertas do tipo PLOT e WCOT, estudadas neste trabalho, não tenham apresentado desempenho semelhante ao das colunas empacotadas e, por isso, as mesmas foram consideradas inadequadas para aplicação em cromatografia líquida, os dados coletados sugerem resultados promissores, se variarmos algumas características destas colunas, como o diâmetro interno, o comprimento e a espessura da fase estacionária. Mesmo com baixa eficiência as colunas OT mostraram-se capazes de realizar a separação dos 5 analitos testes, confirmando a usabilidade desse tipo de coluna em LC.

A programação de temperatura apresentou-se como uma forte aliada a cLC, uma vez que foi possível reduzir consideravelmente o tempo das análises seguida da elevação da eficiência, tanto em colunas empacotadas quanto em colunas tubulares abertas. 


\subsection{PERSPECTIVAS FUTURAS}

A miniaturização da cromatografia líquida capilar é um tema bastante recente e embora, nos últimos anos, o interesse da comunidade cientifica tenha aumentado com relação à cLC, muitos aspectos ainda podem ser explorados, tanto no que se refere à instrumentação quanto ao desenvolvimento de colunas capilares.

Desta forma, a metodologia proposta, neste trabalho, para confecção das colunas capilares empacotadas mostrou bons resultados e novos estudos poderão ser realizados com outros tipos de fases estacionárias. Poderão também, ser realizados estudos para o desenvolvimento de F.E.s exclusivas para colunas capilares e que apresentem uma maior uniformidade de distribuição de tamanho de partículas pois, provavelmente, resultaria em colunas com eficiências mais elevadas do que as obtidas com as colunas desenvolvidas neste trabalho.

Recomenda-se o estudo com colunas analíticas tubulares abertas do tipo PLOT e WCOT em cLC com diâmetros internos menores que $25 \mu \mathrm{m}$, para que se possa alcançar o desempenho esperado para esses tipos de colunas. Novas fases estacionárias para as colunas OT também poderão ser investigadas.

Não foi possível demostrar a utilização das colunas desenvolvidas e nem a aplicação de programação de temperatura em amostras reais, por isso, novos estudos deverão ser realizados para utilização destes recursos, na separação de diferentes classes de compostos em amostras reais. 


\section{REFERÊNCIAS BIBLIOGRÁFICAS}

1 LANÇAS, F. M. Vantagens e limitações da miniaturização em cromatografia liquida. Scientia Chromatographica, v. 1, p. 51-60, 2009.

2 COUTINHO, L. F. M.; LANÇAS, F. M. Cromatografia liquida capilar: 1. Principais características da técnica. Scientia Chromatographica, v. 3, p. 115-130, 2011.

3 SILVA, R. G. C.; COLLINS, C. H.; BOTOLLI, C. B. G. Cromatografia líquida capilar: estado da arte e aplicações. Quimica Nova, v. 34, p. 841-849, 2011.

4 HORVATH, C. G.; PREISS, B. A.; LIPSKY, S. R. Fast liquid chromatography investigation of operating parameteres and the separation of nucleotides on pelicular ion exchangers.

Analytical Chemistry, v. 39, p. 1422-1428, 1967.

5 STASSEN, C.; DESMET, G.; BROECKHOVEN, K.; LOKEREN, L. V.; EELTINK, S. Characterization of polymer monolithic columns for small-molecule separations using totalpore-blocking conditions. Journal of Chromatography A, v. 1325, p. 115-120, 2014.

6 SVEC, F. Preparation and HPLC applications of rigid macroporous organic polymer monoliths. Journal of Separation Science, v. 27, p. 747-766, 2004.

7 SCOTT, R. P. W.; KUCERA, P. properties of some commercially available silica gels. Journal of Chromatography, v. 25, p. 251- 263, 1976.

8 ISHII, D.; ASAI, K.; HIBI, K.; JONOKUCHI, T.; NAGAYA, M. A study of micro-highperformance liquid chromatography: I. development of technique for miniaturization of highperformance liquid chromatography. Journal of Chromatography, v. 144, p. 157-168, 1977.

9 ISHII, D.; HIBI, K.; ASAI, K.; JONOKUCHI, T. Studies of micro high-performance liquid chromatography: II. application to gel permeation chromatography of techniques developed for micro high-performance liquid chromatography. Journal of Chromatography, v. 151, p. 147-154, 1978.

10 TSUDA, T.; NOVOTNY, M. Packed microcapillary columns in high performance liquid chromatography. Analytical Chemistry, v. 50, n. 2, p. 271-275, 1978.

11 SCOTT, R. P. W.; KUCERA, P. Mode of operation and performance characteristics of microbore columns for use in liquid chromatography. Journal of Chromatography, v. 169,p. 51-72, 1979. 
12 HIRATA, Y.; NOVOTNY, M. Techniques of capilar liquid chromatography. Jounal of chromatography, v. 186, p. 521-528, 1979.

13 TAKEUCHI, T.; ISHII, D. High-performance micro packed flexible columns in liquid chromatography. Joumal of Chromatography, v. 213, p. 25-32, 1981.

14 YANG, F. J. Fused-silica narrow-bore microparticle-packed-column hihg-performance liquid chromatography A. Journal of Chromatography A., v. 236, p. 265-277, 1982.

15 BAREFOOT, A. C.; REISER, R. W. Packed capillary liquid chromatography-mass spectrometry using both direct-coupling and moving-belt interfaces. Journal of Chromatography, v. 398, p. 217-226, 1987.

16 TAKEUCHI, T.; YEUNG, E. S. Signal enhancement in on-column fluorometric detection in open-tubular capillary liquid chromatography. Journal of Chromatography, v. 389, p. 310, 1987.

17 JORGENSON, J. W.; GUTHRIE, E. J. Liquid chromatography in open-tubular columns theory of column optimization with limited pressure and analysis time, and fabrication of chemically bonded reversed- phase columns on etched borosilicate glass capillaries. Journal of Chromatography, v. 255, p. 335-348, 1983.

18 KREJČÍ, M.; TESAŘÍK, K.; RUSEK, M.; PAJUREK, J. Flow characteristics and technology of capillary columns with inner diameters less than $15 \mu \mathrm{m}$ in liquid chromatography. Journal of Chromatography, v. 218, p. 167-I 78, 1981.

19 VAN BERKEL-GELDOF, O.; KRAAK, J. C.; POPPE, H. Preparation of silicone-coated $5525 \mathrm{pm}$ i.d. fused-silica capillary columns for open-tubular liquid chromatography. Journal of chromatography, v. 499, p. 345-359, 1990.

20 COUFAL, P.; CIHÁK, M.; SUCHÁNKOVÁ, J.; TESAROVÁ, E.; BOSÁKOVÁ, Z.; STULÍK, K. Methacrylate monolithic columns of $320 \mathrm{~mm}$ I.D. for capillary liquid chromatography. Journal of Chromatography A, v. 946, p. 99-106, 2002.

21 GHARBHARAN, D.; BRITSCH, D.; SOTO, G.; WEED, A. M. K.; SVEC, F.;

ZAJICKOVA, Z. Tuning preparation conditions towards optimized separation performance of thermally polymerized organo-silica monolithic columns in capillary liquid chromatography. Journal of Chromatography A, v. 1408, p. 101-107, 2015.

22 MIYABEA, K.; GUIOCHON, G. Estimation of the column radial heterogeneity from an analysis of the characteristics of tailing peaks in linear chromatography. Journal of Chromatography A, v. 830, p. 29-30, 1999. 
23 NEUE, U. D. HPLC columns: theory, technology, and practice. Milford: Wiley-VCH, 1997. v. 1.

24 YE, J.; CAO, X.; CHENG, Z.; QIN, Y.; LU, Y. Rapid determination of parabens in seafood sauces by high-performance liquid chromatography: a practical comparison of core-shell particles and sub-2 $\mu \mathrm{m}$ fully porous particles. Journal of Separation Scienci, v. 38, p. 39834158, 2015.

25 NAZARIO, C. E.; SILVA, M. R.; FRANCO, M. S.; LANÇAS, F. M. Evolution in miniaturized column liquid chromatography instrumentation and applications: an overview. Journal of Chromatography A, v. 1421, p. 18-37, 2015.

26 MONTEIRO, A. M. Cromatografia liquida capilar: desenvolvimento de colunas empacotadas capilar e monolíticas, cela de detecção UV e aplicação de programação de temperatura. 2009. 188 f. Tese (Doutorado em Química Analítica) - Instituto de Química de São Carlos, Universidade de São Paulo, São Carlos, 2009.

27 RUO-NAN, L.; WANG, Y. N.; PENG, M. H.; WANG, X. Y.; GUO, H. S. Preparation and application of porous layer open tubular capillary columns with narrow bore in liquid chromatography. Chinese Journal of Analytical Chemistry, v. 45, p. 1865-1873, 2017.

28 COLLINS, D. A.; NESTERENKO, E. P.; PAUL, P. Porous layer open tubular columns in capillary liquid chromatography. Analyst, v. 139, p. 1292-1302, 2014.

29 TOCK, P. P. H.; DUIJSTERS, P. P. E.; KRAAK, J. C.; POPPE, H. Theoretical optimization of open-tubular columns for liquid chromatography with respect to mass loadability. Journal of Chromatography, v. 506, p. 185-200, 1990.

30 SWART, R.; KRAAK, J. C.; POPPE, H. Recent progress in open tubular liquid chromatography. Trends in Analytical Chemistry, v. 16, p. 332-341, 1997.

31 DESMET, G.; EELTINK, S. Fudamental for LC miniaturization. Analitical Chemistry, v. 85, p. 543-556, 2013.

32 GÖHLIN, K.; BUSKHE, A.; LARSSON, M. Kinetic performance of open-tubular and packed columns in LC using the same stationary phase: immobilized polymethyloctadecilsiloxane. Chromatographia, v.39, p. 729-739, 1994.

33 COUTINHO, L. F. M.; LANÇAS, F. M. Cromatografia líquida capilar: 1. Principais características da técnica. Scientia Chromatographica, v. 3, p. 115-130, 2011. 
34 YANG, P.; WANG, W.; XIAO, X.; JIA, L. Hydrothermal preparation of hybrid carbon/silica monolithic capillary column for liquid chromatography. Journal Separation Science, v. 37, p. 911-1918, 2014.

35 FONSECA, J. R. Avaliação dos processos de pré-tratamento da superfície da sílica fundida no preparo de colunas capilares inertes para cromatografia gasosa. $2009.78 \mathrm{f}$. Dissertação (Mestrado em Química Analítica) - Instituto de Química de São Carlos, Universidade de São Paulo, São Carlos, 2009.

36 CHERVET, J. P.; M., U.; SALZMANN, J. P. Instrumental requirements for nanoscale liquid chromatography. Analytical Chemistry, v. 9, p. 1507-1512, 1996.

37 STASSEN, C.; DESMET, G.; BROECKHOVEN, K.; VAN LOKEREN, L.; EELTINK, S. Characterization of polymer monolithic columns for small-molecule separations using totalpore-blocking conditions. Journal of Chromatography A, v. 1325, p. 115-120, 2014.

38 HARA, T.; FUTAGAMI, S.; EELTINK, S.; MALSCHE, W.; BARON, G. V.; DESMET, G. Very high efficiency porous silica layer open-tubular capillary columns produced via incolumn sol-gel processing. Analytical Chemistry, v. 88, p. 10158-10166, 2016.

39 LANÇAS, F. M. A cromatografia líquida moderna e a espectrometria de massas: finalmente "compatíveis"? Scientia Chromatographica, v. 1, p. 35-61, 2009a.

40 GIDDINGS, J. C. Dynamics of chromatography. New York: Marcel Dekker, 1965. 340 p.

41 LANÇAS, F. M. Efeitos de temperatura em cromatografia liquida de alta eficiencia (HPLC). Scientia Chromatographica, v. 4, p. 13-19, 2012.

42 MORAVCOVÁ, D.; PLANETA, J.; WIEDMER, S. K. Silica-based monolithic capillary columns modified by liposomes for characterization of analyte-liposome interactions by capillary liquid chromatography. Journal of chromatography A, v. 1317, p. 159-166, 2013.

43 COUTINHO, L. F. M. Desenvolvimento de instrumentação dedicada a cromatografia liquida capilar (cLC). 2008. 219 f. Tese (Doutorado em Química Analítica) - Instituto de Química de São Carlos, Universidade de São Paulo, São Carlos, 2008.

44 SCOTT, R. P. W. Design of liquid. chromatography capillary columns. Journal of Chromatography, v. 517, p. 297-304, 1990.

45 SCOTT, R. P. W. Microbore columns in liquid-chomatography. Journal of Chromatographic Science, v. 18, p. 49-54, 1980. 
46 STRAIN, H. H. Condictions affecting sequence of organic compounds in tswett adsorption columns. Industrial Engineering Chemistry-Analytical Edition, v. 18, p. 605-609, 1946.

47 HENSSE, G.; ENGELHARDT, H. Temperaturprogrammierung bei der absorptionschromatographie von lösungen. Journal of Chromatography, v. 21, p. 228-238, 1966.

48 GRUSHKA, E.; KIKTA, E. J. New polar bonded liquid chromatography phase. Analytical Chemistry, v. 46, p. 1370-1375, 1974.

49 HIRATA, Y.; SUMIYA, E. Temperature-programmed reversed-phase liquid chomatography with packed fused-silica columns. Journal of Chomatography, v. 267, p. 125-231, 1983.

50 BOWERMASTER, J.; MCNAIR, H. Microbore high-performace liquid chomatographuc columns: speed, efficiency, sensitivity and temperature programming. Journal of Chomatography, v. 279, p. 431-438, 1983.

51 MCNAIR, H.; BOWERMASTER, J. Microborehplc column performance and temperature programming capabilities. Journal of High Resolution Chromatography, v. 10, p. 27-31, 1987.

52 JINNO, K.; PHILLIPS, J. B.; CARNEY, D. P. Temperature-controlled high-speed microcolumn liquid chomatography. Analytical Chemistry, v. 57, p. 574-576, 1985.

53 DJORDJEVIC, N. M.; STEGEHUIS, D.; LIU, G.; ERNI, F. Improved ultravioleta detection in high-temperature open-tubular liquid chomatography. Journal of Chomatography, v. 629, p. 135-141, 1993.

54 HAZOTTE, A.; LIBONG, D.; CHAMINADE, P. High-temperature micro liquid cromatography for lipid molecular species analisis with evaporative ligh scattering detection. Journal of Chromatography A, v. 1140, p. 131-139, 2007.

55 ANDERSEN, T.; SKULAND, I. L.; HOLM, A.; TRONES, R.; GREIBROKK, T. Temperature-programmed packed capillary liquid chromatography coupled to evaporative ligh-scattering detection and eletrospray ionization time-of-flight mass spectrometry for characterization of high-molecular-weight hindered amine light stabilizers. Jounal of Chromatography A, v. 1029, p. 49-56, 2004.

56 TIAN, H.; XU, J.; GUAN, Y. Axial temperature gradiente and mobile phase gradiente in microcolumns high-performace liquid chomatography. Talanta, v. 72, p. 813-818, 2007. 
57 BOWERMASTER, J.; MCNAIR, H. Temperature programmed microborehplc-part I. Journal of Chromatography Science, v. 22, p. 165-170, 1984.

58 CHEN, M. H.; HORVÀTH, C. Temperature programming and gradiente elution in reversed-phase chomatography with packed capillary columns. Journal of Chromatography A, v. 788, p. 51-61, 1997.

59 GREIBROKK, T.; ANDERSEN, T. Temperature programming in liquid chromatography. Journal Separation Science, v. 24, p. 899-909, 2001.

60 FREITAS, S. S. Otimização de metodologia para o preparo de colunas capilares para cromatografia líquida. 1999. 135 f. Dissertação (Mestrado em Química Analítica) -Instituto de Quimica de São Carlos, Universidade de São Paulo, São Carlos, 1999.

61 MEYER, V. R. Practical High-Performance Liquid Chromatography. New York: John Wiley \& Sons, 2010. Disponivel em:

<https://pt.wikipedia.org/wiki/Cromatografia_1\%C3\%ADquida_de_alta_efici\%C3\%AAncia>. Acesso em: 25 set. 2018.

62 LANÇAS, F. L. Aumentando a eficiência das colunas de HPLC por meio da diminuição do diâmetro das partículas da fase estacionária: até onde? Scientia Chromatographica, v. 3, p. 17-23, 2011.

63 COLLINS, C. H.; BRAGA, G. L.; BONATO, P. S. Fundamentos de cromatografia. Campinas: Editora da UNICAMP, 2009. 453 p.

$64 \mathrm{KNOX}$, J. H. Theoretical aspects of LC with packed and open small-bore columns. Journal of Chromatografic Science, v. 18, p. 453-461, 1980.

65 KNOX, J. H.; T.; GILBERT, M. T. Kinetic optimization of straight open-tubular liquid chromatography. Jornal of Chromatography, v. 186, p. 405-418, 1979.

66 BRISTOW, P. A.; KNOX, J. H. Standardization of test condiction for high performance liquid chromatography columns. Chromatographia, v. 10, p. 279-289, 1997.

67 BARTH, H. G.; BARBER, W. E.; LOCHMUELLER, C. H.; MAJORS, R. E.; REGNIER, F. E. Column liquid chromatography. Analytical Chemistry, v. 60, p. 387-435, 1988. 
68 VISSERS, J. P. C.; CLAESSENS, H. A.; CRAMERS, C. A. Microcolumn liquid chromatography: instrumentation, detection and applications. Journal of Chromatography A, v. 799, p. 1- 28, 1997.

69 COUTINHO, L. F.; NAZARIO, C. E.; MONTEIRO, A. M.; LANÇAS, F. M. Novel devices for solvent delivery and temperature programming designed for capillary liquid chromatography. Journal Separation Science, v. 37, p. 1903-1910, 2014.

70 KROMASIL. AkzoNobel, separation Products, Bohus, 2018. Disponivel em: <https://www.kromasil.com/support/dac_packing.php>. Acesso em: 11 março 2018.

71 WAHAB, M. F.; PATEL, D. C.; WIMALASINGHE, R. M.; ARMSTRONG, D. W. Fundamental and practical insights on the packing of modern high-efficiency analytical and capillary columns. Analytical Chemistry, v. 89, n. 16, p. 8177-8191, 2017.

72 REISING, A. E.; GODINHO, J. M.; JORGENSON, J. W.; TALLAREK, U. Bed morphological features associated with an optimal slurryconcentration for reproducible preparation of efficient capillaryultrahigh pressure liquid chromatography columns. Journal of Chromatography A, v. 504, p. 71-82, 2017.

73 CABOOTER, D.; BILLEN, J.; TERRYN, H.; LYNEN, F.; SANDRA, P.; DESMET, G. Detailed characterisation of the flow resistance of commercial sub-2m reversed-phase columns. Journal of Chromatography A, v. 1178, p. 108-117, 2008.

74 BARHATE, C. L.; WAHAB, M. F.; BREITBACH, Z. S.; BELL, D. S.; ARMSTRONG, D. W. High efficiency, narrow particle size distribution, sub-2 $\mathrm{mm}$ based. Analytica Chimica Acta, v. 898, p. 128-137, 2015.

75 YUE, G.; LUO, Q.; ZHANG, J.; WU, S. L.; KARGER, B. L. Ultratrace LC/MS proteomic analysis using 10-ím-i.d. porous layer open tubular poly(styrene-divinylbenzene) Capillary Columns. Analytical Chemistry, v. 79, p. 938-946, 2007.

76 BERG, S. H.; SETERDAL, K. E.; SMETOP, T.; ROZENVALDS, R.; BRANDTZAEG, O. K.; VEHUS, T.; LUNDANES, E.; WILSON, S. R. Self-packed core shell nano liquid chromatography columns and silica-based monolithic trap columns for targeted proteomics. Journal of Chromatography A, v. 1498, p. 111-119, 2017.

77 VEHUS, T.; ROBERG-LARSEN, H.; WAALER, J.; ASLAKSEN, S.; KRAUSS, S.; WILSON, S. R.; LUNDANES, E. Versatile, sensitive liquid chromatography mass spectrometry - Implementation of $10 \mu \mathrm{m}$ OT columns suitable for small molecules, peptides and proteins. Scientific Reports, v. 6, p. 1-10, 2016. 